\title{
Part I: Introduction
}





\section{Alexander's commentary on the Metaphysics}

\subsection{Scope and contents of the commentary}

Editing Alexander of Aphrodisias' (fl. 200 AD) commentary on Aristotle's Metaphysics is a complicated task for both historical and scholarly reasons. To begin with, there

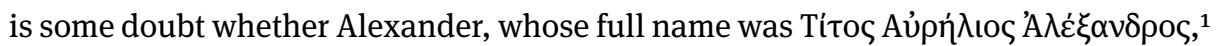
commented on the entire treatise or only on some of its books. At any rate, the direct Greek tradition of the text delivers no commentary beyond book Delta. Nevertheless, Averroes has preserved some thirty fragments of Alexander's commentary on book $L a m b d a^{2}$ and Syrianus refers to some of Alexander's comments in his own commentary on books $M u$ and $N u .^{3}$ Taken together with three mentions of Alexander in Asclepius' commentary on book Zeta, ${ }^{4}$ these references suggest that Alexander composed a commentary on the entire Metaphysics.

This, of course, is hardly surprising. Quite in opposition to modern and contemporary interpreters, ${ }^{5}$ Alexander adopted a unitarian approach to the Metaphysics, ${ }^{6}$ which, of course, in his time was already a single treatise and had already been the object of commentaries. As a 'diadoch' and holder of the Peripatetic chair, rivalling the chair-holders of the other Schools (Platonic, Stoic and Epicurean) founded in Athens by Marcus Aurelius in $176 \mathrm{AD},{ }^{7}$ Alexander naturally had to present his auditors and readers with a coherent doctrine of the Peripatetic School on the basis of Aristotle's own writings but also to defend the Peripatetic tradition, renewed some two hundred

1 According to the epigraphic evidence from Aphrodisias discussed by Chaniotis 2004: 388-389. Alexander had a homonymous father, who was awarded Roman citizenship by the governor of Asia (135/136 AD) Titus Aurelius Fulvus Antoninus (the later emperor Antoninus Pius), as the pronomina Titus Aurelius imply.

2 See Freudenthal 1885; Genequand 1986. Di Giovanni - Primavesi 2016 raise some issues as to whether Averroes had access to Alexander's genuine commentary.

3 Syrianus, In Metaph. [= Kroll 1902] 96.18, 111.34, 122.12 and 18, 160.8, 166.27, 186.16, 195.12. In 186.16, Alexander is quoted by Syrianus as an authority for the traditional division between books $\mathrm{Mu}$ and $\mathrm{Nu}$. Alexander's commentary on $\mathrm{Nu}$ is mentioned in the Kitāb al-Fihrist of the tenth century; see below, p. xlviii, n. 3.

4 Asclepius, In Metaph. [= Hayduck 1888] 408.5 and 20, 428.13.

5 The only exception is Menn (forthcoming), who proposes, to my mind magisterially and convincingly, a unitary approach to the treatise.

6 On this see lately Guyomarc'h 2015; see, characteristically, p. 12: "L'Exégète travaille à faire de la Métaphysique un livre, et de la métaphysique une science une”.

7 See Toulouse 2008. Alexander was appointed as an imperial teacher of Peripatetic philosophy at some time between 198 and 209 AD, given that he addresses his De fato to Septimius Severus and Caracalla, who were joint emperors from 198 to 209; see Todd 1976: 1 n. 3. In the inscription discovered

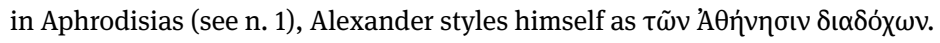


years earlier through the publication of Aristotle's so-called esoteric treatises. ${ }^{8}$ The very structure and unity of Aristotle's single books (бvyypó $\mu \mu \alpha \tau \alpha)$, larger wholes or treatises $(\pi \rho \alpha y \mu \alpha \tau \varepsilon \tilde{\alpha} \alpha)^{9}$ and philosophical system $\left(\varphi \iota \lambda о \sigma o \varphi^{\prime} \alpha\right)^{10}$ was part and parcel of that tradition.

\subsubsection{A unitary reading of the Metaphysics}

Alexander lays out his unitary approach to the Metaphysics in his commentary on the

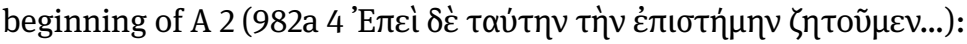

From the present treatise we must therefore demand knowledge of the first principles and causes. These would be the principles of being qua being, ${ }^{11}$ in virtue of which [principles] each being is, ${ }^{12}$ [each being, that is] each thing of which we predicate being. The first substances, those that are

8 On this renewal see lately Primavesi 2007.

9 The division of Aristotle's newly discovered treatises into larger wholes related by content is, in my opinion, what Porphyry credits to Andronicus of Rhodes (fl. $60 \mathrm{BC}$ ) with regard to Aristotle's newly

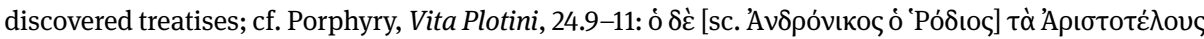

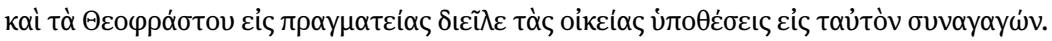

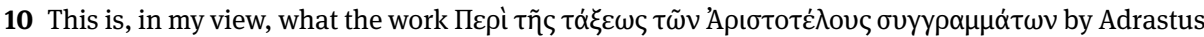
of Aphrodisias (cf. Simplicius, In Cat. [= Kalbfleisch 1907] 18.16-17 and In Phys. [= Diels 1882] 4.11-12

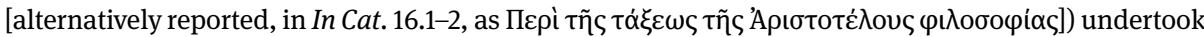
to establish (next to quantitative matters as, e.g., the number of lines of a given treatise). His work was surely influential. Adrastus may have been the first holder of the Peripatetic chair in Athens. Sim-

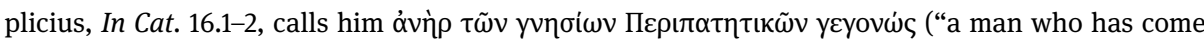
to belong to the genuine Peripatetics"); yvíбı ('genuine', 'legitimate') seems related to an official function and yeyovís to a promotion.

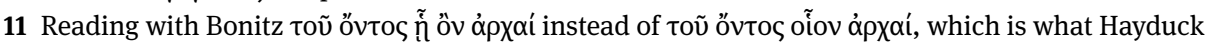
prints (in accordance with the manuscripts) and Donini 2011: 109, Bonelli 2012: 260 n. 3, Guyomarc'h 2015: 102 and others adopt. It is remarkable that Bonitz's conjecture is not even discussed, whereas not one of these scholars explains why the principles of being (qua being), which are principles par excellence, would be "quasi-principles". Bonitz's conjecture is confirmed by the anonymous prolegomena

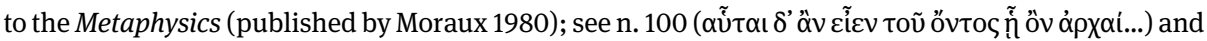

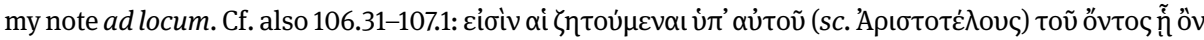

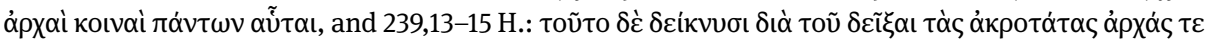

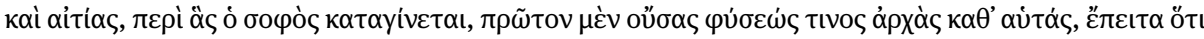

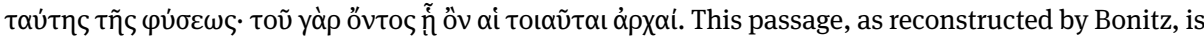
sufficient to discredit Merlan 1957, who thinks that for Alexander being qua being is identical with the first substance. The first substances are the principles of being qua being and, of course, the principle itself is not identical with that of which it is the principle.

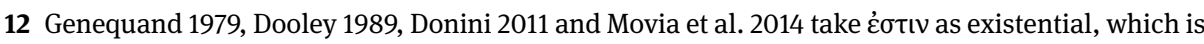
fine if by ' $s$ exists' they mean ' $s$ is ö $v$ ' in virtue of its having a form regardless of the particular form ( $\tau$ i

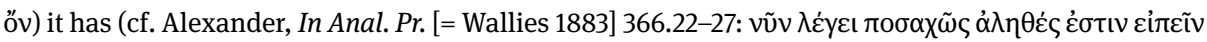

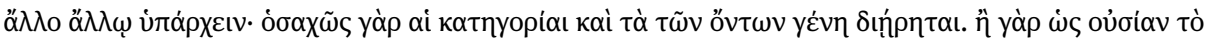

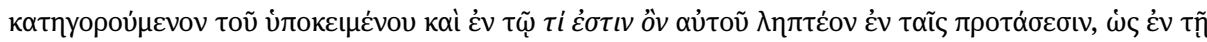

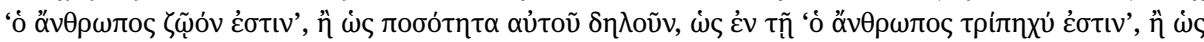




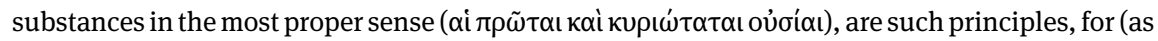
[Aristotle] will show) they are the principles of substances, and these latter are the principles of all other things. It is therefore the knowledge of these first substances that we must demand from the present treatise, and further of whatever contributes to the knowledge of them; [Aristotle] indeed devotes the greater part of his discussion to these accessory questions, for it is impossible to acquire knowledge of the first substances in any other way than by having first established [some

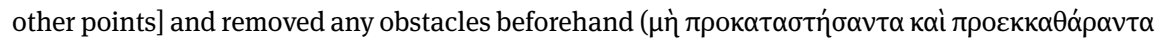
$\tau \grave{\alpha} \dot{\varepsilon} \mu \pi о \delta \dot{v} v)^{13}$

Aristotle will explicitly say that the substances (ov'oía) are "the principles of all other things", i.e. the things said in the categories other than the category of substance, in book Gamma but also in book Lambda, ${ }^{14}$ in which he will precisely show what are the first substances, mentioned by Alexander, which are principles of all other substances, namely perpetual heavenly substances and perishable sublunary substances. ${ }^{15}$ Indeed, for Alexander at least, the first oúoi $\alpha$, of which the Metaphysics will yield knowledge in its culmination in book Lambda, are the immaterial forms (öv $\lambda \alpha$ $\varepsilon ` \delta \eta$ ) or vóç in the proper sense; ${ }^{16}$ these are the (forty-eight?) unmoved movers ${ }^{17}$ of the heavenly spheres, which account for their eternal and regular celestial motions, ${ }^{18}$ which in their turn are responsible for the perpetual generation and corruption (and the periodic growth and decay) of all sublunary substances. Following Aristotle's usage in $\Lambda 8$, in the passage quoted above Alexander specifically employs the word

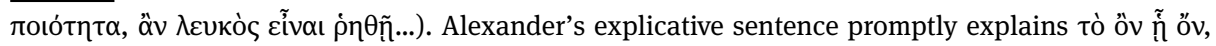

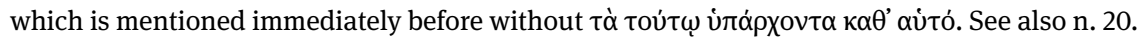

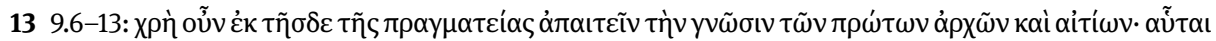

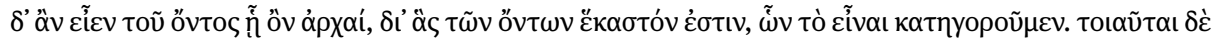

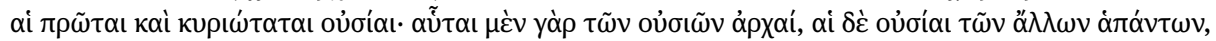

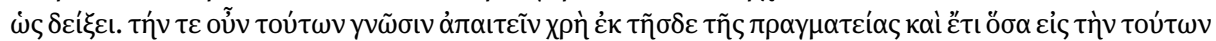

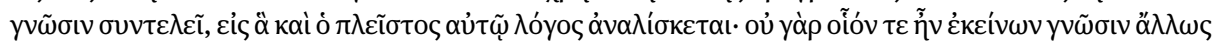

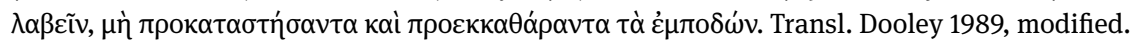

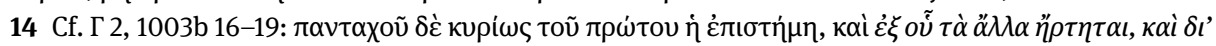

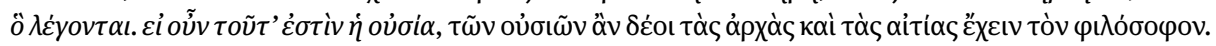

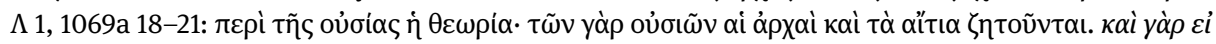

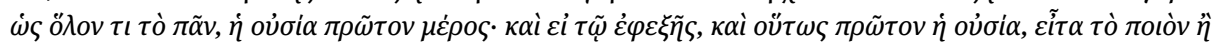

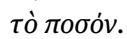

15 On the three different kinds of substances, discussed by Aristotle in $\Lambda$ 2-5, see Rapp 2016.

16 See n. 47. It has to be stressed, though, that whereas pseudo-Alexander, i.e. Michael of Ephesus, does use the plural form voĩ in his commentary on the posterior books, Alexander never does (the form vó£ৎ is first attested in Plotinus). I take it, however, that his speaking of first ov̉oía in the plural legitimizes this light anachronism.

17 Only one of them, however, i.e. the First Principle, is unmoved both per se and per accidens; cf. $\Lambda$, 1073a 23-25. The rest of the vó $\varsigma$ are unmoved per se but "are moved accidentally by another" insofar as they are, in a way, in the higher celestial sphere; cf. Phys. VIII 6, 259b 28-31 and see Menn 2012: 440-442.

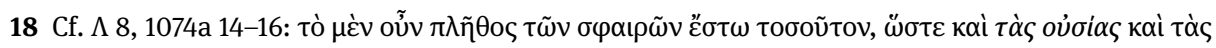

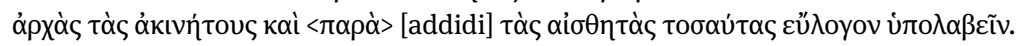


oúría to refer to the unmoved movers of the celestial spheres. ${ }^{19}$ The First and the other unmoved movers are the immediate causes of the particular eternal motions of the celestial substances and, through them, they are also causes of being (Tò cĩval) to all sublunary substances; in other words, the immaterial forms, which are the unmoved movers, ultimately account for the fact that everything in the universe has and retains, eternally or for a longer or shorter span of time, its form, ${ }^{20}$ which is what is best for it. It is in this comprehensive sense that the first substances are said by Alexander to be the principles and causes of being qua being.

Being qua being (ôv $\tilde{\tilde{n}}$ őv) is meant to denote being in its most indeterminate sense

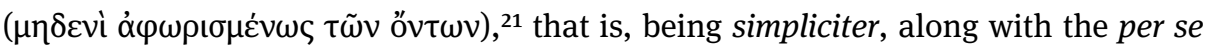
attributes of being ${ }^{22}$ which are common in (and true of) all heavenly and sublunary

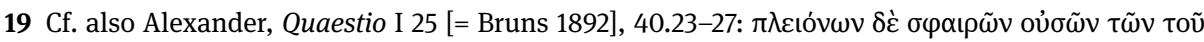

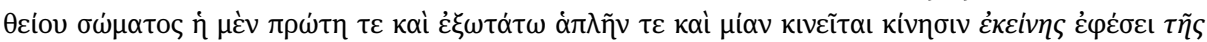

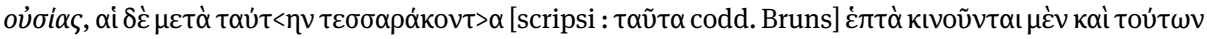

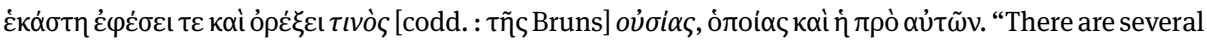
spheres in the divine body, and the first and outermost is moved in a simple and single motion by desire for that substance [i.e. the First unmoved mover]; and of the $<$ forty->seven after it, each one too is moved by desire and appetite for some substance [i.e. the other separate unmoved movers] of the sort by which the sphere before them [i.e. the outermost sphere] is also moved". It would be a gross error on Alexander's part to identify the number of the heavenly spheres, which explain the orbits of

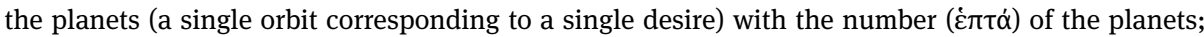
hence my emendation of the transmitted text. Aristotle concludes, albeit tentatively, to the existence of forty-seven (or, alternatively, fifty-five) heavenly spheres (without counting the outermost sphere) in $\Lambda 8,1074$ a 13-14, in a notorious passage that has caused many difficulties to his interpreters. I defend the reading of the manuscripts (47, emended to 49 by Sosigenes) in a forthcoming publication.

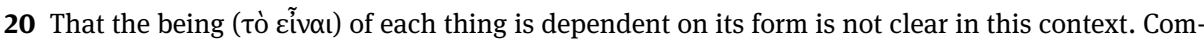
pare, however, what I suggest should be considered as Alexander's prolegomena to the Metaphysics

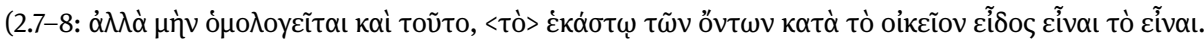
"Everyone agrees on that too, namely that to einai belongs to each being according to its form") and,

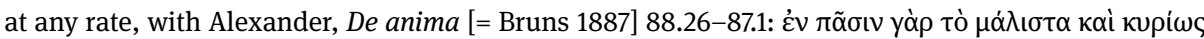

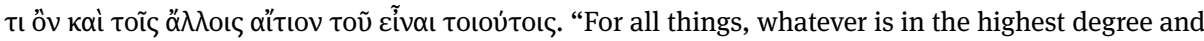
properly $x$ is also the cause of other things' being $x$ ", where 'properly $x$ ' is a form per se, e.g. light, and 'being $x$ ' is a property of some other thing, e.g. being visible. Speaking of tò عĩvaı toเoútoıs in the context of the Metaphysics would be misplaced, since in the Metaphysics there is no question of a particular being but of being qua being.

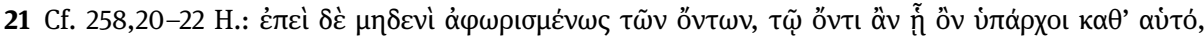

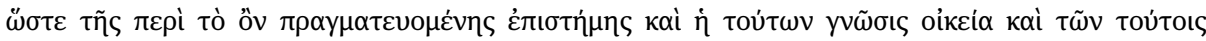
$\sigma \nu \mu \beta \varepsilon \beta \eta \kappa \tau_{\tau} \omega \nu$. "Since [sameness and otherness and whatever things are objects of inquiry concerning contraries] do not belong to any [particular] kind of being determinately, they would belong per se to being qua being, so that the knowledge of these things and of their accidents would be proper to the science which treats of being [qua being]"; transl. Madigan 1993, modified.

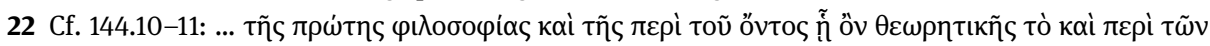

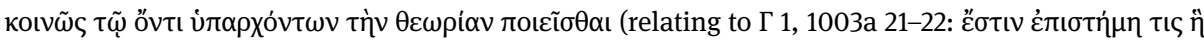

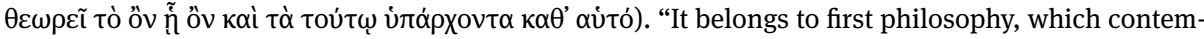


substances, ${ }^{23}$ regardless of their qualified or particular being (e.g. their being separate and eternally moved, which belongs to the heavenly sensible substance, or their being separate and generated and corrupted, which belongs to the sublunary sensible substance, or their being unmoved and inseparate, which belongs to the intelligible, i.e. mathematical, substance); particular being is not studied by the Metaphysics or "first philosophy" but by the particular sciences:

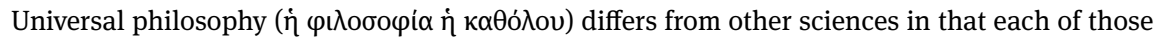
sciences is concerned with particular being ( $\tau \mathrm{i}$ öv), while universal philosophy is concerned not with particular being but with being qua being. ${ }^{24}$

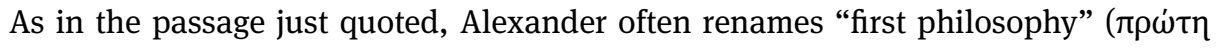
$\varphi \iota \lambda о \sigma o \varphi$ i $\alpha$ ), which is an expression repeatedly used by Aristotle to refer to the science of the things that exist separately from matter, ${ }^{25}$ to "universal philosophy" ( $\dot{\eta}$

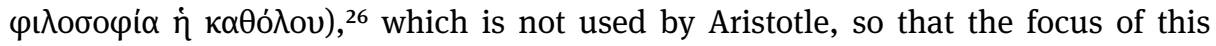

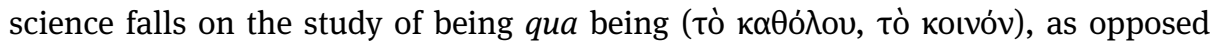
to particular being, and its per se attributes (unity and plurality and connected attributes). Nonetheless, on Alexander's view, who naturally wishes to be faithful to Aristotle, ${ }^{27}$ "first philosophy" is also specifically related to the study of the first sub-

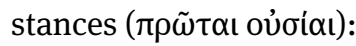

So it is concerning substances: the ungenerated and imperishable, incorporeal and unmoved substances are first, and first philosophy would be concerned with these; the philosophy concerned with substances that are eternal but in motion would be second; the philosophy con-

plates being qua being, to carry out a contemplation of those things, too, which commonly belong to being".

23 I.e. unity, the things that fall under unity (sameness, equality, likeness etc.) and the things opposed to unity, i.e. plurality and what falls under it (otherness, contrariety); cf. 238,5-14 H. The per se attributes of being will also include axioms, that is, truths that hold for all things such as the principle

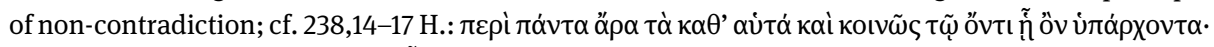

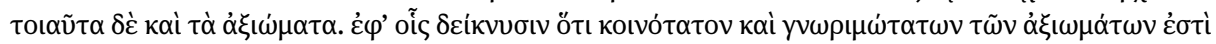

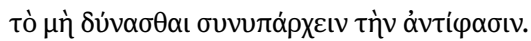

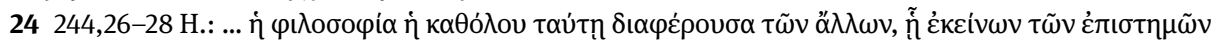

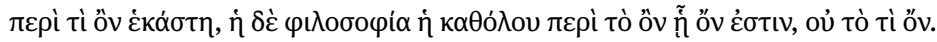

25 See Metaph. E 1, 1026a 24 and K 4, 1061b 19; Phys. I 9, 192a 34-36 and II 2, 194b 14-15; Cael. I 8, 277b 10; An. I 1, 403b 16; Mot. An. 6, 700b 9.

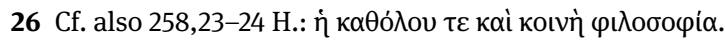

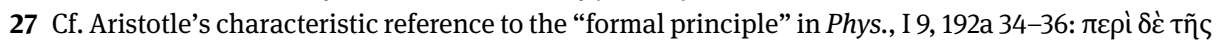

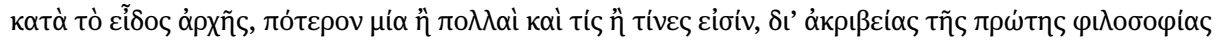

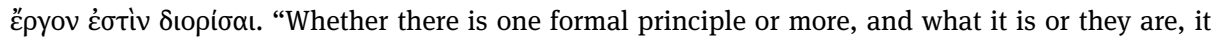
belongs to First Philosophy to determinate it with accuracy". This passage looks forward to book Lambda, and specifically to chapters 7-9, in which it will be shown that there is a number of separate substances that intelligize themselves. 
cerned with substances involved in coming-to-be and perishing would be third, since these are the last among substances. ${ }^{28}$

Moreover, and seemingly more problematically, in one passage Alexander enumerates first philosophy, along with physics and ethics, as one of the species of sophia or universal philosophy, which itself deals with being qua being:

The genus, i.e. the common nature of being, is the object of science for common and generic philosophy, and so the parts of being are objects of science for the parts of philosophy. Thus each of the sciences which are ranged under philosophy as a sort of generic science would be a science of each species of being [...]. And the species of generic philosophy match the species of being. For

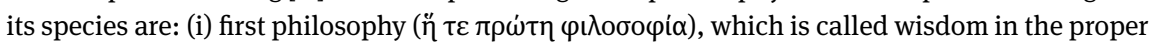
sense ( $\kappa v i(\omega \varsigma)$ ), being the science of things eternal, unmoved, and divine [[it is wisdom that is

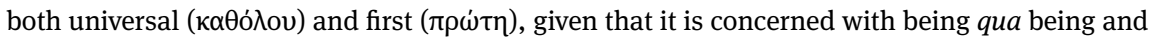
not with a particular being; and, under wisdom, there is a particular first philosophy concerned

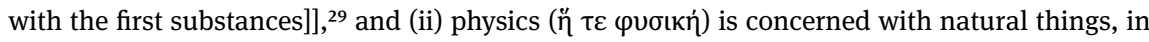
which there is already motion and change. There is also a particular [philosophy, i.e. ethics,] which considers matters of action (for there are also beings that are of this sort). ${ }^{30}$

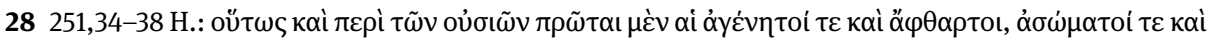

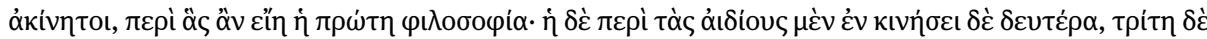

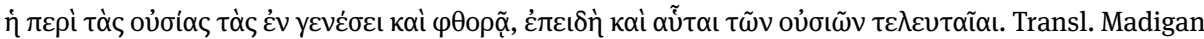
1993, modified.

29 I take this to be a marginal scholium by a reader objecting to or, rather, confused by Alexander;

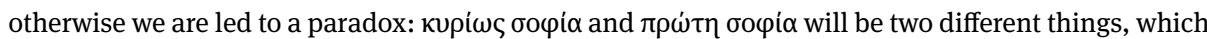
is against the standard usage of kupi $\omega \varsigma$ and $\pi \rho \omega \dot{\tau} \omega \varsigma$ as equivalent (so the problem is not only, as most scholars justly remark, that Alexander speaks of two first philosophies, the one being general and

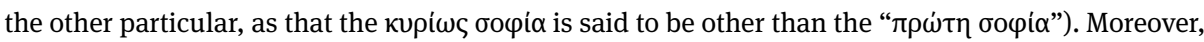
Alexander says explicitly that it is first philosophy, i.e. "the science of things eternal, unmoved and divine", which is "wisdom in the proper sense", so that it is hard to see how wisdom as universal science could be first, that is, prior to wisdom in the proper sense. Rather, universal science is wisdom because, by studying being qua being, it studies the effect of the first substances, the knowledge of which constitutes wisdom in the proper sense. Donini 2011 argues that Alexander uses 'first' in two different meanings, referring to the science of (axiologically) first substances and to the (generically) first science. But using the same word in two different meanings in quite a short passage like this would not be appropriate of a good commentator, all the more so because Alexander could have conveyed

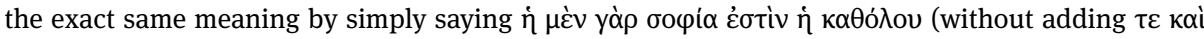
$\pi \rho \omega \dot{\tau} \eta)$. The fact that generic wisdom is also qualified as $\pi \rho \omega \dot{\tau} \eta$ rather points to a kind of objection

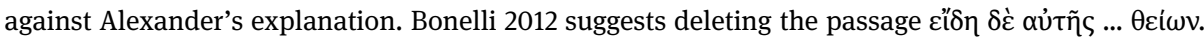

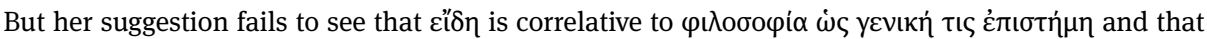
what comes in between (245,33-37 H.) is parenthetical; see also below, p. xliv-xlv. Besides, if this were a gloss, it would be a very elliptical one.

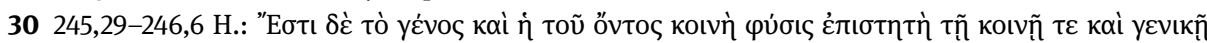

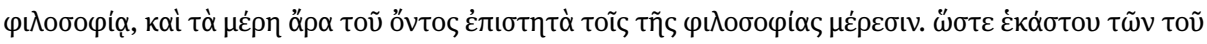

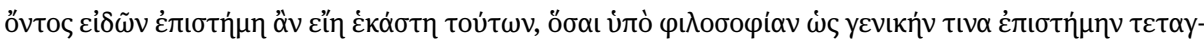

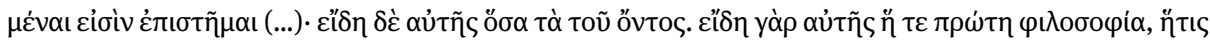

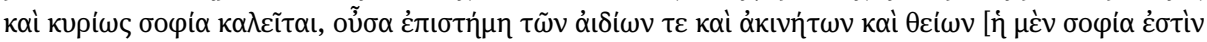




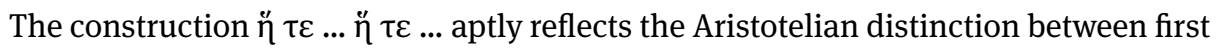
philosophy [= metaphysics] and second philosophy [= physics], which are considered as the chief theoretical sciences by both Alexander and Aristotle. ${ }^{31}$ Ethics comes only afterwards as a further particular philosophy, so that the traditional division of philosophy in Alexander's time, of Stoic origin, is satisfied. ${ }^{32}$

Despite appearances, the passage quoted above does not imply that, for Alexander, first philosophy is different from universal philosophy and that first philosophy is subordinate to universal philosophy, or that Alexander separates the Metaphysics into two blocs or different objectives, the one dealing with theology and the other with "ontology", as in the late scholastic distinction between metaphysica specialis and metaphysica generalis ${ }^{33}$ or in modern interpretations of the Metaphysics. ${ }^{34}$ Alexander adheres to a unitary reading of the Metaphysics and explains a bit later in the commentary that "universal philosophy" and "first philosophy" are one and the same science, which is "first" in two ways:

First [philosophy] would be both (i) the philosophy which is concerned with the first substances and (ii) the philosophy which is concerned universally with all substance and the things which are themselves beings by virtue of belonging to substance. The same [philosophy] turns out to be first in both ways: both (i) the philosophy which contemplates the first substances also contemplates all other things whose being depends on these, and (ii) the philosophy which commonly contemplates being qua being, since being is among the things spoken of as derived from one thing and with reference to one thing, will mostly consider this [first] nature, to which the other things which it discusses are referred, and from which they derive their being. ${ }^{35}$

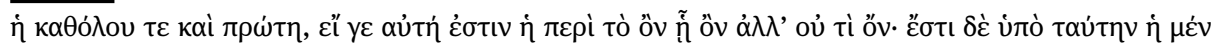

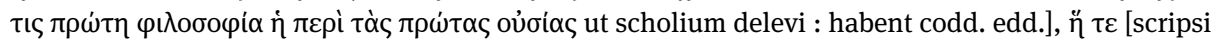

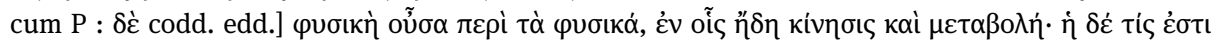

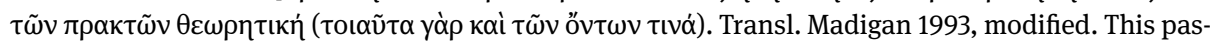
sage was perceived as problematic by Andronicus Callistus (one of the scribes of Parisinus gr. 1878;

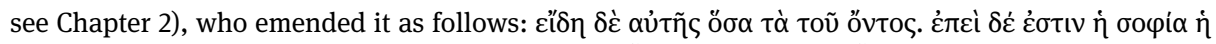

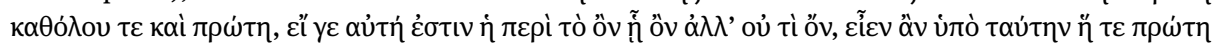

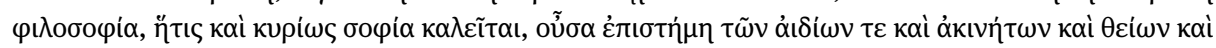

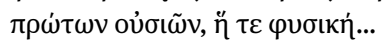

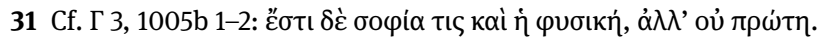

32 See Guyomarc'h 2015: 179.

33 Genequand 1979.

34 See, eminently, Jaeger 1912.

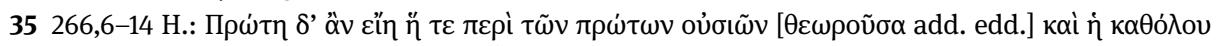

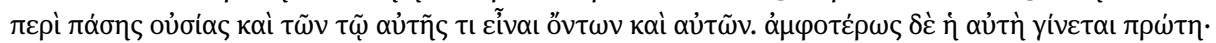

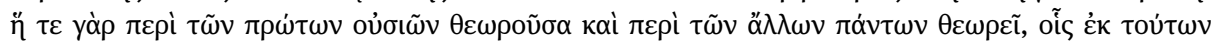

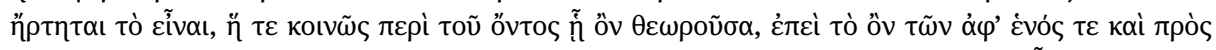

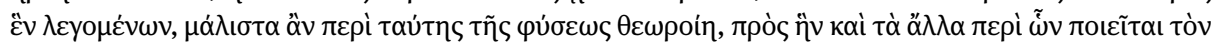

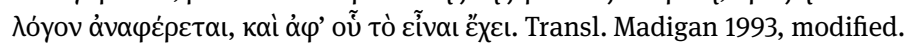


First philosophy and universal philosophy are two aspects of the same science. By studying the immaterial divine substances, which are "first" because all other substances (and, in virtue of the latter, all beings said in the categories other than the category of substance) derive their being from them (or acquire their form for the sake of them), first philosophy studies all other things in that it studies the first principles and causes to everything else; and, on this account, first philosophy is also universal philosophy. For knowledge of the first principles as immaterial forms that function as final causes to everything else yields to the first philosopher the universal knowledge that the form of each thing, regardless of what each thing is, is what is best for each thing to be and that according to which each thing has unity and being, sameness and otherness etc. By studying being universally, that is, being qua being, universal philosophy studies the widest effect of, and discovers as its cause, the eminent being, i.e. the divine and first substance, from which all other being derives and with reference to which it is (and is said) being; and, on this account, universal philosophy is also first philosophy. For knowledge that to be, to be one, to be one-and-many, to be the same as and other than, to be similar to and dissimilar to etc. in a universal sense (i.e. regardless of what each thing is), is to have a form yields to the universal philosopher knowledge of a First Form or Substance, from which each form (or being) is derived.

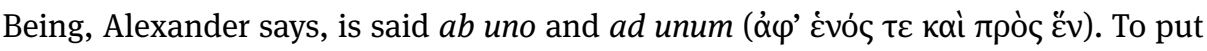
it simply, this means that there are beings which are more beings than other beings and that there is a being which is being in an absolute sense, that is, it is being in such a way that no other being is. These beings are indeed the first principles and causes,

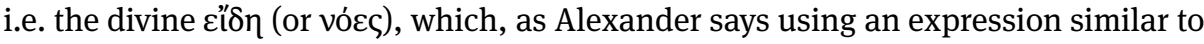

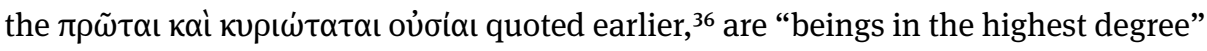

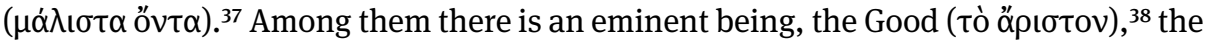
knowledge of which constitutes wisdom; this is what the Metaphysics strives for:

The knowledge of that which is being in the most proper sense, and the best of beings, and being in the highest degree, is the greatest good [for man] and the end of wisdom. ${ }^{39}$

In order to understand what is absolute being and how one being is more being than another, we now have to turn to Alexander's noetics and its relation to cosmology.

36 See 9.8-9 (quoted above, p. xxv).

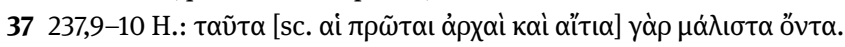

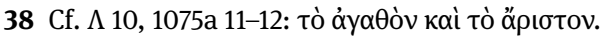

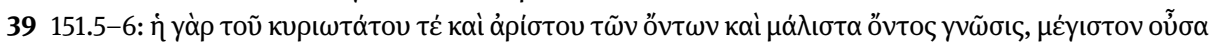

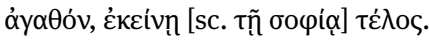




\subsubsection{The significance of Aristotelian noetics for a unified reading of the Metaphysics}

In his treatise On the soul Alexander says that "for all things, whatever is in the highest

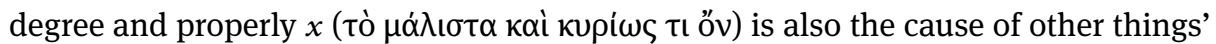
being $x " \cdot{ }^{40}$ For instance, what is visible in the highest degree, i.e. light, is the cause of the greater or lesser visibility of all other things. ${ }^{41}$ This principle being valid overall, ${ }^{42}$ and since all things have forms, there must be a Form that is the cause, to a greater or a lesser degree, of the form of all other things, a "Form of forms", as Aristotle says, ${ }^{43}$ or, in Alexander's words, a "First Form":

Now, the First Form would be cause also qua efficient cause. For [Aristotle] says in the Metaphysics that that which is moved by it, "that" being the fifth body, "moves the other things", i.e. those that come to be and perish. It is in this way that [the First Form] moves qua efficient cause. On the other hand, insofar as everything achieves its perfection through its desire for [the First Form], as we said a little earlier, and insofar as, as Aristotle himself says again in the Metaphysics, "it moves qua being loved", it would be cause qua end and that for the sake of which; for this is "what is desired". ${ }^{44}$

Since each thing is what it is according to its form, the First Form will be the cause of being or essence of all other things; indeed, the Form of forms will be the First cause, since it will be the immediate or mediate cause of all forms or essences and, through them, of all secondary beings (i.e. beings which depend on essences or substances). ${ }^{45}$

40 See above n. 20.

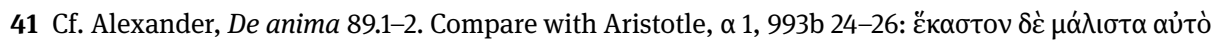

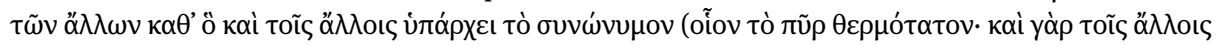

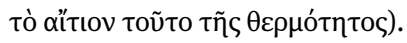

42 Gyuomarc'h (2015: 21) calls it "principle of maximum causality" (principe de causalité du maximum) and rightly describes it as "one of the cardinal schemes of Alexander's thought".

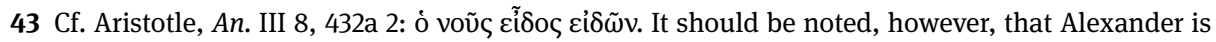

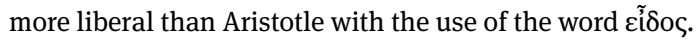

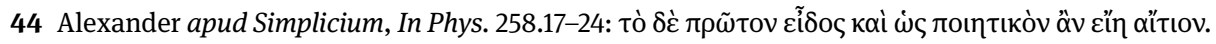

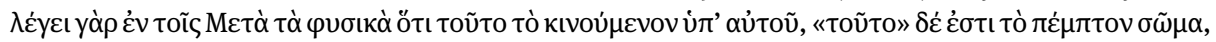

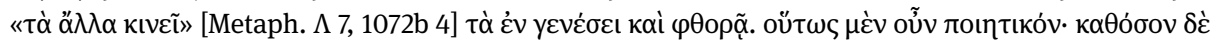

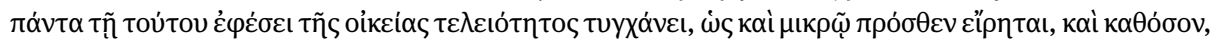

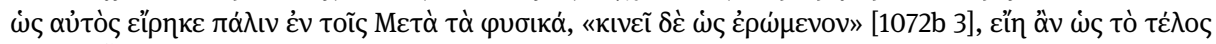

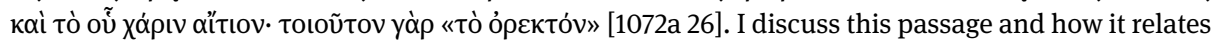
to Alexander's contention that God (or First Form) is solely the final cause of the universe in Golitsis 2017.

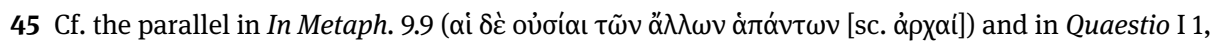

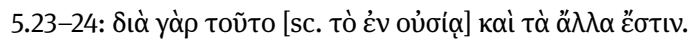


Now, that which is form in the highest degree is the form which has no matter at all, i.e. either in knowledge or in the thing itself. ${ }^{46}$ This form is "the intelligence in the

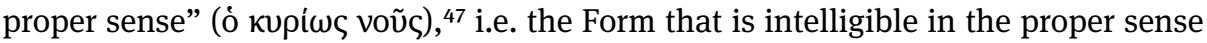

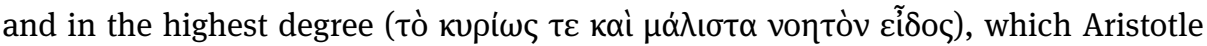

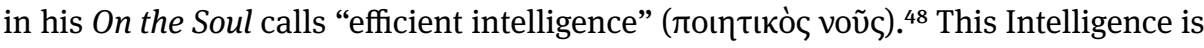

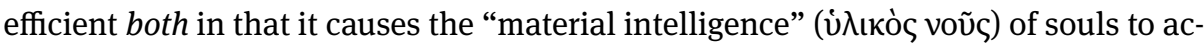

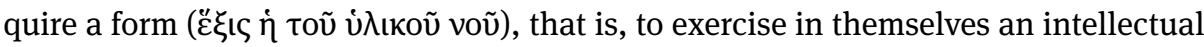
activity, ${ }^{49}$ and in that it is the cause of being of all intelligences ( $\tau \dot{\alpha}$ vooú $\mu \varepsilon v \alpha$ ), in other words the immaterial vó $\varsigma$ which are responsible for the motions of the ensouled bodies of the heavens. ${ }^{50}$ This means that the kupí $\omega \varsigma$ voũ is responsible for all intelligibles,

46 Composite things, such as horse and tree for instance, are enmattered forms but are without matter

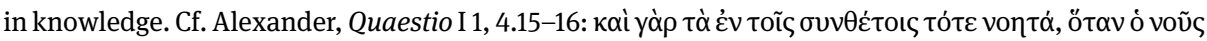

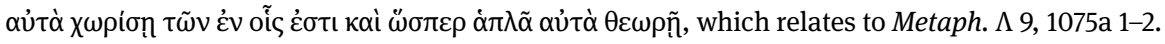

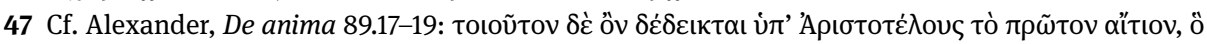

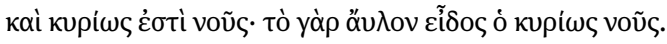

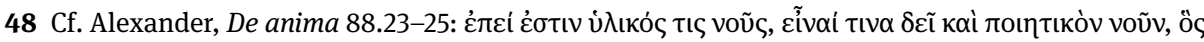

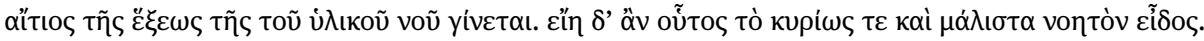
"Since there is some sort of material intelligence, there must also be some sort of efficient intelligence, which is the cause of the content that is present in the material intelligence. This [Intelligence] would be the form that is intelligible both in the proper sense and in the highest degree". Cf. Aristotle, $A n$. III 5, 430a 10-15; Aristotle speaks rather of $\pi \alpha \theta \eta \tau$ เкò voṽ (430a 24) but he relates this kind of voṽ s to what is potentially all things, i.e. matter (vँ $\lambda \eta)$, at the beginning of the chapter. The expression $\mu \alpha \dot{\lambda} \lambda \mathrm{s} \sigma \alpha$

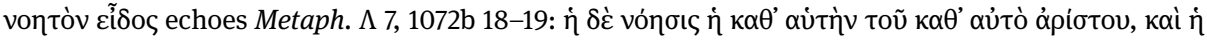

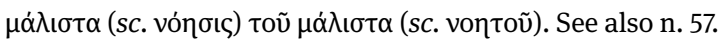

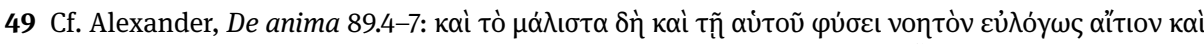

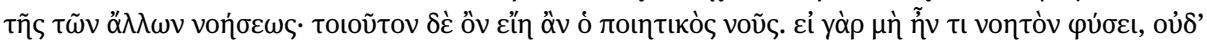

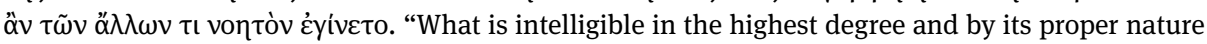
would reasonably be the cause of the intellection that other things have; this sort of thing would be the efficient intelligence. For if there were not something intelligible by [its own] nature, no other thing would become intelligible". The cause of the forms of all things is also the cause of the intellection of these forms by other intellects.

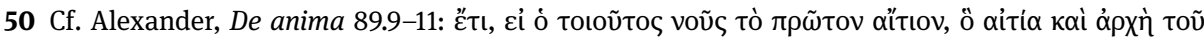

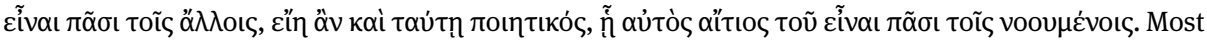
scholars (see lately Guyomarc'h 2015: 274-275) think that vooú $\mu \varepsilon v \alpha$ are equivalent to the $\alpha \lambda \lambda \alpha$ that become vontó (see preceding note). But, if this is the case, one cannot explain why Alexander intro-

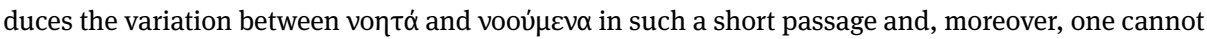

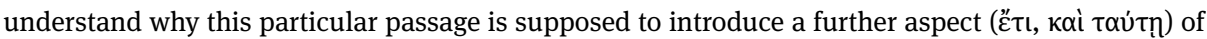
the efficiency of voṽc. In my opinion, Alexander here uses voov́ $\mu \varepsilon v \alpha$ as Aristotle uses it in $\Lambda 9$, where he says that "for things that have no matter", i.e. pure forms, "voũ

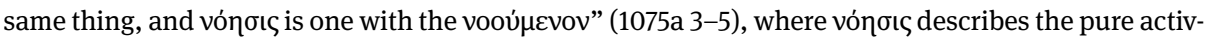

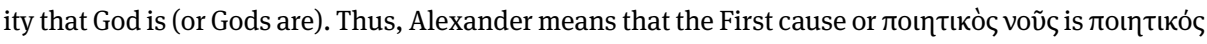
not only in that it produces the intelligible form that resides in the soul of the heaven but also in that it gives being to other pure vó $\varsigma$ which, by being present in the souls of the heavenly bodies, produce the rest of the heavenly motions. That the First cause is a cause of being for the other vóєs (and not merely a cause of motion for the outermost heavenly sphere) is an important idea, in itself absent in Aristotle, 
existing either per se or in intelligizing souls, which as objects of perpetually actual intellection are responsible for the formation of matter. ${ }^{51}$

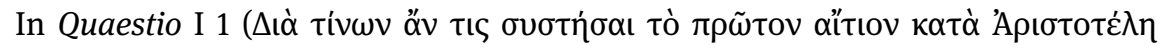
[Through what arguments one might establish the first cause according to Aristotle]), ${ }^{52}$ Alexander follows a different procedure. He argues that the best body, that is, the heavenly body, which, as best, is of course ensouled, is moving eternally and continuously in accordance with the impulse ( $\kappa \alpha \theta^{\prime}$ ò $\left.\rho \mu \eta \dot{v}\right)$ of its soul towards an eternal object that it intelligizes and desires. ${ }^{53}$ This object is "the ovjoí $\alpha$ that causes motion in the universe", ${ }^{54}$ which is unmoved (for if it were moved, it would itself require a cause of motion) and has no potentiality but is eternally actual (for if it had potentiality, it would potentially be the object of intellection and desire and the motion of the heavenly bodies would eventually cease). ${ }^{55}$ Being unmoved, this ov́oí $\alpha$ will be incorporeal, ${ }^{56}$ i.e. Form, and being by its own nature intelligible and eternally actual, this pure

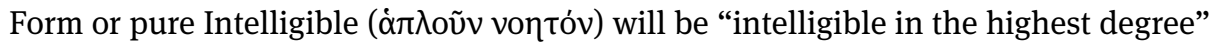

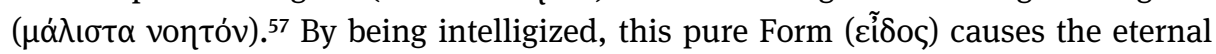
circular motion of the outer sphere of the fixed stars, ${ }^{58}$ which encompasses all other motions. Other such oúoía, we may add, are responsible for the rest of the heavenly motions.

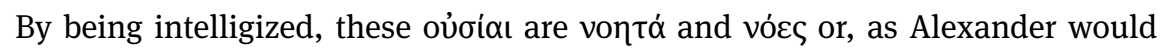
put it, immaterial forms ( $\left.\varepsilon^{\prime} \delta \eta \eta\right)$, and by being most intelligible, they are more forms

which we later encounter in the Metaphysics of the Book of Cure of Avicenna and in the subsequent Arabic tradition.

51 Matter is local in the case of heavenly bodies and substantial in the case of sublunary ones.

52 See Sharples 1992; Rashed 2007: 291-293.

53 Cf. Alexander, Quaestio I 1, 3.17-19:

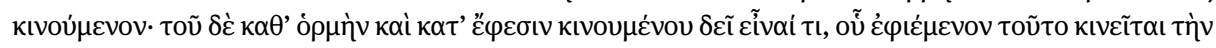

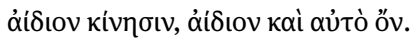

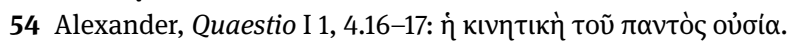

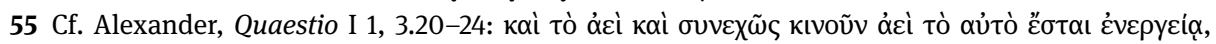

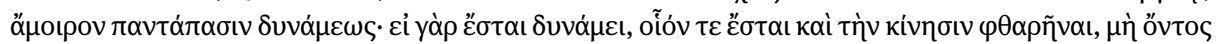

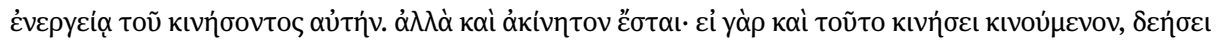

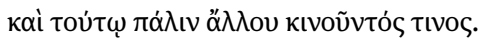

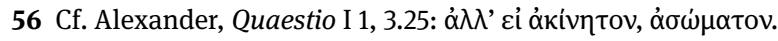

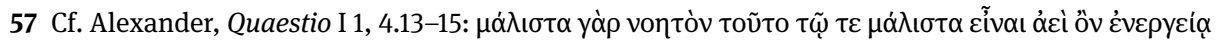

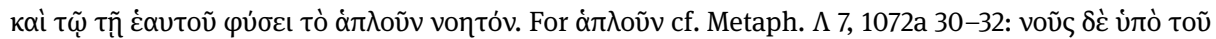

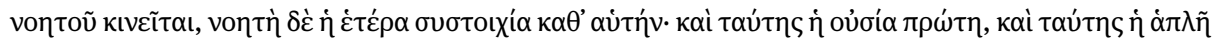

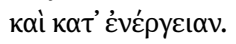

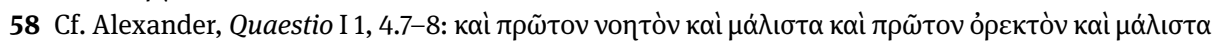

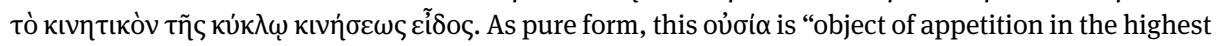

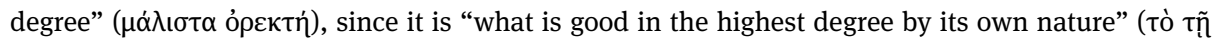

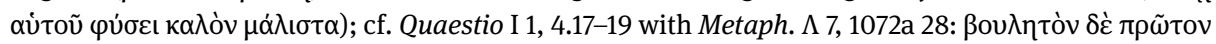

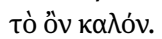




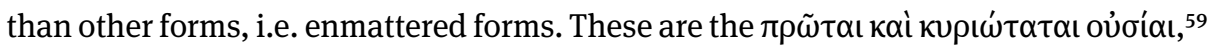
which Alexander mentions in his commentary on Metaph. A 2 as causes of being in its widest sense, namely being qua being. (Strictly speaking, it is only the First Form that is the cause of being qua being absolutely, since it gives being to the other immaterial forms too.) Indeed, whatever is, that is, "each thing of which we predicate being” (or each thing that has a form), ${ }^{60}$ is for the sake of - that is, it achieves its proper perfec-

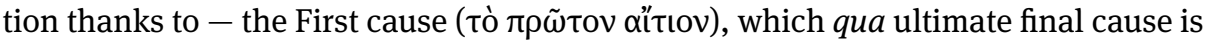
the Good:

All beings desire the supreme of the goods, that is, the Good, and the Good is the first cause. ${ }^{61}$

The rest of the $\pi \rho \tilde{\omega} \tau \alpha$ o oú ${ }^{\prime} \alpha$, the vooú $\mu \varepsilon v \alpha$, are subordinate to this First cause. They are the per se unmoved movers, the final causes of the eternal heavenly locomotions and thereby of the perpetual generations and corruptions that take place in the sublunary world, through which all material things preserve their form (which is what is best for each one of them) for a period of time. If the eternal heavenly bodies, Alexan-

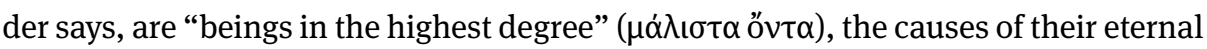
being - which, for Alexander, means the causes of their eternal motion ${ }^{62}-$ will be

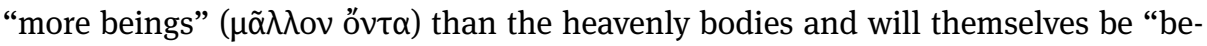
ings in the highest degree". ${ }^{63}$ The cause of being $x$ is "more being" than $x$ itself, ${ }^{64}$ and since being is to have a form, the Form which is the cause of all forms, i.e. the kupíws

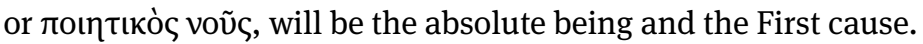

\subsubsection{The general structure of the Metaphysics and its culmination}

With this in mind, let us return to Alexander's unitary reading of the Metaphysics. When Alexander says, in his On the soul, that "Aristotle has shown that [a form separate from potentiality and matter] is the First cause, which is Intelligence in the proper sense", ${ }^{65}$ he must think of the Metaphysics and, in particular, of book Lambda. In the

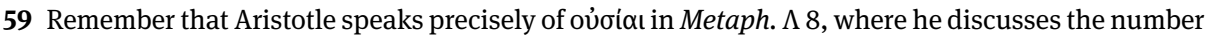
of the unmoved movers of the heavenly spheres; see n. 18.

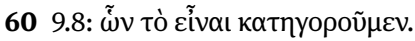

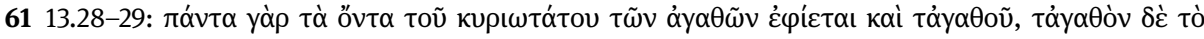

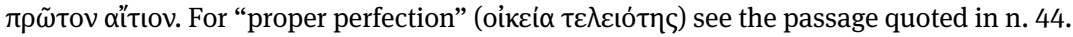

62 See Golitsis 2017.

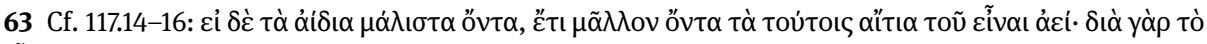

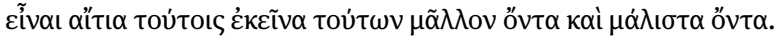

64 Thus, by transitivity, the heavenly beings, which are the causes of the eternity of the sublunary

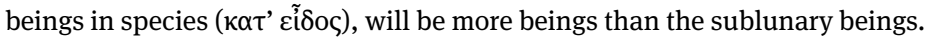

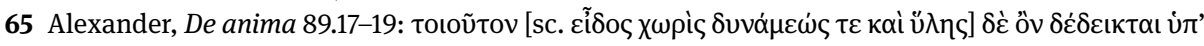

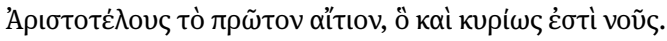


commentary on the Metaphysics, while commenting on the starting phrase of book Beta,${ }^{66}$ he gives a pertinent description of the science with which the Metaphysics is concerned:

\begin{abstract}
The science which is the object of the present inquiry and lies before [Aristotle] is both wisdom and the theological science, [contained in a treatise] which he also entitles 'Metaphysics' because it comes after the [treatise of ${ }^{67}$ physics in the order relative to us. He also calls it [i.e. both the science and the treatise which contains this science] 'First philosophy', because it contemplates

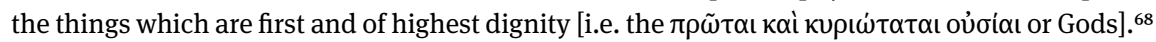
For this same reason it is also 'theological'. For Aristotle's discussion in the Metaphysics is chiefly ( $\pi \rho \circ \eta y o u \mu \varepsilon \dot{v} \omega \varsigma$ ) concerned with the cause, that is, the Form, which is on his view in every way an immaterial substance, which he calls both 'first god' and 'intelligence'. ${ }^{69}$
\end{abstract}

As a matter of fact, Aristotle does not speak of a 'first god' ( $\pi \rho \tilde{\omega} \tau 0 \varsigma \theta \varepsilon o ́ \varsigma)$ but he does speak of "the principle, that is, the first among beings, which is immobile both per se and per accidens" in book Lambda (Chapter 8), ${ }^{70}$ where he also discusses God as voũ

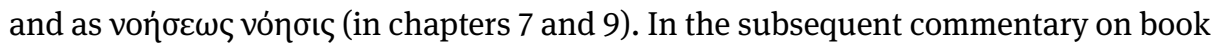
Beta, Alexander makes clear that Aristotle will discuss "whether there exists a cause that is separate and immaterial, and whether this cause is one or many in number

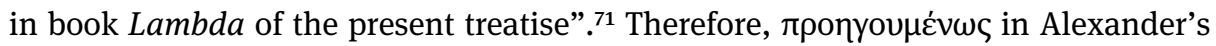
passage refers to the governing goal of the Metaphysics, which is the path leading to the possession of the divine science or knowledge of divine things, ${ }^{72}$ especially of the

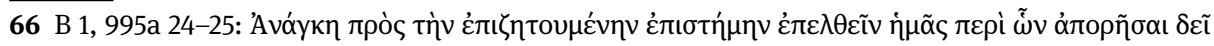
$\pi \rho \tilde{\omega} \tau o v$.

67 I take it that, had Alexander wished to designate not the treatise but the science of physics, i.e.

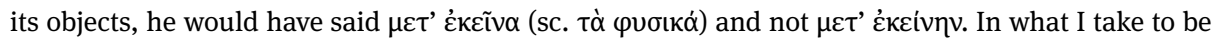
Alexander's prolegomena to the Metaphysics (see 1.8-11), Alexander says that Aristotle conceived of the Metaphysics as coming after the teaching of the Meteorology and the treatise On the Heavens, which thus belong to the general treatise of physics. This ordering reflects a bottom-to-top conception in the ordo cognoscendi of Aristotle's system.

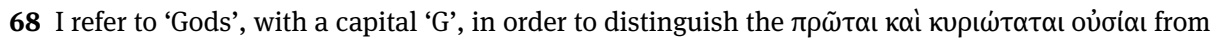
the lesser gods, i.e. the heavenly substances.

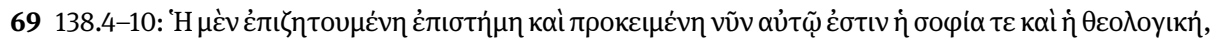

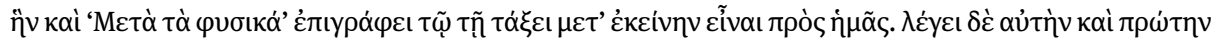

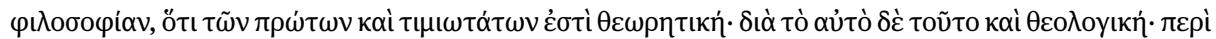

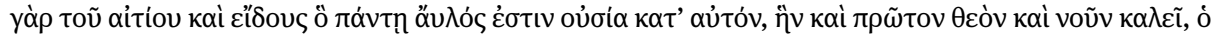

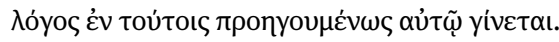

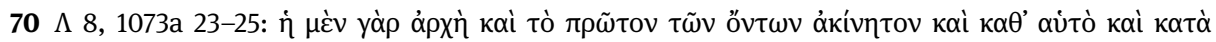

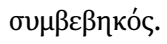

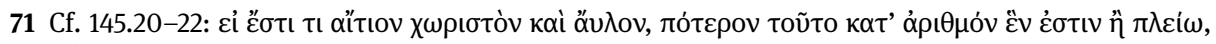

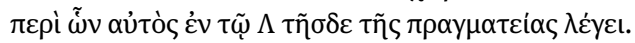

72 Cf. (in what I take to be, although possibly not in his very own words, Alexander's prolegomena to

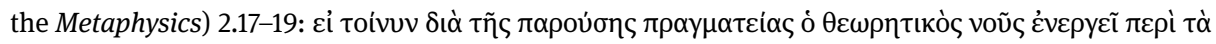

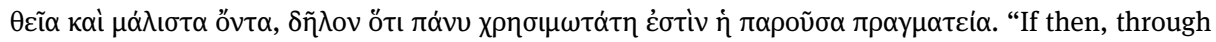
the present treatise, the theoretical intelligence [in us] becomes active with regard to the divine things 


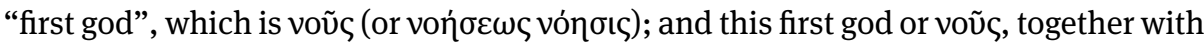
the rest of the vóç, are explored by Aristotle in book Lambda.

It is, thus, unfortunate that Alexander's commentary on Lambda and the preceding books did not survive, since it was in all probability through them that the Peripatetic exegete achieved his unitary reading of the Metaphysics. ${ }^{73}$ Nevertheless, thanks to some anticipating passages and to other works, as we have seen, we may safely surmise that Lambda, in which the first substances are made known and explored, represented for Alexander the culmination of the Metaphysics. Besides, Averroes testifies that Alexander rendered this approach clear in his prolegomena to Lambda:

\begin{abstract}
Alexander begins by saying that those who say that this book $\operatorname{La} m[=L a m b d a]$ is the last of this science are right because some of the other books [Aristotle] wrote concerning this science contain the difficulties that must be solved in it after they have been critically examined and others [contain] the solutions of these difficulties; this is what he did in the books which come before [scripsi : after codd. Genequand] this book..$^{74}$ In some books, he talks about the properties of being qua being; but in this book, he talks about the principles of being qua being and about the principle [(i.e. the First Principle) scripsi : principles codd. Genequand] of the first [domain of] substance [i.e. the intelligible substances], which is absolutely real..$^{75} \mathrm{He}$ does it by showing that there is a substance which is in this state and what this substance is; the elucidation of this substance is the final aim of this discipline. ${ }^{76}$
\end{abstract}

The intermediate books of the Metaphysics are accessory books, in which predominantly false paths ${ }^{77}$ towards the quest of the first substances are progressively done away with in accordance with the aporiae brought forth by Aristotle in book Beta. This

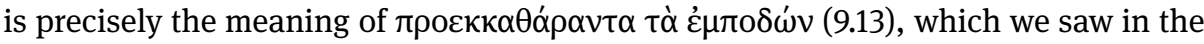

and beings in the highest degree, it is clear that the present treatise is extremely useful". Cf. A 2, 983a

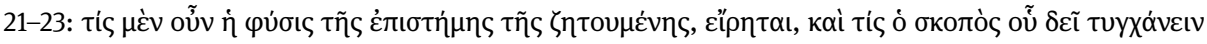

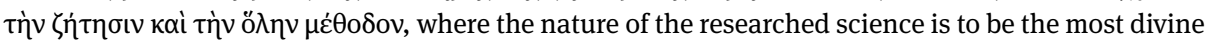
( $\theta \varepsilon ı \tau$ เó $\eta$ ) among the theoretical sciences and the skopos its possession by human beings (983a 11-12:

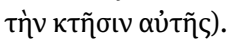

73 This point is also made by Movia et al. 2014: vi.

74 Aristotle, of course, raises and solves the difficulties that pertain to the science of the first principles in the books that precede book Lambda. That he should do so in the books following Lambda contradicts what Averroes says immediately afterwards about $M u$ and $N u$ ("In the two books which come after it, he does not explain anything pertaining to his primary aim”). Besides, as Stephen Menn tells me, the Arabic text employs the plural and not the dual, as one would expect from Averroes, had he in mind books $\mathrm{Mu}$ and $\mathrm{Nu}$. Notice that Averroes' comment may have influenced John Argyropoulos (1415-1487), who did not include books $M u$ and $N u$ in his Latin translation of the Metaphysics; see Argyropoulos 1515.

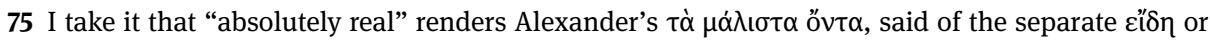
vóєs, causes of the eternal heavenly substances; "absolutely real" cannot qualify the first sensible substance, i.e. the heavenly substances.

76 Bouyges 1948: 1394; transl. Genequand 1986, modified.

77 I borrow the expression from Menn (forthcoming). 
beginning of this chapter, and to which Averroes' testimony also refers ("some of the other books [Aristotle] wrote concerning this science contain the difficulties that must be solved..."). ${ }^{78}$ The expression denotes a discourse that contributes, albeit in a negative way, to the knowledge of the issues related to the researched science, which has a single aim, i.e. the knowledge of the First substances. This is made clear also in the beginning of the commentary on Beta, where Alexander explains that, according to some interpreters, Beta could be seen as the first book of the treatise, since it is from this book onwards that Aristotle's main discourse is developed; by contrast, Alpha

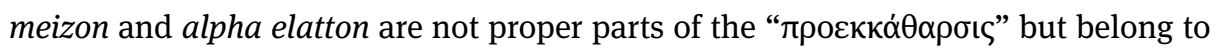

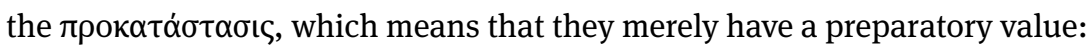

For Aristotle this is the starting point of the present treatise; for here he begins to speak of matters which have a necessary bearing on the issues proposed. The matters discussed in books alpha [i.e. Alpha meizon and alpha elatton] would be preliminary to this treatise and contribute to making

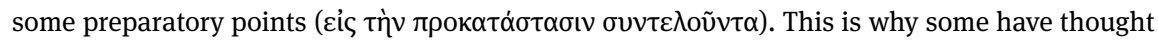
that the present book is the first of the treatise Metaphysics. ${ }^{79}$

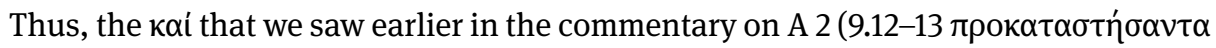

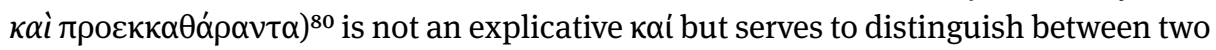

78 Di Giovanni - Primavesi 2016 have reservations as to the reliability of Averroes' testimony, considering that the book-by-book analysis (presented as part III) of Averroes' proem to book Lambda comes from the same source as Averroes' quotations from "Alexander"'s commentary on Lambda (including the passage quoted above, presented as part II), which would be the work of an unknown Greek reviser of Alexander's original work (hence "Alexander"). Here I cannot go into the details of their analysis, which is full of useful observations. I remain skeptical, however, as to their claim (against Freudenthal 1885) that the expression "we say" (Bouyges 1948: 1395.11), with which the book-by-book analysis is introduced, marks the beginning of Alexander's (or "Alexander's”) quotation, granted that such a device would lead to confusion, whereas Averroes systematically introduces his quotations of Alexander with the expression "Alexander says”. After quoting Alexander's passage which I quoted above, Averroes says (Bouyges 1948: 1395.9-10) "Yet what [Alexander] says with regard to understanding the contents of the other books [my italics] written on this discipline is open to interpretation [Stephen Menn suggests "is an overall survey"], and the passage best suited for being expounded [i.e. within the two thirds of Alexander's commentary on Lambda, which was all that was known to Averroes; see below, p. xlviii, n. 3] is perhaps this passage" (transl. Di Giovanni - Primavesi 2016: 23). In my interpretation, Averroes refers to the passage that he has just quoted, in which the content of book Lambda is explicitly specified by Alexander, whereas the contents of the other books are only alluded to. Averroes, therefore, uses Alexander's passage not only as an introduction to Lambda but also as a transition to his book-by-book analysis, which is based, of course, on sources other than Alexander's commentary (though some of them may somehow relate to Alexander's commentary).

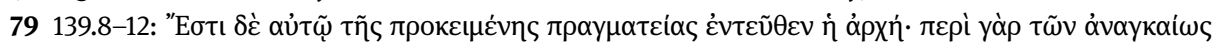

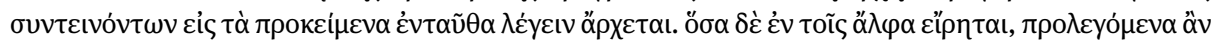

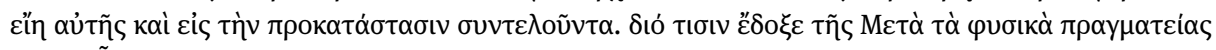

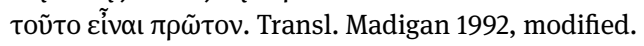

80 See above, p. xxv. 


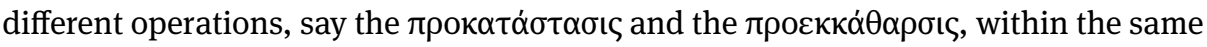
treatise, before the culmination arrived at in book Lambda.

Alexander's prolegomena to book Gamma enable us further to see how he conceives of the sequence of the first four books of the Metaphysics:

Having proposed to consider being qua being in the treatise Metaphysics, a treatise which he also calls 'wisdom' and 'first philosophy', and which he is accustomed at times to call 'theological [science]' as well; and having shown [in A 1] that the proposed treatise is not one of those arts or sciences concerned with the knowledge of the necessaries of life, nor of those concerned with the useful, but rather will pursue the things which it pursues for the sake of knowledge and of science as such; and having shown [in A 2] that it contemplates the first principles and causes (for these are beings in the highest degree); and having, before inquiring which principles are the first principles, set in motion in general terms [in $A$ 3] the discussion of the causes; having presented [in A 4-6] the views of his predecessors concerning the principles, having related them and replied to them [in A 7-10]; having shown that there are certain first principles and [in $\alpha$ ] that the ascent to principles does not go to infinity; and further, having raised [in $B$ ] certain aporiae concerning being and the principles, as well as related matters (this being useful and necessary for the discovery of the objects proposed to wisdom), after the aporiae he henceforth begins the present book $[\Gamma]$, hereafter telling and establishing his own doctrines and solving the points of aporia from this book onwards. In this book he shows what things wisdom, which [in this book] he also calls 'philosophy' and 'first philosophy', is concerned with. ${ }^{81}$

Further, Alexander claims that book Delta rightly comes after book Gamma, since in it Aristotle discusses those plurivocal terms which are not peculiar to any particular science but to all sciences, as is to be expected from the universal science of being qua being, whose content has been clarified in Gamma:

That this is also the proper place for the book [= Delta] is obvious, on the one hand, from the fact that [in it] Aristotle distinguishes those things expressed in various ways that [all] the sciences employ and that are the common concomitants of being. He said in book Beta, too, that the philosopher must treat of these things, distinguishing the number of ways in which each of

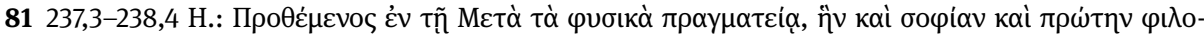

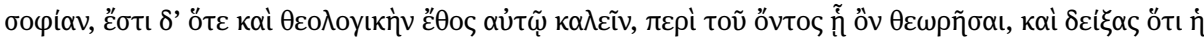

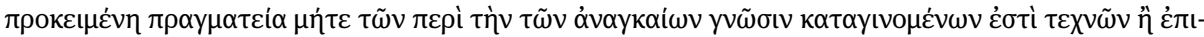

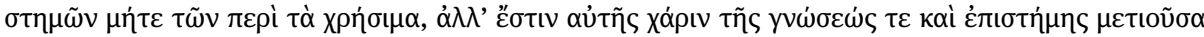

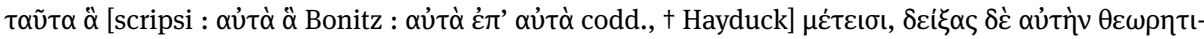

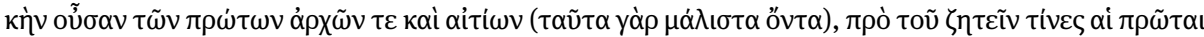

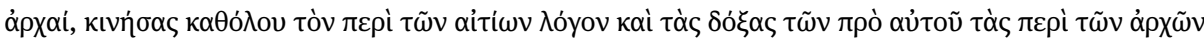

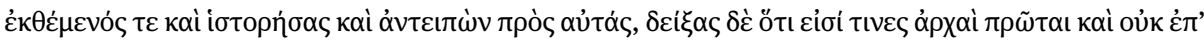

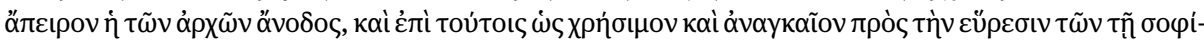

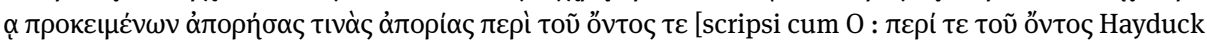

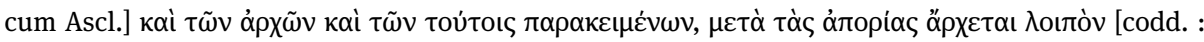

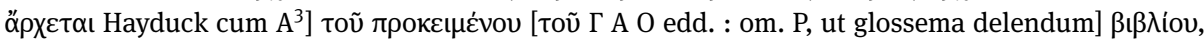

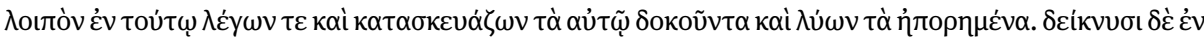

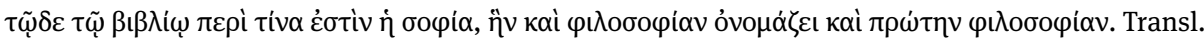
Madigan 1993, modified. 
them is said. On the other hand, book Gamma showed what things first philosophy contemplates; and the immediate sequel to this last point is to examine those first [items] that must be used in order to investigate and prove the other things that are going to be proved. Hence [Aristotle] spoke first about the axiom which [says] that in every case either the affirmation or the denial must [be true], since this axiom is useful for formulating proofs. After that inquiry, he distinguishes, in this book, the things that are thus expressed in various ways. ${ }^{82}$

According to Alexander's unitarian reading, the four books that follow Delta (the commentary on which unfortunately does not survive) will precisely treat the most important of those plurivocal items, namely being, the principles of which are investigated throughout the Metaphysics: Epsilon will treat being per accidens and veridical being, Zeta and Eta will treat being per se, and Theta will treat actual and potential being. ${ }^{83}$ All this preliminary study of being contributes to the knowledge of the first principles, which will be shown (in Lambda) to be eternally actual immaterial substances, causes of being per se.

\subsection{Alexander's commenting method}

Alexander taught Aristotle because he philosophised with Aristotle. ${ }^{84}$ Several repetitions and asyndeta in the course of the commentary betray its oral origin. ${ }^{85}$ (By con-

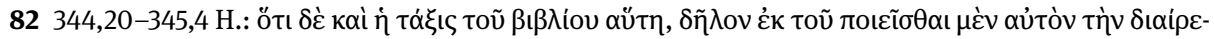

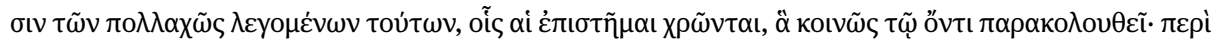

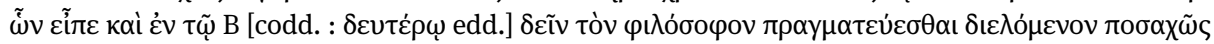

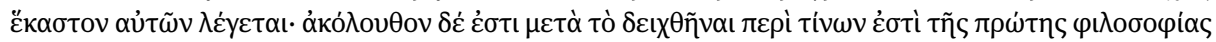

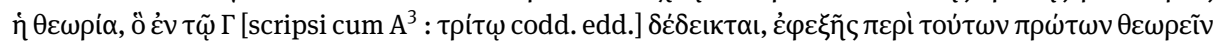

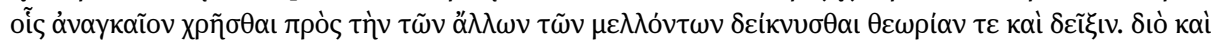

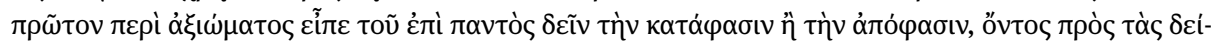

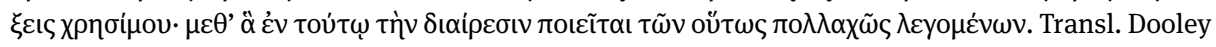
1993, modified.

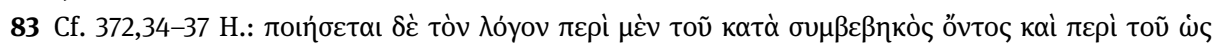

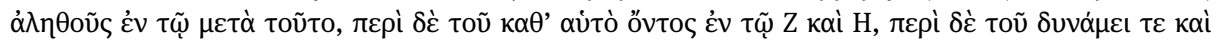
$\dot{\varepsilon} v \tau \varepsilon \lambda \varepsilon \chi \varepsilon \dot{\alpha} \alpha \dot{\varepsilon} v \tau \tilde{\omega} \Theta$. Rashed 2007 offers a reconstruction of how Alexander would interpret the central books of the Metaphysics.

84 In this respect, his approach is different from that of the Neoplatonists (for instance, Plotinus, Syrianus, Proclus, Ammonius and Simplicius) who taught Aristotle but stricto sensu did not philosophize with him but with Plato.

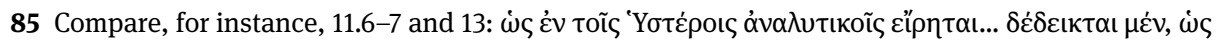

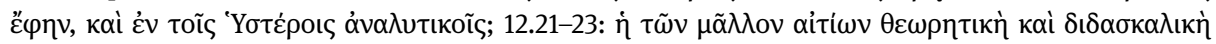

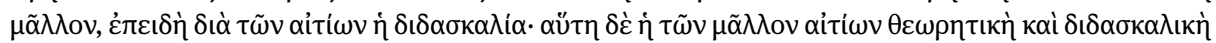

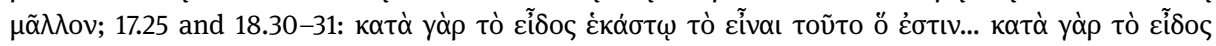

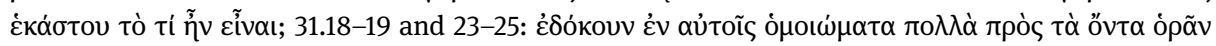

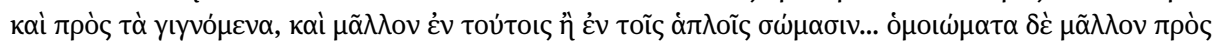

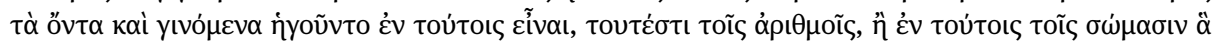


trast, Alexander's monographs ( $\mu$ ovó $\beta \iota \beta \lambda \alpha$ ), such as the De anima, the De fato and the De mixtione, were conceived right from the start as written works.) While lecturing on Aristotle's Metaphysics, the Peripatetic 'diadoch' would apparently use all exegetical works that were available to him. ${ }^{86}$ These certainly included Aspasius' commentary, ${ }^{87}$ as well as anonymous scholia of various origins probably mentioned by Aspasius himself or transmitted in the margins of papyrus rolls next to Aristotle's text.

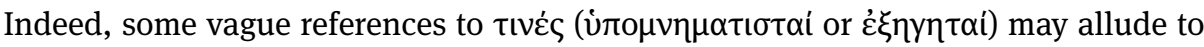
such marginal scholia, ${ }^{88}$ which, together with Aspasius' commentary and the memory of (his) Aristotle's oral teaching, ${ }^{89}$ must have been his sources also for the variae lectiones that he reports. At 85.5, Alexander refers to a passage of Aristotle's text that

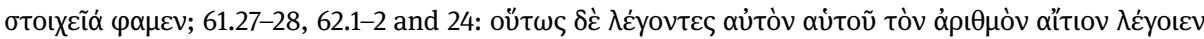

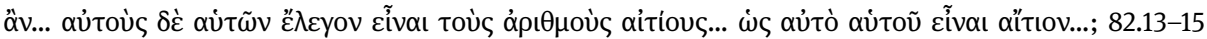

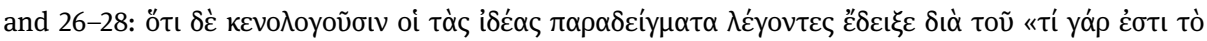

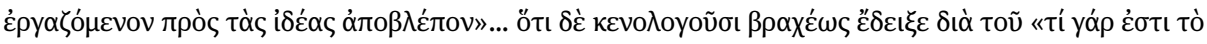

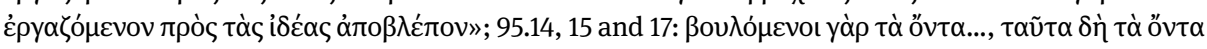

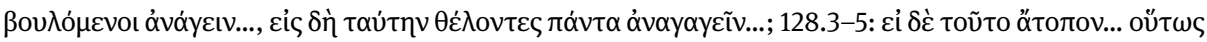

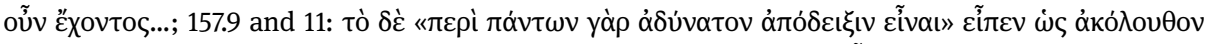

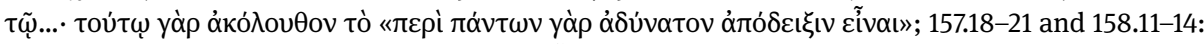

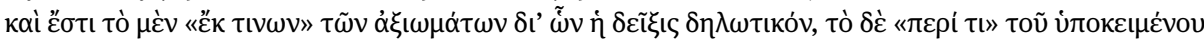

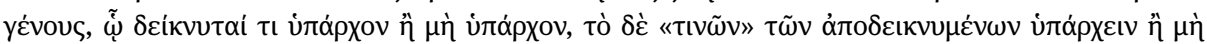

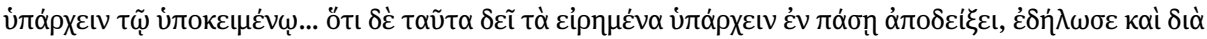

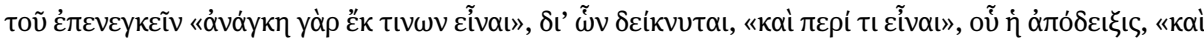

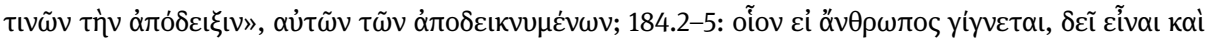

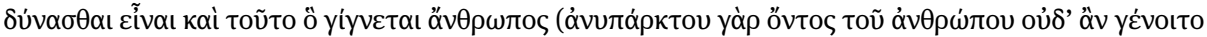

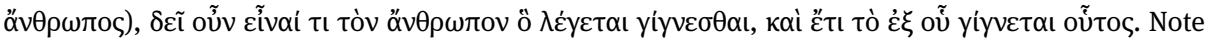

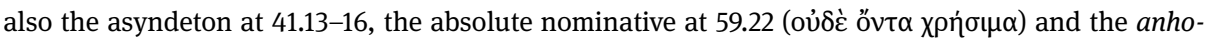

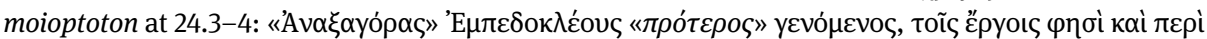

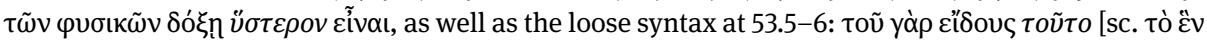

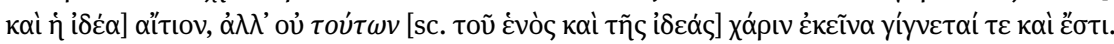

86 On Aristotelian commentators before Alexander see Sharples 1987 and Gottschalk 1990.

87 Alexander refers explicitly to Aspasius only three times, twice $(34.27,379,3 \mathrm{H}$.) with regard to an alternative interpretation that, although it is not endorsed by Alexander, is deemed worthy to be quoted, and once (48.28) with regard to the origin of an interpolation in Aristotle's text, towards which Alexander seems to be skeptical. Nevertheless, Alexander's tacit borrowings from Aspasius, each time the latter explained Aristotle's text well, must have been much more. The minutiae, with which Aspasius deals in these three known cases, suggest that Aspasius composed a proper commentary on the Metaphysics (such as the commentary he also composed on the Nicomachean Ethics).

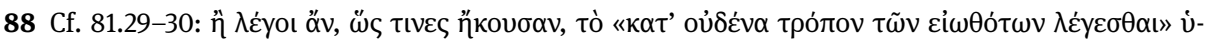

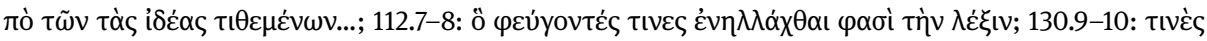

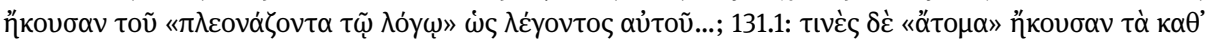

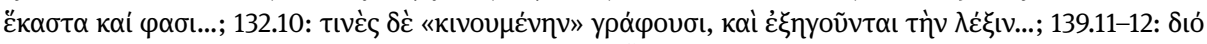

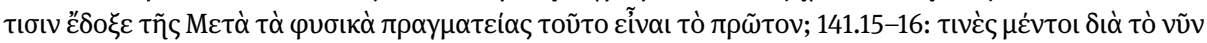

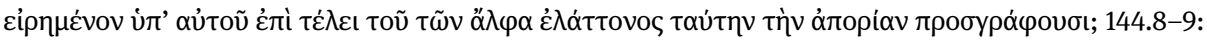

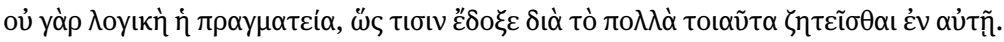

89 Aristotle (of Mytilene?) was one of Alexander's teachers in aristotelicis - his other teachers were Sosigenes (cf. Alexander, In Meteor. [= Hayduck 1899] 143.13) and Herminos (cf. Simplicius, In Cael. [= 
is not transmitted in all manuscripts and, hence, did not receive a commentary ( $\delta$ ıò

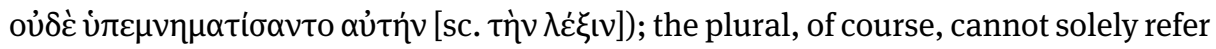
to Aspasius. It is possible that passages preceding an alternative explanation, which are introduced by Alexander with an $\eta$, are actually bits of Aspasius' commentary. ${ }^{90}$

Alexander uses a form of commentary which is less sophisticated and less "scholastic" than the Aristotelian commentaries of later centuries. ${ }^{91}$ Indeed, Alexander's exegetical activity predates important technical works of late antiquity, such as

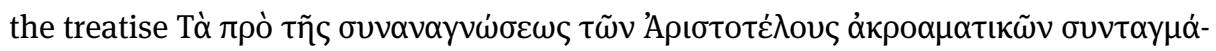
$\tau \omega \nu$ [What comes before the reading in class of Aristotle's acroamatic writings] by Proclus, ${ }^{92}$ which must have had quite an impact on the systematization of the form of the Aristotelian commentary. Still, one finds in Alexander's commentaries a discussion, which was later made compulsory, of introductory points to a treatise (the so-called $\kappa \varepsilon \varphi \alpha \dot{\lambda} \alpha \iota \alpha$ in the later tradition), although this is not made in a straightforward and systematic way. In his prolegomena to the Prior Analytics, Alexander explains, among

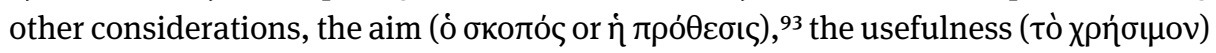

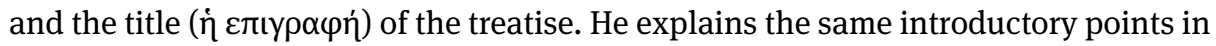
his commentary on the Topics, but this time as part of the commentary on the opening sentence of the treatise, which specifically calls for such explanations. ${ }^{94}$ In his commentary on On the Sense and What Is Sensed, Alexander only briefly discusses the aim of the treatise (since this is immediately made clear by its title) and its arrangement

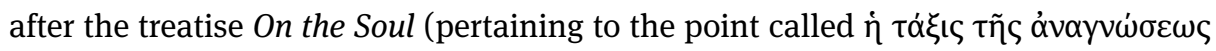
by later commentators). His commentary on the Meteorology does not contain any prolegomena at all; nonetheless, as with the Topics, this is only apparently so, since Alexander's commentary on the opening lines of the Meteorology, in which Aristotle resumes his investigation on nature, ${ }^{95}$ makes by itself a sort of prolegomena, in which the ordering ( $\dot{\eta} \tau \dot{\alpha} \xi ı \varsigma$ ) of the treatises belonging to the second branch of Aristotle's theoretical philosophy, i.e. physics, is thoroughly articulated.

Our manuscripts of the commentary on the Metaphysics lack its beginning, so we cannot be certain whether Alexander wrote prolegomena to the Metaphysics or not.

Heiberg 1894] 430.32-33); on these Peripatetics see lately Kupreeva 2016. Alexander mentions, albeit with some slight criticism, (his) Aristotle's proof of the causes not being infinite in the context of $\alpha 2$, 994b 27-31 (see 134.6-20).

90 E.g. 23.3-5, 23.23-27, 26.6, 27.30-32, 31.3-4 etc.

91 On the form and content of late antique philosophical commentaries see Hoffmann 2006.

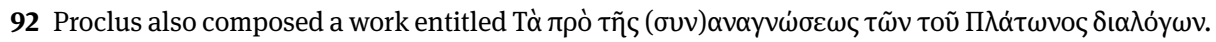
On these two works see Mansfeld 1994: 7 and 22.

93 The term бколо́ ̧ becomes prevalent in the later tradition.

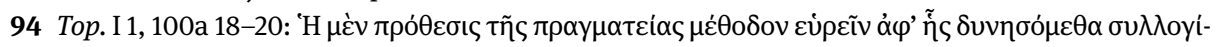

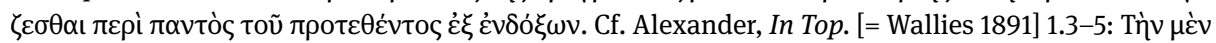

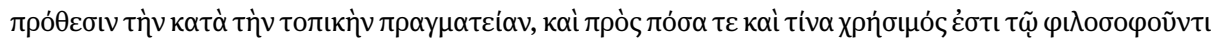

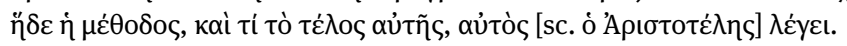

95 Cf. Meteor. I 1, 338a 20-339a 9. 
Nevertheless, as this lack of beginning was probably due to the loss of the first folio of the archetype, i.e. a late antique codex written in uncial letters, ${ }^{96}$ and since the equally missing beginning of the commentary proper is approximately only half a CAG page (as we can deduce from a comparison with the so-called "recensio altera"), ${ }^{97}$ we are compelled to posit that Alexander wrote some prolegomena to the Metaphysics; for half a CAG page would correspond only to the verso of the lost first folio of the archetype. A possible counter-argument would be that the "recensio altera" itself, which closely follows Alexander's commentary, delivers the beginning of the commentary proper but no prolegomena; so Alexander's commentary should have likewise omitted any prolegomena. This argument, however, is weak. For it is quite probable that the anonymous late antique prolegomena to the Metaphysics contained in codex Parisinus Coislin 161 [C], published by Paul Moraux, ${ }^{98}$ are the prolegomena to the equally anonymous "recensio altera", which was copied without prolegomena on the model of the extant manuscripts, probably because there was a need of strict correspondence between Aristotle's text and the surrounding commentary (as it indeed happens in manuscripts Laurentianus plut. 87,12 [L] and Ambrosianus F 113 sup. [F], which contain the "recensio altera"). ${ }^{99}$ Moraux showed that these prolegomena are to be dated to the 6th/7th century, just like the "recensio altera". Not surprisingly, these anonymous prolegomena incorporate elements drawn from the commentaries of both Alexander and Asclepius, as generally happens in the "recensio altera" ${ }^{100}$ Most importantly, it seems that there is a back reference to these prolegomena in the

96 See below, Section 2.1.

97 On this anonymous late antique commentary on the Metaphysics, misleadingly known since Hayduck's edition as the "recensio altera" of Alexander's commentary, see below, Section 2.1.

98 See Moraux 1980.

99 Given that the monk Malachias, who is the scribe of $\mathbf{C}$, restored some problematic passages in Alexander's commentary with the help of a copy of the so-called "recensio altera", different from the extant copies which could be known to him, that is, $\mathbf{L}$ and $\mathbf{F}$ (see the description of $\mathbf{C}$ in 3.1), we may surmise that the copy he used also contained the prolegomena. Besides, it is unlikely that these ancient prolegomena were transmitted from late antiquity separately as part of some mysterious miscellany.

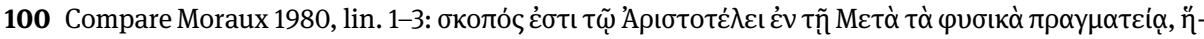

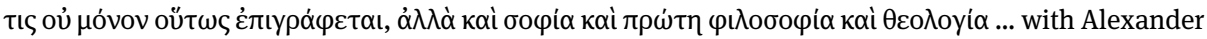

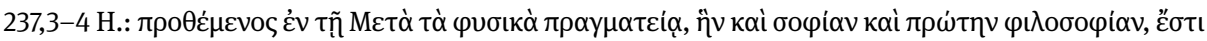

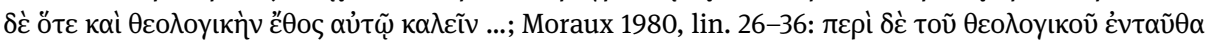

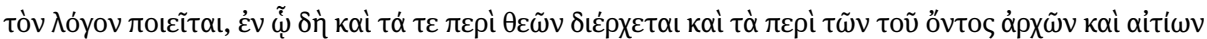

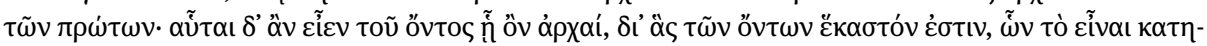

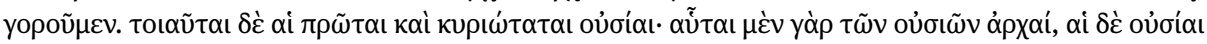

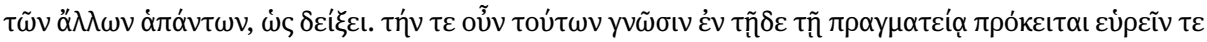

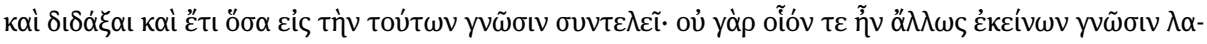

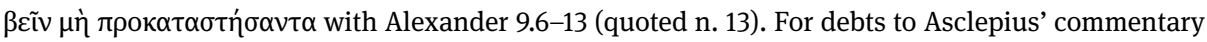
see Moraux 1980: 62-63. The slight reformulations and omissions with regard to Alexander's text are reminiscent of the method of the anonymous commentator. 
prooemion of the anonymous commentary on book Beta. ${ }^{101}$ In the present edition, therefore, I have ventured to reconstruct Alexander's lost prolegomena to the Metaphysics with the help of Asclepius' commentary ("from the voice of Ammonius"), not only because Asclepius' commentary is largely based on Alexander's but also because I have found some strictly parallel ideas between Asclepius' prolegomena to the Metaphysics and Alexander's prolegomena to the Prior Analytics. ${ }^{102}$ Alexander's wording, however, may have undergone some alterations.

Having laid out the prolegomena, the ancient commentators proceeded by divid-

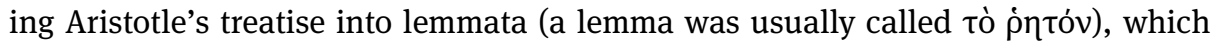
were successively commented upon and explained. The explanation focuses mainly on two aspects of Aristotle's text, namely its sense (ó voũৎ) and its wording ( $\dot{\eta} \lambda \varepsilon \dot{\varepsilon} \xi ı)$. Alexander uses these technical terms in his commentary, ${ }^{103}$ as he also distinguishes once between $\theta \varepsilon \omega \rho i ́ \alpha$ and $\lambda \varepsilon \dot{\xi} \xi{ }^{104}$ a distinction conventionally used in the commentaries produced in late antique Alexandria. The latter terms, however, are used by Alexander as merely equivalent to voũ and $\lambda \dot{\varepsilon} \xi ı$ and do not refer to two different stages of lecturing on Aristotle (the first delivering en bloc the doctrine contained in a given portion of text, the second commenting on the same portion of text bit by bit and focusing on its wording), as in the commentaries of the schools led by Ammonius and Olympiodorus. ${ }^{105}$

Although Alexander rarely makes the distinction between voũ itly, he systematically comments on Aristotle's wording (when needed) at the end of his comment on a given lemma. ${ }^{106}$ Before that, he usually places tò ṕntóv within the larger argument of Aristotle and then paraphrases, selectively quotes (Alexander calls a portion of the lemma tò cipn $\mu$ ćvov) and explains it, occasionally supporting his paraphrase with developments coming from other works of Aristotle. It is typical

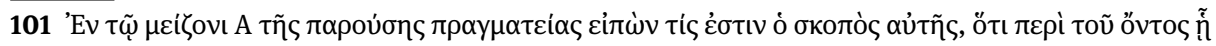

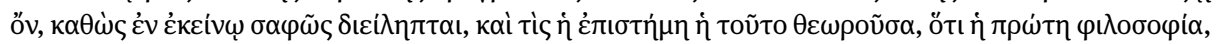

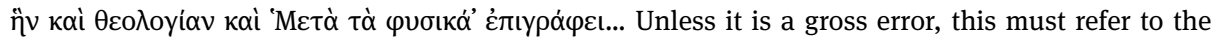
anonymous prolegomena, especially lin. 26-36 in Moraux 1980 (quoted in the previous note). The agent complement of $\delta เ \varepsilon i \lambda \eta \eta \tau \alpha \iota$ is not Aristotle but the anonymous commentator himself.

102 See the apparatus fontium ad locum.

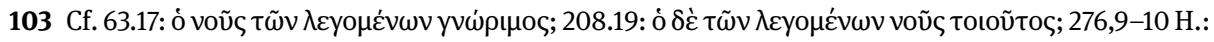

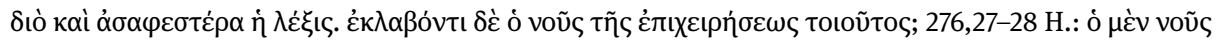

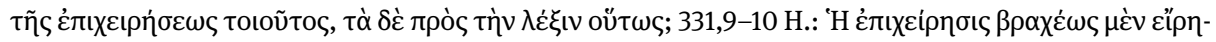

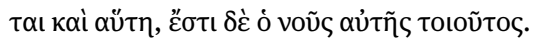

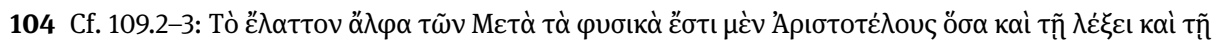

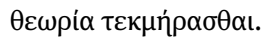

105 See Golitsis 2008: 55-57. Évrard 1957 (an unfortunately unpublished doctoral dissertation) still provides the best discussion of what he thoughtfully labelled "la pratique de la double exégèse".

106 These particular comments on lexis are printed in the present edition in separate paragraphs. Exceptionally, and when this is required in order for the text to be intelligible, the lexis is dealt with by Alexander in the beginning; see 17.11, 58.6 and 153.19. 
of Alexander to explore in his comments diverse possibilities of interpretation without concluding. Seen in a historical perspective, Alexander's commentaries display a primitive form of the more systematic form that we later encounter in the Neoplatonic commentaries.

The extant manuscripts always record as lemma only the beginning of the passage to be commented upon. It is clear, however, that in the course of teaching the passages of the Metaphysics were read out (either by Alexander or, more probably, by

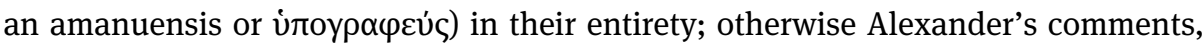
which do not always quote but always presuppose Aristotle's text in its entirety, ${ }^{107}$ could not (and cannot) be understood. A clear case is seen under lemma 980b 25-26, where the past tense $\varepsilon \delta \varepsilon ı \xi \varepsilon v(5.7)$ presupposes Aristotle's text down to 981a 7. Sometimes, however, Alexander's initial comment (that is, the comment that comes immediately after a lemma) is not a freestanding phrase but depends syntactically on the

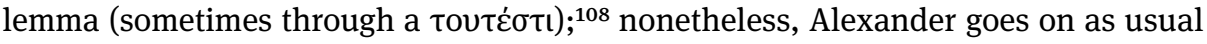
with his comments presupposing much more text than the portion that appears in the lemma. This suggests the following oral practice: the first time the amanuensis would read out in class the entire passage to be commented on; then, Alexander would reread the first sentence (which appears as lemma in the manuscripts) and would directly proceed to elucidate it. It is interesting to notice in this respect that Averroes used a manuscript of Alexander's commentary on Lambda, which contained Aristotle's text in its entirety. ${ }^{109}$ Inasmuch as the separate transmission of Alexander's commentary on book Lambda, to which Averroes had access, ${ }^{110}$ may ultimately go back to an ancient papyrus edition in many volumina (the use of papyrus rolls clearly prevailed over the use of codex in AD 200), it is possible that Averroes' testimony reflects the very first edition of Alexander's commentary, in which full lemmata alternated with the comments.

It is only natural to think that, throughout his teaching career, Alexander would return to his commentary in order to improve his comments or to make additional ones, which he would confine to the margins of his manuscript. We may adduce some examples. It is evident that, in a passage that we have quoted and discussed before, ${ }^{111}$

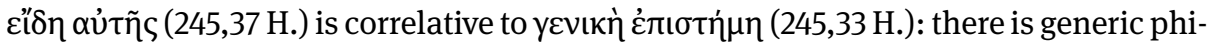

107 This characteristic of Alexander's exegesis enables the editor to detect a few omissions in the manuscripts of the Metaphysics used by Alexander, that is, passages that he leaves without comment. In the present edition, these omissions are signalled in the apparatus lectionum aristotelicarum.

108 Cf. 8.18, 17.29, 21.13, 26.22, 27.5, 28.22, 35.23, 41.7 and 42.29.

109 Cf. Bouyges 1948: 1538: "I found the section which I transcribed first in the manuscript of Alexander blended with the text of Aristotle", and 1545: "I found that in the rest of this section the text of Aristotle is lacking in the commentary of Alexander and I completed it from the second translation"; transl. Genequand 1986.

110 See below, p. xlviii, n. 3.

111 See n. 30. 
losophy and there are also its species, i.e. first philosophy, physics and ethics. But this correlation is interrupted by the following passage (which has caused some trouble for interpreters):

It is shown through the things said [by Aristotle] that the division of being into genera, which he carried out in the Categories, belongs to first philosophy. At the same time, he has also indicated to us, through these considerations, how philosophy is one science: by being universal.112

This is an isolated statement by Alexander, who nowhere else in the commentary ascribes the division of the categories to first philosophy. I think that this is best explained perhaps as an afterthought and a supplementary comment, made by Alexander himself in the margin of his manuscript and copied later into the main text. Similarly, at 13.20-23 there is a second explanation of the same passage (982b 5-6), which is not an alternative but actually an improved and more complete explanation of what we read at 13.12-15:

(1) Having said "The science which knows for what end each thing must be done", [Aristotle] shows what kind of cause is one for the sake of which each thing must be done, saying: "This is the good"; for the final cause is of this short [...]. (1a) Wishing to make clear how the first cause is cause of the things that are, namely that it is [their cause] as an end, and that the science capable of knowing this kind of cause is more architectonic than those that produce the things that are for its sake, he made the statement that "The science that knows to what end each thing must be done is more authoritative than the ancillary science". ${ }^{113}$

That the second chunk of the passage may be a later addition seems to be supported by the fact that, whereas in the first chunk Aristotle's text is quoted according to Metaph. ${ }^{\beta}$

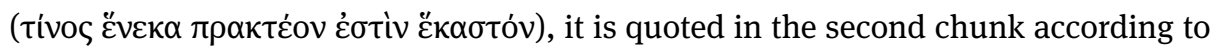

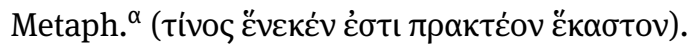

There are further passages of this sort that reflect this state of affairs. ${ }^{114}$ In $113.28-$ 114.4, for instance, the sentence "at the same time, he establishes through these considerations that the theoretical studies are worthy of our most serious efforts" (113.31-

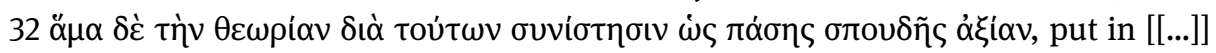

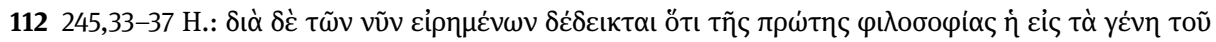

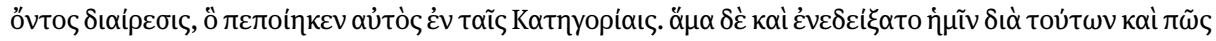

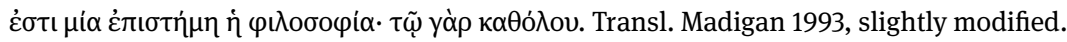

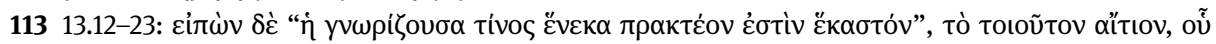

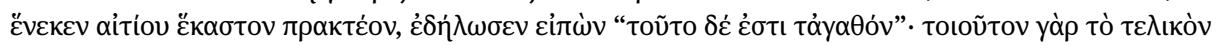

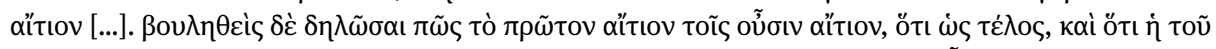

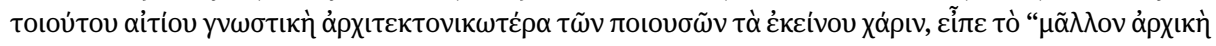

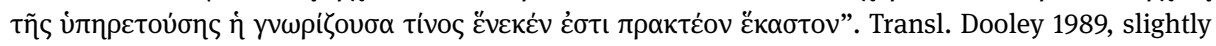
modified.

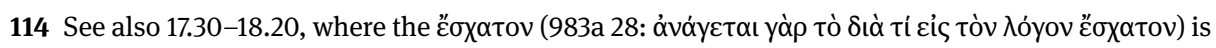
explained twice, and 47.17-22 with my note. 
in the quote below) interrupts a single train of thought, in which Aristotle's reverence towards earlier thinkers is explained:

Having said that none of the philosophers who dealt with [theoretical philosophy] spoke adequately about it, [Aristotle] now says that we should not for this reason simply dismiss them, but should be grateful to them for having been of no small benefit to those who came after them [[...]]; for he thinks it right that we be grateful not only to those who expressed such opinions as we ourselves might find useful and adopt as our own because we think them correctly stated, but also to the earlier thinkers, though they seem to have spoken very superficially about these matters. The reason he gives is that even these men have helped us in some way to discover what we are seeking. ${ }^{115}$

$\delta ı \grave{\alpha} \tau o u ́ \tau \omega \nu$ does not, of course, mean "he uses the example of these men" (as Dooley translates it, trying to make a single argument); rather, it is a technical expression, which means "through these considerations".

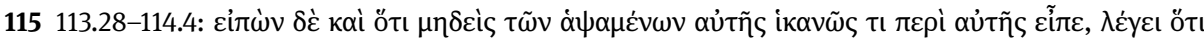

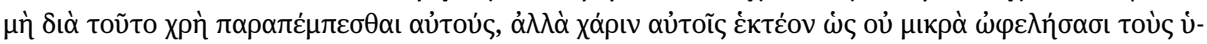

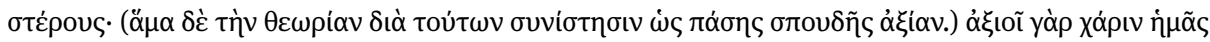

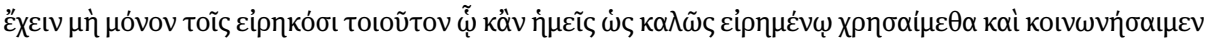

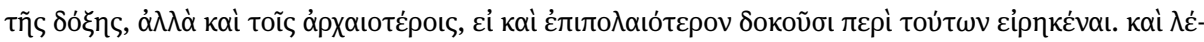

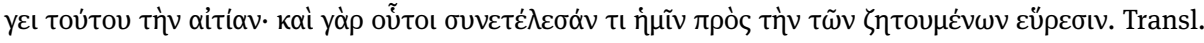
Dooley 1992. 


\section{The textual tradition of Alexander's commentary on the Metaphysics}

\subsection{The transmission of the genuine text in Late antiquity, Byzantium, and beyond}

It is almost certain that Alexander's commentary on books E-N did not survive antiquity. The two independent witnesses of the text, namely Parisinus graecus 1876 [A] and Laurentianus pluteus 85,1 [0], both produced in Constantinople in the second half of the thirteenth century, ${ }^{1}$ provide peculiar titles at the beginning of the commentary on Alpha meizon and Gamma, which are quite telling of the model(s) from which

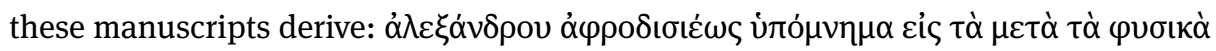

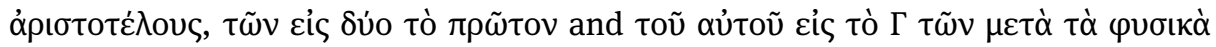

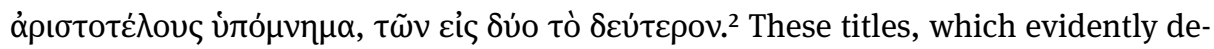
rive from the same lost model, imply that at the time this model was produced, Alexander's commentary was available in two codices: the first codex contained the commentary on books Alpha meizon, alpha elatton and Beta, whereas the second codex contained the commentary on books Gamma and Delta. We may surmise that these two ancient codices were what was available in Constantinople out of a complete edi-

$\mathbf{1}$ On the dating of $\mathbf{O}$ see Golitsis 2020. The importance of this manuscript for the text of Alexander's commentary was brought to light by Harlfinger 1975. At several places $\mathbf{O}$ provides a text that is not

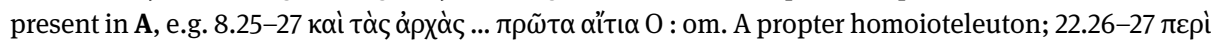

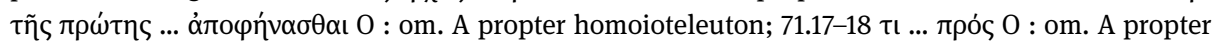

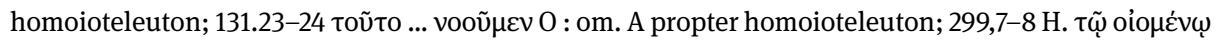

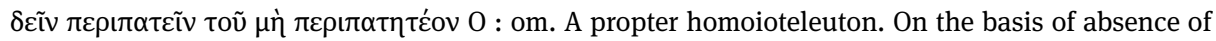
errores disjunctivi in the De ideis Harlfinger cautiously considered the possibility that $\mathbf{A}$ is a copy of $\mathbf{0}$. This, however, cannot be true since $\mathbf{A}$ provides at other places a text that is not present in $\mathbf{0}$; cf. the

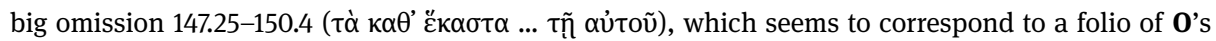

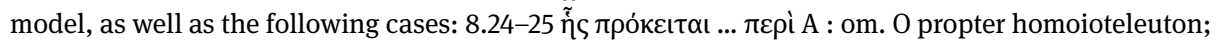

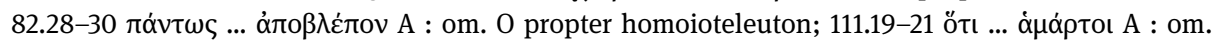

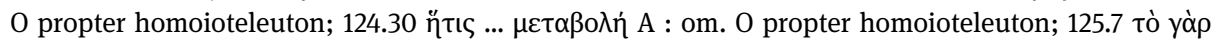

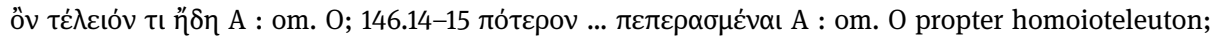

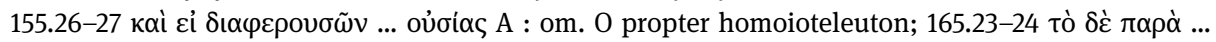

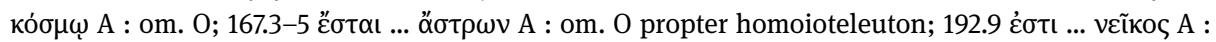

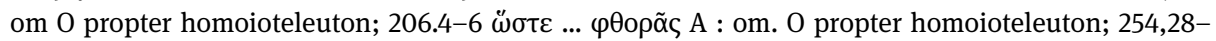

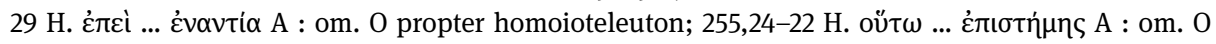

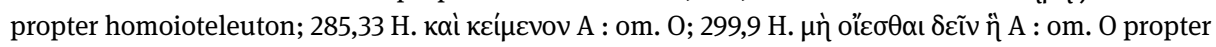
homoioteleuton.

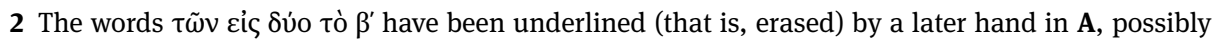
the hand of John Chortasmenos (see below, Section 2.2), who was apparently unable to make sense of them. 
tion of Alexander's commentary from late antiquity, probably in five or six codices, ${ }^{3}$ when a transliteration of them was commissioned, probably in late ninth/early tenth century.

It is noteworthy that $\mathbf{A}$ and $\mathbf{0}$, both Palaeologan manuscripts, are the earliest witnesses of Alexander's text. This is striking enough in comparison with the Byzantine transmission of other commentaries on Aristotle, all the more so because Alexander's commentary on the Metaphysics was probably unknown to the Byzantine exegete Michael of Ephesus (ca.1050-1130). ${ }^{4}$ Although it has commonly been held since the nineteenth century that Michael knew Alexander's commentary because he allegedly produced a continuation of it, in fact Michael continued a commentary which was not by Alexander and which probably did not stop with book Delta but with book Epsilon. The earliest witness of Michael's commentary, namely Laurentianus pluteus 87,12 [L], produced in Michael's lifetime, ${ }^{5}$ transmits an entirely anonymous commentary on the Metaphysics, of which only the commentary on Z-N can be safely ascribed to Michael, whereas the commentary on A-E appears to be the work of an anonymous author of the sixth/seventh century (a reasonable guess would be Stephanus of Alexandria). ${ }^{6}$ The first five books of this anonymous commentary have been mislead-

3 This does not mean, of course, that Alexander's commentary was first published in codex format, nor that it circulated in late antiquity only in codex format. On the contrary, Alexander himself quotes "the [sheets of the] book", that is, of a papyrus roll, as a case of "continuous things that are glued

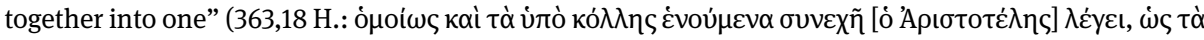
$\beta \iota \beta \lambda i \alpha)$. Much later, in the Book of the Index (Kitāb al-Fihrist) completed in 988, Ibn al-Nadìm says that "Letter 'N' [of the "Book of the Letters" (= the Metaphysics)] does exist, but in Greek with Alexander [of Aphrodisias]'s commentary" (Bertolacci 2005: 244), and Averroes says in the twelfth century that he found no commentary by Alexander on any book of the Metaphysics except for the two thirds of Lambda (cf. Bouyges 1948: 1393). Although copying books separated from the whole to which they belong seems to have been a usual Arabic practice (especially with regard to Metaphysics Lambda; see Bertolacci 2005: 253-257), we may wonder whether "Letter N and Alexander's commentary" were contained in a single papyrus volumen, which was originally part of a complete edition of Alexander's commentary in fourteen (?) volumina. A damaged papyrus volumen might have also been at the origin of the Syriac translation of Alexander's commentary on Lambda by Hunayn ibn Ishaq, which was later translated into Arabic by Abu Bishr Matta ibn Yunus.

4 Two marginal scholia attributed to Michael in codex Parisinus gr. 1901 imply that Michael knew of Alexander's commentary on the Metaphysics only through Asclepius' commentary; see Golitsis 2014: 218-221. It is worth noting in this respect that no mention of Alexander's commentary is encountered in the indices that accompany the editions of Michael Psellos' philosophical and theological works. The first reference to Alexander's commentary is actually found in the margin of a late twelfth century manuscript of the Metaphysics, namely Scorialensis Y. III. 18 [ $\left.\mathbf{E}^{\mathrm{s}}\right]$, where an emendation by Alexander

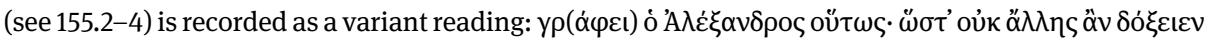
غ̇ंı

5 On the dating of $\mathbf{L}$ see Cavallo 2000: 233.

6 The same arrangement of texts appears in Ambrosianus F 113 sup. [F], copied around 1330, with the exception that $\mathbf{F}$ delivers for books K-N George Pachymeres' commentary (composed ca. 13101315) instead of Michael's commentary. Recently, Silvia Fazzo (Fazzo 2017/2018) has taken F to be an 
ingly known since Hayduck's edition as "recensio altera” of Alexander's commentary on A- $\Delta$. Although it relies heavily on Alexander, the so-called "recensio altera" is for its most part an independent commentary, in which Alexander's exegesis is restructured, parts of Asclepius' commentary are thoughtfully integrated and several further additions are made, which suggest a teaching context in a Christian Platonist vein. ${ }^{7}$ This is important for the reconstruction of Alexander's text, since sound readings in $\mathbf{L}$ (or F) should not be uncritically interpreted as genuine readings that were transmitted mechanically; they may also be conscious corrections made by the anonymous teacher.

The situation is more complicated, though. The conscious modifications of Alexander's commentary by Anonymous are more present in books Alpha meizon, alpha elatton, and Delta than they are in books Beta and Gamma. This does not have much significance in itself, since it would be natural for the anonymous teacher to leave untouched some well-formulated explanations of difficult passages by Alexander. ${ }^{8}$ At any rate, the anonymous teacher rewrote the prolegomena to both Beta and

apographon of $\mathbf{L}$, but this claim is readily invalidated by the fact that the scribe of $\mathbf{F}$ changed his model at the beginning of the commentary on book Kappa. If he were copying $\mathbf{L}$, why did he do so? $\mathbf{L}$, before its completion by Francesco Zanetti in the sixteenth century, stopped abruptly with Michael's commentary on $\Lambda 7$ in virtue, as it seems, of a defective model. It seems that $\mathbf{F}$ was copied from what was also the model of $\mathbf{L}$, having in the meantime lost more quires, that is, the folia that contained Michael's commentary on Kappa (or the major part of it) and $\Lambda 1-7$. With regard to Fazzo's thesis, it is interesting to notice that, whereas $\mathbf{F}$ (and not $\mathbf{L}$ ) is for her the manuscript par excellence of the $\beta$-branch of the textual tradition of the Metaphysics and has therefore to be used in a new critical edition of the treatise (see Fazzo 2012), it is completely useless for reconstructing Alexander's (and pseudo-Alexander's) commentary on the Metaphysics. By getting rid of $\mathbf{F}$ and by re-baptizing the "recensio altera" as "recensio laurentiana", Fazzo wants, in fact, to rehabilitate $\mathbf{L}$, which she takes to be the most ancient witness of Alexander's commentary, and which, as such, should be granted the same textcritical value as the manuscripts of the so-called "recensio vulgata". Fazzo practically adopts Bonitz's thesis, which led Hayduck to unsurmountable difficulties. I need not refute Fazzo's relativistic counter-arguments e.g.: "Si donc des lemmes ou des explications plus analytiques se trouvent chez $\mathrm{Al}^{\mathrm{L}}$ [= recensio altera] par rapport à $\mathrm{Al}^{\mathrm{A}}$ [= recensio vulgata] [...], il est difficile de s'assurer qu'Al ${ }^{\mathrm{L}}$ ait subi des additions et des suppléments; il n'est pas moins probable que ce soit $\mathrm{Al}^{\mathrm{A}}$, qui comporte aussi, à l'occasion, des altérations et des raccourcis" (Fazzo 2017/2018: 698) or "[Le] premier argument [de Golitsis] est que l'auteur de la recensio laurentiana ajoute de nouveaux lemmes. Mais comment s'assurer que ce n'est pas la recensio vulgata qui a perdu des lemmes?" (Fazzo 2017/2018: 700) - not only because Fazzo herself feels the need to relativize her thesis ("Cela donne l'impression qu'ici, peut-être ici seulement, la recensio laurentiana quitte Alexandre”, p. 693) but also because Fazzo, by trying to refute those who wish to take away "toute valeur à la recensio laurentiana" (Fazzo 2017/2018: 698), fights against windmills. Like Asclepius' commentary, this anonymous commentary on the Metaphysics should be used in a new critical edition of Alexander's text - and is actually used in the present one - chiefly as an indirect witness.

7 See Golitsis 2014.

8 On the commentary as recomposition of previous commentaries see Golitsis 2008: 58-64. 
Gamma and slight changes and additions do appear here and there. ${ }^{9}$ There are, however, in $\mathbf{L}$ and $\mathbf{F}$ several sensical errors in the commentary on books Beta and Gamma, which are also found in the direct witnesses of Alexander's commentary (A and $\mathbf{0}) .^{10}$ Such errors are unlikely to have been left untouched, had the anonymous commentator come across them. This peculiar situation can be explained, if we posit that some parts of the commentary preserved in $\mathbf{L}$ and $\mathbf{F}$ were supplied extrinsically, that is, were copied mechanically from the transmitted text of Alexander's commentary. This happened either because the anonymous commentator worked on the Metaphysics selectively (but on what basis?) leaving completely untouched some extensive parts of Alexander's commentary, or, rather more plausibly, because some parts of his commentary had been lost or illegible and were later filled out with parts of Alexander's commentary. It might seem that such a work of restoring the anonymous commentary with the help of Alexander's commentary on the Metaphysics was related to its completion, assigned to Michael of Ephesus in the end of eleventh century. But this can hardly square with the idea that Michael thought that no book of Alexander's commentary survived in Byzantium and, at any rate, it would be strange that Michael (or some peer), who was responsible for the restoration of the first part of the commentary, did not care about the intelligibility of the restored text. Rather, $\mathbf{L}$ and $\mathbf{F}$ look like the descendants of a typical product of the late ninth/early tenth century, when Byzantine scholars and scribes were more interested in preserving and restoring the ancient heritage rather than reading it.

In such restored parts of the anonymous commentary, which can be identified by their being theoretically identical to Alexander's commentary (as preserved in A

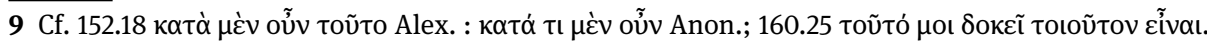

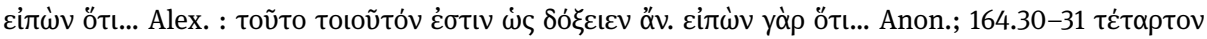

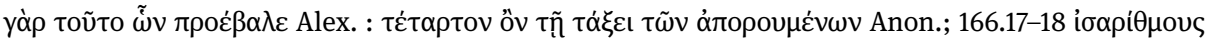

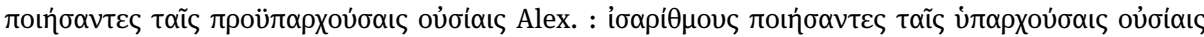

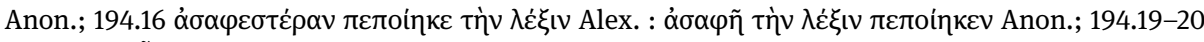

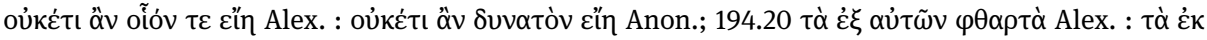

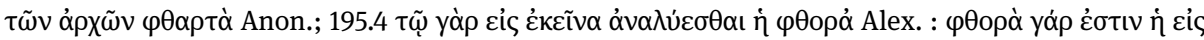

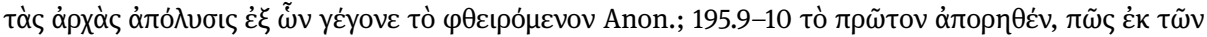

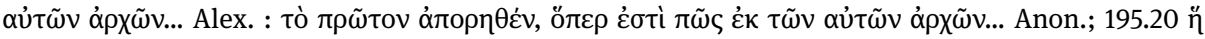

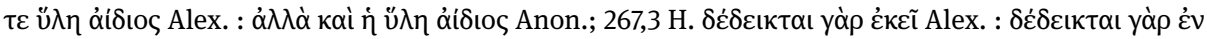

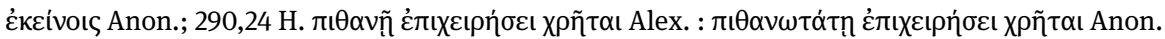

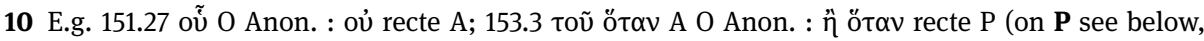

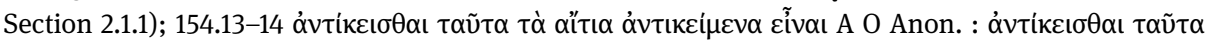

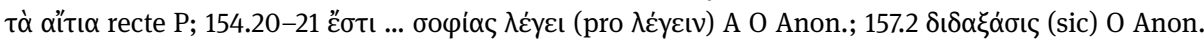

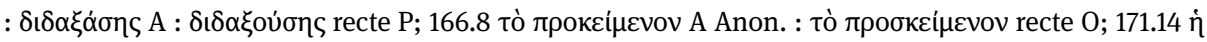

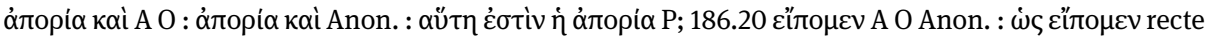

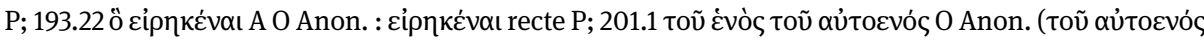

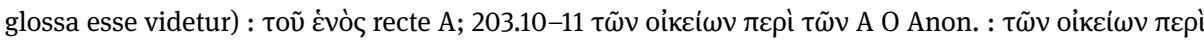

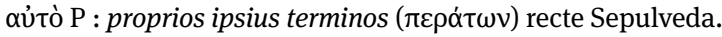


and $\mathbf{0}$ ) for large portions of text, ${ }^{11}$ the text preserved in $\mathbf{L}$ and $\mathbf{F}$ has its own peculiar readings ${ }^{12}$ but shares some significant omissions with $\mathbf{A}$ and $\mathbf{O}$ (such omissions can be detected through Asclepius' commentary) in virtue of a common model, which can be called $\boldsymbol{\alpha}$; but $\mathbf{A}$ and $\mathbf{O}$ have their proper omissions and other errors in virtue of their own common model, which can be called $y \cdot{ }^{13}$ For these parts, $\mathbf{L}$ and $\mathbf{F}$ practically have the value of an independent direct witness of Alexander's text. In order to be distinguished from those parts of Alexander's commentary that are attested indirectly in the anonymous commentary (= Anon.), the testimony to these parts is referred to in the critical apparatus as that of $\mathbf{L}$ and $\mathbf{F}$. The first sensical error that is common in $\mathbf{A}, \mathbf{O}$ and $\mathbf{L}$ is found at $141.13,{ }^{14}$ that is, shortly after the prooemium of the anonymous commentary on book Beta. One may speculate that the anonymous commentary on A-B was also transmitted in a separate codex, which had lost many folia from its last quires.

The sequence 'Alexander's commentary on A- $\Delta+$ anonymous commentary on $\mathrm{E}+$ Michael's commentary on Z-N' appears for the first time in A itself, ${ }^{15}$ in which the commentary on book Epsilon has been attributed to Michael by a later corrector $\left[=A^{2}\right]$, namely the monk Malachias, in the third quarter of the fourteenth century. ${ }^{16}$

$\mathbf{1 1}$ It should be noticed that both $\mathbf{L}$ and $\mathbf{F}$ maintain on each folio a strict correspondance between commentary and commented text. They look more like aesthetic objects ( $\mathbf{L}$ is particularly luxurious) than books of study. The result is that several bits of commentary are omitted - more in $\mathbf{F}$ than in $\mathbf{L}-$ so that this correspondance be maintained.

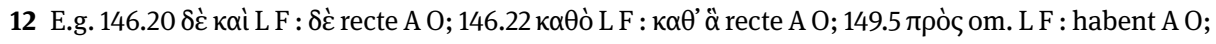

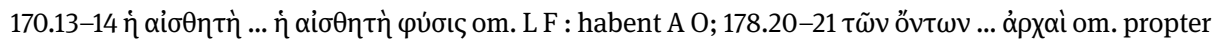

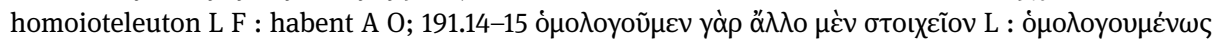

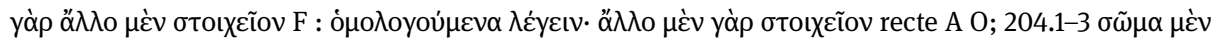

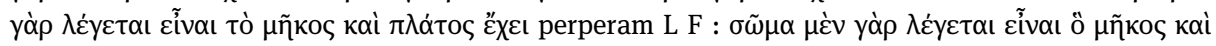

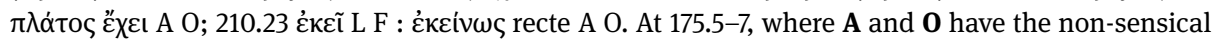

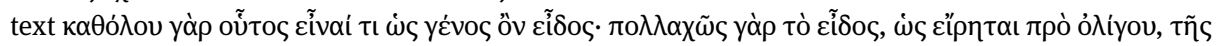

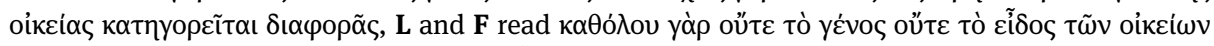

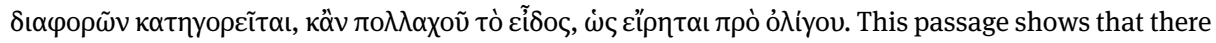
has been a correction of the non-sensical text in the model of $\mathbf{L}$ and $\mathbf{F}$, which therefore was not the model of $\mathbf{A}$ and $\mathbf{0}$.

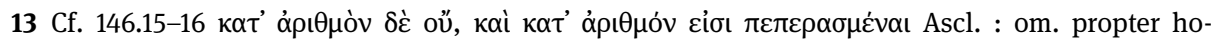

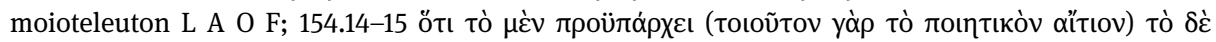

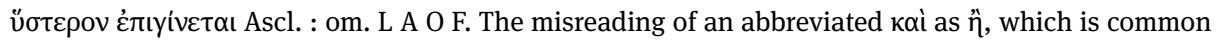

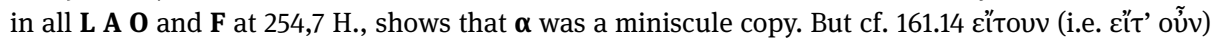

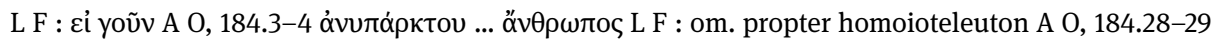

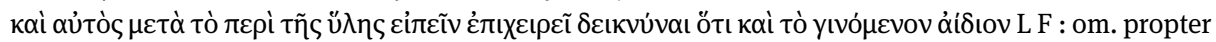

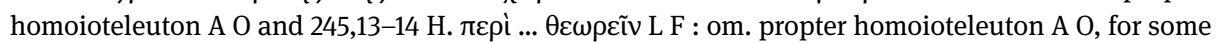
errors peculiars to $y$.

14 See plate I.

15 Notice that $\mathbf{O}$ does not contain a commentary on books $E-\Theta$.

16 See plate V. On Malachias (previously known as 'Anonymus Aristotelicus' [Harlfinger]) see Mondrain 2004: 268-292 and Mondrain 2005: 24-25. Teresa Martínez Manzano (Martínez Manzano 
This is contradictory to the fact that Michael himself states that he started his commentary on the Metaphysics with book Zeta. ${ }^{17}$ Nevertheless, the originator of the misleading attribution to Michael of the anonymous commentary on book Epsilon is not Malachias but, as it seems, George of Cyprus (1241-1289), who later became Patriarch of Constantinople as Gregory II (1283-1289). ${ }^{18}$ George is the main scribe of Parisinus Supplément grec 642 [S], which transmits under Michael's name the commentary on books E-N of the Metaphysics (ff. 224r-368v). It curiously does not contain Alexander's commentary on books A- $\Delta$, while it contains other Aristotelian texts: Aristotle's On the Heavens (with scattered scholia that do not go beyond book III), On Generation and Corruption (with scanty scholia), Meteorology I (with full-blown scholia), Alexander's commentary on Meteorology II-IV, in which Aristotle's text is integrated, and the Metaphysics. ${ }^{19}$ Although $\mathbf{S}$ is useless for an edition of Alexander's genuine commentary, it does have an indirect significance for its textual tradition. For it is reasonable to assume that, as George actually did for the Meteorology, he also wished to have a commentary not only on books E-N but on the entire Metaphysics, which precisely precedes the commentary on books E-N in the codex (ff. 142r-223v). Therefore, George must have owned also a (nowadays lost) copy of Alexander's commentary on A- $\Delta$, say $\boldsymbol{\delta}$. One may retort that George simply did not have at his disposal a copy of Alexander's commentary and had therefore to be satisfied with what he found, namely the copying of the commentary on $\mathrm{E}-\mathrm{N}$. But this seems unlikely for the following reasons.

2019) suggests with plausibility that Malachias was the monacal name of Matthew Cantacuzenus, who was joint emperor of Byzantium from 1353 to 1357.

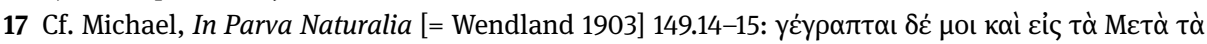

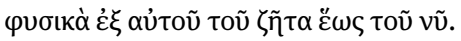

18 Thus, George of Cyprus may be at the origin - and, if so, serve as terminus post quem - of the

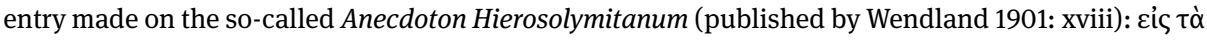

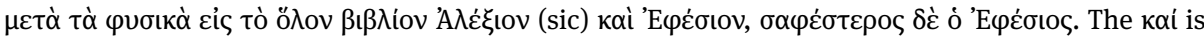
conjunctive, referring to a composite commentary by Alexander and Michael. When the anonymous cataloguer wants to designate two different commentaries on the same treatise, he uses the disjunctive

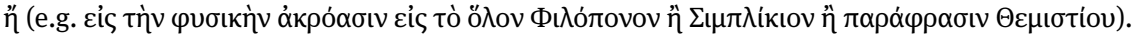

19 Of course, $\mathbf{S}$ need not have formed a single codicological unity from the very beginning. Although the original numbering of the quires has has for the most part not survived, the actual f. 57, which is blank and the last of a quire, implies that the On the Heavens and the On Generation and Corruption once formed a singly codicological unity (f. 1-57). The Meteorology with Alexander's commentary formed a second one (ff. 58-141). A third unity was formed by the Metaphysics (number $\delta^{\prime}$ at the bottom of f. 173v, which is the last of a quire). Finally, a fourth unity was formed by the commentary on Metaphysics E-N (the numbers ' $y^{\prime}$ and ' $\delta$ ', which can still be read on f. 321r and f. 329r respectively, make f. 225 the first folio of the first quire). One can easily see that a further copy by George, namely the Marcianus gr. 227, which contains Aristotle's Physics with Simplicius' commentary, also belonged to this group of Aristotelian manuscripts. 
$\mathbf{S}$ was made by four scribes, one of whom was Ioannikios. ${ }^{20}$ Ioannikios also took part in the production of $\mathbf{0} .^{21}$ It would be strange to assume that a collaborator of a collaborator of George's, that is, the anonymous scribe who copied in $\mathbf{O}$ the commentary on the Metaphysics, had access to Alexander's commentary on Metaphysics A- $\Delta$ but George himself did not. George's editorial activity on $\mathbf{S}$ leaves no doubt that he was the leading force behind the production of the manuscript. The text copied by Ioannikios starts imperfectly (at 442,25 H.) on the first folio of a quire with the lemma (E

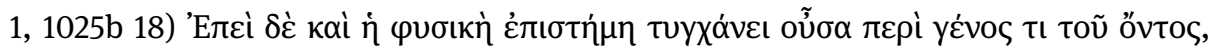
obviously because of a defective model; it also ends imperfectly just before the end

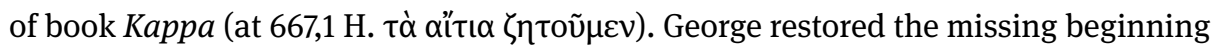
of the commentary on book Epsilon (440,1-442,24 H.) on a supplementary folio (224) - perhaps because he wished to leave no book without authorship, he ascribed by himself the commentary on Epsilon to Michael - and added on f. 304v the last lines of

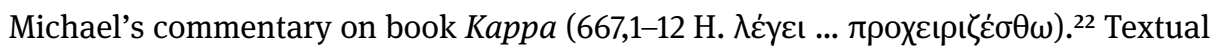
criticism suggests that George used a copy of $\mathbf{L}$ for this restoration; this copy was the model of the model of $\mathbf{A}$ and $\mathbf{S} .^{23}$

It is indeed highly probable that Ioannikios used for $\mathbf{S}$ the same defective models that were also used for the copying of the commentary on Metaphysics E-N in A. Ioannikios began immediately with the lemma at 445,25 H., thus deliberately leaving out lines 442,21-24 H., with which A begins imperfectly (f. 141r), ${ }^{24}$ and the text he copied, which was afterwards restored by George, ${ }^{25}$ initially presented all the fenestrae that are present in $\mathbf{A}$, plus its own. This means that this part of $\mathbf{S}$ is a copy of the model of A, which in the meanwhile had deteriorated. ${ }^{26}$ This is a particularly interesting obser-

20 Here is the division of labour among the scribes of $\mathbf{S}$ : $<$ George of Cyprus $>$ : 1r-73v, 142r-224v, 304v, 367r-368v; <Manuel Neokaisarites>: 74r-141r; <Ioannikios>: 225r-304v; D: 305r-358v. Ioannikios is of course not to be confused with the more famous homonymous scribe of the twelfth century.

21 See Golitsis 2020.

22 See plate II.

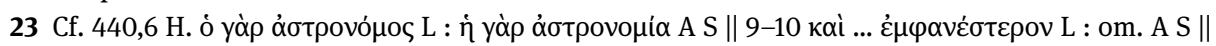

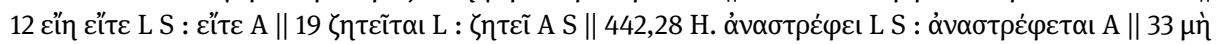

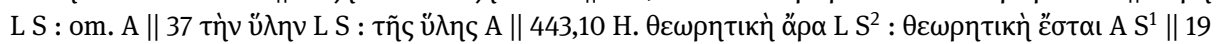

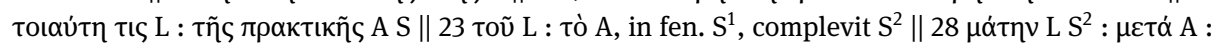

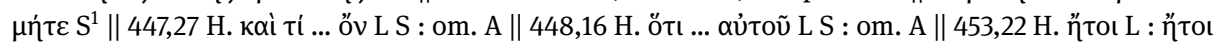

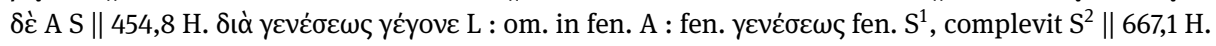

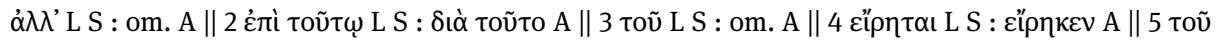
(pr.) L : om. A S $\| 8$ yò̀ L : $\delta \dot{\varepsilon} \mathrm{A}$ S.

24 See the description of $\mathbf{A}$ below, in Section 3.1.1.

25 See plate III.

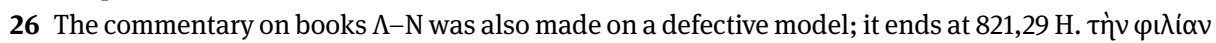

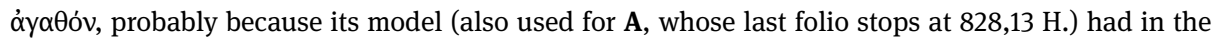

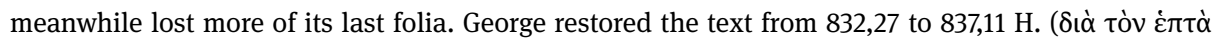

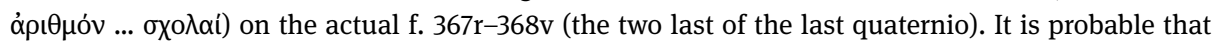
he had also restored the text that is still missing in $\mathbf{S}$ on a supplementary bifolium now lost. As the 
vation, since it gives us the year of George's death, i.e. 1289, as terminus ante quem for the production of $\mathbf{A}$.

All the above remarks point to a number of manuscripts circulating among the same circle of Palaeologan scholars and scribes. It is unlikely that George was left bereft of a commentary on Metaphysics A- $\Delta$, whereas his collaborator Ioannikios, on the one hand, partook in the production of $\mathbf{O}$ and, on the other hand, used as a model for $\mathbf{S}$ one of the models that were previously used for the production of $\mathbf{A}$. Thus, George must have owned a manuscript of Alexander's commentary on A- $\Delta$, say $\boldsymbol{\delta}$, which like $\mathbf{S}$ with regard to the commentary on $\mathrm{E}-\mathrm{N}$ was a copy of the model of $\mathbf{A}$, that is, $\boldsymbol{\gamma}$. It seems that $\boldsymbol{\delta}$ was the model of $\mathbf{O}$ and was occasionally corrected with the same copy of $\mathbf{L}$ which was used for the restoration of $\mathbf{S} .^{27}$

Indeed, there is reason to believe that $\boldsymbol{\delta}$ was related as a "father" to $\mathbf{0}$. George, as patriarch Gregory II, probably initiated the production of the monumental manuscript that $\mathbf{O}$ is, ${ }^{28}$ whilst at least one of his manuscripts was used as a model for $\mathbf{0 .}{ }^{29} \mathrm{Granted}$ (i) that a lost manuscript of Alexander's commentary was owned by the bibliophile and scholarly patriarch, (ii) that this manuscript, just like $\mathbf{S}$, was related as a "brother" to $\mathbf{A}$, (iii) that a fenestra in $\mathbf{0}$ at $170.2 \mathrm{H}$., which is not attested in $\mathbf{A},{ }^{30}$ and a large omission in 0 between 147.26-150.4, possibly corresponding to a lost folio, which is equally not attested in $\mathbf{A}$, taken together, suggest the use of a model different than the model of $\mathbf{A}$, (iv) that $\mathbf{0}$, unlike $\mathbf{A}$, is a copy of a manuscript in which at least two passages were restored in the margins, ${ }^{31}$ and (v) that at least one manuscript belonging to George of Cyprus was used as a model of $\mathbf{0}$, we may posit $\boldsymbol{\delta}$ as the direct model of $\mathbf{0}$. Our considerations so far can be put into the following stemma codicum:

commentary in $\mathbf{L}$ (before its completion by Francesco Zanetti) stops with the commentary on $\Lambda$ 7, the model used for this restoration cannot derive from $\mathbf{L}$.

27 Traces of such a supplementary use of the anonymous commentary are visible in $\mathbf{O}$ at 95.30 ci $\mathrm{A}$ :

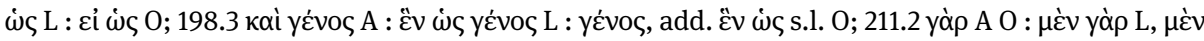
s.l. 0 .

28 See Golitsis 2020.

29 Namely the Marcianus gr. 227, which contains Simplicius' commentary on the Physics; see Harlfinger 1987.

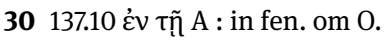

$31 \mathbf{O}$ can be seen at two places to have problematically integrated into the text a restored passage;

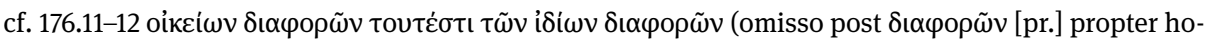

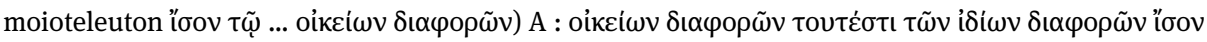

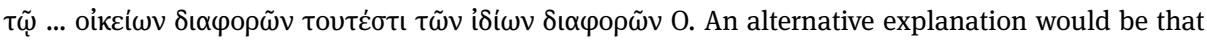
the scribe of $\mathbf{O}$ made the same saut du même au même as the scribe of $\mathbf{A}$ but then made a further saut du même au même from the third occurrence of $\delta\llcorner\alpha \varphi \rho \rho \tilde{v} v$ to the first; this seems improbable. Cf. also

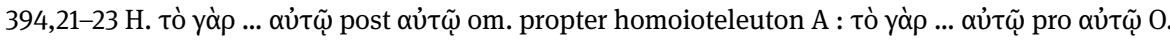




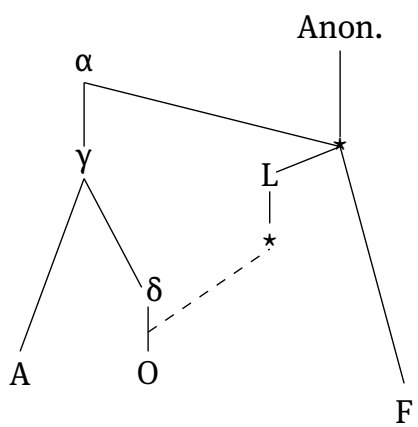

\subsubsection{Further genuine readings in one branch of the manuscript tradition}

In an article published in 2016, I claimed that $\boldsymbol{\alpha}$ was not the archetype of the Byzantine transmission of Alexander's commentary on the Metaphysics but the first of two hyparchetypes. A codex recentior, i.e. Parisinus graecus 1878 [P], produced probably in Rome in $1471 / 72$, seemed to me to be a copy of a second lost hyparchetype $(\boldsymbol{\beta}){ }^{32}$ This was a hasty conclusion, which was partly made "under the spell" of Hermann Bonitz and based upon the defective documentation that is available in Michael Hayduck's critical apparatus. ${ }^{33}$ In an online publication of the same year, ${ }^{34}$ Laurent Calvié rejected the existence of the $\boldsymbol{\beta}$-hyparchetype and interpreted $\mathbf{P}$ as a fully derivative manuscript, that is, as a joint copy (either directly or indirectly) of $\mathbf{O}$ and $\mathbf{A}$; therefore, says Calvié, $\mathbf{P}$ should not be taken into consideration in a new critical edition of Alexander's commentary, save for conjectures that are due to Andronicus Callistus, one of the two scribes of the codex.

32 See Golitsis 2016b: 67-68.

33 Most of the conclusive cases that I present in my article (see Golitsis 2016b: 72-73) make the false assumption that the text present in $\mathbf{P}$ is absent in $\mathbf{0}$; but, in fact, it is absent only in $\mathbf{A}$ and is present in $\mathbf{O}$ (see my apparatus ad 36.21-22, 67.20, 70.16-17 and 91.22-24), as it is also present in $\mathbf{M}$, a direct copy of $\mathbf{0}$, pace Christian Brandis, who affirmed having fully collated $\mathbf{M}$ for the commentary on Alpha meizon (see below, Section 5.1, n. 26). Thus, as $\mathbf{P}$ seemed to preserve at places a text unknown in Greek but present in Juan Ginès Sepúlveda's Latin translation, it seemed to me to be the "liber melior", to which Bonitz refers in his edition (see below, Section 5.1, n. 11). These precisions are meant to illustrate the risks involved in partial collations and surely not as an excuse; I alone am responsible for the problematic aspects and defective elements in Golitsis 2016b.

34 Calvié 2016. For some reason of haste Calvié did not actually take into account the arguments presented in my article, which was published shortly after Calviés publication, but only the basic formulation of my thesis which was made public through Kotwick 2016, namely that there are two hyparchetypes and, whilst $\mathbf{A}$ and $\mathbf{O}$ are copies of the first hyparchetype, $\mathbf{P}$ is a copy of the second hyparchetype. 
My full collation of $\mathbf{P}$, as well as the consideration of other manuscripts that transmit Alexander's commentary, have come to confirm and refine Calvié's thesis. ${ }^{35} \mathbf{P}$ is a composite manuscript, constituted by three quaterniones and fourteen quiniones, which was produced by two erudite scribes who belonged to Cardinal Bessarion's circle in Rome: $\mathrm{P}^{1}$, i.e. the (hiero)monk Gregorios, a former pupil of Pletho's in Mistra, who copied in the first three quaterniones (f. 1r-24v) of the codex the Section 3.4-

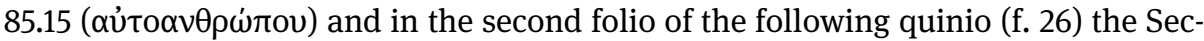
tion 88.22-91.26 (= 113,16 H.), and $\mathrm{P}^{2}$, i.e. Andronicus Callistus ( $\left.+1476 / 1484\right)$, a former teacher of Greek in Bologna, who copied the Section 85.15-88.22 ( $\dot{\alpha} \pi \lambda \tilde{\omega} \varsigma$ ) in the first folio of the first quinio (f. 25) and the rest of the commentary, i.e. 113,16 (= 91.27 G.)$439,13 \mathrm{H}$., in the rest of the codex. ${ }^{36}$ The two parts are codicologically independent from each other (each scribe uses his own paper) so that the production of $\mathbf{P}$ was probably not a joint enterprise.

The part copied by Gregorios presents, most significantly, an omission that corresponds exactly to a line in $\mathbf{0},{ }^{37}$ which allows for no other explanation than that $\mathbf{P}$, for this part of the text, is a (direct or indirect) copy of $\mathbf{0}$. Similarly, an omission observed in the part copied by Callistus corresponds exactly to a line in A. ${ }^{38}$ As the same omission occurs in the manuscripts Mutinensis gr. $208\left[\mathbf{E}^{\mathbf{a}}\right]$ and Mutinensis gr. $214\left[\mathbf{E}^{\mathbf{b}}\right]$, copied around 1510 and 1515 respectively, P must be seen, for that part of the text, as a copy of a common model, call it $\lambda,{ }^{39}$ a nowadays lost manuscript copied some time between 1360 and $1430 .{ }^{40}$ As with Callistus and $\mathbf{A}$, the part produced by Gregorios was also not directly copied on $\mathbf{0}$. Although Gregorios left fenestrae at four places where

35 Calvie construed his thesis exclusively on the basis of arguments from omissions propter homoioteleuton, which are indicative but not conclusive.

36 See below, in Section 3.1.1, the description of the codex.

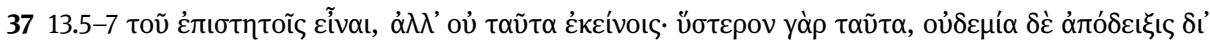

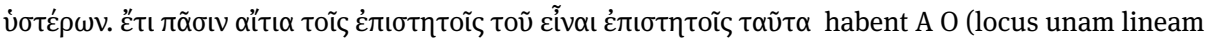
in $O$ complectens) : om. $P$.

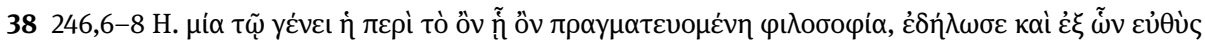
habent $\mathrm{A} O$ (locus unam lineam in A complectens) : $\delta \iota^{\prime} \tilde{\omega} \nu \mathrm{PE}^{\mathrm{a}} \mathrm{E}^{\mathrm{b}}$. The omission must have occurred in a direct copy of $\mathbf{A}$, which can be called $\lambda$; a scholar remedied this omission ope ingenii through $\delta \mathrm{t}^{\prime} \tilde{\omega} v$, which appears in all copies of $\boldsymbol{\lambda}\left(=\mathbf{P}, \mathbf{E}^{\mathbf{a}}\right.$ and $\left.\mathbf{E}^{\mathbf{b}}\right)$. A similar omission, remedied this time by Callistus

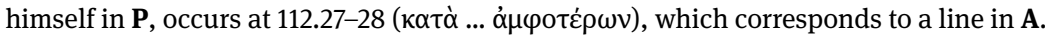

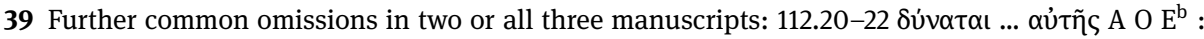

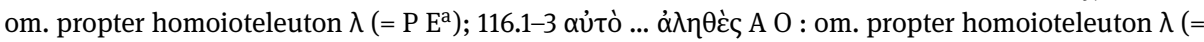

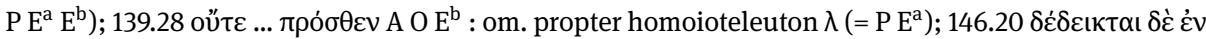

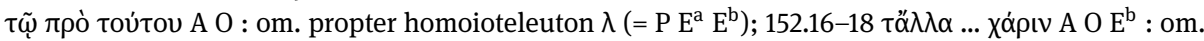

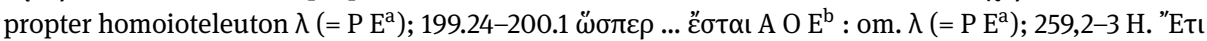
$\ldots \pi \dot{\alpha} \theta \eta \mathrm{A} \mathrm{O} \mathrm{E}^{\mathrm{b}}:$ om. $\lambda\left(=\mathrm{P} \mathrm{E}^{\mathrm{a}}\right)$. Notice that $\mathbf{E}^{\mathrm{b}}$, which is the younger manuscript, was produced after $\boldsymbol{\lambda}$ was corrected with the help of another manuscript, namely $\mathbf{0}$.

$40 \boldsymbol{\lambda}$ was made before John Chortasmenos $\left[=\mathrm{A}^{3}\right]$ undertook his numerous interpolations in $\mathbf{A}$ (see below, Section 2.2) but after Malachias' $\left[=\mathrm{A}^{2}\right]$ interventions, since $\mathbf{P}, \mathbf{E}^{\mathbf{a}}$ and $\mathbf{E}^{\mathbf{b}}$ provide at two places

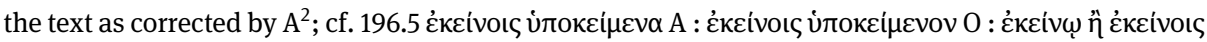


the ink in $\mathbf{O}$ has faded ${ }^{41}$ and at two places he copied the text as restored or modified by a hand of the fifteenth century in $\mathbf{O}\left(=\mathrm{O}^{2}\right),{ }^{42}$ his manuscript presents fenestrae at places where the text in $\mathbf{0}$ is perfectly legible. ${ }^{43}$ Moreover, Gregorios omitted the Section 85.15-88.22 (later supplied by Callistus on $\mathrm{f}$. 25), which is present in $\mathbf{0}$ but was probably absent in his model (possibly a lost folio; this folio does not correspond to a folio in $\mathbf{0}$ ). Therefore, we should posit that the part copied of Gregorios is an indirect copy of $\mathbf{0}$, namely a copy of a copy of $\mathbf{0}$ that was undertaken either shortly before the Fall of Constantinople or shortly thereafter in Crete (where $\mathbf{0}$ was found by Janus Lascaris in 1492) perhaps by $\mathrm{O}^{2} .{ }^{44}$ This copy, which possibly ended with 91.26 (or shortly thereafter), ${ }^{45}$ was probably a working manuscript that could not be directly used as a part of a new edition of Alexander's commentary. Gregorios undertook to make a clear copy of it, which was taken over by Callistus on the basis of a different model. This new edition of Alexander's commentary on the Metaphysics, which was completed by Callistus shortly before or after Bessarion's death, was probably meant to enrich the Cardinal's munus to the Republic of Venice.

The fenestrae left by Gregorios were subsequently completed by Callistus with the help of a copy of $\boldsymbol{\lambda}$, call it $\boldsymbol{\mu} .{ }^{46}$ This procedure is obvious in the following example, which also exemplifies Callistus' formidable inclination to conjecturing:

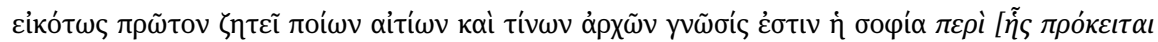

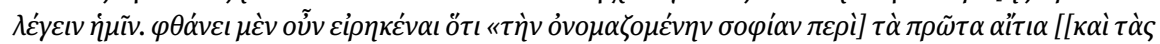

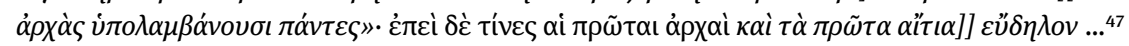

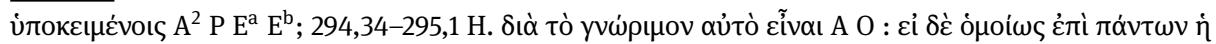

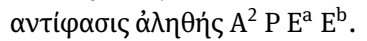

41 At 9.26 koเvñ A $\mathrm{P}^{2}$ : oblitteratum est in 0 , in fenestra om. $\mathrm{P}^{1} ; 10.20 \tau \iota \nu \omega \nu$ A $\mathrm{P}^{2}$ : oblitteratum est in $\mathrm{O}$, in fenestra om. $\mathrm{P}^{1} ; 11.21$ (ं்

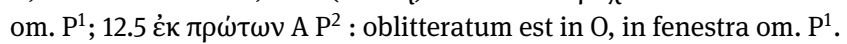

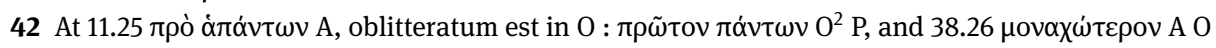
: $\mu \alpha \lambda \alpha \kappa \omega \dot{\tau} \varepsilon \rho \circ \mathrm{O}^{2} \mathrm{P}$.

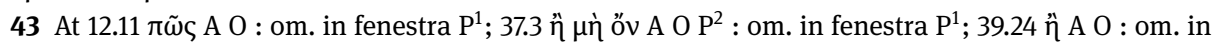

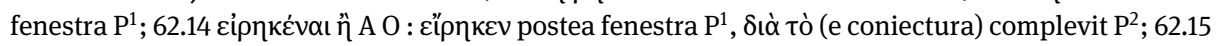

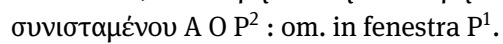

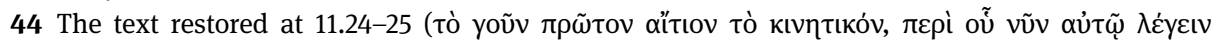

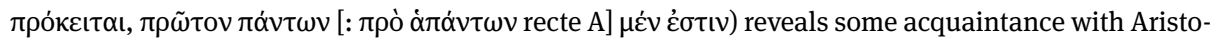

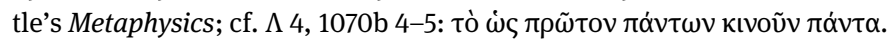

45 If it were a complete copy of Alexander's commentary, it would probably be a bound codex, and if it were a bound codex, it is likely that it would have left further traces.

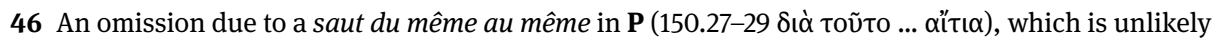
to be due to Callistus, is not attested in $\mathrm{E}^{\mathrm{a}}$ and $\mathrm{E}^{\mathrm{b}}$, i.e. $\boldsymbol{\lambda}$; see also $\mathrm{n}$. 86 .

47 8.23-27. Transl. Dooley 1989: “[Aristotle] first asks, as we might expect, of what sort are the causes and what are the principles the knowledge of which is the wisdom we propose to discuss. He has already said, in fact, 'All men suppose that what is called wisdom deals with the first causes and principles'; but since it is not clear...” 


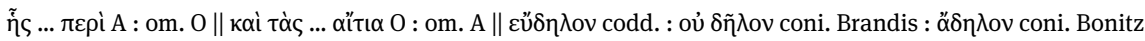

This passage is problematically transmitted in both $\mathbf{A}$ and $\mathbf{O}$ due to two different omissions propter homoioteleuton (respectively put between [...] and [[...]] in the quotation

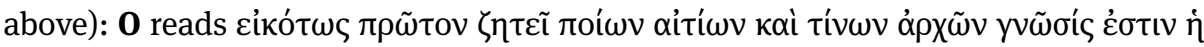

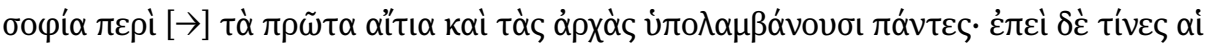

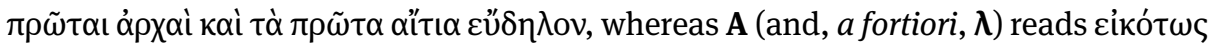

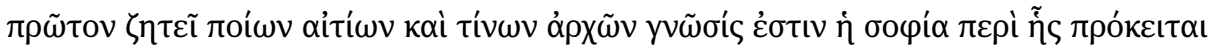

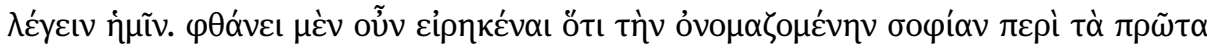

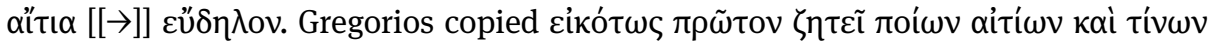

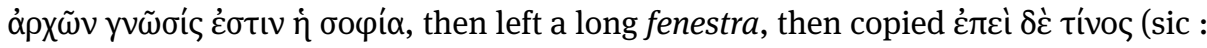

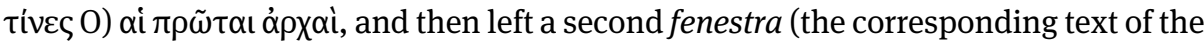
fenestrae is given in italics in the quotation above). The fenestrae, absent in $\mathbf{0}$ itself, show that either the scribe of the model copied by Gregorios, say $\mathrm{O}^{2}$, or Gregorios himself perceived the textual problems in their model and deliberately left blank spaces in their copies, so that they would be able to complete them later with the help of a better manuscript. The two fenestrae in $\mathbf{P}$, however, were completed by Callistus partly by conjecture $(<\ldots>)$ :

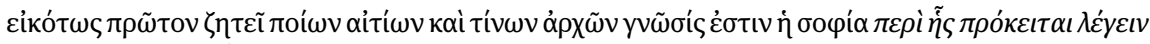

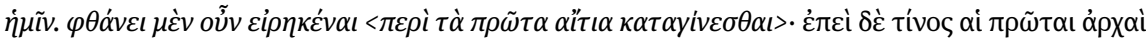

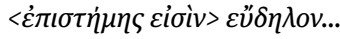

It is obvious that Callistus was working with a manuscript related to $\mathbf{A}$, which due to its own omission did not offer him a satisfying text. This is why he transformed

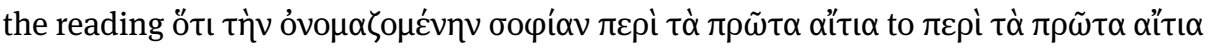

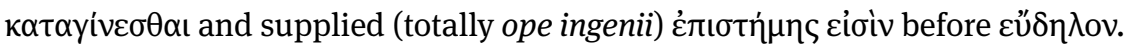

In sum, $\mathbf{P}$ is an indirect copy successively of $\mathbf{O}$ (for the first three quires) and $\mathbf{A}$ (for the rest of the quiniones + the supplementary folio in the third quire). Calvie is therefore right. Nonetheless, the situation is not quite so simple for the editor. A comparison of $\mathbf{P}$ first with the indirect tradition of Alexander's commentary, i.e. the commentaries of Anonymous [=Anon.] and of Asclepius [=Ascl.] (the latter is actually "from the voice" of Ammonius, who also made use of Alexander's commentary) and then with its direct tradition will now illustrate the editor's viewpoint.

This is how the prooemion of the commentary on book alpha elatton reads in Alexander, according to the testimony of $\mathbf{A}$ and $\mathbf{0 , 4 8}$ and in Anonymous:

48 Notice that Hayduck, following Bonitz who follows Brandis, omits the words kai $\tau \tilde{n} \lambda \hat{\varepsilon} \xi \varepsilon$, attested both in $\mathbf{A}$ and $\mathbf{0}$. Alexander refers to the distinction between exegesis of the content and exegesis of the wording within a commentary. Surely both criteria must be satisfied when it comes to asserting the authenticity of the commented text. 
Alexander, In Metaph. 109.2-4

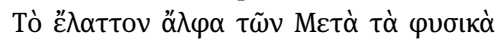

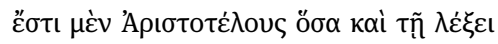

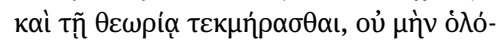

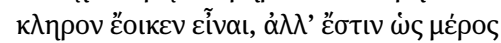

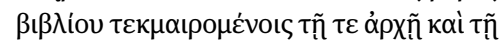

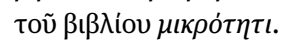

The book "Alpha elatton" of the Metaphysics is the work of Aristotle so far as we can judge both from its philosophical content and its wording; but if we are to base our opinion on the evidence of its beginning and brevity, it seems to be a part of a book rather than a complete book. (Transl. Dooley in Madigan 1992, modified.)

\begin{abstract}
Anonymous

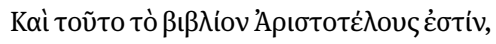

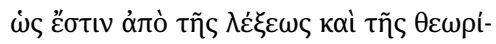

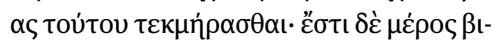

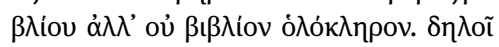

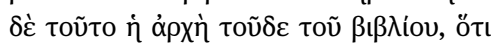

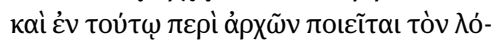

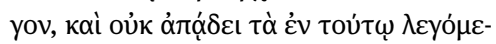

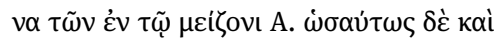

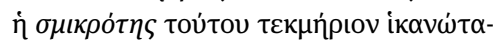

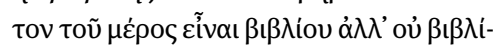
ov ö入ov.
\end{abstract}

This book too is the work of Aristotle so far as we can judge from its wording and its philosophical content; but it is a part of a book rather than a complete book. Evidence for this [i.e. that it is work of Aristotle] is the beginning of this book, since [Aristotle] speaks of the principles in this book too, and what he says in it does not deviate from what he has said in book "Alpha meizon". In like manner, its brevity too is a very sufficient evidence for the claim that it is a part of a book rather than a complete book.

It comes as no surprise that the anonymous commentator develops Alexander's somewhat condensed commentary. But it may strike us that $\mathbf{P}$, differently from $\mathbf{A}$ and $\mathbf{0}$,

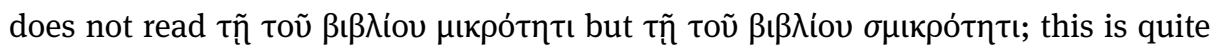
close to $\dot{\eta} \sigma \mu$ кко́тn probable that Callistus, who copied this part of the commentary from a descendant of $\mathbf{A}$, made this meaningless correction on the basis of the anonymous commentary, which he might otherwise have occasionally consulted, we would be inclined to see the agreement between $\mathbf{P}$ and Anon. in this case as a coincidence, prompted by a similar usus eloquendi.

When we move to the prooemion of the commentary on book Beta, we are faced with a similar situation:

Alexander, In Metaph. 138.4-7

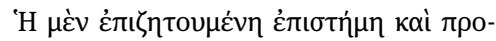

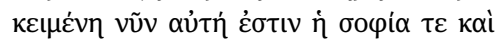

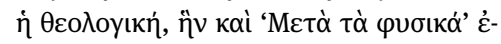

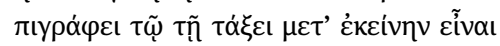

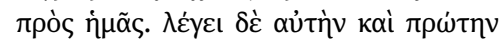

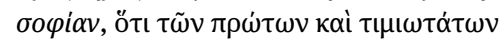

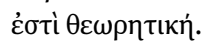

\begin{abstract}
Anonymous

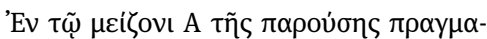

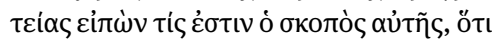

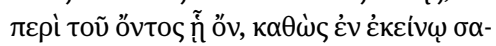

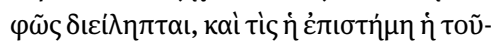

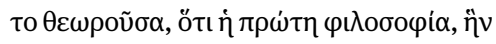

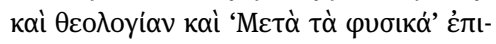

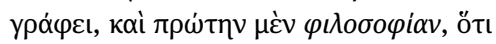

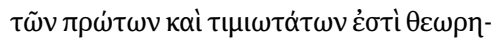
тเкท́...
\end{abstract}


The science that is the object of the present inquiry and lies before us is both the wisdom and the theological science, [contained in a treatise] which [Aristotle] also entitles 'Metaphysics' because it comes after the [treatise of] physics in the order relative to us. He also calls it 'First wisdom', because it contemplates the things which are first and of highest dignity.
Having said in book "Alpha meizon" of the present treatise what is the aim of this treatise, namely that it is about being qua being, as we have ascertained it in that book, and what is the science that contemplates being qua being, namely that it is first philosophy, which [Aristotle] also entitles 'theology' and 'Metaphysics'; and [he entitles it] 'First philosophy', because it contemplates the things which are first and of highest dignity...

Although the anonymous commentator now seems to have in mind his own prolegom-

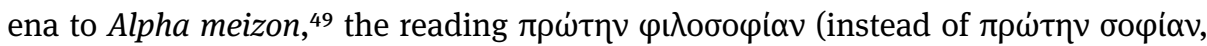
which is the reading of $\mathbf{A}$ and $\mathbf{0}$, adopted by the previous editors) must be Alexander's genuine wording: the expression "first wisdom" is not attested in Aristotle, ${ }^{50}$

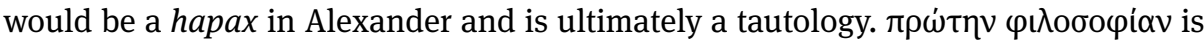
what we actually read in $\mathbf{P}$. As Callistus was a scholar familiar with Aristotle's philosophy, we may in this case ascribe his agreement with Anon. to an emendation ope ingenii.

But if we go on comparing the text in $\mathbf{P}$ (not only the part copied by Callistus but also the part copied by Gregorios) with the indirect tradition of Alexander's commentary, we will soon realize that the cases of "coincidence" start to multiply:

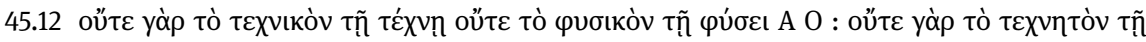

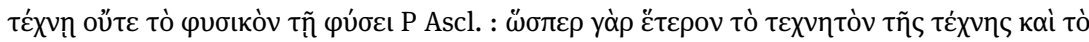

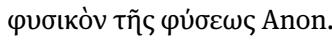

45.14-15 oi ò

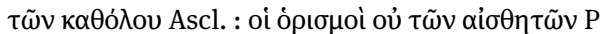

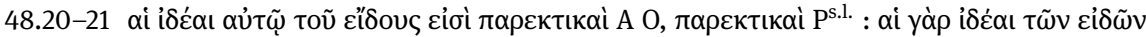

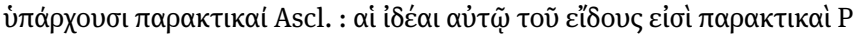

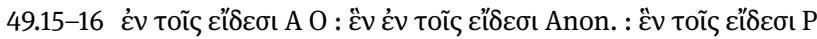

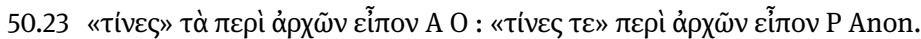

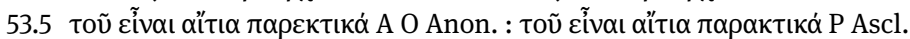

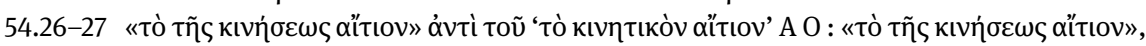

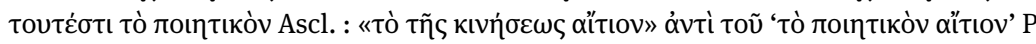

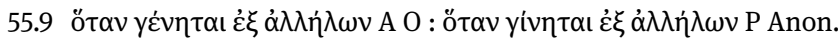

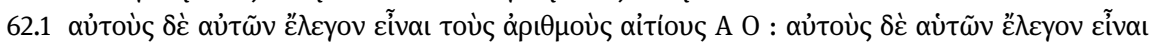

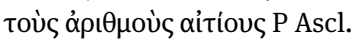

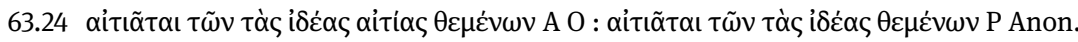

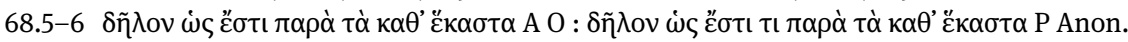

49 See above, p. xliii and n. 101. The agent complement of $\delta เ \varepsilon \dot{\imath} \lambda \eta \pi \tau \alpha \iota$ must be $\dot{\eta} \mu \tilde{\imath} v$, that is, Anonymous himself.

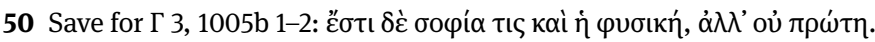




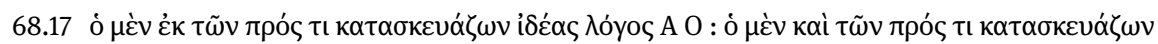

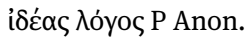

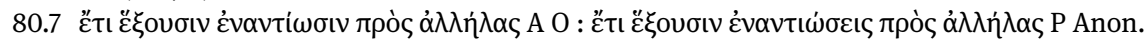

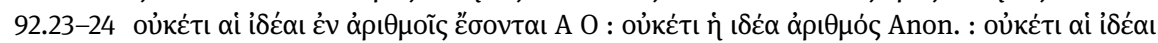

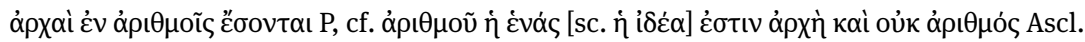

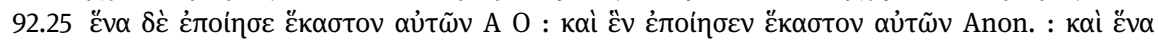

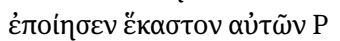

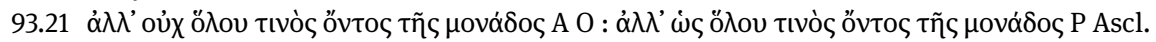

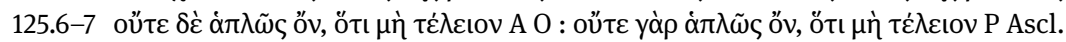

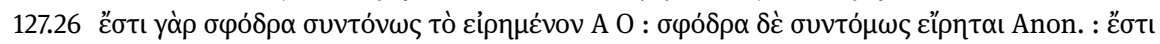

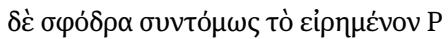

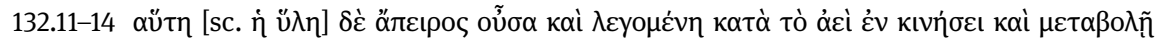

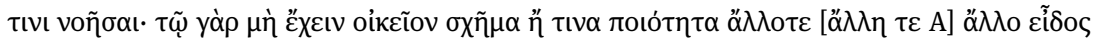

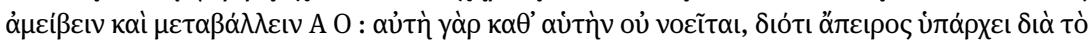

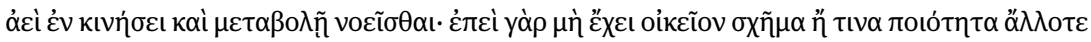

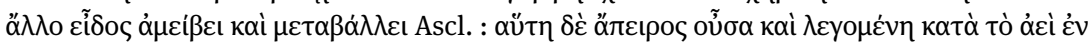

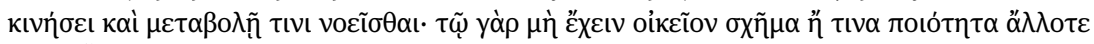

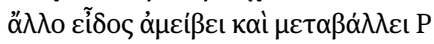

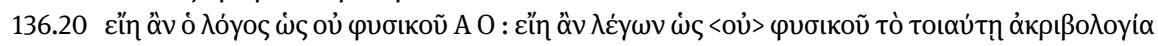

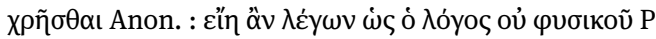

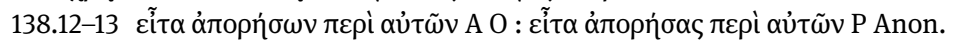

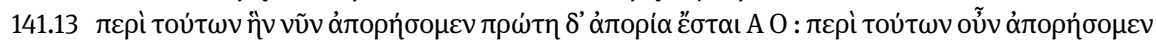

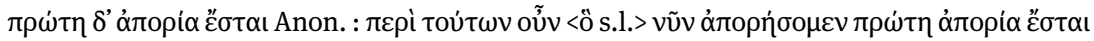
$P$

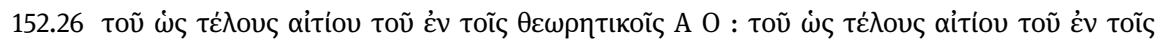
$\theta \varepsilon \omega \rho \eta \tau$ тoí L P Ascl.

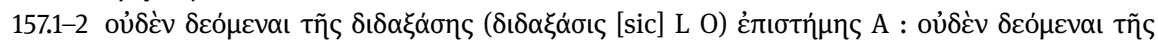

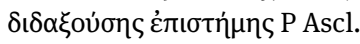

157.6

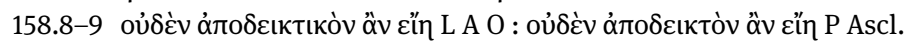

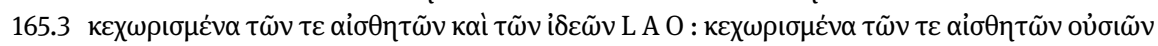

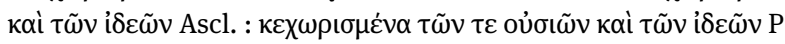

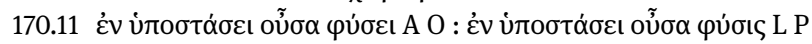

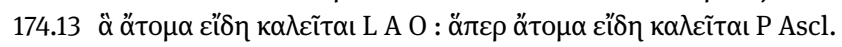

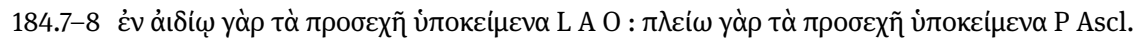

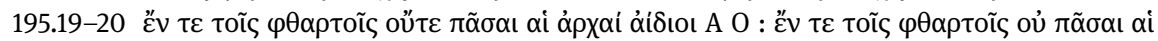

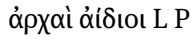

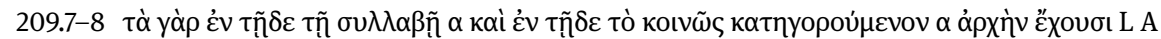

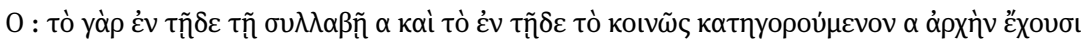

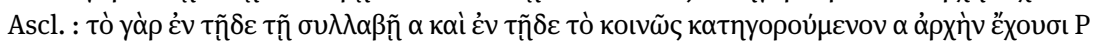

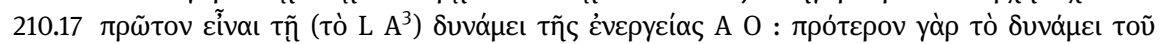

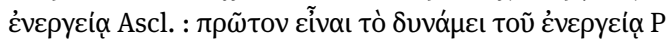

Of course, not all of these cases are necessarily due to a collation. Take, for instance, 92.23-25, where the divergences in $\mathbf{P}$ are partly confirmed by Anon. and (remotely) by Ascl.: 


\section{A 0}

El yó

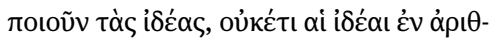

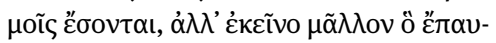

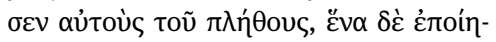

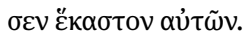

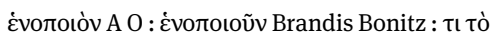

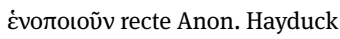

If there is <something that > confers unity on the numbers and [thus] produces the Ideas, it is no longer the Ideas that will be in numbers, but rather that which puts an end to their multiplicity and has made each of them a unity [will be in numbers].

\section{$\mathbf{P}$}

Ẻ yó

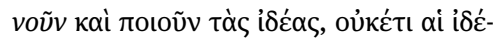

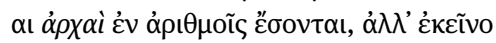

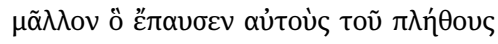

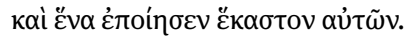

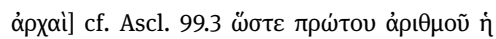

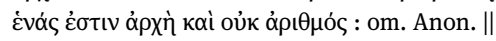

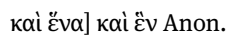

If what confers unity on the numbers and [thus] produces the Ideas produces unity, it is no longer the Ideas that will be principles in numbers [= principles that generate numbers], but rather that which puts an end to their multiplicity and has made each of them a unity [will be their principle].

As it reads in A and $\mathbf{0}$, Alexander's text is contradictory; it claims that the Ideas, which are unified numbers (such as the decad), are not among numbers. In fact, Aristotle's objection is that the principles (which will be principles of numbers and through them principles of everything else) cannot be Ideas such as the Dyad and the Decad; rather, the principle will be what gives unity to 'two' (and thus makes it Dyad) and to 'ten'

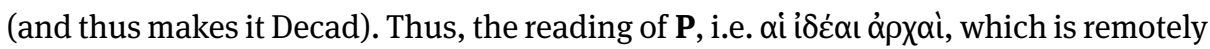
confirmed by Asclepius, must be correct. Still, granted that $\alpha \rho \chi \alpha$ is absent in Anon.,

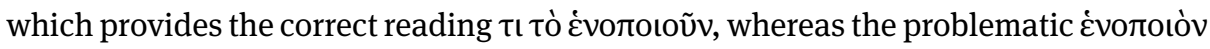

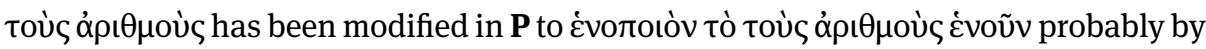
conjecture, it would seem that $\alpha \rho x \alpha i$ was also supplied by conjecture. ${ }^{51}$ If this is true,

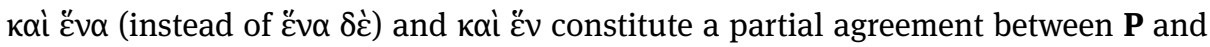
Anon. by coincidence. Too much coincidence, though, is self-refuting. ${ }^{52}$

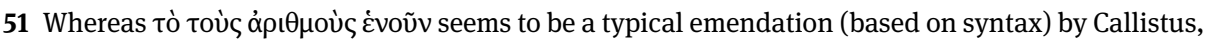
for reasons that will become evident later and in the next subsection I am reluctant to grant him the

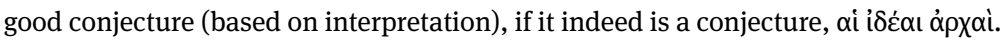

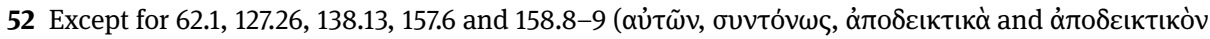
were nonetheless adopted by Brandis), I list above only cases in which the modern editors (Brandis, Bonitz, Hayduck) sided with A without sensing a textual problem. Here are readings of the indirect

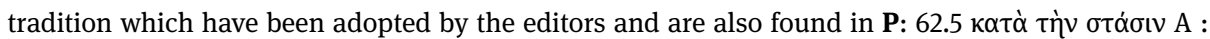

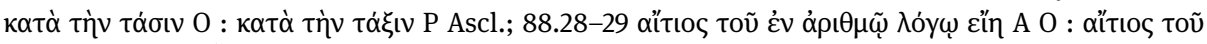

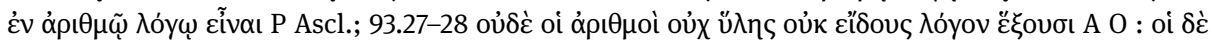

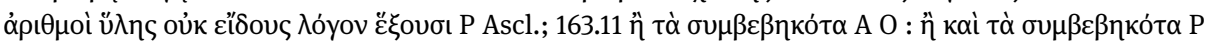

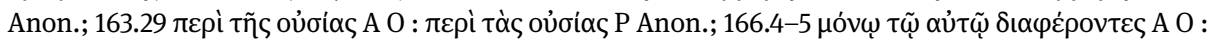

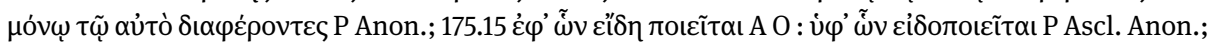

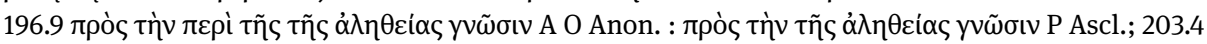

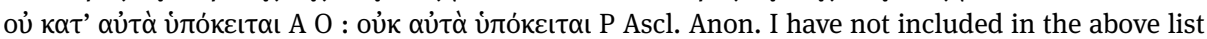


We may therefore think that, in order to produce a better text, both Gregorios and Callistus collated their exemplars, at least at some places in which they sensed that there was a textual problem, with Asclepius' commentary and with the anonymous commentary that is contained in $\mathbf{L}$ and $\mathbf{F}$. Indeed $\mathbf{L}$ was in the library of the monastery of San Marco in Florence since 1444 and Gregorios is actually known to have spent some months in Florence in the late 1460's or early 1470's studying philosophy with John Argyropoulos. ${ }^{53}$ Moreover, Argyropoulos was once a possessor of F. ${ }^{54}$ But the case for coincidence now cedes its place to a moment of perplexity. Was the idea of emending a text with the help of its indirect tradition, especially Asclepius (which by its very title transmits a text that deviates from the text as known through its direct tradition), ${ }^{55}$ conceivable for the scholars of the Renaissance? And if it was, why is it that more serious textual problems were not solved with the help of the indirect tradition? Indeed, if Gregorios and, afterwards, Callistus had consulted L, why did they not also use it to complete, for instance, the fenestrae in $8.24-25,{ }^{56}$ which we discussed before? If Callistus had access to a copy of Asclepius' or the anonymous commentary, why did he not also use one of them to restore severely problematic passages and omissions but instead had frequent recourse to conjecture? A plausible answer is that Callistus was exploiting an unfinished editorial work that was not his own. The exemplar that he used in order to produce (the second part of) $\mathbf{P}$ was provided at places with corrections in textu and marginal variant readings that were due to emendations and collations undertaken at an earlier time by some other scholar. Indeed, Callistus' use of a foreign editorial work is rather evident in some cases.

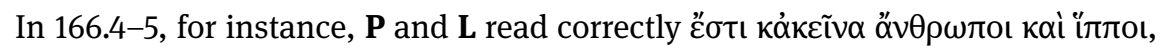

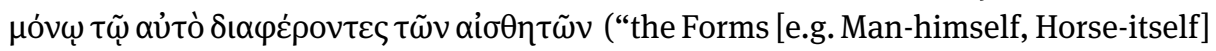
are themselves men and horses, differing from the sensibles only in virtue of the it-

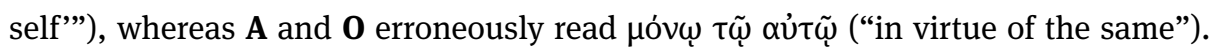

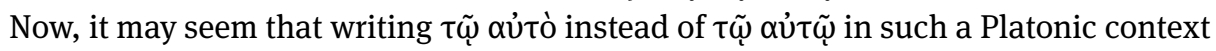

cases of agreement that may be simply due to a conjecture, such as restitution or omission of articles

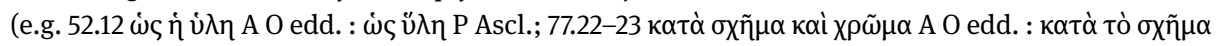

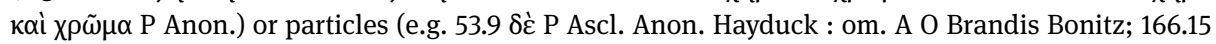

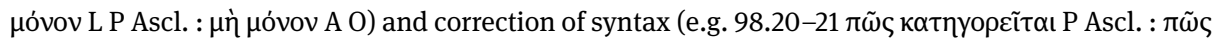
катпуореі̃ $\theta \alpha$ เ А O).

53 See Giacomelli - Speranzi 2019: 125-126.

54 See below, Section 3.2.1.

55 It is relevant to notice in this connection that at two places $\mathbf{A}$ records in margine readings that are

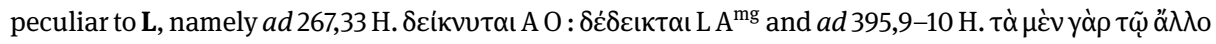

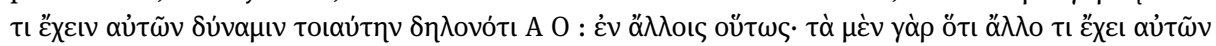

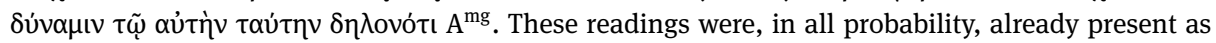
variant readings in the model of $\mathbf{A}$, namely $\boldsymbol{\gamma}$. This yields the interesting observation that some parts of $\boldsymbol{y}$ were collated against the anonymously transmitted commentary.

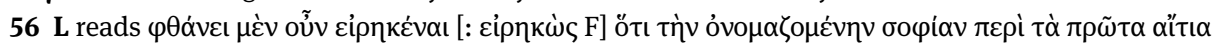

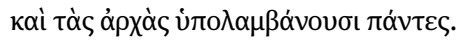


was not a difficult emendation to make. Still, in fewer than a dozen lines $\mathbf{P}$ reads er-

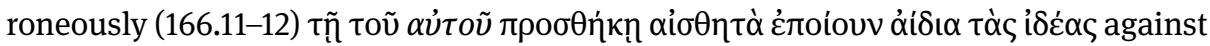

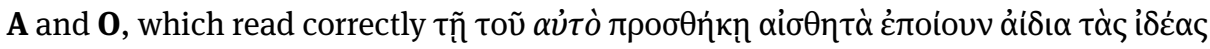
("with the addition of 'itself' [the Platonists] were rendering the Forms into eternal sensibles"). There is clearly a non sequitur here, which makes evident that Callistus was exploiting an editorial work that was not his own. ${ }^{57}$

In 165.1-3, to quote another example, Alexander's text, as it reads in $\mathbf{P}$, does not make good sense:

Asclepius, In Metaph. 166.19-21

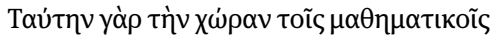

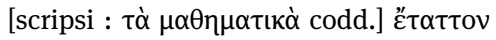

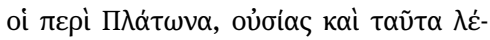

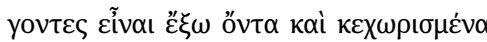

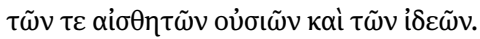

The Platonists assigned this [intermediary] realm to the mathematicals, claiming that they too are substances, which are outside and separate from both the sensible substances and the Forms.

\begin{abstract}
Alexander, In Metaph. 165.1-3 [P]

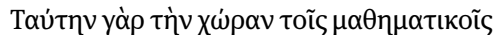

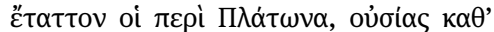

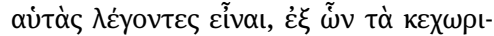

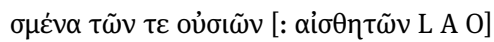

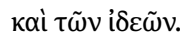
The Platonists assigned this [intermedi- ary] realm to the mathematicals, claim- ing that they are substances per se, from which [come] the realities that are sepa- rate from both the substances [: the sensibles] and the Forms.
\end{abstract}

The text in $\mathbf{P}$ says that the things that are separate from the substances and the Forms

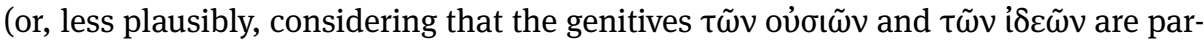
titive, that among both substances and Ideas, those that are separate) come from ( $\dot{\varepsilon} \xi$ $\tilde{\omega} v)$ the mathematicals. This is philosophical nonsense, and is so because $\mathbf{P}$ shares

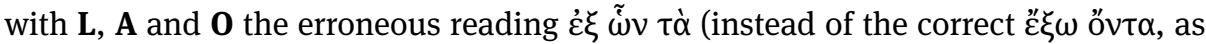

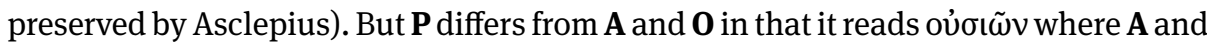

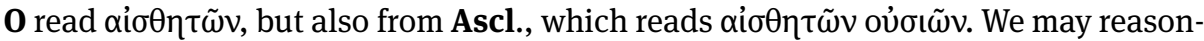

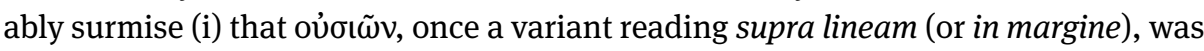
erroneously taken by Callistus as replacing $\alpha i \sigma \theta \eta \tau \tilde{\omega} v$, whereas it was meant to sup-

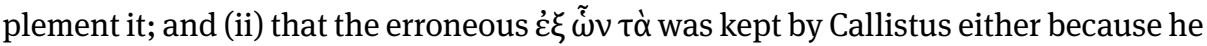
was not able to read correctly the emendation in its model or, more plausibly, because the editorial intervention was not made in accordance with Asclepius' commentary but in accordance with an independent manuscript of Alexander's commentary that

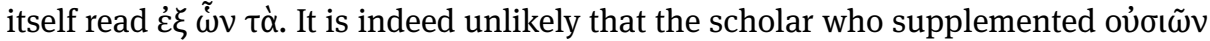
onto Callistus' exemplar drew it from Asclepius' commentary - not to mention further

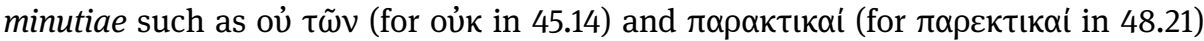
in the part copied by Gregorios. Thus, we have to consider the possibility that such emendations were not made in accordance with the indirect tradition of Alexander's

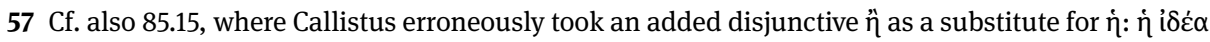

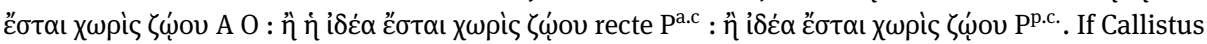
misinterpreted the emendation, the emendation was not his. 
commentary, which in itself seemed rather implausible, ${ }^{58}$ but in accordance with the direct tradition of Alexander's commentary. In this case, when $\mathbf{P}$ does not agree with Ascl. or Anon. by coincidence, it reveals a deviation from the genuine text in $y$ (i.e. the model of $\mathbf{A}$ and $\mathbf{0}$ ) or even $\boldsymbol{\alpha}$ (when $\mathbf{L}$ is equally concerned), from which those emendations obviously did not depend.

This possibility becomes evident at the end of the commentary on book Beta. Aristotle finishes the last chapter of this book (that is, our B 6) by developing an aporia regarding the first principles, which he first mentioned in B $1 .{ }^{59}$ He says that if the first principles are universals, they will not be substances; for every substance is a tó $\delta \varepsilon$

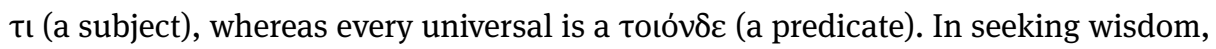
however, we investigate the principles and causes of substances, which have to be themselves substances; the principles, therefore, cannot be universals. If then the principles are not universals, they must be individuals. But if they are individuals, they cannot be an object of science; for every science has the universal as its object. We are thus found in a state of genuine aporia: (i) if the first principles are universals, they will be an object of science but they will not be substances and thus non-substances will be the principles of substances (which is absurd); (ii) if the first principles are like the individuals, they will be substances but the theological science or first philosophy will have no object (which is self-contradictory). Here is Aristotle's text (the reason for putting a sequence of words in bold will become evident shortly):

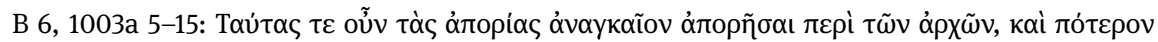

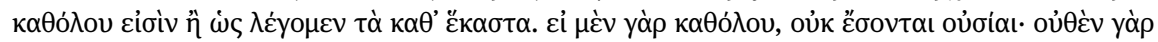

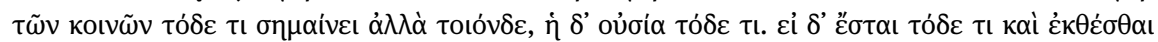

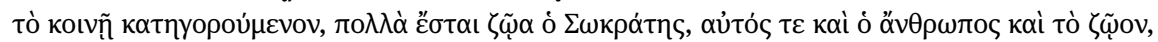

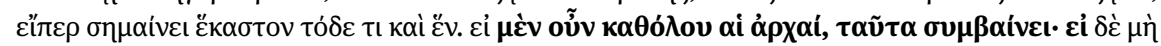

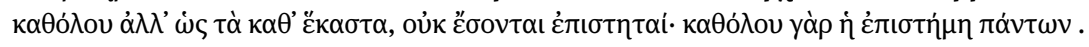

$\mathbf{5 8}$ There is, in my view, only one case in which $\mathbf{P}$ agrees with both Ascl. and Anon. against $\mathbf{A}$ and $\mathbf{O}$

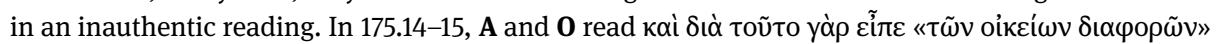

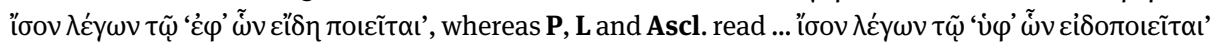

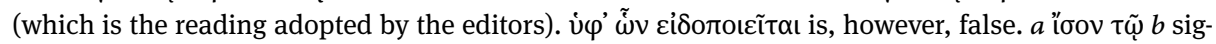
nifies in Alexander that $b$ can replace $a$, which obviously does not work in this context. Aristotle says

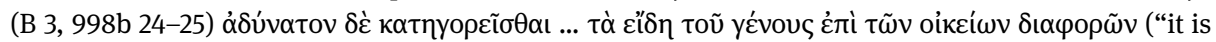
impossible that the species of the genus are predicated of their proper differences"), and even if one

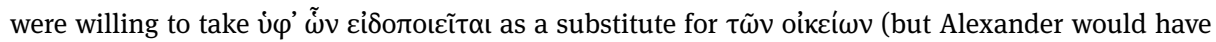

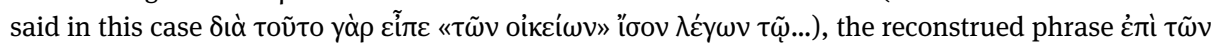

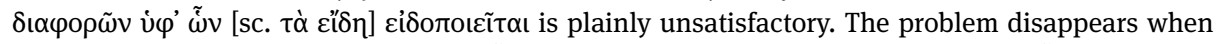

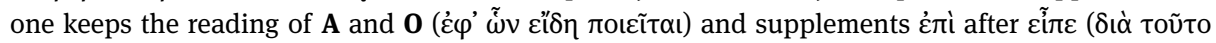

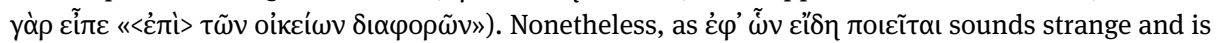

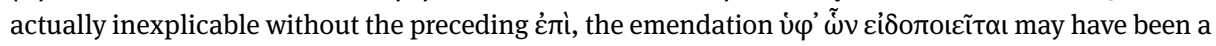
Verschlimmbesserung that was made independently.

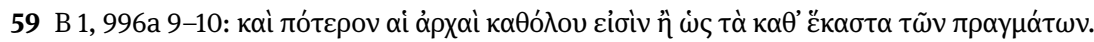


These are, then, the questions we must raise about the [first] principles, and also whether they are universals or [they are] as we say the individuals [are]. For if they are universals, they will not be substances; for everything that is common denotes not a 'this' but a 'such', but the substance is a 'this'; and if the common predicate is a 'this' and [may be] exposed, Socrates will be many animals: [Socrates] himself and the man and the animal, if each of these [items] denotes a 'this' and a single thing. If then the principles are universals, this is what follows; if they are not universals but are like the individuals, they will not be objects of science; for the science of anything is [science of a] universal.

As Alexander explains in his commentary, ${ }^{60}$ Aristotle draws the absurd conclusion

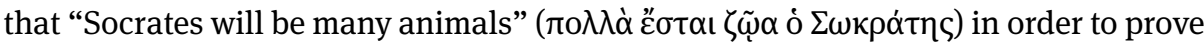

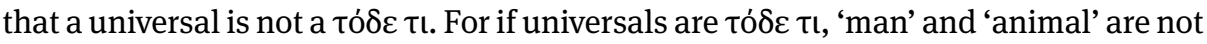
essential attributes, which are predicated of an individual subject and are not separate

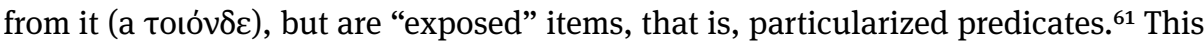
means that they are not the essence of Socrates but separate essences in Socrates that can be counted and thus have their own essential attributes (thus, the man in Socrates will be an animal). And since being Socrates, being a man and being an animal is not the same thing, three animals will be in Socrates: (1) the animal in Socrates, (2) the animal that the man in Socrates is, and (3) the animal that Socrates himself is.

The thesis that the first principles are universals resulting in such an absurdity, Aristotle tackles the contrary thesis, namely that the first principles are not universals

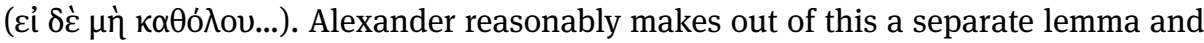

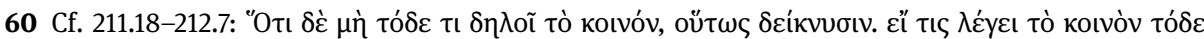

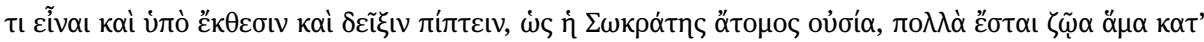

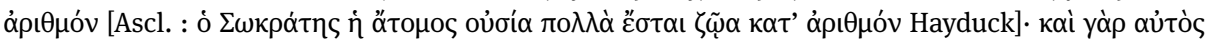

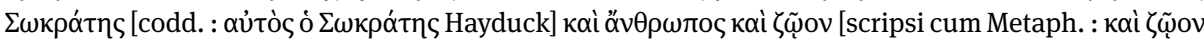

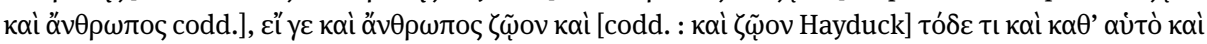
ن்

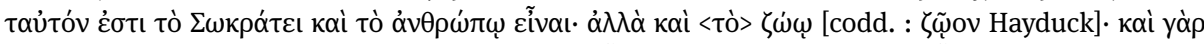

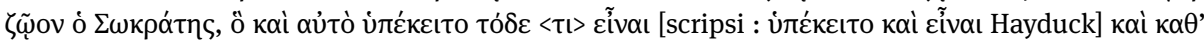

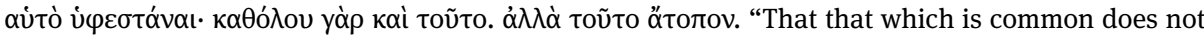
signify an individual thing he proves as follows. If someone says that that which is common is an individual thing and is subject to exposition and exhibition, like the individual substance Socrates, there will be numerically many animals at once: Socrates himself and man and animal, given that man too is an animal and an individual and a thing per se that is subject to exhibition and exposition. For Socrates too is a man, and to be Socrates and to be a man are not the same thing; but to be an animal is also not the same thing; and indeed Socrates is an animal, which was itself supposed to be an individual thing and to exist per se; for it too is universal. But this is absurd".

$61 \varepsilon \dot{\varepsilon} \kappa \theta \dot{\varepsilon} \sigma \theta \alpha \iota$ is cognate to हैk $\theta \varepsilon \sigma \iota \varsigma$, a part of a geometrical procedure, which in a Platonic context has the technical meaning of "exposing" (literally "placing outside", "setting out") the concrete element by participation in which things are commonly said to be what they are (see the explanation given by Alexander, In Metaph. 99.33-100.16). 'To particularize' or 'to individualize' would be a pertinent translation of the way in which Aristotle uses this term. Alexander reformulates śk $\theta \dot{\varepsilon} \sigma \theta \alpha \mathrm{I}$ (see previous

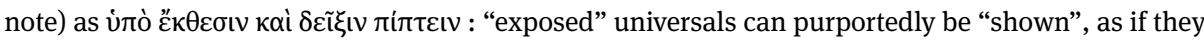
were things per se. 
proceeds to his commentary, which is nonetheless transmitted somewhat differently in $\mathbf{A}$ and $\mathbf{O}$ (and $\mathbf{L}$ ) on the one hand, and in $\mathbf{P}$ on the other; compare the two columns (corresponding to $212.10-213.1$ [= 236,14-21 H.]), in which the divergences between the two traditions are given in italics:

\section{A O L}

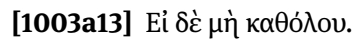

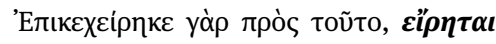

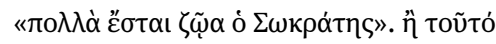

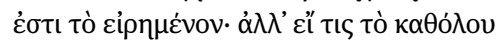

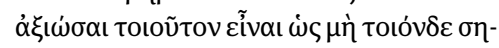

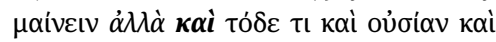

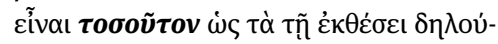
$\mu \varepsilon v \alpha$. عĩٓ

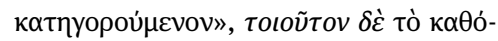

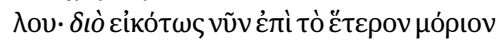

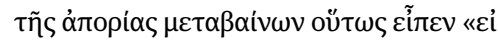

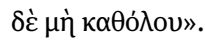

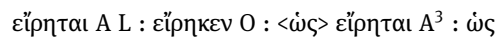

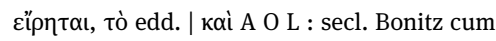

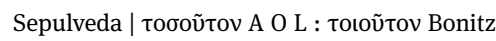
cum Sepulveda

1003a 13 But if [the principles are] not universals.

(1) For he has attacked this [thesis]; it has been said "Socrates will be many animals". (2) Or this [part of the] lemma means this: if, on the contrary, someone were to think that the universal is such as to signify not a such but also an individual and a substance and that it is of such quantity as the things that are signified by exposition. Indeed he said "and the common predicate [may be] exposed"; and the universal is such. This is why he now appropriately shifts to the other side of the aporia and thus says: "But if [the principles are] not universals".
$\mathbf{P}$

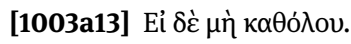

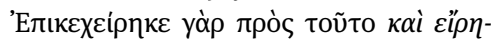

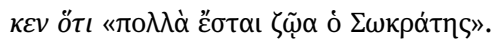

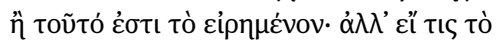

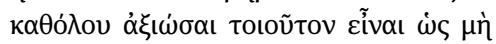

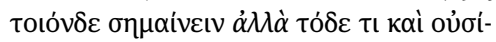

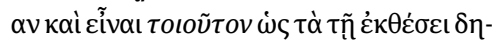

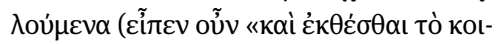

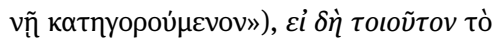

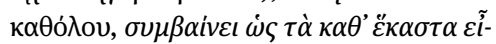

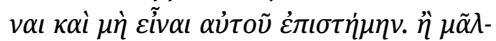

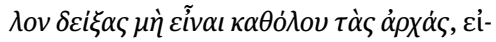

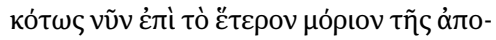

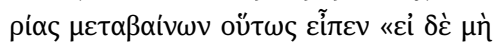

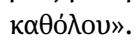

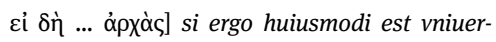
sale efficitur ut sit tanquam singularia, nec eius habeatur scientia. Vel potius cum docuisset principia non esse vniuersalia Sepulveda, Bonitz in apparatu : om. Hayduck

1003a 13 But if [the principles are] not universals.

(1) For he has attacked this [thesis] and has said that "Socrates will be many animals". (2) Or this [part of the] lemma means this: if, on the contrary, someone were to think that the universal is such as to signify not a such but an individual and a substance and that it is such as the things that are signified by exposition (indeed he said "and the common predicate [may be] exposed"), if then the universal is such, it follows that it is like the particulars and that there will be no science of it. (3) Or rather, having shown that the principles are not universals, he now appropriately shifts to the other side of the aporia and thus says: "But if [the principles are] not universals”. 
$\mathbf{P}$ provides a fuller text than the other manuscripts by proposing three alternative

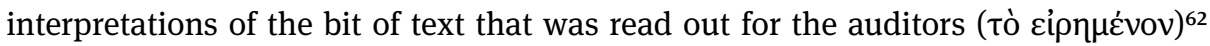
instead of two. Proposing different interpretations of a given passage, which are demarcated through the disjunctive particle $\eta$, but without necessarily opting for one, is a standard method applied by Alexander throughout his commentary. In order to comprehend these alternative intepretations, we have to understand first what the

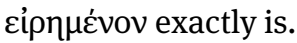

As it stands in all manuscripts (including P), Alexander's text does not yield a sat-

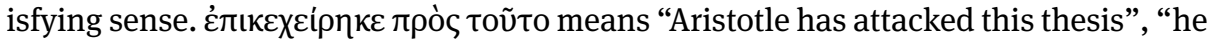
has argued against this thesis", ${ }^{63}$ that is, against the $\varepsilon i \rho \eta \mu \varepsilon ́ v o v$, namely that the first

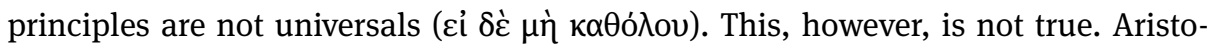
tle has argued against the thesis that the first principles are universals, and this is actually supported by what comes next in Alexander's text: "Socrates will be many animals" is an argument against the (Platonic) option that the universals themselves

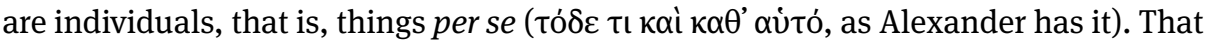
Socrates will be many animals is an absurd consequence of the Platonic third way, which would seem to overcome Aristotle's aporia, namely the thesis that the first principles are neither universals in the sense of being essential attributes of individual subjects nor individual sensible things, but are universals that exist per se. Now, if we consider that the cipqućvov, which is admittedly quite short for a (part of a) lemma, has suffered from an omission due to a saut du même au même (printed in bold in the quotation of Aristotle above), we can make far better sense of Alexander's commentary:

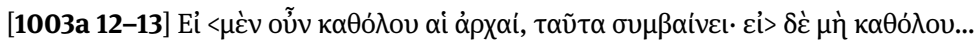

It immediately becomes clear that Alexander's alternative interpretations do not con-

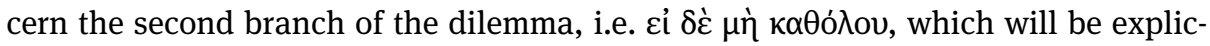

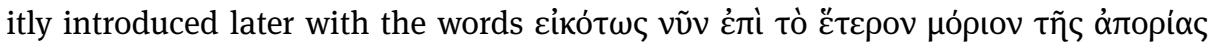

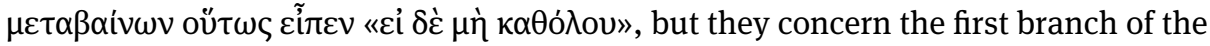

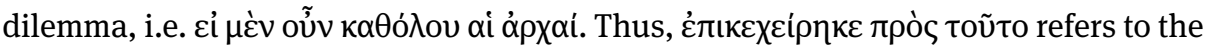
absurd consequences that follow from the thesis that the principles are universals. What Alexander actually explains is how to interpret $\tau \alpha \tilde{\tau} \tau \alpha \sigma \nu \mu \beta \alpha i v \varepsilon \iota^{64}$

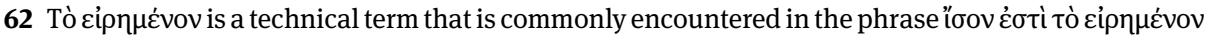
$\tau \tilde{\omega}$... (vel sim.). It normally does not designate the lemma as a whole, called tò ṕntóv, but a part of the lemma that is being elucidated.

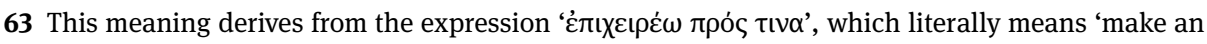

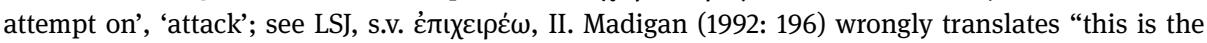
conclusion towards which Aristotle argued".

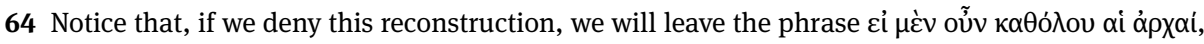
$\tau \alpha \tilde{\tau} \tau \alpha \sigma v \mu \beta \alpha i v \varepsilon ı$ without commentary or paraphrase. In light of Alexander's exegetical method, this would be bizarre. 


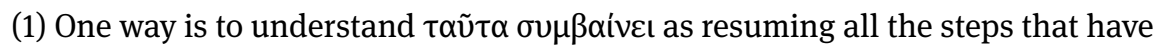
led to the absurd consequence that "Socrates will be many animals": if the principles are universals, then they must be universals that exist per se (as Platonists want; for we know that if the principles do not exist per se, they cannot be principles of substances); but universals cannot exist per se, for otherwise Socrates will be many animals. (2) A second way to understand $\tau \alpha \tilde{\tau} \tau \alpha \sigma u \mu \beta \alpha i v \varepsilon$ is to take the consequences of the principles' being universals as annihilating not their existence, as in the previous case, but as eradicating their knowability: if the principles are singular universals, then they are like the individual substances and, like the individual substances, they cannot be objects of science. In the first case, the plural $\tau \alpha \tilde{u} \tau \alpha$ refers to the absurd consequence that Socrates will be many animals and its antecedent; in the second case,

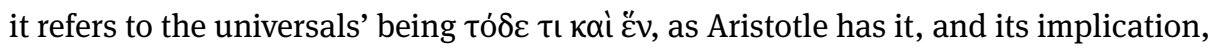
which will be made explicit in the second branch of the dilemma. (3) A third way to

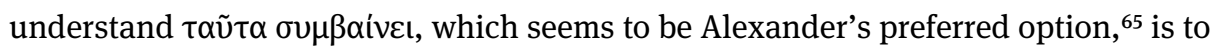
take it comprehensively and emphatically: Aristotle has refuted both branches of the possibility that the principles are universals, either as essential attributes or as selfexisting universals, and now shifts to the other side of the aporia, namely that the principles are not universals.

It is evident that $\mathbf{A}, \mathbf{O}$ and $\mathbf{L}$ cannot really account for alternative intepretations: "Socrates will be many animals", which appears as part of the first interpretation, is an argument specifically against the alternative interpretation, namely the Platonic "exposition" of the common predicate, which is here trivially explained as "the univer-

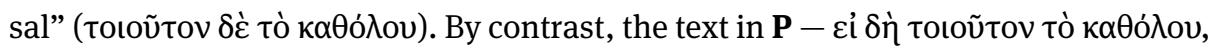

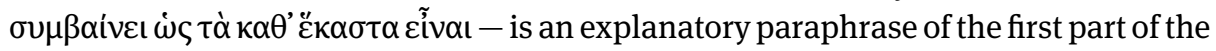

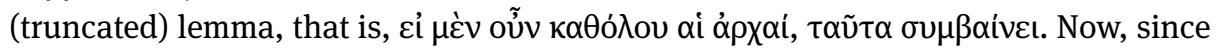
the intelligibility of the text, as it reads in $\mathbf{P}$, depends on the lemma before its truncation, it is improbable that this text, which is in itself rather sophisticated, ${ }^{66}$ is the product of a conjecture; and if it were, the truncated lemma would have been restored too. On the contrary, by inversing the last two words of P's varia lectio, that is, read-

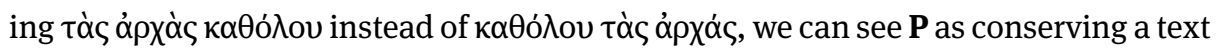

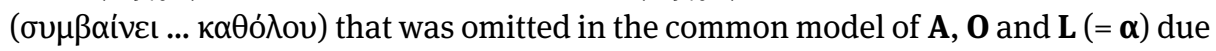

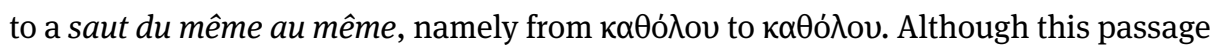

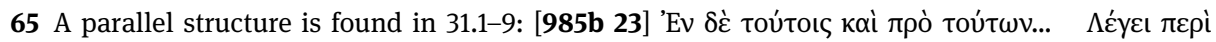

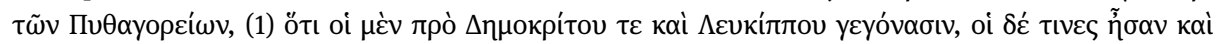

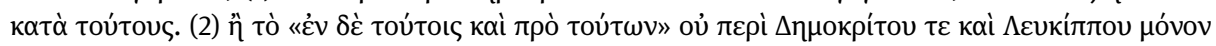

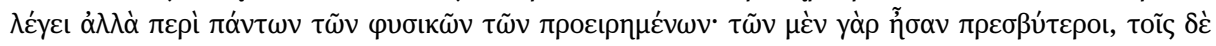

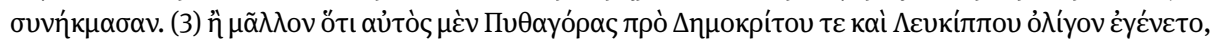

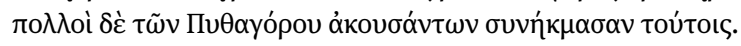

66 By contrast, as it reads in $\mathbf{A}, \mathbf{O}$ and $\mathbf{L}$, the text says somewhat awkwardly that, because Aristotle by treating the "exposed" universal has not yet dealt with the principles as non-universals, he now appropriately shifts to considering the principles as non-universals. 
was retained in Juan Ginès de Sepúlveda's Latin translation and was quoted in Latin as probably authentic by Hermann Bonitz, it has escaped the attention of scholars of the twentieth century and contemporary scholars due to Michael Hayduck's edition. Although Hayduck reproduced Bonitz's Latin entries at other places, he neglected to do

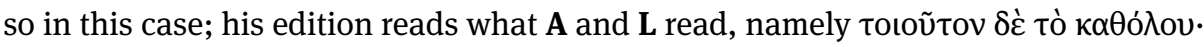

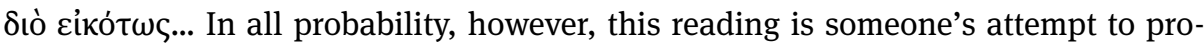
duce an intelligible text, once the saut from $\kappa \alpha \theta$ ó $\lambda$ ov to $\kappa \alpha \theta$ ó $\lambda$ ou had occurred. ${ }^{67}$ Thus, Alexander's comment on the end of book Beta should read as follows:

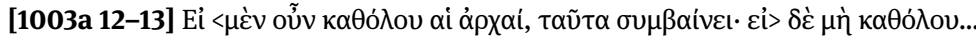

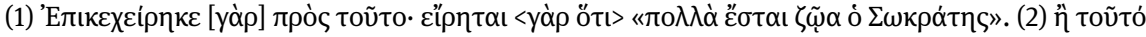

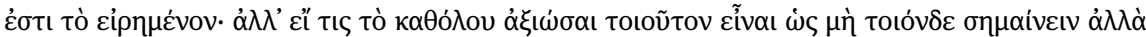

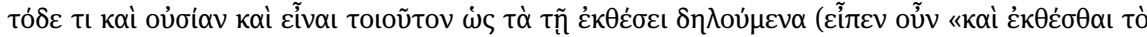

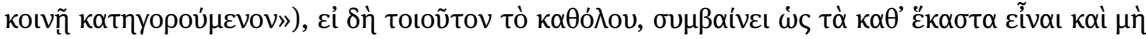

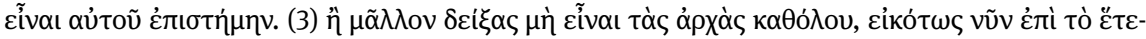

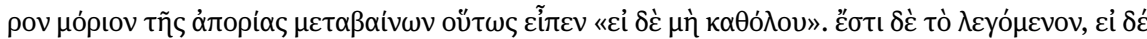

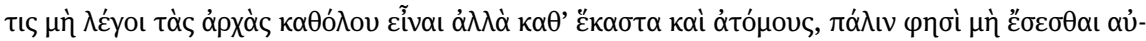

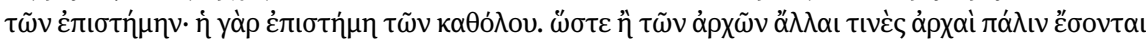

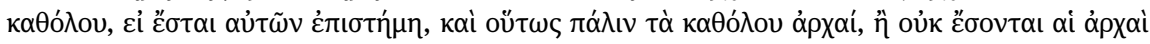

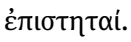

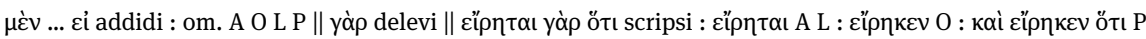

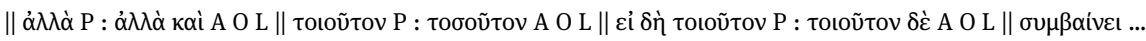

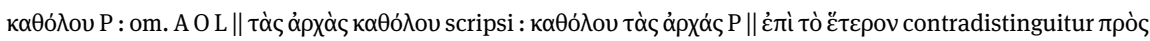

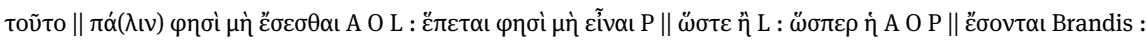

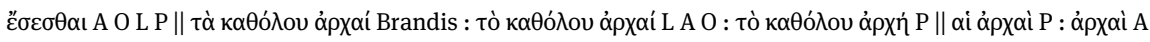
$\mathrm{OL}$

1003a 12-13 (I) If <then the principles are universals, this is what follows; (II) if $>$ they are not universals...

(I.1) He has attacked this [thesis]; for it has been said that "Socrates will be many animals". (I.2) Or the [first part of the] lemma means this: if, on the contrary, someone were to think that the universal is such as to signify not a such but an individual and a substance, and that it is such as the things that are signified by exposition (for he said "and the common predicate [may be] exposed"), if then the universal is such, it follows that it is like the particulars and that there will be no science of it. (I.3) Or rather, having shown that the principles are not universals [on both ways], (II) he now appropriately shifts to the other side of the aporia and thus says: "But if [the principles are] not universals...". What this means is that, if someone denies that the principles are universals and says that they are particulars and individuals, ${ }^{68}$ [Aristotle] retorts that once

67 A similar attempt at restoring a problematic passage in $\alpha$ occurs a little earlier, in 211.16-17: $\dot{\eta} \mu \dot{\varepsilon} v$

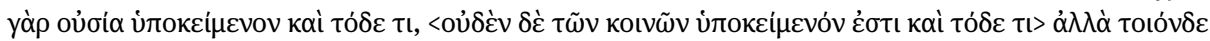
("For substance is a subject and an individual thing; but none of the things that are common is a sub-

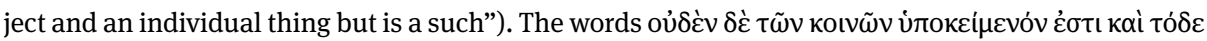

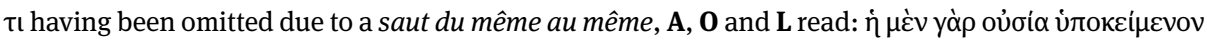

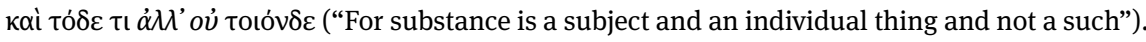

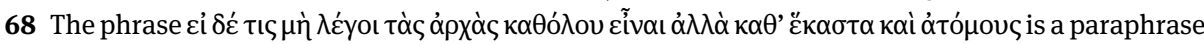

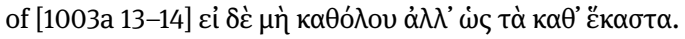


again there will not be science of them; for science is of universals. Therefore, either there will be of these principles other principles which will be once more universal, if there is to be science of them, and then once again universals will be principles; or else the principles will not be objects of science.

"Once again" ( $\pi \dot{\alpha} \lambda \iota v)$ refers to the consequence that Alexander has already articulated according to the text in $\mathbf{P},{ }^{69}$ namely that "it follows that [the universal] is like the particulars and that there will be no science of it".

Let us consider a further example from the commentary on B 3, 998b 19-27, where Aristotle argues that One and Being are not genera (therefore, granted the Platonic thesis that the highest genera are the first principles, One and Being cannot be the first principles). One of Aristotle's arguments is that every difference dividing a genus is itself one and being; therefore, if One and Being are genera, they will be predicated of their proper differences, which leads to an absurd regress: if being as genus is predicated of, and therefore is constituent of, the difference (say, 'rational' = being $+\mathrm{X}$ ), then the difference $(X)$ of the difference will also include being as its constituent (being $+Y$ ), and infinitely so. Although Alexander does not appeal to infinite regress, he does point in his commentary on Aristotle's Topics to the absurdity of having the genus predicated of the species many times instead of once, if the genus is predicated of the difference:

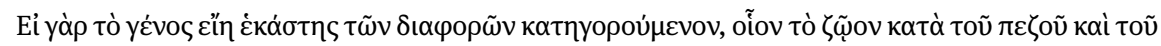

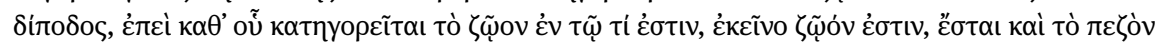

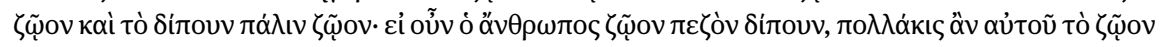

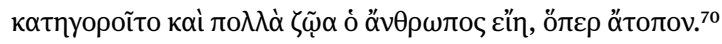

If the genus were predicated of each difference, for instance 'animal' of 'walking' and 'biped', since that of which 'animal' is predicated in the what-it-is, that [thing] is an animal, 'walking' will be an animal and 'biped' will also be an animal; therefore, if man is 'animal walking biped', 'animal' will be predicated of him many times and man will be many animals, which is absurd.

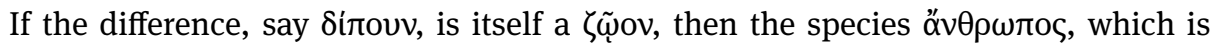

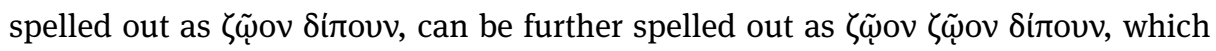
is absurd. Now, the same point is made in the commentary on the Metaphysics, but only as it reads in $\mathbf{P}$ :

ed. Hayduck (205,10-19)

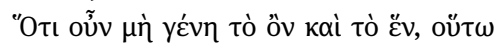

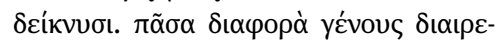

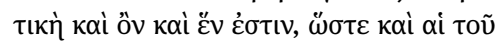

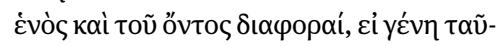

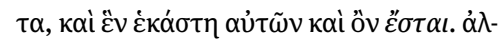

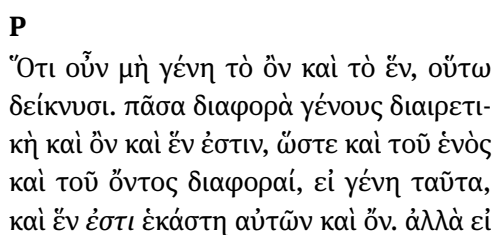

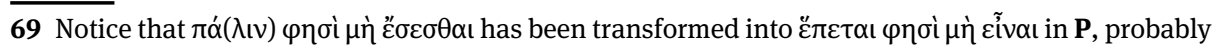
because Callistus was unable to decipher the abbreviation of $\pi \dot{\alpha} \lambda \mathrm{tv}$.

70 Alexander, In Top. 452.6-11. 


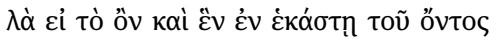

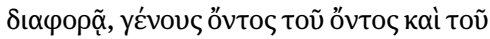

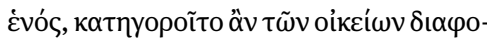

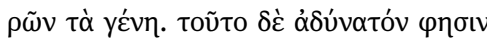

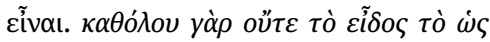

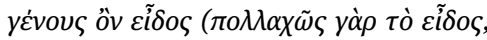

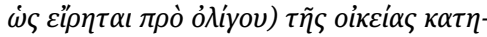

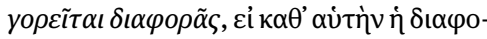

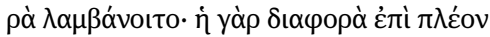

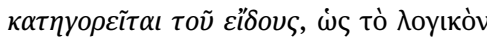

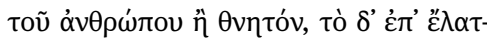

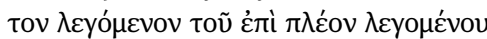

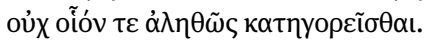

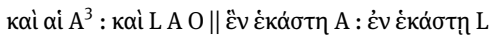

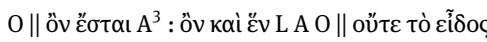

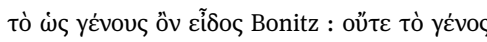

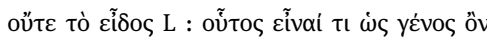

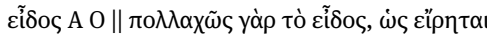

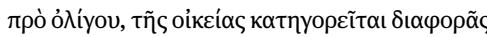

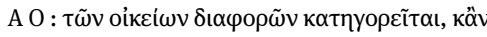

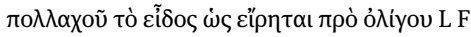

That Being and One are not genera, then, he proves as follows. Every difference that divides a genus is both a being and a one. Therefore, assuming that One and Being are genera, their differences will $b e$, each of them, a one and a being. But if Being and One are found in each difference of Being, while Being is a genus and One is a genus, then the genera would be predicated of their proper differences. But this, he says, is impossible. For, [speaking] universally, the species, that is, the species which belongs to a genus ('species' is used in many ways, as was said a little earlier), is not predicated of its proper difference, if the difference is taken by itself. For the difference is predicated more extensively than the species; for example, rational and mortal [are predicated] more extensively than man. But it is impossible for that which is said less extensively to be truly predicated of that which is said more extensively. (Transl. Madigan 1992, adapted.)

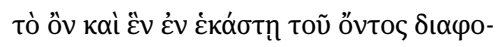

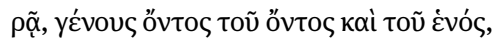

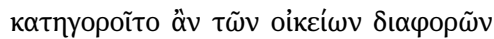

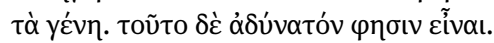

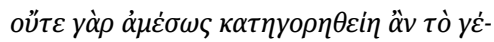

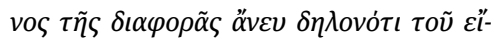

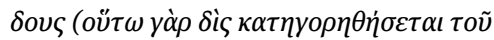

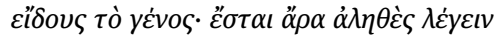

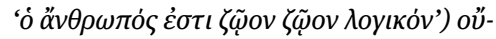

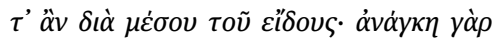

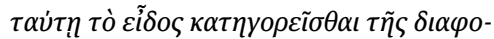

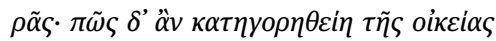

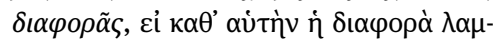

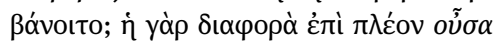

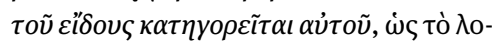

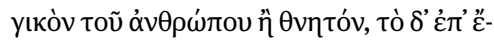

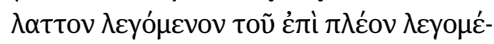

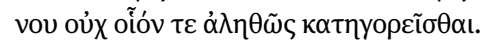

That Being and One are not genera, then, he proves as follows. Every difference that divides a genus is both a being and a one. Therefore, assuming that One and Being are genera, their differences are, each of them, a one and a being. But if Being and One are found in each difference of Being, while Being is a genus and One is a genus, then the genera would be predicated of their proper differences. But this, he says, is impossible. For the genus can be neither directly predicated of the difference, manifestly without the species (for, in this case, the genus would be predicated twice of the species; therefore, the statement 'man is a rational animal animal' will be true), nor with the mediation of the species; for in this way it is necessary that the species be predicated of the difference; but how can the species be predicated of its proper difference, if the difference is taken by itself? For the difference is more extensive than the species and is [therefore] predicated of $i t$; for example, rational and mortal [are predicated] more extensively than 
man. But it is impossible for that which is said less extensively to be truly predicated of that which is said more extensively.

The text in $\mathbf{P}$ is considerably different from what the other manuscripts transmit. ${ }^{71}$ As

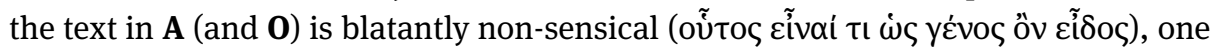
may be tempted to see in $\mathbf{P}$ an extensive interpolation by Callistus. But it is hard to square this temptation with a rather sophisticated text, which makes sense of Aristotle's argument and finds a remote parallel in Alexander's commentary on the Topics. ${ }^{72}$

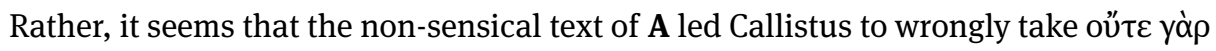
... ठı $\alpha \varphi о \rho \tilde{\alpha} \varsigma$ as a replacement of the problematically transmitted passage, while it was

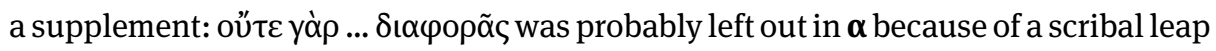
from $\delta \iota \alpha \varphi \circ \rho \tilde{\alpha} \varsigma$ to $\delta \iota \propto \varphi \circ \rho \tilde{\alpha}$ and was later supplied in the margin. We should notice, of

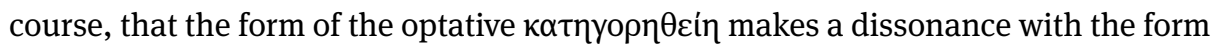
катпуороі̃т, which is used by Alexander immediately before. Nonetheless, we must guard against seeing in this reading a sign of interpolation; ${ }^{73}$ it should rather be interpreted as an erroneous expansion of an abbreviated form ( $\alpha^{2} \nu \alpha \tau \eta \gamma о \rho \eta \sim$ ?). Thus, the text (174.27-175.14) should be edited as follows:

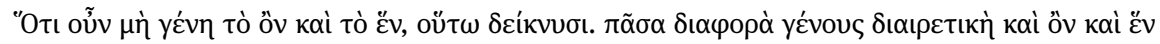

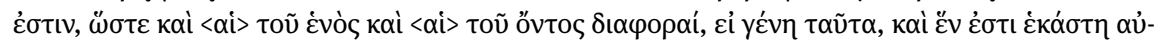

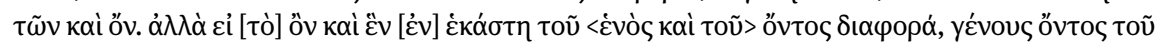

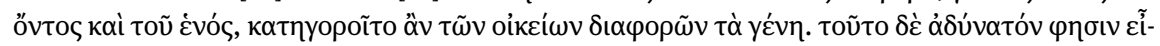

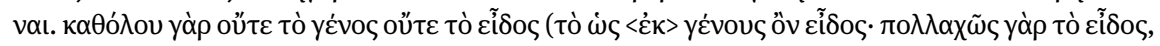

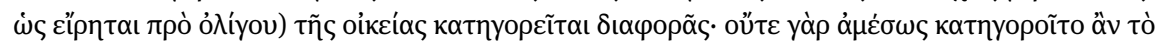

71 Note that Sepúlveda follows the text of $\mathbf{P}$ in his translation, which is quoted by Bonitz in the apparatus. As with the case of the commentary on B 6 previously considered, Hayduck deviates from Bonitz and does not record in his apparatus Sepúlveda's (different) Latin text.

72 Callistus' sophistication was rather limited, as we shall shortly see. Besides, if one goes through Callistus' conjectures, which I have assembled in Appendix B, one will soon understand Callistus' method of interpolation. Callistus normally rearranges the problematic text (see p. xxix, n. 30 for an example of such an interpolation) or supplies words in order to improve it syntactically. Thus, in the text above, ท่ yò

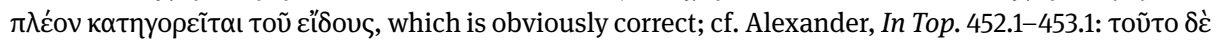

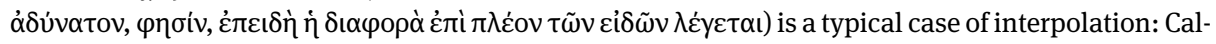

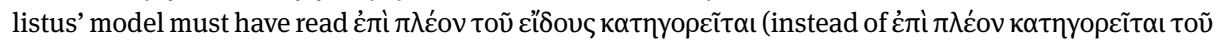

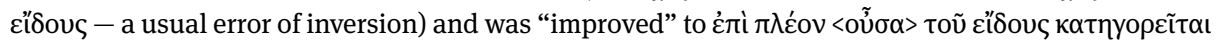

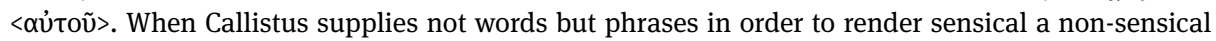
passage (cf. 91.5-6, 149.7-11, 172.22-25, 173.29-174.2 and 211.18-212.2 in Appendix B), these supplements consist of either one or two propositions. Both here and in the case previously considered the particular text of $\mathbf{P}$ is considerably longer. Admittedly, then, the extensive and sophisticated readings of the commentary on B 3 and B 6 attested in $\mathbf{P}$ can hardly be due to Callistus. And since they say something that could be said by Alexander, they can hardly be interpolations.

73 An interpolator, I guess, would have imitated Alexander's usus eloquendi in the immediate context. 


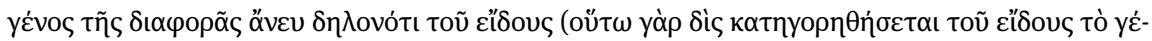

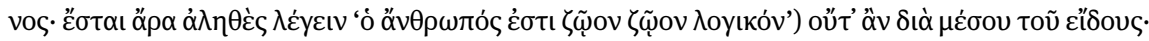

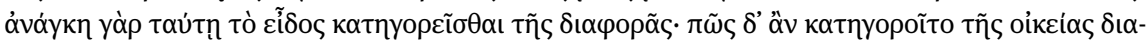

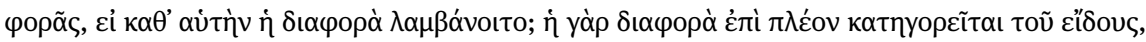

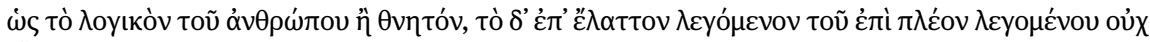

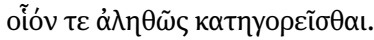

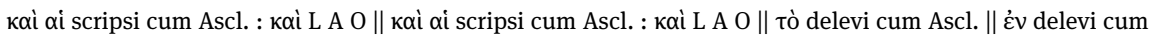

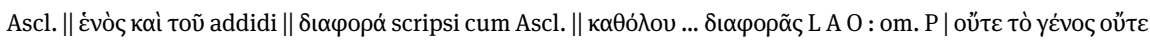

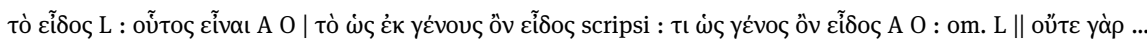

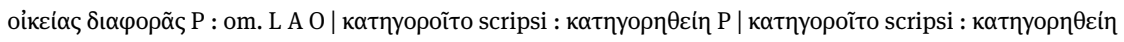

That Being and One are not genera, then, he proves as follows. Every difference that divides a genus is both a being and a one. Therefore, assuming that One and Being are genera, their differences are, each of them, a one and a being. But if each difference of One and Being are a one and a being, while Being is a genus and One is a genus, then the genera would be predicated of their proper differences. But this, he says, is impossible. For, on the whole, neither the genus nor the species ([that is,] the species as derived from the genus; for 'species' is used in many ways, as was said a little earlier) ${ }^{74}$ are predicated of their proper difference. For the genus can be neither directly predicated of the difference, manifestly without the species (for, in this case, the genus would be predicated twice of the species; therefore, the statement 'man is a rational animal animal' will be true), nor with the mediation of the species; for, in this way, it is necessary that the species be predicated of the difference; but how can the species be predicated of its proper difference, if the difference is taken by itself? For the difference is predicated more extensively than the species; for example, rational and mortal [are predicated] more extensively than man. But it is impossible for that which is said less extensively to be truly predicated of that which is said more extensively.

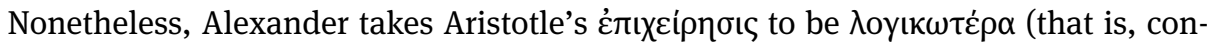
forming more to logic than to reality) and tries to moderate the validity of his argu-

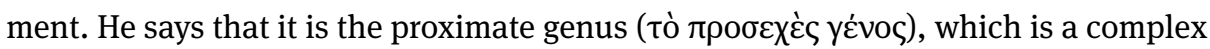

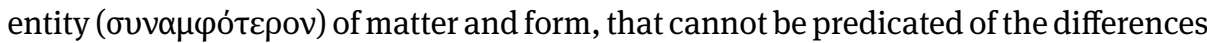
dividing the genus, which taken in themselves are not complex but simple (say, 'ani-

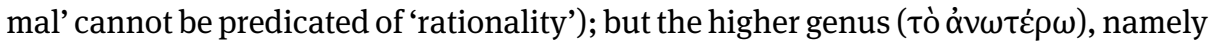

74 Cf. 173.9-10 The species (عĩ $\delta$ oৎ) is also distinguished from and opposed to matter. 


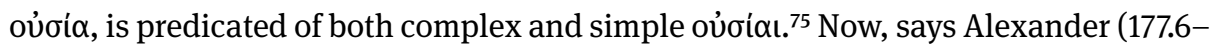
8), the Being, which is questioned by Aristotle, ${ }^{76}$ is precisely such a higher genus:

\section{A O L}

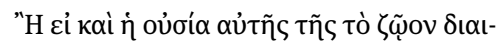

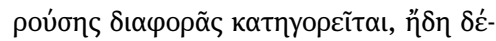

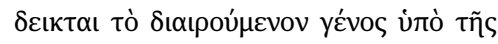

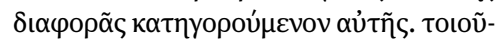

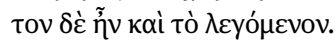

Now if substance is also predicated of that difference which divides [the kind] animal, then it is eo ipso proven that the kind which is divided by the difference is predicated of the difference. But such was the point in question. (Transl. Madigan 1992.)
$\mathbf{P}$

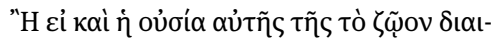

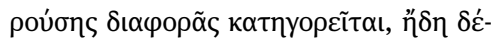

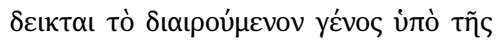

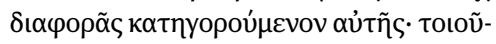

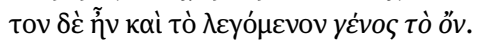

Now if the essence is also predicated of that difference which divides [the genus] animal, then it is eo ipso proven that the genus which is divided by the difference is predicated of the difference. But such was the genus Being, of which it is spoken [in this passage].

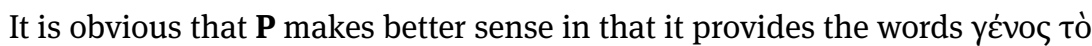
ôv, which are justified in this context and had been probably omitted in $\boldsymbol{\alpha}$ by a saut du même au même. As the text goes on (177.8-12), it still makes better sense in $\mathbf{P}$ than it makes in $\mathbf{L}, \mathbf{A}$ and $\mathbf{0}$ :

\begin{abstract}
A O L

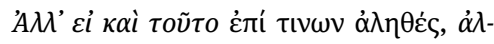

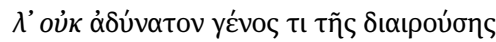

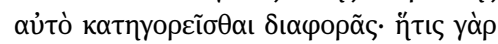

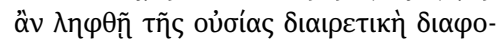

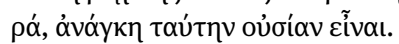

\begin{abstract}
$\mathbf{P}$

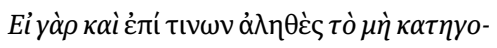

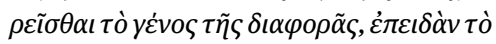

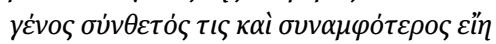

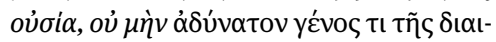

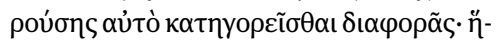

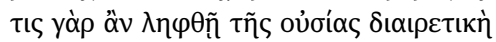

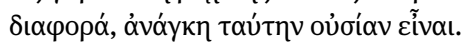

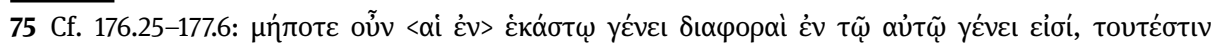

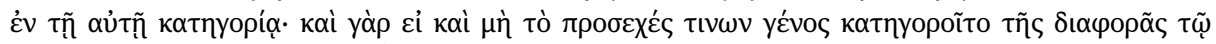

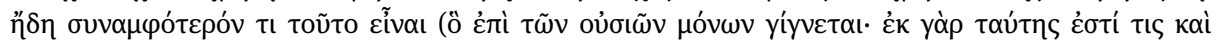

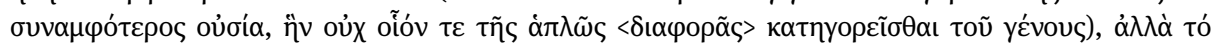

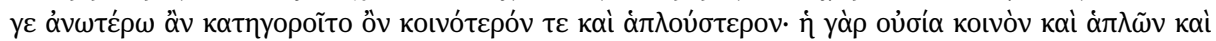

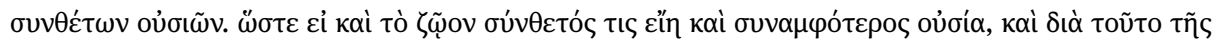

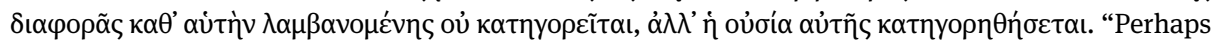
then the differences in each genus are in the same genus, that is, in the same category. And indeed, even if the genus that is proximate to particulars is not predicated of the difference because it is already something complex - something which takes place in the case of essences alone; for from essence there comes also a certain kind of complex essence, which cannot be predicated of the difference of the genus taken simply [i.e. by itself] - still the higher genus, being more common and simpler, can be predicated of the difference; for essence is common and [inclusive] of both simple and composed essences. Therefore, even if [the genus] animal should be a composed and a complex substance, and on this account is not predicated of its difference taken by itself, still essence will be predicated of it." (Transl. Madigan 1992, modified.)

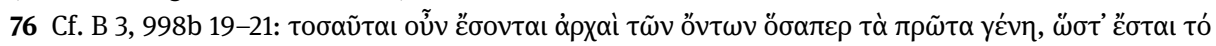

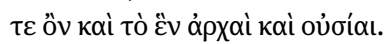


But even if this is true in some cases, still it is not impossible for some kind to be predicated of the difference that divides it. For, whatever difference that divides substance is taken, it is necessary that this difference be a substance. (Transl. Madigan 1992.)
For even if it is true in some cases that the genus cannot be predicated of the difference, whenever the genus is some composed and complex essence, still it is certainly not impossible for the genus to be predicated of the difference that divides it. For, whatever difference that divides the essence is taken, it is necessary that this difference be an essence.

It is unlikely that the text in $\mathbf{P}$, which again makes perfect sense, respects Alexander's vocabulary and shows no signs of artificiality, ${ }^{77}$ can be the product of a conjecture.

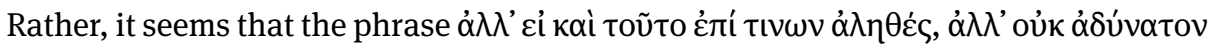
is an emendation in $\boldsymbol{\alpha}$ of a text that did not include what is here put in $<$... >: દi yò $\rho$

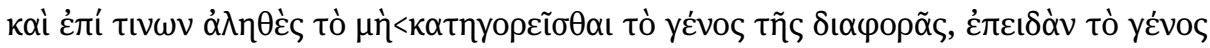

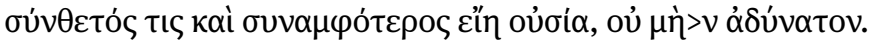

At 187.20-23, to quote a last example, Alexander's text is again presented differently in P:

\section{A O L}

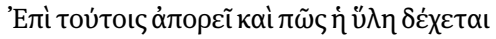

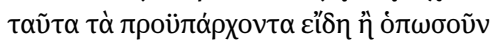

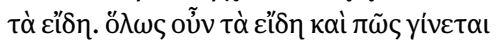

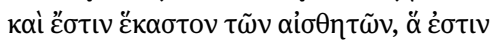

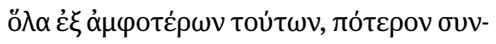

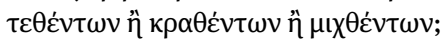

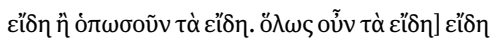

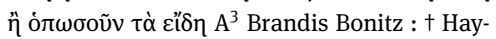

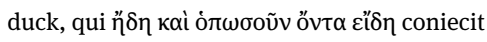

Aristotle raises a further aporia: how does matter receive these pre-existing forms or, in any way whatever, the forms? In fact, how do the forms generally both become and be each of the sensibles, which are wholes composed of both [matter and form]? Are [matter and form in them] combined, or blended, or mixed?

\section{P}

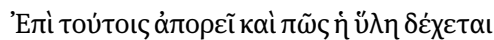

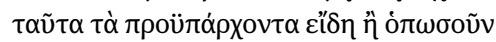

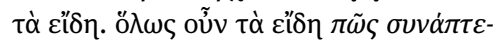

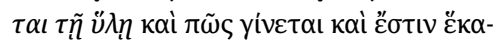

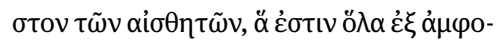

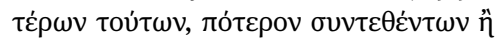

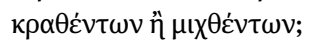

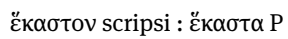

Aristotle raises a further aporia: how does matter receive these pre-existing forms or, in any way whatever, the forms? In fact, how are the forms generally <attached to matter> and how does each of the sensibles, which are wholes composed of both [matter and form], become and be? Are [matter and form in them] combined, or blended, or mixed?

Although the text in $\mathbf{P}$ might seem at first sight to be due to a conjecture (the text of the "vulgata" is sensically not satisfactory), it is likely that it is not. The obvious emenda-

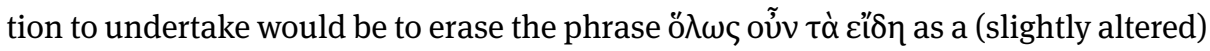

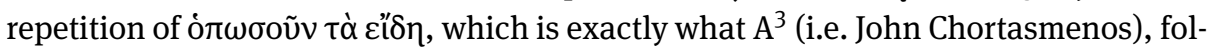

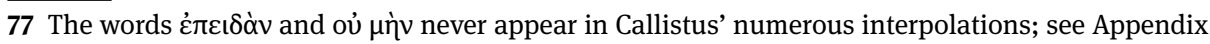
B. 


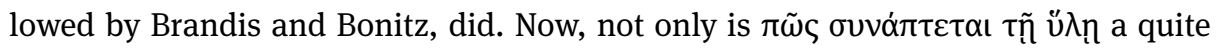
rare expression, ${ }^{78}$ but a saut du même au même (from $\pi \tilde{\omega} \varsigma$ to $\pi \tilde{\omega} \varsigma$ with a subsequently added $\kappa \alpha i$ ) can account for the omission of this phrase in $\boldsymbol{\alpha}$ (iotacism and a leap from $\mathrm{EI} \Delta \mathrm{H}$ to the similar-looking $\mathrm{Y} \Lambda \mathrm{H}$ while transliterating from a majuscule script might also account for this omission). It seems that ő $\lambda \omega \varsigma$ oũv is not the product of an unconscious repetition but stands for Aristotle's $\alpha$ $\mu \alpha$ $\delta \dot{\varepsilon}$ in Alexander's paraphrase. ${ }^{79}$

We may thus conclude that the exemplar copied by Callistus was provided with emendations, some of which ultimately stemmed from a manuscript that was independent from the main branch of the manuscript tradition of Alexander's commentary on the Metaphysics. ${ }^{80}$ We have detected the presence of variant readings also in Grego-

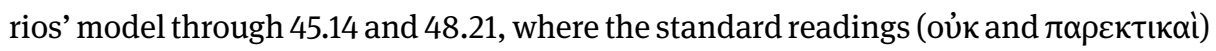
have been copied in $\mathbf{P}$ supra lineam and the variant readings (ov่ $\tau \tilde{\omega} v$ and $\pi \alpha \rho \alpha \kappa \tau \iota \kappa \alpha i$, confirmed by Asclepius) in linea; variant readings are evident in several other cases that do not relate at all to the indirect tradition. ${ }^{81}$ The access to variant readings drawn from a single manuscript that was independent from both $\mathbf{A}$ and $\mathbf{0}$ may account for rather unexpected agreements between $\mathbf{O}$ and $\mathbf{P}$ in the part copied by Callistus, ${ }^{82}$ as

78 A similar expression is only found in Proclus' commentary on Plato's Parmenides; cf. 768.12 Cousin:

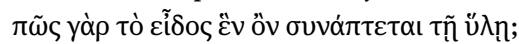

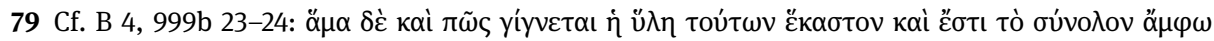

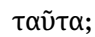

80 My collations have not yet revealed the use of such a parallel source for Alexander's commentary on books $\Gamma-\Delta$.

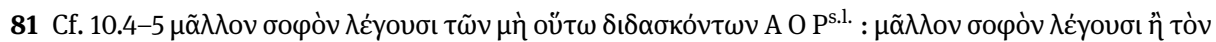

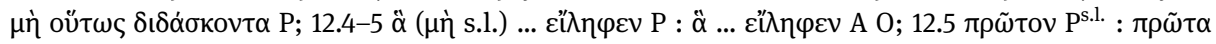

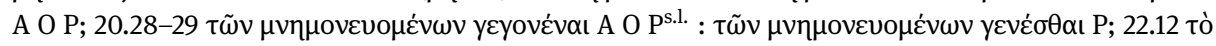

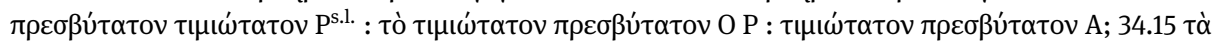

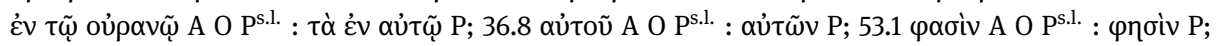

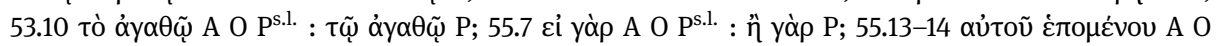

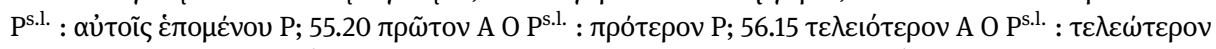

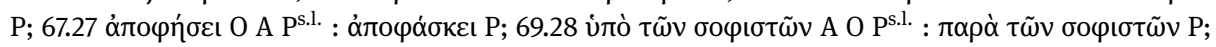

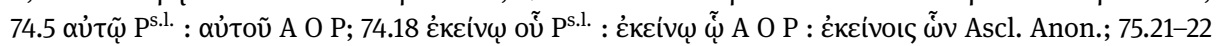

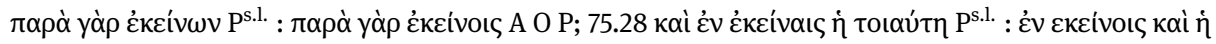

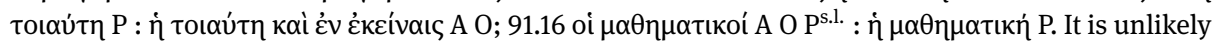
that variant readings such as $\tau \varepsilon \lambda \varepsilon \omega \dot{\tau \varepsilon \rho o v ~(i n s t e a d ~ o f ~ \tau \varepsilon \lambda \varepsilon เ o ́ \tau \varepsilon \rho o v) ~ a n d ~ \pi \alpha \rho \alpha ̀ ~(i n s t e a d ~ o f ~ u ́ m o ̀) ~ a r e ~ d u e ~}$ to emendation. Besides, some of the above readings (in linea) are erroneous.

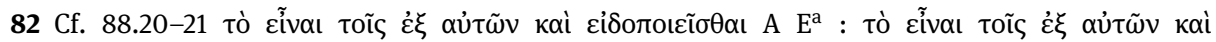

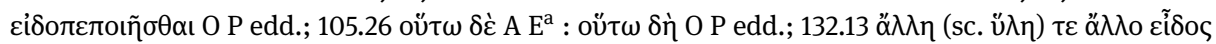

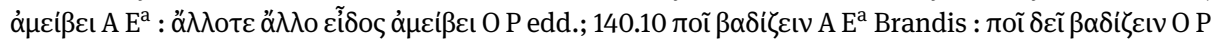

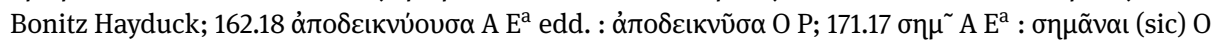

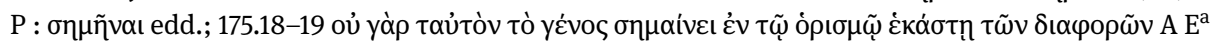

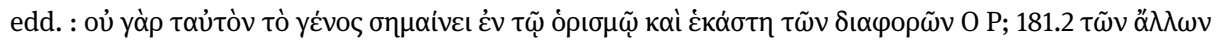

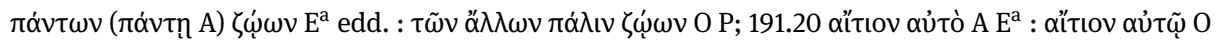

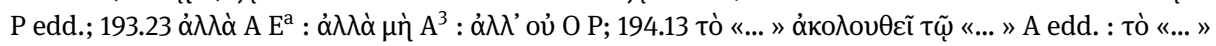

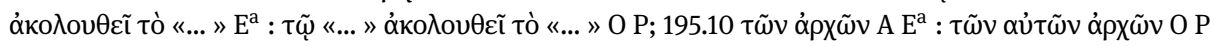


well as between $\mathbf{A}$ and $\mathbf{P}$ in the part copied by Gregorios. ${ }^{83} \mathrm{~A}$ plausible explanation of the way in which $\mathbf{P}$ was produced is the following. Before making a new copy of Alexander's commentary on the Metaphysics at Bessarion's instigation, Gregorios collated and emended his exemplar, an unfinished copy of $\mathbf{0}$, with the help of another manuscript. Once he had to change his exemplar, he would go on with the same procedure in the new exemplar, now a remote copy of $\mathbf{A}$, namely the manuscript that was later to be used by Callistus. It is probable that the editorial work that Callistus exploited (and occasionally did not understand) was Gregorios' work. When Gregorios left Bessarion's house and settled in Florence, ${ }^{84}$ Callistus took over this project. While copying the manuscript previously annotated by Gregorios, Callistus made his

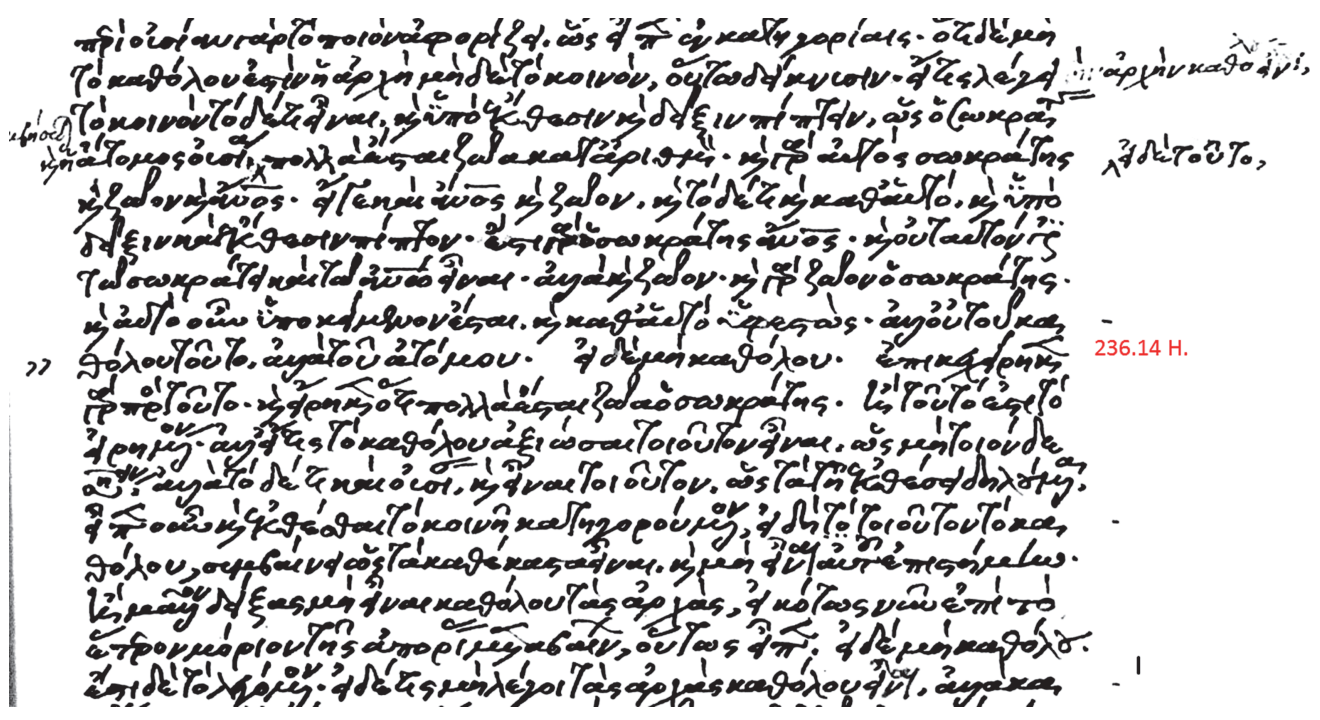

211.15-213.3 as copied by Andronicus Callistus (Par. gr. 1878, f. 72r)

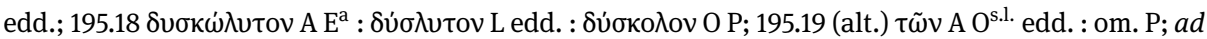

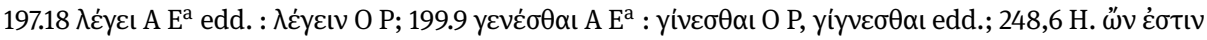

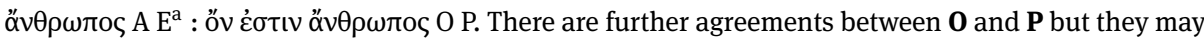
be too easily due to a conjecture.

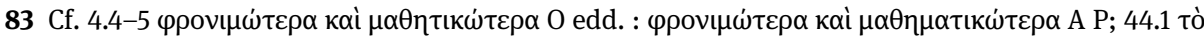

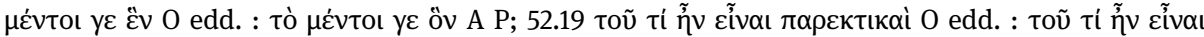

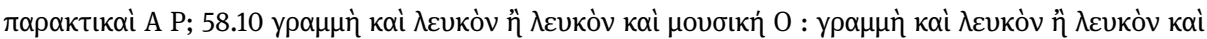

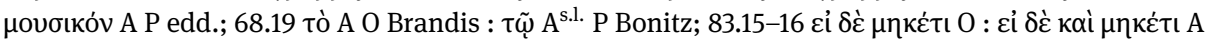
P edd.; 85.13 عi $\delta \dot{\varepsilon} O$ edd. : $\varepsilon \dot{\varepsilon} \delta \dot{\varepsilon} \mu \eta \dot{~ A ~ P . ~ Q u i t e ~ t e l l i n g l y, ~} \mathbf{P}$, as copied by $\mathrm{P}^{1}$, agrees twice with the text of

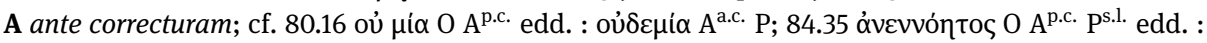
ảvevvóntov A.c. P.

84 Gregorios refers to his relocation to Florence in a letter that he adresses to Bessarion begging for his pardon, because he had allegedly offended the Latin Church; see Patrologia Graeca, ed. J.-P. Migne,

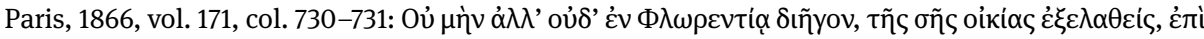


own emendations by conjecture. In the meantime Bessarion died and the new copy remained in Callistus' hands for 3-4 years, before it was sold to Niccolò Leoniceno in 1475/76 (or shortly thereafter). ${ }^{85}$ We may visualise this procedure with regard to the text that we discussed previously, namely the end of the commentary on book Beta (212.10-213.1; see illustration on the preceding page).

Callistus worked with a manuscript, namely $\boldsymbol{\mu}$, which bore emendations in its

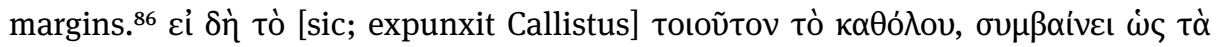

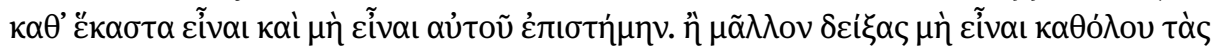

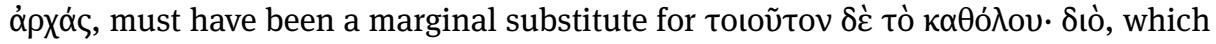
was underlined in Callistus' model and was replaced in P itself (lines 13-15). The fact that Callistus had to erase a redundant tò suggests that he was working with a model that had undergone editorial work that was not his own. At the same time, Callistus himself intervened in the text. His interventions, which in this particular case must have come as an afterthought, are visible in the preceding comment (211.19-212.2): he

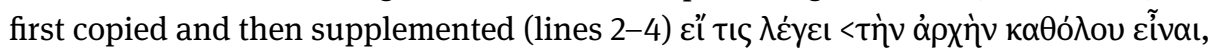

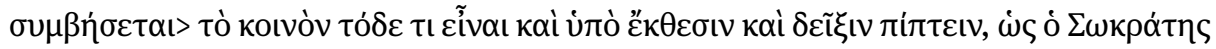

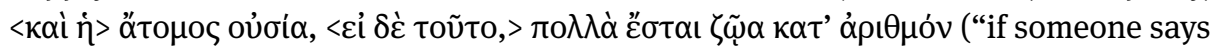
that the principle is universal, it will follow that that which is common is an individual thing and is subject to exposition and exhibition, like Socrates and the individual substance, and if this [happens], there will be numerically many animals"). This, however, is an unnecessary emendation, which possibly came to Callistus' mind once he

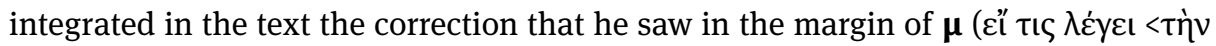

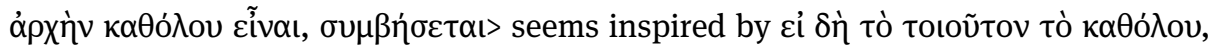

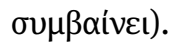

There remains, of course, the problem of P's sharing errors with $\mathbf{0}$ in the part copied by Gregorios and with A in the part copied by Callistus. If Gregorios had at his disposal a Nebenvorlage that was independent of both $\mathbf{A}$ and $\mathbf{0}$, how is this situation to be explained? It seems that this Nebenvorlage was not a full copy of Alexander's commentary but probably a collection of excerpts. It is interesting to notice that in the inventory of Bessarion's manuscripts which was made in 1474, when the whole of his collection arrived in Venice, a liber appears with the following content: Super metaphysicam expositio diversorum, in papiro. ${ }^{87}$ This manuscript, which does not ap-

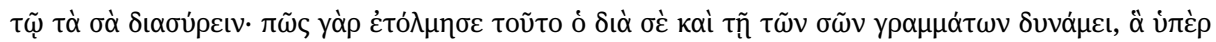

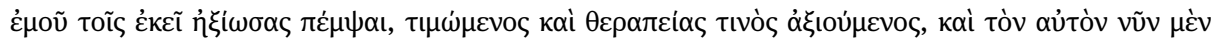

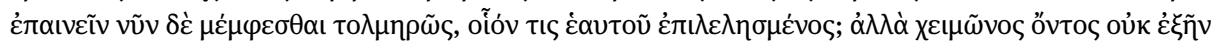

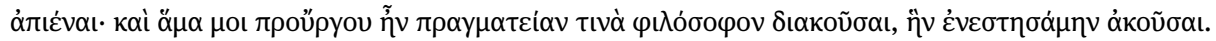

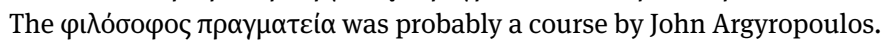

85 See the decription of the codex in Section 3.1.1.

86 If these emendations had been made on $\boldsymbol{\lambda}$, they would have left some traces in $\mathbf{E}^{\mathbf{a}}$ and $\mathbf{E}^{\mathbf{b}}$. I have found no common errors between $\mathbf{E}^{\mathbf{a}}$ and $\mathbf{E}^{\mathbf{b}}$ that could not have been corrected by Callistus.

87 See Labowsky 1979: 221 (Inventory of 1474, $n^{\circ}$ 564). "In papiro" implies a Palaeologan manuscript. 
pear among the books that arrived in Venice in $1469,{ }^{88}$ was either acquired between 1468-1472 or simply kept by Bessarion. It does not reappear in the inventory compiled for the purpose of the consignatio of the Library of San Marco by Andrea Navagero in 1524. It may have been a collection of pertinent passages of various commentaries on the Metaphysics, probably made by Bessarion himself, ${ }^{89}$ which was scrupulously exploited by Gregorios ${ }^{90}$ and possibly at some point also by Callistus. There may be a hint at Callistus' copying an excerpt at the end of the commentary on book alpha elatton. Here is the text with a critical apparatus:

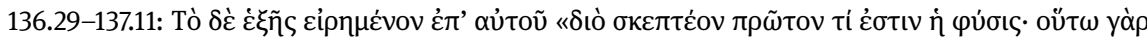

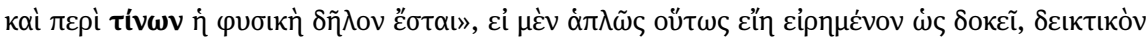

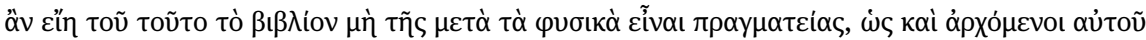

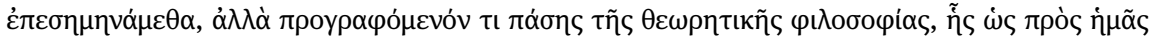

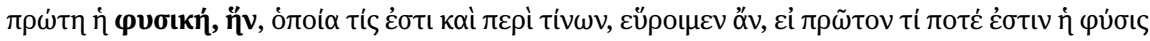

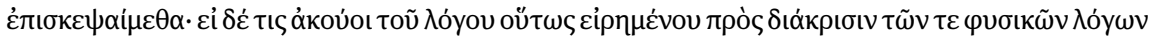

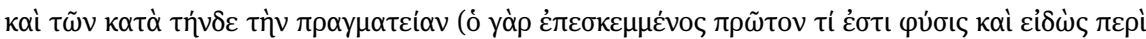

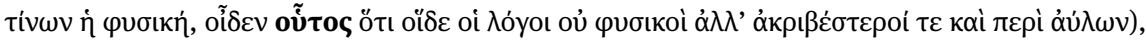

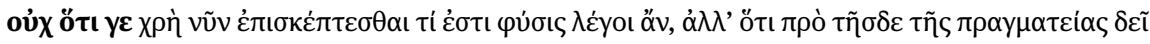

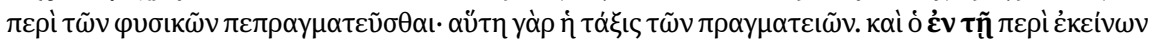

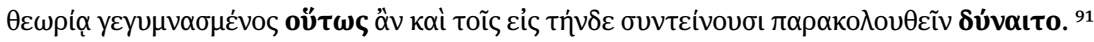

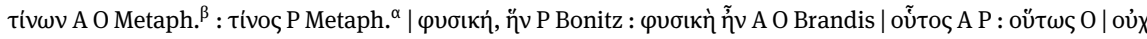

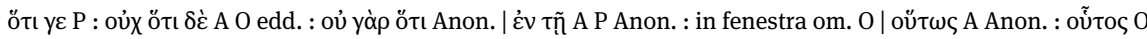

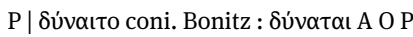

88 By contrast, Marcianus gr. 255, which contains Alexander's commentary on the Metaphysics, was part of the first lot of manuscripts; see Labowsky 1979: 172 (Inventory of 1468, ${ }^{\circ} 377$ ).

89 The Parisinus gr. 2042, identified as Bessarion's autograph by Harlfinger 1971b: 10 (see lately Lorusso 2014), is such a manuscript; it contains numerous excerpts from several Aristotelian treatises.

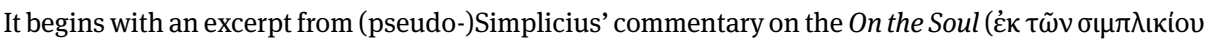

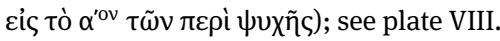

90 Gregorios himself is the copyist of a collection of excerpts from Plotinus' Enneads, namely codex Vindobonensis phil. gr. 226, which is related to Marcianus gr. 240, copied for Bessarion by Demetrios Trivoles. His master Pletho was also fond of excerpting; see Berger 2005: 165-171.

91 Transl. Dooley 1992, modified: "What Aristotle says next, 'Hence we must first inquire what nature is, for thus it will also be clear what things physics deals with' [can be understood in two ways]. [1] If it is said simply as it seems, it would indicate that this book does not belong to the treatise that follows physics, but is, as we pointed out when we started commenting on this book, a kind of prolegomenon to theoretical philosophy as a whole; and since the first part of theoretical philosophy, so far as we are concerned, is physics, we would find out what sort of [science] this latter is and what are its objects if we were first to inquire what nature in general is. But one can also understand [2] that he stated the matter thus in order to distinguish the lectures on physics from the treatise that now occupies us (for one who has first investigated what nature is and has learned with what objects physics deals knows that the present lectures are not about nature, but that they are more accurate and deal with immaterial objects), it would not mean that we must here and now investigate what nature is, but that the treatise on physics must precede the present one; for this is the order of the treatises. And one who has been trained in the intellectual contemplation of those [natural realities] will thus also be able to follow the lectures that pertain to the present treatise". 
This passage is interesting in more than one respect. The first entry in the critical apparatus reveals a correction in the model of $\mathbf{P}$ ( $\tau$ ivos) in accordance with the $\alpha$-branch of the manuscript tradition of the Metaphysics. ${ }^{92}$ That $\mathbf{A}$ and $\mathbf{O}$ preserve the genuine reading of Alexander's commentary ( $\tau \dot{i} v \omega v$ ) is suggested not only because $\mathbf{P}$ is allegedly a derivative manuscript but also for the following reasons: (i) in general, Alexander sides with Metaph. ${ }^{\boldsymbol{\beta}}{ }^{93}$ (ii) in particular, the same passage of the epilogue of alpha elatton has already been quoted and discussed in Alexander's prolegomena to alpha elatton, to which Alexander now refers back, where all A, $\mathbf{O}$ and $\mathbf{P}$ unanimously read

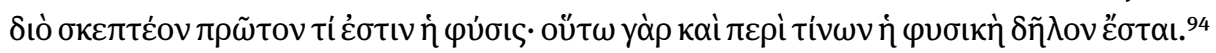

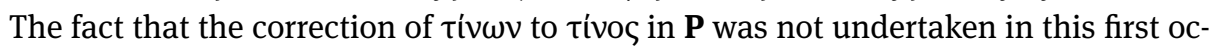
currence of the epilogue of alpha elatton points, once again, to the case that we have already discussed, namely that Callistus was exploiting a foreign editorial work: what was, in all probability, once a varia lectio added onto Alexander's text in accordance with the text of the Metaphysics (as transmitted in the $\alpha$-branch) has come to replace in $\mathbf{P}$ the original reading. There are further cases of $\alpha$-readings appearing in $\mathbf{P}$ against $\beta$-readings which are genuinely transmitted by $\mathbf{A}$ and $\mathbf{0} .{ }^{95}$ We may reasonably think that such variae lectiones were available in $\boldsymbol{\mu}$, which Callistus was copying. Some lines later, however, $\mathbf{P}$ strangely appears to side with $\mathbf{O}$ in an error: "One who has

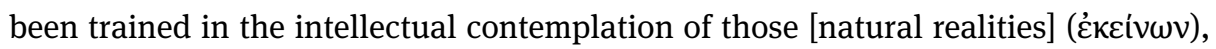
this person (oṽ̃os) will also be able to follow the lectures that pertain to the present treatise" instead of "One who has been trained in the intellectual contemplation of those [natural realities] will thus (ov" $\tau \omega \varsigma$ ) also be able to follow the lectures that pertain to the present treatise", which is what $\mathbf{A}$ (and $\mathbf{E}^{\mathbf{a}}$ ) reads. ${ }^{96}$ We may be tempted to ascribe the agreement between $\mathbf{O}$ and $\mathbf{P}$ to coincidence (viz. a conscious modification

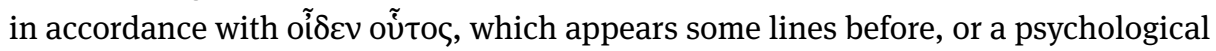

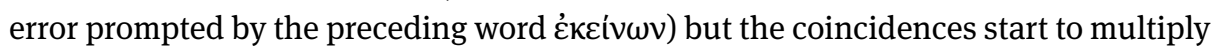

$\mathbf{9 2}$ On the textual tradition of Aristotle's Metaphysics and its two branches, $\boldsymbol{\alpha}$ and $\boldsymbol{\beta}$, see Harlfinger 1979; Primavesi 2012; Golitsis 2016a.

93 This means that Alexander's main manuscript of the Metaphysics and the reconstructed manuscript $\boldsymbol{\beta}$ of the Metaphysics, which is one of the two origins of the Byzantine transmission of Aristotle's treatise (the other origin is $\boldsymbol{\alpha}$ ), ultimately have a common ancestor, on which the reconstructed manuscript $\boldsymbol{\alpha}$ of the Metaphysics does not depend. See also p. clv, n. 46.

94 Cf. 109.14-15.

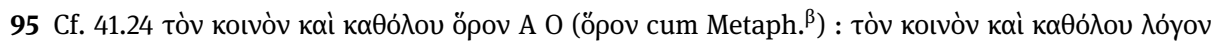

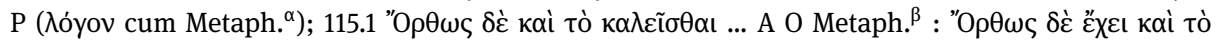

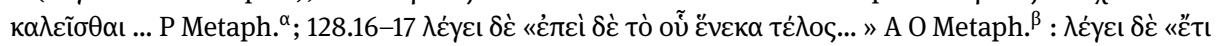

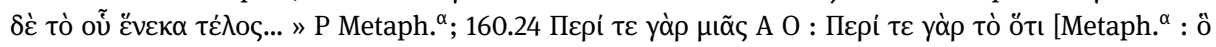

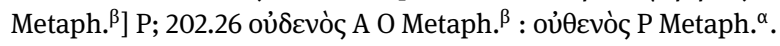

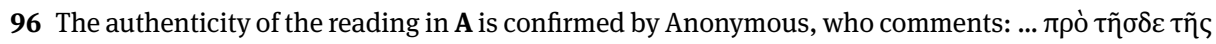

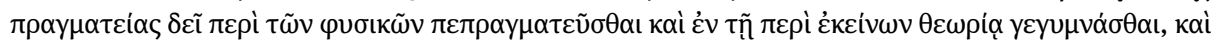

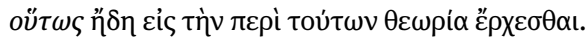




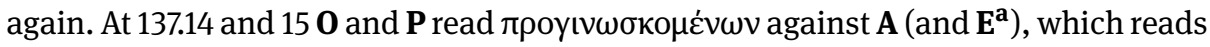
$\pi \rho о \gamma \iota \gamma \nu \omega \sigma \kappa о \mu \varepsilon \dot{v} \omega \nu:{ }^{97}$

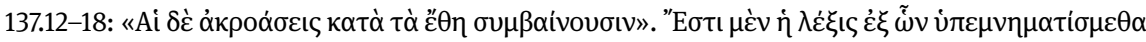

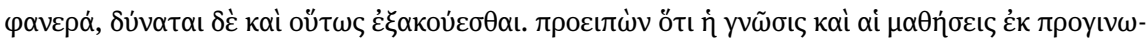

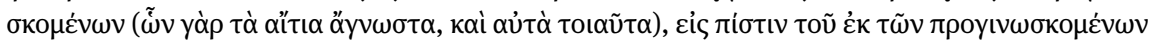

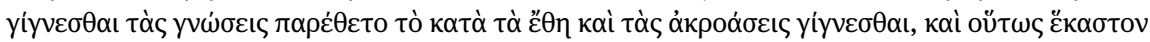

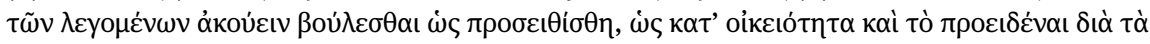

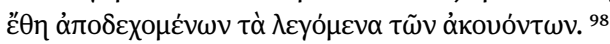

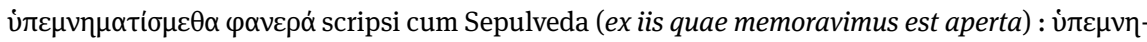

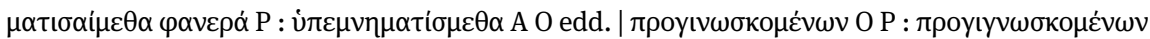

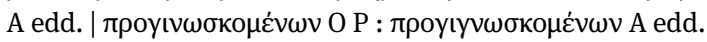

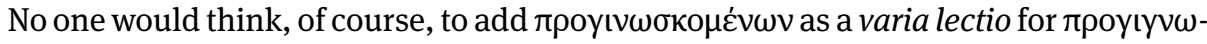
$\sigma \kappa o \mu \varepsilon \dot{v} \omega \nu$. Unless we want to make an appeal to coincidence (an appeal which is never entirely satisfactory), we should consider the possibility that, albeit only for a small bit of text, Callistus actually copied $\mathbf{O}$. But this is impossible, since by 1471/72 $\mathbf{O}$ was still in Crete. ${ }^{99}$ Thus, we may think that Callistus directly copied an excerpt, which he could easily identify as the end of the commentary on alpha elatton. Now, if this excerpt was independent not only from $\mathbf{A}$ but also from $\mathbf{0}$, the reading $\pi \rho \log \nu \omega \sigma \kappa o \mu \varepsilon \dot{v} \omega \nu$ must have been the original reading of Alexander's commentary. ${ }^{100}$ But if this is true, how is the erroneous oũंos in $\mathbf{O}$ and $\mathbf{P}$ to be accounted for, if not by coincidence? It

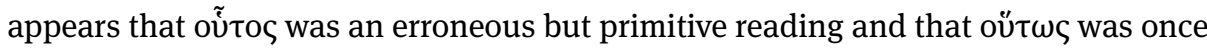
a correction in $\mathbf{\gamma}$; but whereas $\mathbf{A}$ has correctly integrated this correction into Alexander's text, $\mathbf{0}$ has misleadingly reported it to the first ou்tos that occurs in the passage:

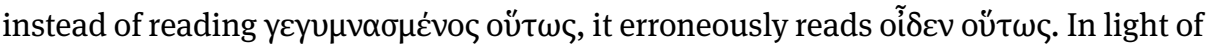

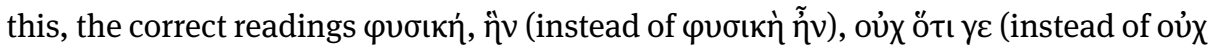

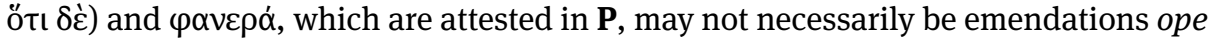
ingenii.

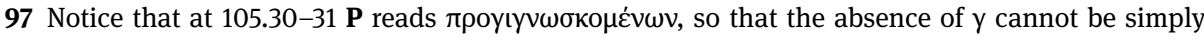
attributed to Callistus' usus scribendi.

98 Transl. Dooley 1992, slightly modified: "Lectures affect the hearer according to his habits. The meaning of the wording is clear from our previous comments, but it can also be understood as follows. Aristotle has said that the knowledge [acquired through] learning [depends] on things known beforehand (for things whose causes are unknowable are themselves unknowable). To convince [us] that knowledge comes from things beforehand, he adds that [the effect of] lectures depends on the habits [of their auditors], and that thus each auditor wishes to understand what is said [in light of that] to which he has been accustomed, because the auditors interpret what they hear in accordance with the personal disposition and prior knowledge [they have acquired] through their habits".

99 See the description of $\mathbf{O}$ in Section 3.1.1.

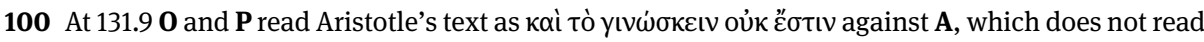

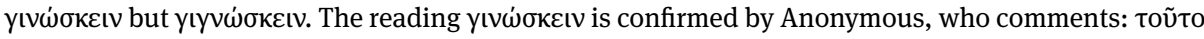
yò 


\subsubsection{Stemma codicum of the manuscripts and the indirect sources that should be used in a critical edition}

All the above considerations may be conveniently put in the following stemma codicum:

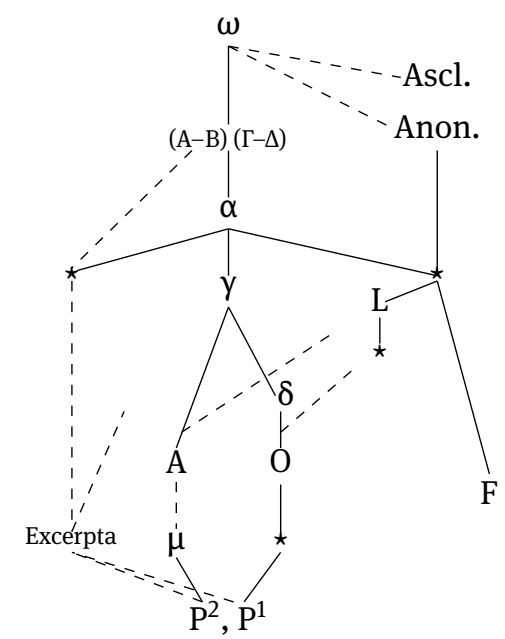

\subsection{Textual interpolations by John Chortasmenos and Andronicus Callistus}

Two of the three historically most important manuscripts of Alexander's commentary on the Metaphysics, that is, $\mathbf{A}$ and $\mathbf{P}$, bear several interpolations. ${ }^{101}$ These are always visible in $\mathbf{A}$ and sometimes in P. Bonitz and Hayduck usually take notice of the interpolations in $\mathbf{A}$ in their apparatus ( $=\mathrm{A}^{2}$; they do not, however, seem to consider them as emendations ope ingenii) but they do not do this very consistently. Since there are in A a few interventions by Malachias (see Illustration 1), which are chronologically prior to Bonitz's and Hayduck's $\mathrm{A}^{2}, \mathrm{~A}^{2}$ should actually be labelled $\mathrm{A}^{3}$.

101 By 'interpolation' I mean large-scale interventions that aim at leaving no non-sensical passage in a transmitted text by producing ope ingenii a correct text in syntax and, at least prima facie, a better text in meaning. Isolated corrections, currente calamo or occasionally with the help of another manuscript, probably also occurred also during the genesis of $\mathbf{A}$ and $\mathbf{0}$. 


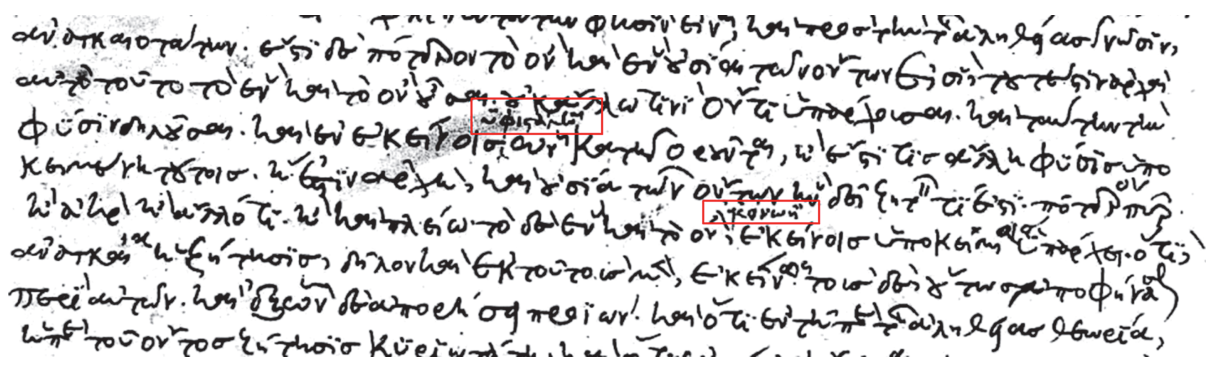

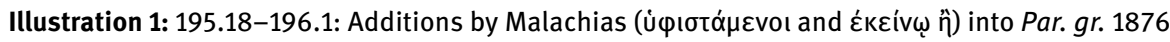
[A, f. 63v].

$\mathrm{A}^{3}$, whose emendations we sometimes read in the available editions as if they were genuine readings, ${ }^{102}$ has remained unknown so far. ${ }^{103} \mathrm{I}$ believe that this scholar is John Chortasmenos (ca. 1370-1431/1437), once an owner of A, as can be inferred from his monocondyle signature on the first folio. ${ }^{104}$ Chortasmenos had various writing styles and, due to the nature of the interventions in $\mathbf{A}$, it is difficult to say with certainty that Bonitz's and Hayduck's $\mathrm{A}^{2}$ is indeed Chortasmenos. Nevertheless, it is difficult to imagine that a scholar of such a calibre did not take pains to read and revise the manuscript he himself owned. If we compare (see Illustration 2) the specimen of Chortasmenos' writing style given in RGK I (191a) with the marginal notes in A, f. 21r and $49 \mathrm{r}$ - in particular, the है $\sigma \tau \mathrm{l}$ and the combination $-\sigma \mu$, which forms an apex and has the ending of $\sigma$ going downwards so as to form the beginning of $\mu$, as well as the letter $\zeta$ and the ligature - - o -, we may claim with reasonable probability that Chortasmenos is the scholar who corrected and revised $\mathbf{A}$.

There may be further evidence for this. In a well-known controversial passage

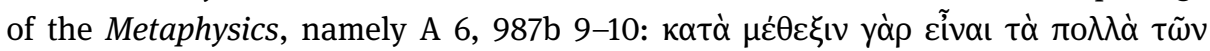

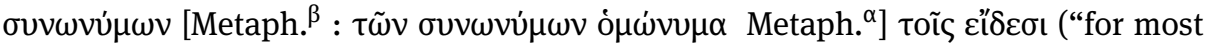
of the things synonymous with the Forms are by participation [in them]" or "for most synonymous things are by participation homonymous with the Forms"), ó $\mu \omega \dot{v} v \mu \alpha$, as Bonitz (38.1-2) and Hayduck (50.17-18) correctly record, has been supplied in the lemma by $\mathrm{A}^{2}\left(=\mathrm{A}^{3}\right)$, who appears here to have corrected the transmitted lemma of the

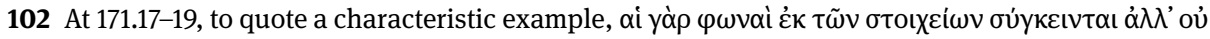

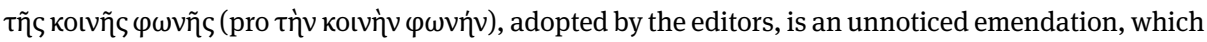

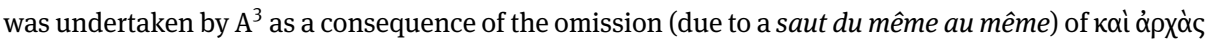

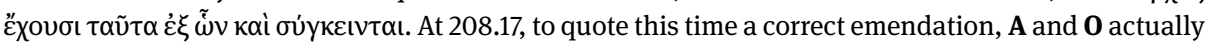

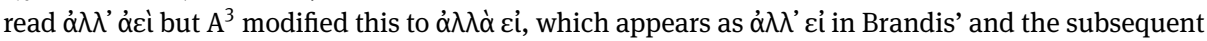
editions. See also ad 160.21, 170.21, 170.28, 172.1, 172.21-23, 180.7, 185.11, 193.23 and 212.6.

103 Dieter Harlfinger (RGK II 61) identified the scholar who made several annotations in the margins of $\mathbf{A}$ as Bessarion, without making the connection between the marginal annotations and the interpolations in the text itself, written by the same hand.

104 See plate VII. 


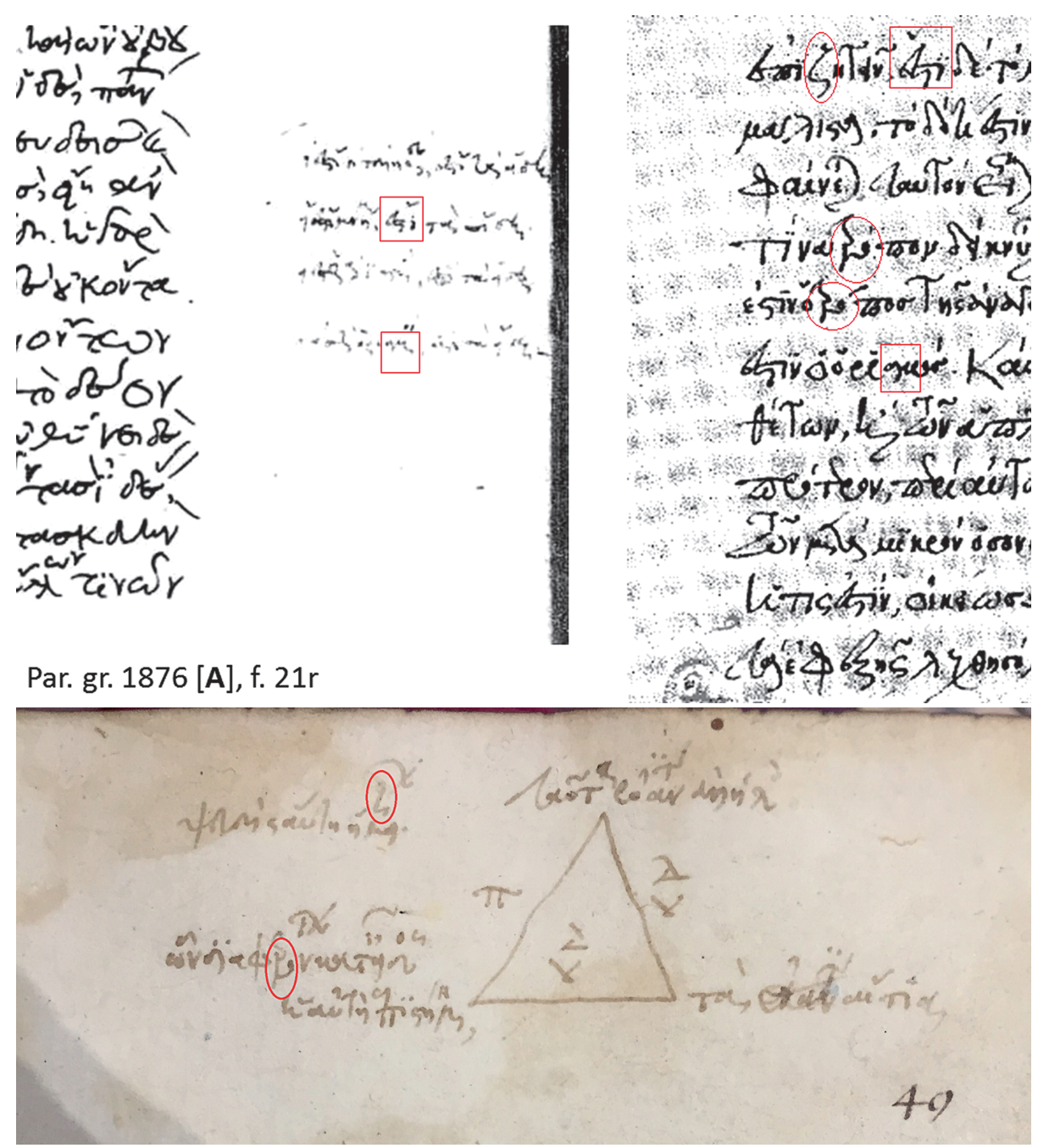

Illustration 2: Comparison of Par. gr. 1876 [A, f. 21r and 49r] with RGK I 191a (upper right).

commentary according to a manuscript of the $\alpha$-family of the Metaphysics, whereas at other places he appears to follow a manuscript of the $\beta$-family. It may not be irrelevant to $\mathrm{A}^{2}$ 's identification that such a "mixed" manuscript of the Metaphysics was the manuscript $\zeta$, ${ }^{105}$ for which there are reasons to believe that it was linked to Chortasmenos' scholarly activity. ${ }^{106}$

105 According to the stemma codicum provided by Harlfinger 1979.

$106 \zeta$ was used as a model by George Scholarios (for the actual Vaticanus gr. 115 [Vk]), who was a disciple of Chortasmenos. 
Contrary to his attitude towards the lemmata of the commentary, most (if not all) of Chortasmenos' interventions in the commentary proper do not appear to have been based on another manuscript of Alexander's text. Had he used such a manuscript, we would have encountered restorations of textual omissions, as well as some variant readings, which however never happens. Quite on the contrary, Chortasmenos intervened only when he faced a syntactically problematic text, either by undertaking rather obvious corrections, prompted by the Aristotelian text, or by making arbitrary guesses. Thus, this Byzantine scholar inaugurates the somewhat overcritical attitude towards transmitted texts, ${ }^{107}$ which we detect at a larger scale in the next generation of scholar-scribes of the Renaissance, such as Andronicus Callistus.

Callistus is the scholar behind the visible interpolations in $\mathbf{P}$. We encountered such an interpolation earlier, when we discussed the textual transmission of Alexander's commentary on the end of book Beta (211.19-212.2). But there can be no doubt that he was also making several emendations currente calamo. His readiness to emend is without parallel in Greek scholarship. ${ }^{108}$ As if he were frightened to be severely reprimanded by Bessarion, in case the Cardinal opened a page of a manuscript prepared by him and found the slightest bit of nonsense, Callistus intervened in any nonsensical passage in Alexander's transmited text. His interpolations are easily detectable not only through comparison with $\mathbf{A}$ and $\mathbf{O}$ (they occur when there is a lighter or heavier sensical problem in the transmitted text) but also because they are betrayed by some sort of extravagance and artificiality that do not respect Alexander's style and vocabulary.

Callistus worked with no real diligence. It is surprising that he did not even seek a manuscript of the Metaphysics, when one was obsviously needed. The most striking case is a lemma (991b 27-28) that should be copied, as it happens regularly in the first three quires of the manuscript, into the space intentionally left blank by Gre-

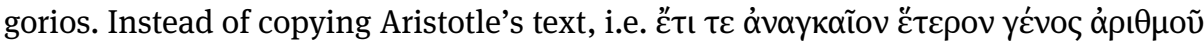

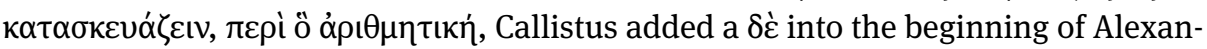

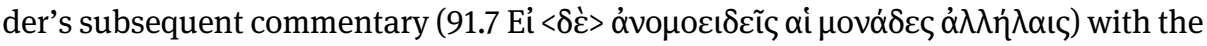
intention to make better sense of the arbitrary text with which he filled in the blank

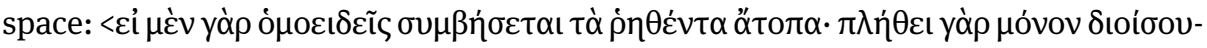

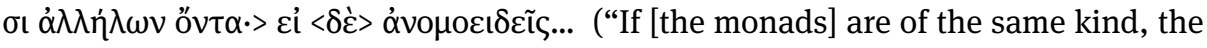
aforementioned absurdities will follow; they will differ from each other only in virtue of their plurality; if, on the contrary, they are of the same kind...”). ${ }^{109}$ The observa-

107 By 'overcritical' I mean the scholarly attitude which is interested in providing a seemingly sane text at any place.

108 It is worth noting that the need for a caveat against such an attitude was being felt in the middle of the sixteenth century. See the note of Michael Sophianos in the description of codex $\mathbf{M}$ (Monacensis gr. 81) below (Section 3.1.1).

109 Something similar occurs at 152.29-30, where B 2, 996b 14-16, is problematically quoted: $\pi 0 \lambda \lambda \alpha-$

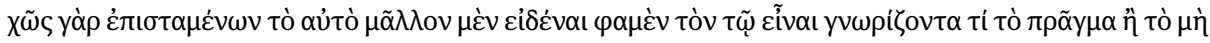


tion that Callistus had no manuscript of the Metaphysics on his desk is important. For any emendations that were made in $\mathbf{P}$ in accordance with the text of the Metaphysics should not be ascribed to him but to Gregorios (or some other scholar). ${ }^{110}$

Callistus did not make any real effort to cope with Alexander's exegesis. We may consider here some characteristic examples of his hastiness. At 141.25-142.1, A reads:

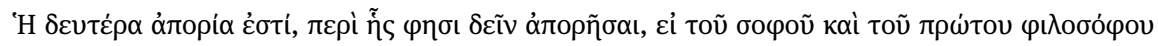

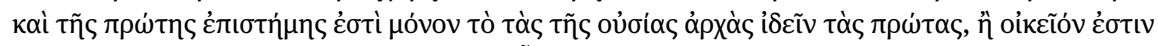

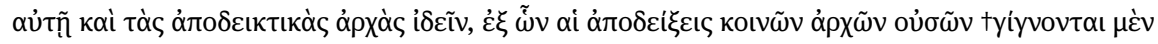

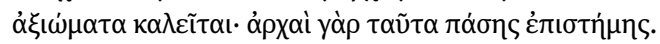

The second aporia which Aristotle says we must face is whether it belongs to the wise man and first philosopher, and to the first science, to survey only the first principles of substance, or whether it is proper for it to survey the principles of demonstration as well, that is, the common principles from which demonstrations tderive, are called axiomst; for these are the principles of every science. ${ }^{111}$

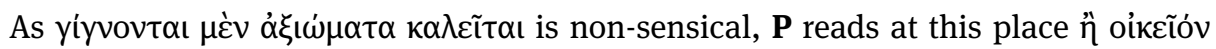

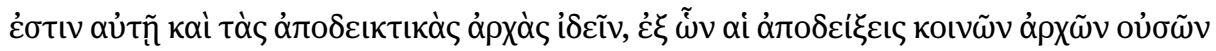

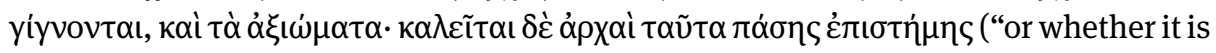
proper for [the first science] to survey the principles of demonstration as well, that is, the common principles from which demonstrations derive, and the axioms; for these are called principles of every science"). The axioms, however, are the demonstrative principles and not something additional to them (as the kai comes after the subordinate clause, it is not meant as explicative). Moreover, the sequence ó $\rho x \alpha i$ $\tau \alpha \tilde{v} \tau \alpha$

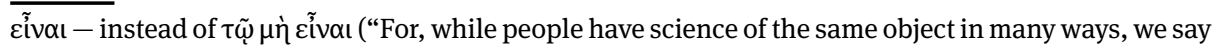
that the one who knows what the object is by way of its being knows it to a higher degree [than one who

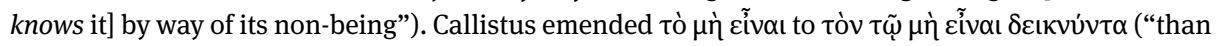
one who shows it by way of its non-being”); he thus altered and included in Aristotle's quotation the

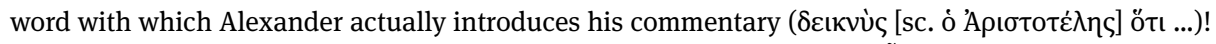

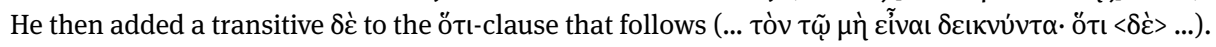
110 At 142.19, where $\mathbf{A}$ (and $\mathbf{0}$ ) has عi்

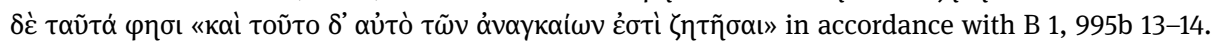
The lemma at 147.5-7 is in $\mathbf{P}$ longer than it is in $\mathbf{A}$ (and in $\mathbf{0}$ ), since it additionally provides the words

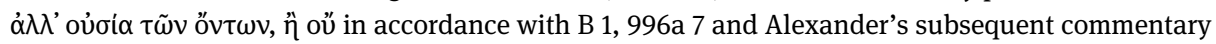

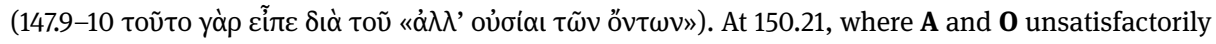

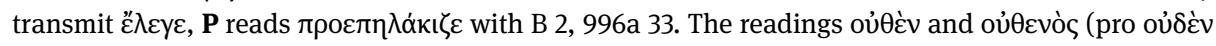

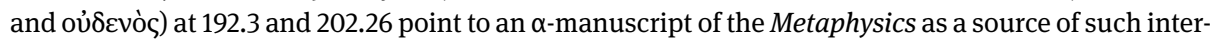

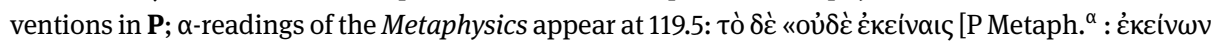

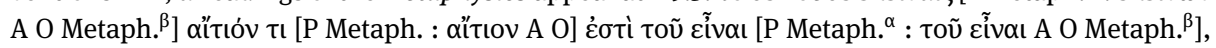

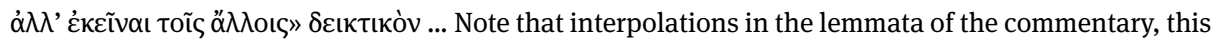
time in accordance with a $\beta$-manuscript of the Metaphysics, occurred also in some model of $\mathbf{A}$ and

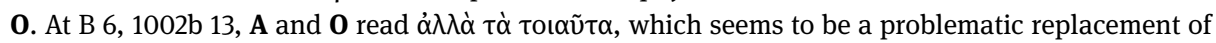
Alexander's genuine reading ( $\left(\dot{\alpha} \lambda \lambda^{\prime}\right.$ o $\tau \tau \tau \alpha$, attested in Metaph. $\left.{ }^{\alpha}\right)$ with the reading of Metaph. ${ }^{\beta}(\dot{\alpha} \lambda \lambda \dot{\alpha}$

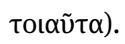

111 Transl. Madigan 1992, adapted. 


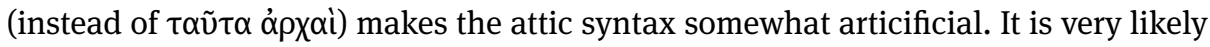
that Callistus was making such emendations currente calamo. The correct reading, of

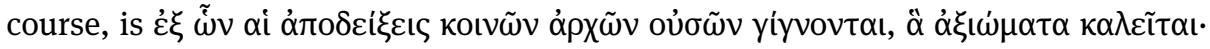

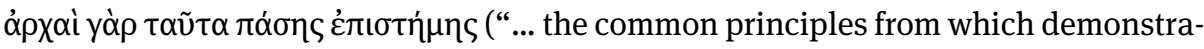
tions derive, which are called axioms; for these are called principles of every science”), which is what $\mathbf{0}$ reads.

Similarly, to give one more among many possible examples, at 155.14-17 Callistus emended the transmitted text in a blatantly false way. He makes Alexander say that the matter is cause to a higher degree (!) than the formal, efficient and final causes. Alexander, of course, explains that the matter merely has the status of a necessary condition:

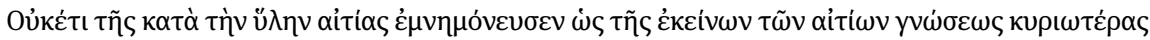

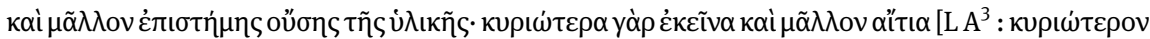

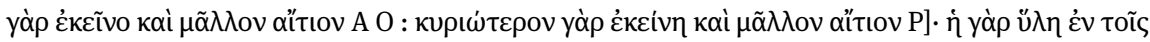

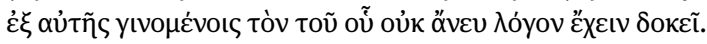

[Aristotle] has not mentioned the material cause, for he supposes that knowledge of those [three] causes is [knowledge] in a stricter sense and is science to a higher degree than [the science of] the material cause; for they are [causes] in a stricter sense and causes to a higher degree [Callistus: for it (= matter) is [cause] in a stricter sense and cause to a higher degree]; for matter, in the things that come to be from it, seems to have the status of a [mere] necessary condition. ${ }^{112}$

Finally, it is useful to consider two final passages, in which interpolations by both Chortasmenos and Callistus appear.

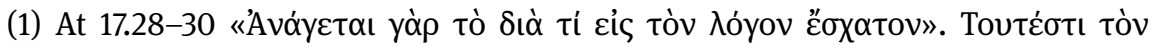

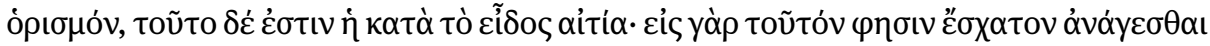

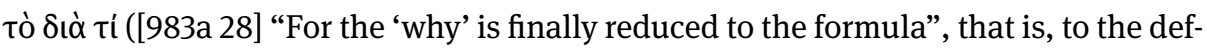
inition, and this is the formal cause; for he says that the 'why' is finally reduced to the

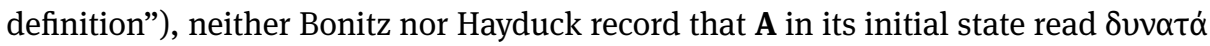

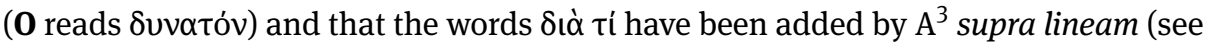

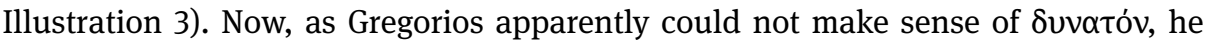
decided to leave a fenestra at that place in $\mathbf{P}$, which was completed afterwards by Callistus. 


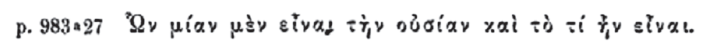

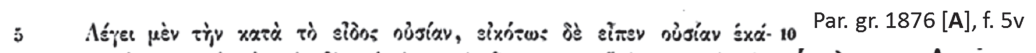

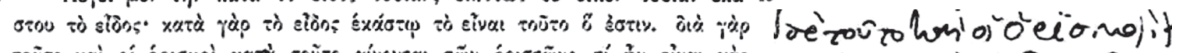

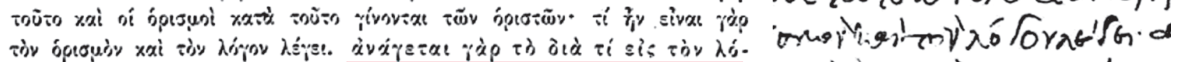

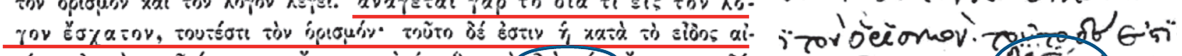

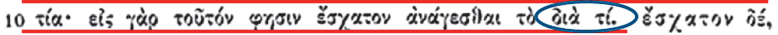

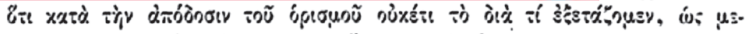

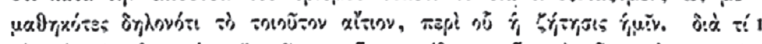

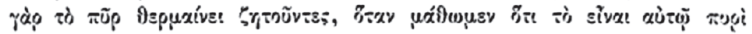

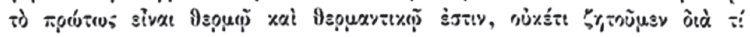

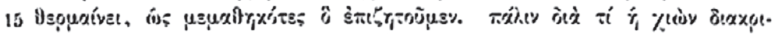

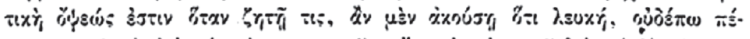

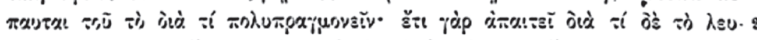

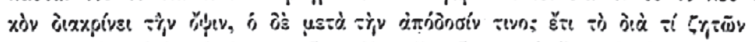

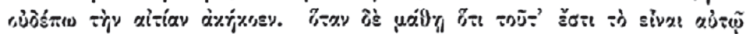

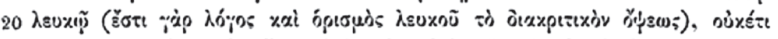

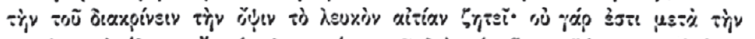

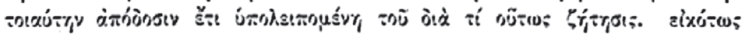

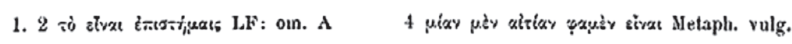

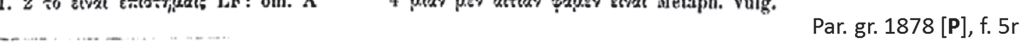

ed. Hayduck, p. 20
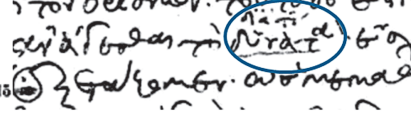

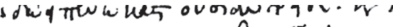

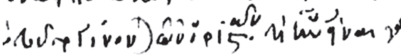

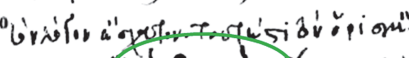

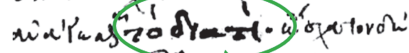

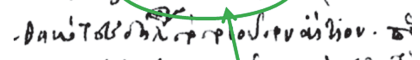

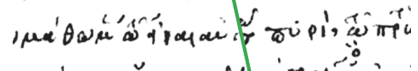

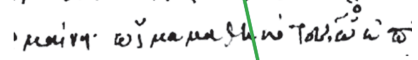

Andronicus Callistus $\left[=\mathrm{P}^{2}\right]$

Illustration 3: 17.28-30: Comparison of Par. gr. 1876 [A, f. 5v] and Par. gr. 1878 [P, f. 5r] with Hayduck's edition (20,8-10).

(2) At 171.13, Hayduck missed the opportunity to bring to attention two variae lec-

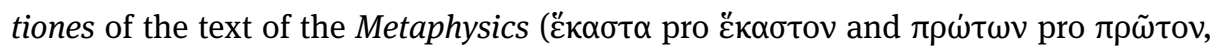
stemming from Alexander's commentary):

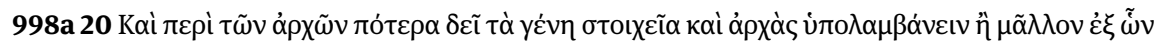

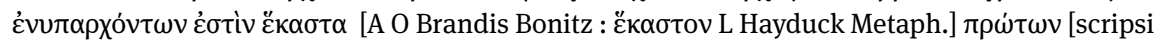
secundum paraphrasin : $\pi \rho \tilde{\omega} \tau \alpha$ A $0: \pi \rho \tilde{\omega} \tau o v$ L Metaph. edd.].

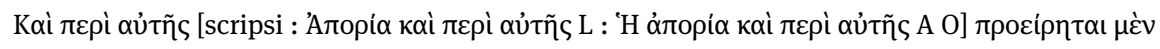

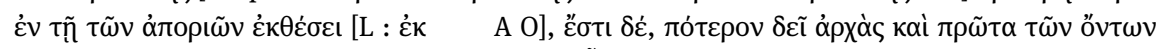

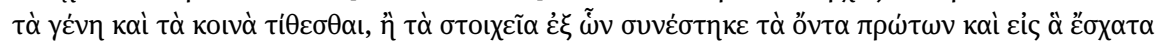
$\delta เ \alpha \lambda \dot{\varepsilon} \varepsilon \alpha \iota$.

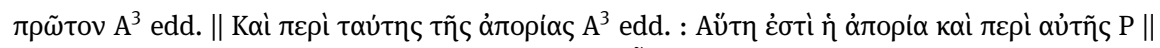

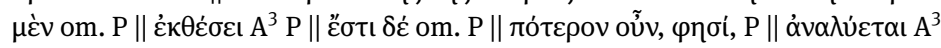

998a 20 Also, concerning the principles, which must one take as elements or principles: (a) the genera or rather (b) those primary constituents of which each particular thing exists?

Aristotle has already spoken of this [aporia] in his initial presentation of the aporiae. This is, whether one must posit that the genera, that is, the common factors, are the principles and primary among beings, or the elements, the primary things out of which the beings have come into existence and the ultimate things into which they are dissolved. ${ }^{113}$

113 Transl. Madigan 1992, adapted. 


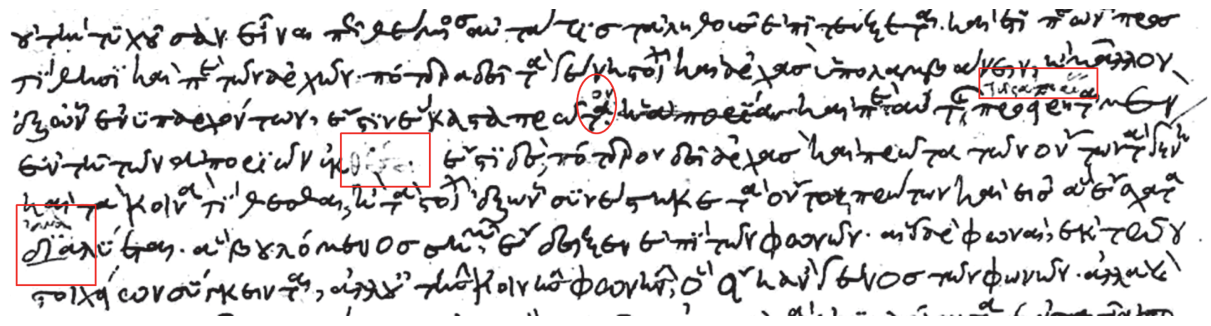

Illustration 4: 171.13-16: Par. gr. 1876 [A, f. 56v] as corrected by John Chortasmenos

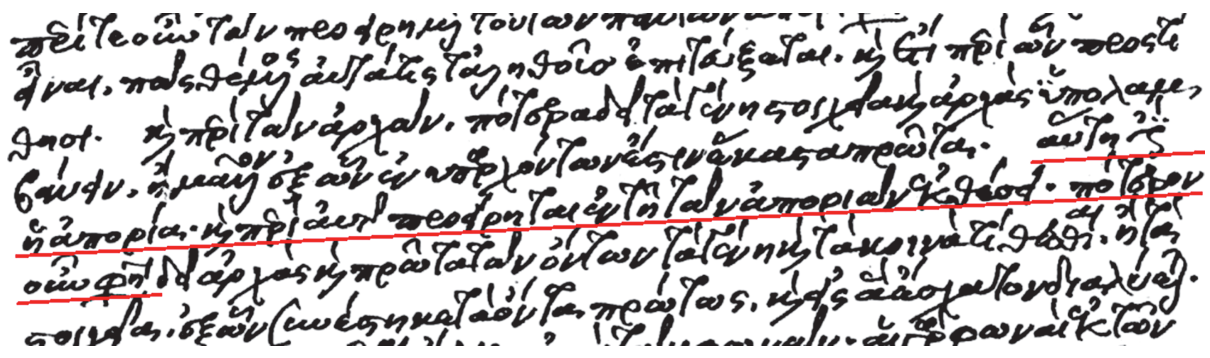

Illustration 5: 171.14-15: Par. gr. 1878 [P, f. 58v] as emended by Andronicus Callistus

This is an interesting case in more than one respect. (i) By adopting in the lemma the reading of $\mathbf{L}$, Hayduck bypassed what was in all probability Alexander's reading, namely $\check{\kappa} \alpha \sigma \tau \alpha$ instead of $\check{\kappa} \alpha \sigma \tau o v$, which seems to be confirmed by the plural used

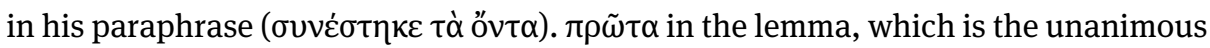
reading of the manuscripts, is obviously false (for primary are not the particular things but the constituents of the particular things) and has been corrected to $\pi \rho \tilde{\omega} \tau o v$ by Chortasmenos (see Illustration 4), a correction adopted by all modern editors. I have corrected it to $\pi \rho \omega \dot{\tau} \omega \nu$, following the testimony of $\mathbf{A}$ and $\mathbf{O}$ in Alexander's paraphrase.

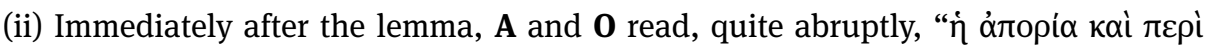

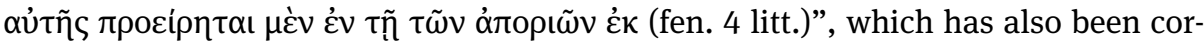

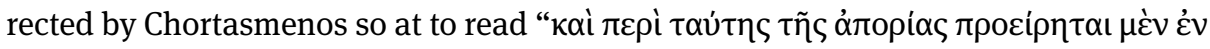

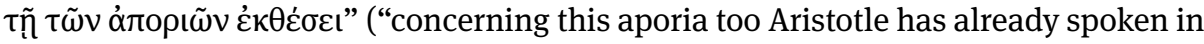
his initial presentation of the aporiae"), a correction which has also been adopted by the modern editors. This, however, is a conjecture, as also is Chortasmenos' rather un-

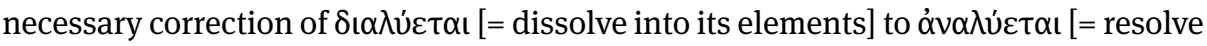
into its elements]. To make sense of the passage, it suffices to adopt the reading of $\mathbf{L}$ and then delete $\alpha \dot{\pi}$ орí $\alpha$ as a marginal postmark that has been wrongly copied into the text. Thus, by privileging here as well as in other places the corrections of the scholar whom they called $\mathrm{A}^{2}$, Bonitz and Hayduck (and Brandis) privileged readings that are mere conjectures without being aware that they were doing so (or, at least, without 
telling the reader that they were aware of doing so). Nonetheless, as is to be inferred from the critical apparatus, Chortasmenos' conjectures were not the only conjectures made with regard to the passage that we are now considering. By adding some words and omitting others, Callistus smoothed ope ingenii and currente calamo (see Illustration 5) the text that he was reading in its model.

A list of the numerous interpolations made by the one and the other scholar is provided in the Appendices A and B. 


\section{The manuscripts of Alexander's commentary on the Metaphysics}

Alexander's commentary on Aristotle's Metaphysics (A- $\Delta$ ) is extant in twenty-three manuscripts. ${ }^{1}$ Only four of them, namely Laurentianus plut. 85.1 [0], Parisinus gr. 1876 [A], Marcianus gr. 255 [Z], and Parisinus Coisl. 161 [C], date before the Fall of Constantinople. Of the remaining nineteen only three were copied outside Italy: Mosquensis Sinod. gr. 6, copied in Ottoman Constantinople, Parisinus Coisl. 331, copied in Paris, and Sacromontanus gr. 2, copied in Granada. This shows the great interest of Italian Renaissance scholars in Alexander's work on first philosophy.

Further four manuscripts, namely Ambrosianus A 8 inf., Ambrosianus F 113 sup. [F], Laurentianus plut. 87,12 [L], Parisinus Coisl. 328 + Vaticanus Reg. gr. 126 [V'r ], contain the anonymous commentary on the Metaphysics (A-E), misleadingly known since Hayduck's edition as “recensio altera” of Alexander's commentary, together with the continuation of this commentary (Z-N), or parts of this continuation, by Michael of Ephesus. This composite commentary is in all cases transmitted anonymously.

The composite commentary on E-N (Anonymous on book Epsilon + Michael on $\mathrm{Z}-\mathrm{N}$, or parts of it) has been copied after Alexander's commentary on books A- $\Delta$ in fifteen cases: A, 0, ${ }^{2}$ Ambrosianus D 115 sup. [D] + Vaticanus gr. 1776, Angelicus 102 [R], ${ }^{3}$ Monacensis gr. 81 [M], Mosquensis Synod. gr. $6\left[\mathbf{M}^{\mathbf{0}}\right]$, Mutinensis gr. $208\left[\mathbf{E}^{\mathbf{a}}\right]$, Mutinensis gr. $214\left[\mathbf{E}^{\mathbf{b}}\right]$, Neapolitanus III. D. $35\left[\mathbf{N}^{\mathbf{d}}\right]$, Neapolitanus III. E. $6\left[\mathbf{N}^{\mathbf{e}}\right]$, Parisini gr. 1878 $[\mathbf{P}]+1879$, Parisinus Coisl. $161[\mathbf{C}]$, Parisini Coisl. $328+331\left[\mathbf{P}^{\mathbf{C}}\right]$, Sacromontanus gr. 2 [G], Vaticani gr. 1621 [Y] + 1620.4 This is, of course, hardly surprising, since readers and buyers would be naturally interested in having a complete commentary on the Metaphysics.

Three of the above manuscripts, namely $\mathbf{A}, \mathbf{C}$ and $\mathbf{M}^{\mathbf{0}}$, as well as the Parisinus Suppl. gr. $642[\mathbf{S}],{ }^{5}$ attribute the commentary on E-N to Michael. Another two, namely M and Par. gr. 1879, as well as the Parisinus gr. 1875 (it only contains the commentary on E-Z), explicitly attribute the commentary from book Epsilon onwards to Alexander. Nonetheless, the rest of the manuscripts seem to imply that the commentary on books $\mathrm{E}-\mathrm{N}$ is by Alexander, since they do not mark a change of author in the commentary on book Epsilon. Such was Sepúlveda's rationale when he produced the Latin translation

1 Or twenty-four codices, since in one case (Vaticani Ottob. gr. 120 and 121) the commentary is divided in two volumes.

$2 \mathbf{0}$, however, does not contain a commentary on books $\mathrm{E}-\Theta$.

$\mathbf{3} \mathbf{R}$ is a composite manuscript that transmits the anonymous commentary after $189,9 \mathrm{H}$.

4 Notice, moreover, that $\mathbf{Z}$ is mutilated, so that we cannot know whether it originally contained a supplement of Alexander's commentary. A further manuscript, Parisinus gr. 1922 [ $\left.\mathbf{P}^{\mathbf{d}}\right]$, is itself a copy of a mutilated manuscript.

5 On $\mathbf{S}$ see above, p. liii. 
of the commentary; he ascribed the translated commentary $(\mathrm{A}-\Lambda)$ to Alexander on the grounds that no indication to the contrary was found in the manuscripts he used. ${ }^{6}$

Some catalogue entries, especially of the Biblioteca Ambrosiana, ${ }^{7}$ falsely record manuscripts of Alexander's commentary, while they really contain the commentary on the Metaphysics by George Pachymeres (previously known as pseudo-Philoponus' commentary). ${ }^{8}$

In the alphabetical classifications that follow (by city name), I register (3.1) the twenty-three Greek manuscripts that transmit Alexander's commentary on books A$\Delta$ (in the majority of cases together with the non-Alexandrian continuation of the commentary); (3.2) the five codices of the so-called "recensio altera" together with six manuscripts of Michael's continuation of this commentary, which are wrongly reported to contain Alexander's commentary; (3.3) two manuscripts of Pachymeres' commentary, which are wrongly reported to contain Alexander's commentary; (3.4) four manuscripts that contain, or are reported to contain, excerpts of Alexander's commentary. ${ }^{9}$

The entries inlcude information on date, physical description, content, scribe(s) and used secondary literature. All manuscripts have been examined in situ, except for the Mosquensis Sinod. gr. 6, for which I consulted the microfilm preserved in the Aristoteles-Archiv of the Freie Universität Berlin. I have not been able to inspect the Oratorianus C. F. 2.11 and the Sacromontanus gr. 2.

6 See Golitsis 2016b: 57, n. 8.

7 Martini - Bassi 1906.

8 On the authorship of this commentary see Alexandru 1999.

9 The manuscripts (1) Ambrosianus Q 74 sup. and (2) Berolinensis gr. 275 (1 $\left.{ }^{\circ} .39\right)$, now in Biblioteka Jagiellońska in Krakow, which appear in the database Pinakes (Institut de recherche et d'histoire des textes, Paris) as manuscripts of Alexander's commentary on the Metaphysics, respectively con-

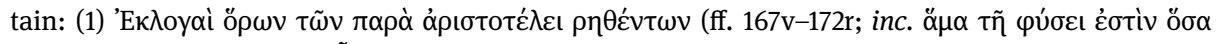

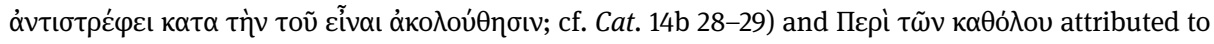
Alexander (ff. 176v-177r; this is actually a copy of a quotation of Alexander in Philoponus, In An. [= Hayduck 1897], 37.32-38.10, followed by an objection attributed to Olympiodorus); and (2) Alexander's De febribus. On Ambr. Q 74 sup. see Rashed 1997. 


\subsection{Alexandrea}

\section{FLORENCE, Biblioteca Medicea Laurenziana}

\section{Laurentianus plut. 85,1 [0]}

1283-1289 Bombycine mm 485×338 ff. 762 (vacuum: $738 v$ )

Scribes: Two of the scribes of Par. gr. 1876 [A] and ten other scribes. The commentary on the Metaphysics was copied by "mano M" (ff. 700-712r) and <the monk Ionas $>(712 \mathrm{v}-$ $754 \mathrm{v}) ;{ }^{10}$ the last quire was provided later by Georgios Dishypatos Galesiotes (ff. $755-$ 762). ${ }^{11}$

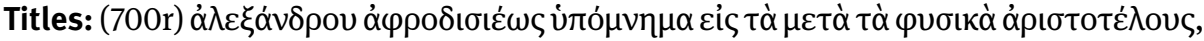

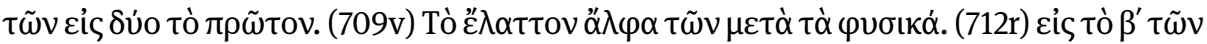

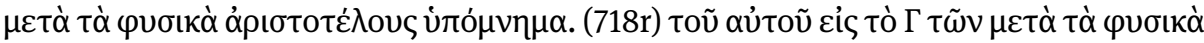

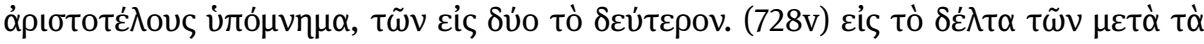

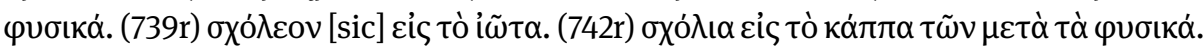

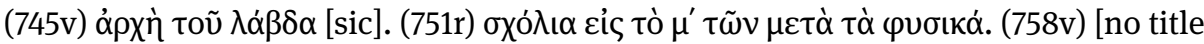
for book $N u$, which was supposed to be added by Galesiotes in red ink].

Contents: (700r-738r) Alexander, In Metaph. A- $\Delta . \quad$ (739r-762r) <Michael of Ephesus>,

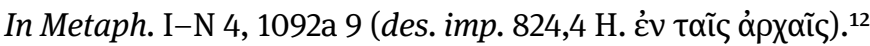

Text: This impressive manuscript, surnamed 'Oceanus' due to its huge dimensions by a librarian of the Biblioteca Laurenziana, ${ }^{13}$ was copied in Constantinople probably during the patriarchate of George of Cyprus (1283-1289). As the numbering of the quires indicates, it was not supposed to form a single codicological unity but several codices as parts of a quasi-complete edition of commentaries on Aristotle, which accompagnied a new edition of Aristotle's treatises. ${ }^{14}$ Alexander's commentary on the Metaphysics, which starts at f. 700r with a quire numbered $\alpha^{\prime}$, was copied after a now lost manuscript ( $\boldsymbol{\delta}$ ) probably owned by George himself; this probably was a copy of $\mathbf{\gamma},{ }^{15}$ which was the model of $\mathbf{A}$. One of the scribes of $\mathbf{0}$ ("copiste B", according to Cacouros) is the principal scribe of $\mathbf{A}$, i.e. the so-called "Anonymus $\Gamma$ ”. The relation between the

10 Acerbi - Gioffreda 2019: 17. See plate IV.

11 See Acerbi - Gioffreda 2019: 17. Acerbi and Gioffreda correct Cacouros, who misleadingly identified this restorator with John Chortasmenos (see Cacouros 1996).

12 See Bandini 1770: 237-247 and Golitsis 2020 for a full description of the contents.

13 The words OCEANUS/ $\Omega$ KEANO $\Sigma$ are read on the label of the exterior binding. On manuscripts surnamed 'Oceani/' $\Omega \kappa \varepsilon \alpha v o i '$ in the sixteenth century see Agiotis (forthcoming).

14 The actual Laurentianus plut. 81,1 is what remains of this early Palaeologan edition of Aristotle; see Golitsis 2020.

15 See above, p. liv. 
two manuscripts, $\mathbf{O}$ and $\mathbf{A}$, is also reflected in the titles given to each book, which are quasi-identical in the two manuscripts. ${ }^{16}$ In $\mathbf{0}$, the commentary on book Delta finishes in the middle of f. $738 \mathrm{r}$ and the empty verso thereafter (738v) implies a change of model (that is, a different codex) for the commentary after book Delta. The manuscript orig-

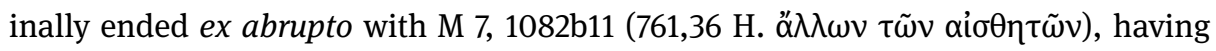
lost its last quire. The missing text (until N 4, 1092a $9=824,4 \mathrm{H}$.) was later restored by Georgios Dishypatos Galesiotes. ${ }^{17}$ It is possible that $\mathbf{O}$ later lost the quires containing the commentary on books E- $\Theta .{ }^{18}$ Otherwise one would have to posit that Galesiotes did not take notice of their absence, which seems less convincing.

Possessors: Janus Lascaris acquired this manuscript in Crete and brought it to Florence for Lorenzo de' Medici in 1492. It is attested in Fabio Vigili’s inventory in 1509.

Bibliography: Bandini 1770: 237-247; Cacouros 1996; Jackson 1998; Cacouros 2000; Mondrain 2000; Golitsis 2016b; Acerbi - Gioffreda 2019; Golitsis 2020.

\section{GRANADA, Archivo secreto de las Cuatro Llaves de la Abadía del Sacromonte}

\section{Sacromontanus gr. 2 [G]}

1582 Paper $\quad \mathrm{mm} 304 \times 214 \quad$ ff. I + 528 (vacua: 527 r, 528) + I

Watermarks: “Croix Latine” 41 Sosower (Toledo, 1582).

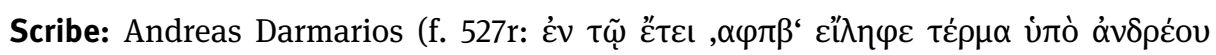

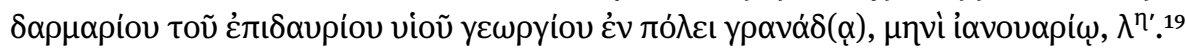

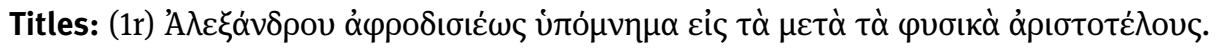

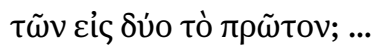

Contents: (1r-527v) Alexander, In Metaph. A- $\Delta . \quad<$ Anonymus $>$, In Metaph. E. $\quad<$ Michael of Ephesus>, In Metaph. Z-N (des. imp. 825,14 H.).

$\overline{16}$ See above, p. xlvii.

17 Thus, Galesiotes did not have access either to George of Cyprus' Par. Suppl. gr. 642 [S] or to Malachias' Par. Coisl. 161 [C], which transmit the commentary on book $N u$ in its entirety.

18 Alexander's commentary starts with a quire numbered $\alpha$, as also does the commentary on book Iota. But this observation does not necessarily imply that the commentary on E-I was absent from the very beginning; the numbering of quires may reflect the models used, namely two tomes containing respectively the commentary on $\mathrm{E}-\Theta$ and the commentary on I-N.

19 In the same colophon, Darmarios asserts that he finished his copy in the impressive time span of

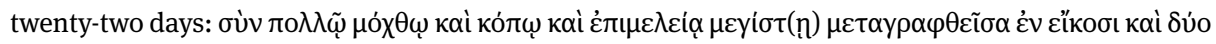
$\dot{\eta} \mu \varepsilon \dot{p} \alpha$ เs. This means that if he worked ten (!) hours per day he copied approximately two and a half folios in an hour. 
Text: Darmarios copied this manuscript in Granada for Pedro Vaca de Castro y Quiñones, archbishop of Granada and founder of the Abadía del Sacromonte; cf.

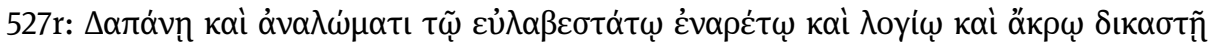

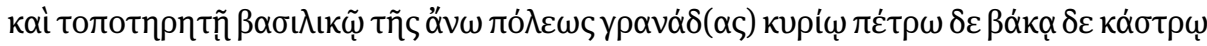

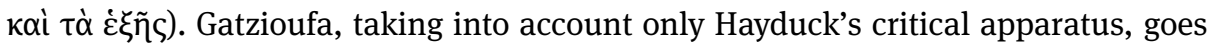
too far in seeing in this very late manuscript an independent witness of Alexander's text, which would be a "brother" ("hermano") of A. As is made clear already by the title of the commentary and some marginal annotations quoted by Gatsioufa (e.g. f. 361r

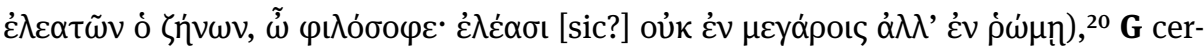
tainly is a descendant of $\mathbf{A}$. However, it is a copy of an intermediate manuscript, which stopped imperfectly at 825,4 H. and not at 831,10 H. (or, alternatively, at 828,13 H.), ${ }^{21}$ as A does. This intermediate manuscript must have been $\boldsymbol{\lambda}$, the model of the two $\mathrm{Mu}$ tinenses $\left(\mathbf{E}^{\mathbf{a}}\right.$ and $\mathbf{E}^{\mathbf{b}}$ ) known to Sepúlveda, ${ }^{22}$ which was transferred to Spain after 1515. Thus, the passage 13,15-17 H., which is quoted by Gatsioufa as peculiar to $\mathbf{G}$ (omission

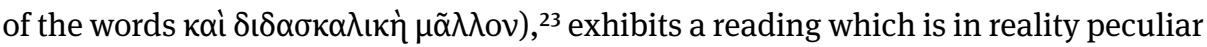
to $\mathbf{G}, \mathbf{E}^{\mathbf{a}}$ and $\mathbf{E}^{\mathbf{b}}$ all. $\boldsymbol{\lambda}$, which could be a manuscript from as early as the fourteenth century - it can thus account for Darmarios' palaeographical appreciation that his

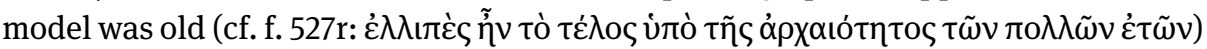
,$-{ }^{24}$ was corrected with the help of $\mathbf{0}$; this explains the presence in $\mathbf{G}$ of readings that are independent from $\mathbf{A}$ (and which are misleadingly considered by Gatsioufa to be peculiar to $\mathbf{G}$ and to Sepúlveda).

Possessor: Don Pedro Vaca de Castro y Quiñones (1534-1623).

Bibliography: Fuentes González 1999; Gatzioufa 2015a; Gatzioufa 2015b.

\section{MILAN, Biblioteca Ambrosiana}

\section{Ambrosianus D 115 sup. (Martini-Bassi 266) [D]}

Paper

$\mathrm{mm} 285 \times 206$

ff. I $+241+V$

20 Cf. Gatsioufa 2015b: 304. This note reads in A (f. 188v, in margine sinistra) as follows: ć $\lambda \varepsilon \alpha \tau \tilde{\omega} v$ ò

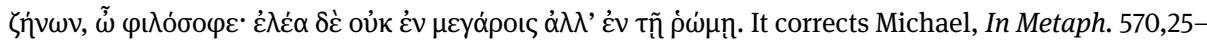

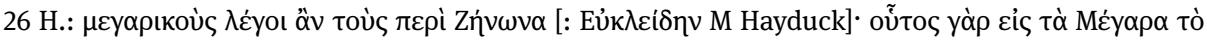

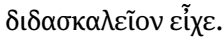

21 See below, the description of $\mathbf{A}$.

22 See below, Section 5.1.

23 See Gatsioufa 2015b: 308.

24 On the age of $\lambda$, see above, p. lvi. 
Watermarks: “Croix" (passim) similar to the watermark found in Par. Suppl.gr. 306 [P'] (partly copied by Demetrios Moschos); “Arbalète” (e.g. ff. 81/88, 148/149) identical to Arbalète 31 Harlfinger (1489). ${ }^{25}$

Scribes: $<$ Demetrios Moschos $>$; addition and marginalia by $<$ Baldassarre Migliavacca $>$.

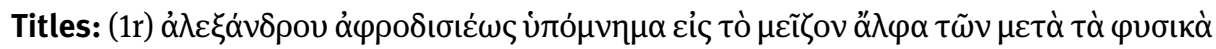

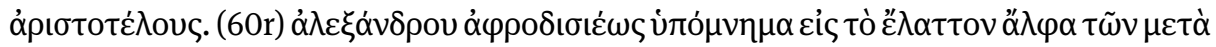

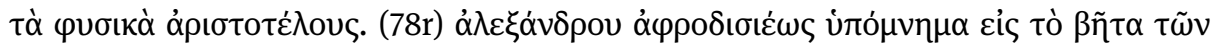

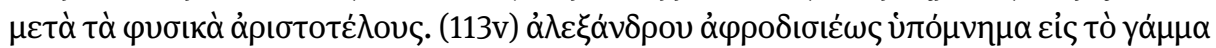

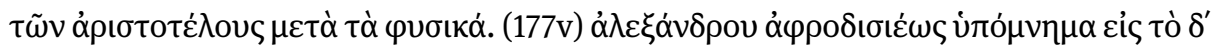

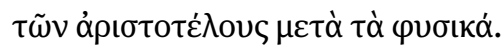

Contents: (Iv) Beginning of the commentary added from the so-called "recensio altera" [1,4-2,3 H.]. (1r-241v) Alexander, In Metaph. A- $\Delta$, with marginal additions from the "recensio altera".

Text: This is a copy prepared by Demetrios Moschos (ca. 1450-1519) most probably in Ferrara on the basis of Par. gr. 1878 [P], when the latter belonged to Nicolò Leoniceno (1428-1524), professor at the University of Ferrara from 1464 onwards. Leoniceno had it copied probably for Giovanni Pico della Mirandola (1463-1494). Some passages are marked with the memory sign (a vertical line slightly curved at the edges and surmounted by two dots), which is characteristic of Pico. ${ }^{26}$ Later, the manuscript belonged to the Milanese scholar Baldassarre Migliavacca, who was acquainted with Pico. ${ }^{27}$ Migliavacca collated the manuscript against a manuscript of the so-called "recensio altera”, namely the Ambr. F 113 sup. [F] brought to Milan by Demetrios Chalcondyles in 1491, and added variant readings and additional passages in margine. It is the first volume of a (quasi-)complete copy of the commentary on the Metaphysics, whose second volume is the actual Vaticanus gr. 1776.

Possessors: Giovanni Pico della Mirandola; Baldassarre Migliavacca (†1524); Gian Vicenzo Pinelli (1535-1601).

Bibliography: Martini - Bassi 1906: 296; Martinelli Tempesta 2013: 137; Golitsis 2016b.

25 Actually, this particular watermark is dated to 1484 by Harlfinger 1974 in accordance with Neap. III. D. $35\left[\mathbf{N}^{\mathbf{d}}\right]$, which Harlfinger takes to be dated to 1484 . However, the colophon of $\mathbf{N}^{\mathbf{d}}$ merely mentions

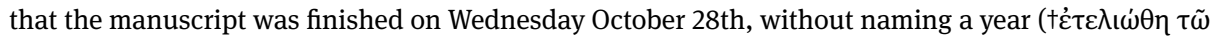

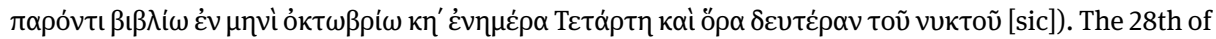
October was a Wednesday in the years 1472, 1478, 1489, 1495, 1500, ... (I thank Nachum Dershowitz for calculating the years) but, since $\mathbf{N}^{\mathbf{d}}$ was copied for Ermolao Barbaro il Giovane (1454-1493), 1495 and later years have to be excluded. Granted that (i) $\mathbf{N}^{\mathbf{d}}$ is partly a copy of $\mathbf{D}$, which belonged to Migliavacca, and (ii) that Ermolao had a correspondence with Migliavacca in 1489 (see Figliuolo 1999: 59), 1489 is the most plausible year for the production of the manuscript by Moschos.

26 See Murano 2018.

27 The two men corresponded with each other to exchange manuscripts. See Orlandi 2014. 


\section{Ambrosianus H 54 inf. (Martini-Bassi 1037) [H]}

Around 1535 Paper $\quad$ mm $225 \times 159$ ff. 113 (vacua: 70v, 71r, 178v, 181v, 182r) ${ }^{28}$

Watermarks: Fleur-de-lis with letters IC, identical to Mazzoldi Nr. 864 (1535).

Scribe: One unknown western scribe.

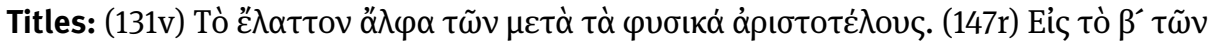

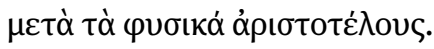

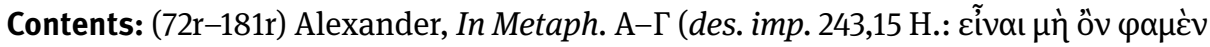

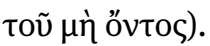

Text: This late manuscript is a copy of Marc. Z 255 [Z], which stops, mutilated, at 243,15 H. Another loss of folios in Z , containing 230,32-238,28 H., also pertains to $\mathbf{H}$.

Possessors: A note on f. 179r probably by the hand of Gian Vicenzo Pinelli (1535-1601) suggests that he owned this manuscript.

Bibliography: Martini - Bassi 1906: 1106; Golitsis 2016b.

\section{MODENA, Biblioteca Estense e Universitaria}

\section{Mutinensis gr. $208(\alpha . V .6 .14)\left[\mathrm{E}^{\mathrm{a}}\right]$}

Around 1510 Paper mm $336 \times 235 \quad$ ff. 470 (vacuum: 470)

Watermarks: “Anker im Kreis mit Stern”, similar to Piccard V 329 (Kaufbeuren, 1511); the paper is identical to the second part of Angelicus gr. 102 [R].

Scribe: Anonymus 34 Harlfinger. ${ }^{29}$

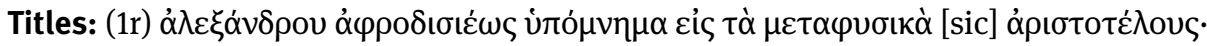

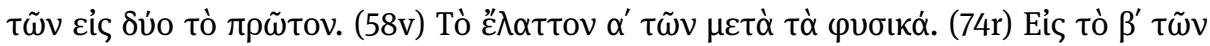

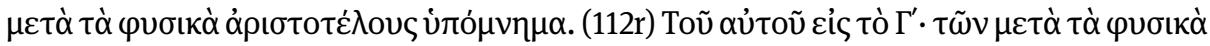

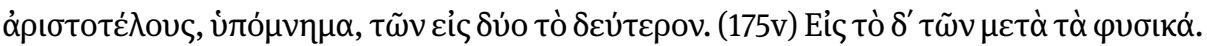

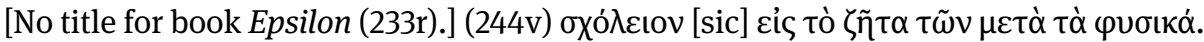

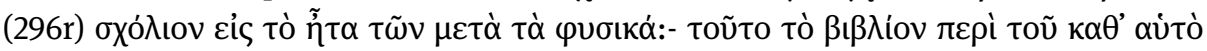

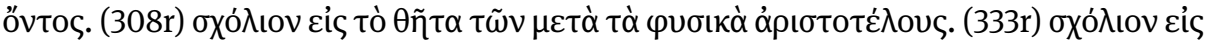

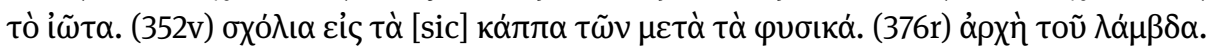

28 The manuscript is bound together with Ambrosiani H 53 inf., H 56 inf., H 62 inf. and H 63 inf.

29 This scribe, who was working for Alberto III Pio, also copied Mutinensis gr. 205 (a.W.3.18), which contains John Philoponus' and Leon Magentenus' commentaries on the Prior Analytics. 


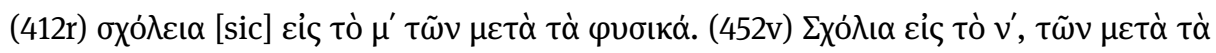

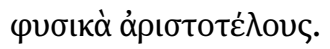

Contents: (1r-233r) Alexander, In Metaph. A-.$\quad$ (233r-244v) <Anonymus>, In Metaph. E. $\quad(244 \mathrm{v}-469 \mathrm{v})<$ Michael of Ephesus>, In Metaph. Z-N (des. imp. 825,14 H.).

Text: This manuscript, which is a descendant of $\mathbf{A}$, was one of the four manuscripts known to Sepúlveda in Rome. ${ }^{30}$

Possessors: Alberto III Pio, Prince of Carpi (1475-1531); Rodolfo Pio da Carpi (15001564).

Bibliography: Mercati 1938: 215 and 229; Golitsis 2016b.

\section{Mutinensis gr. $214(\alpha . W .3 .11)\left[\mathrm{E}^{\mathrm{b}}\right]$}

Around 1515 Paper mm $330 \times 255 \quad$ ff. 583 (vacua: 1-3, 296-298, 492v, 581583)

Watermarks: "Leiter im Kreis mit Stern”, similar to Briquet 5922 (Augsburg, 1506-1510; variations: Sienna, 1495-1524).

Scribes: Three anonymi: A: 1r-267v, 277r-295v; B: 268r-276v, 363r-371v, 476r-492r; C: 299r-362v, 372r-475v, 493r-580v.

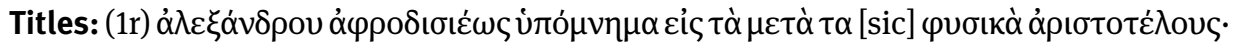

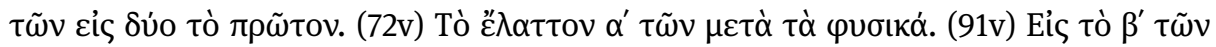

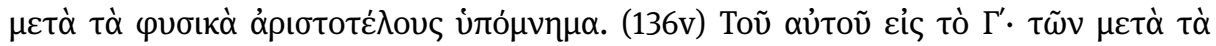

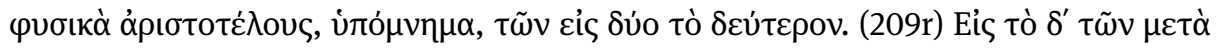

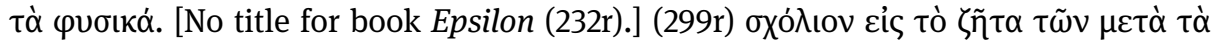

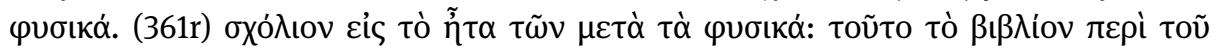

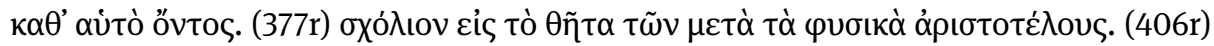

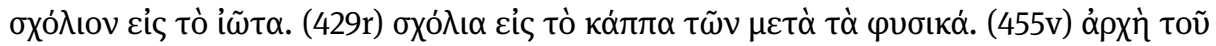

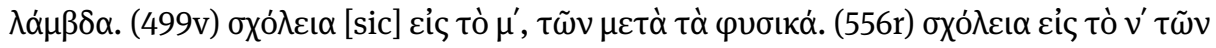

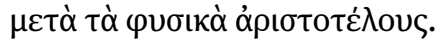

Contents: (1r-281v) Alexander, In Metaph. A- $\Delta . \quad$ (282r-295v) <Anonymus>, In Metaph. E. (299r-580v) <Michael of Ephesus>, In Metaph. Z-N (des. imp. 825,14 H.).

Text: This manuscript is a second copy of the model of $\mathbf{E}^{\mathbf{a}}$, namely $\boldsymbol{\lambda}$, which was in the meanwhile corrected with the help of $\mathbf{0}$ and a manuscript of the so-called "recensio

30 See below, Section 5.1. 
altera"; it is thus slightly younger than $\mathbf{E}^{\mathbf{a}}$. It is one of the manuscripts that Sepúlveda used for his translation. ${ }^{31}$

Possessors: Rodolfo Pio da Carpi (1500-1564).

Bibliography: Mercati 1938: 215 and 229; Golitsis 2016b; Golitsis (forthcoming).

\section{MOSCOW, Gosudarstvennyj Istoričeskij Musej}

\section{Mosquensis Sinod. gr. 6 (Vladimir 450$)\left[\mathrm{M}^{\circ}\right]$}

1484/1485 Paper mm $294 \times 220 \quad$ ff. II +278 (vacua: $226 v$ ) + V

Scribe: <Manuel Korinthios $>$.

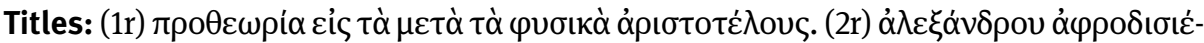

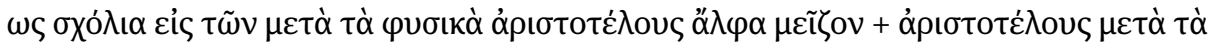

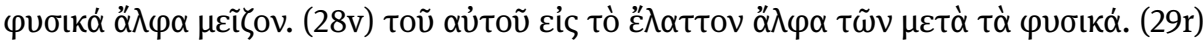

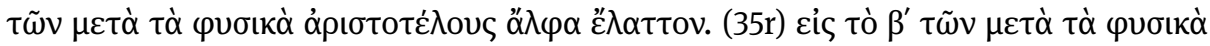

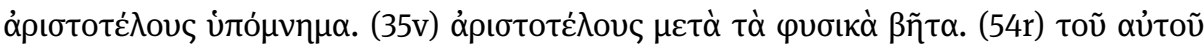

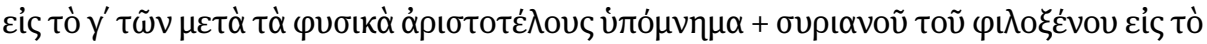

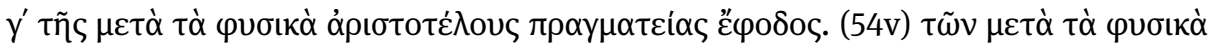

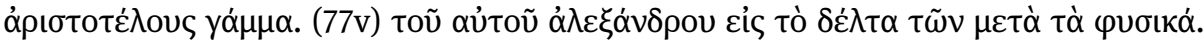

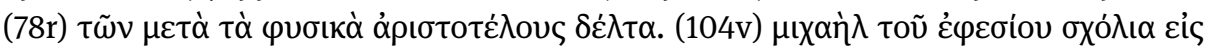

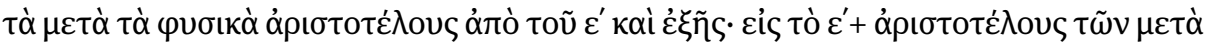

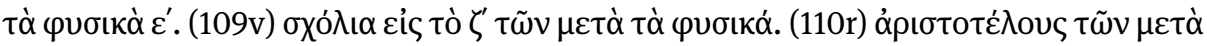

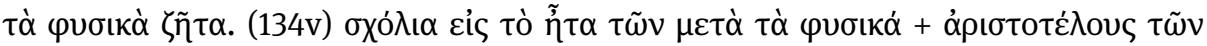

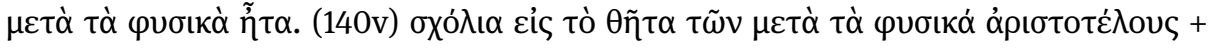

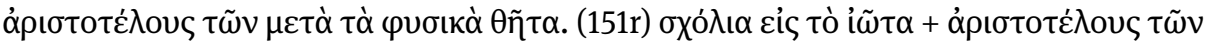

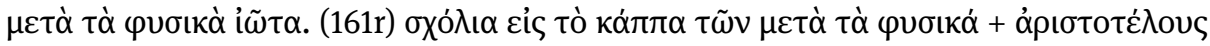

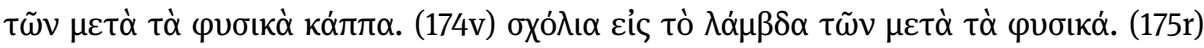

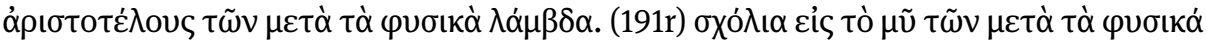

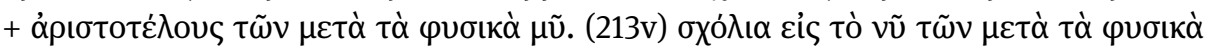

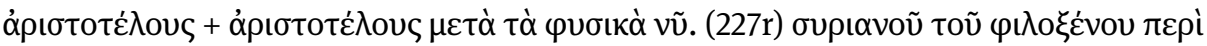

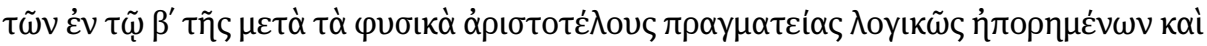

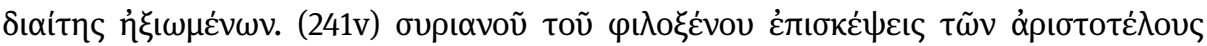

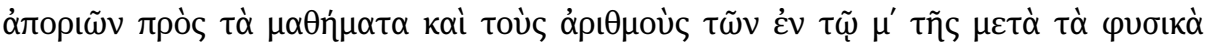

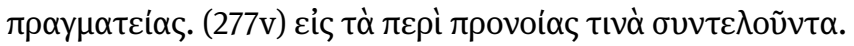

31 See below, Section 5.1. 
Contents: (1r-v) Anonymous prolegomena to the Metaphysics. (2r-226r) Aristotle, Metaphysics; (2r-103v) Alexander, In Metaph. A- $\Delta$; (54r-77v) Syrianus, In Metaph. $\Gamma$; (104v-109v) [Michael of Ephesus], In Metaph. E; (109v-226r) Michael of Ephesus, In Metaph. Z-N. (227r-277v) Syrianus, In Metaph. B, M, N. (278v) List of Neoplatonist (save for Alexander) teachers and pupils. ${ }^{32}$

Text: The mere disposition of contents shows that this is a copy of $\mathbf{C}$ (except for the list of philosophers at the end of the codex), in all probability made in Constantinople, where Manuel Korinthios was active. This manuscript, together with Alexandrinus 87 and Mosquenses 8 and 239, once represented a complete copy of Malachias' edition

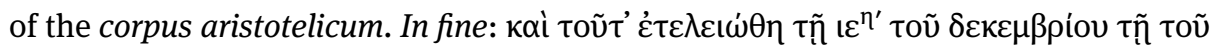

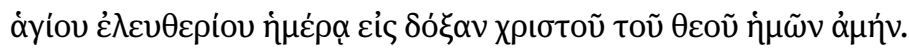

Possessors: Manuel Korinthios (before 1461-1530/31), Megas Rhetor of the Patriarchate of Constantinople copied and later studied this manuscript (cf. at f. 278r a later

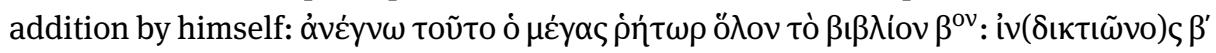

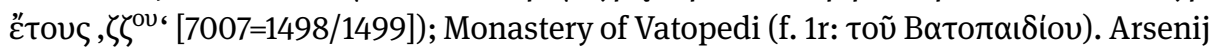
Suchanov (see f. IIv); Suchanov (1600-1668) acquired this manuscript during a trip to Mount Athos between 1654-1656.

Bibliography: Harlfinger 1971a; Moraux 1980; Förstel 1999.

\section{MUNICH, Bayerische Staatsbibliothek}

\section{Monacensis gr. $81[\mathrm{M}]$}

1540-1550 Paper mm $350 \times 245$ ff. I + 520 (vacua: 222A, 222B, 241v, 241A, 241B, 241C, 300v, 300A, 349v, 349A, 369v, 401v, 458v, 479v, 479A, 479B, 480r)

32 Here is a transcription of this peculiar list, probably conceived by Manuel himself: † $\mu \alpha \dot{\alpha} \xi i \mu \circ \varsigma$ ó

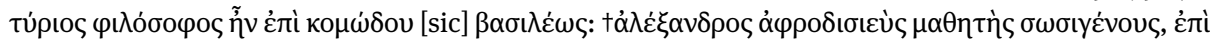

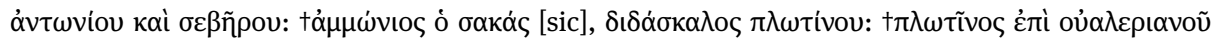

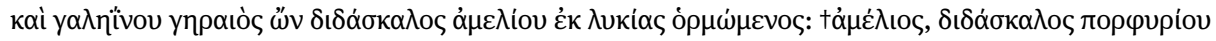

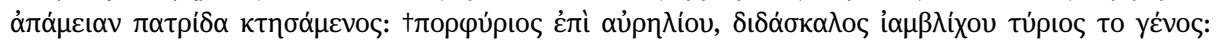

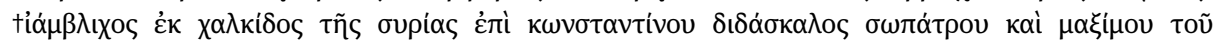

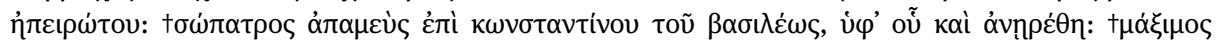

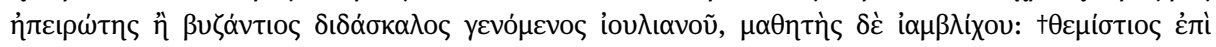

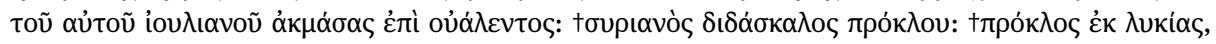

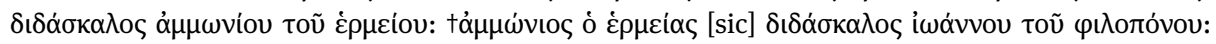

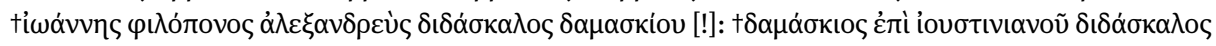

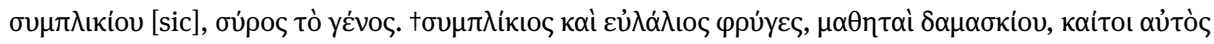

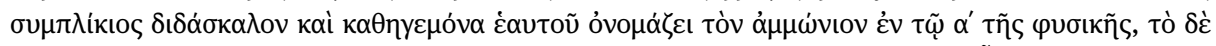

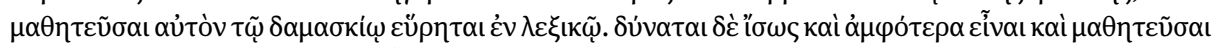

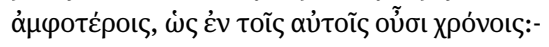


Watermarks: “Lettres SC” (e.g. ff. 50/53, 68/73, 97, 121, 129, 142, 167, 169, 186, 211, 222A, 222B); “Lettres” (e.g. ff. 101/104, 108, 110, 120) identical to Lettres 63 Harlfinger (Venice, 1542); "Flèche” with a star and letters (e.g. ff. 290/297, 292/295, 434/441), identical to Flèche 24a Harlfinger (Venice, 1542); “Lettres” (e.g. f. 447), identical to Lettres 75 Harlfinger (Venice 1548 and 1550).

Scribes: Main 3 Mon. 29 Mondrain: 1r-222v; <Michael Maleas >: 223r-241r; <Petros Karneades >: 242r-442v; <Bartolomeo Zanetti>: 443r-457v; <Emmanuel Bembaines >: $459 r-462^{12}$, 480v-520r; F. 462 $2^{12}-479$ r.

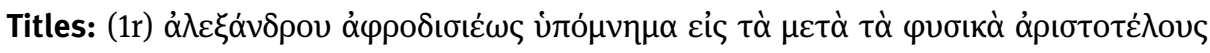

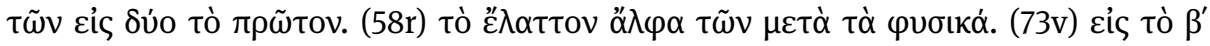

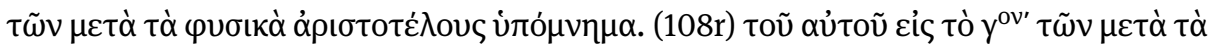

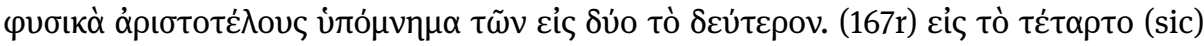

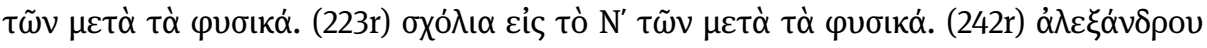

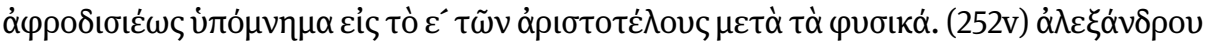

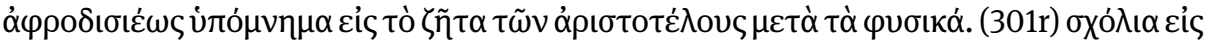

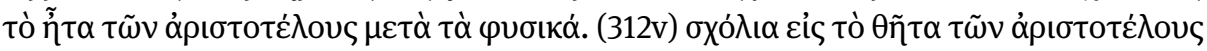

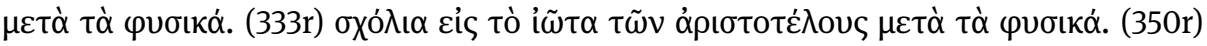

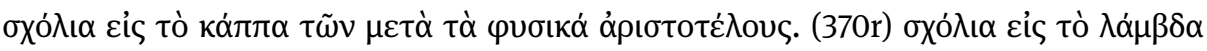

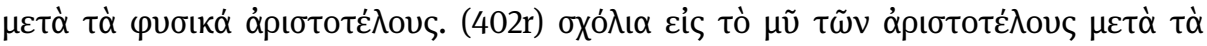

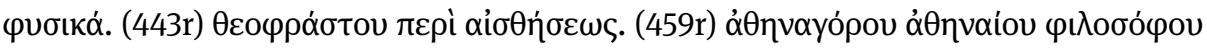

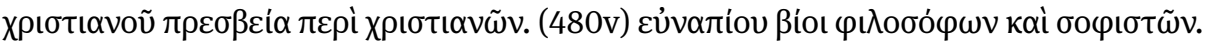

Contents: (1r-222v) Alexander, In Metaph. A- $\Delta . \quad$ (223r-241r) <Michael of Ephesus $>$, In Metaph. N (des. imp. 824.4 Hayduck). (242r-442v) <Anonymus>, In Metaph. E. $<$ Michael of Ephesus>, In Metaph. Z-M. (443r-457v) Theophrastus, De sensibus. (459r-479r) Athenagoras, Legatio pro christianis. (480r-520r) Eunapius, Vitae philosophorum et sophistarum.

Text: This is a composite manuscript made of four distinct codicological unities:

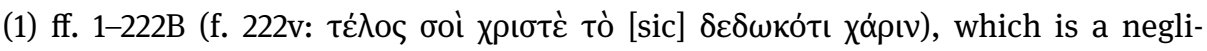
gent copy of $\mathbf{O}$ for books $\mathrm{A}-\Delta$ of Alexander's commentary, corrected throughout by a contemporary hand; (2) ff. 223-241C, which is also a copy of $\mathbf{O}$ for Michael's commentary on book N; (3) ff. 242-442A, a copy of the commentary on books E-M made by Petros Karneades (or Karnabakas), with which a new enumeration $(\alpha)$ of quires begins; ${ }^{33}$ these two parts ( 2 and 3 ) have been corrected throughout by the same later hand; (4) ff. 443-520: this part of the codex has been corrected through-

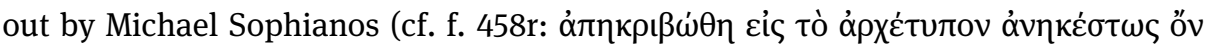

33 The part that includes the commentary on books E-Z is in all probability a copy of Par. gr. 1875, also copied by Petros Karneades, whereas the commentary on books H-M may have been copied from Par. gr. 1879. 


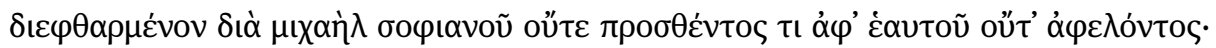

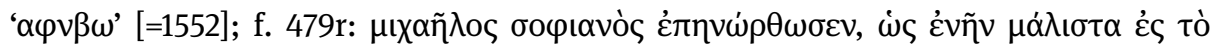

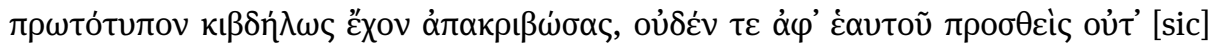
$\dot{\alpha} \varphi \varepsilon \lambda \omega \dot{\omega}$ ). Despite their codicological divergence, all four unities derive from the same Venitian atelier, as is suggested by the watermarks. This indicates the presence, somewhat mysteriously, of the Florentine $\mathbf{0}$ in Venice towards the middle of the sixteenth century. $\mathbf{M}$ played an important role in the nineteenth century editions of Alexander's commentary, since it was partially collated by Brandis, ${ }^{34}$ Bonitz and Hayduck.

Possessors: Johann Jakob Fugger (1516-1575).

Bibliography: Mondrain 1991-1992; Pradel 2013: 176-181; Golitsis 2016b.

\section{NAPLES, Biblioteca Nazionale di Napoli}

\section{Neapolitanus III. D. $35\left[\mathrm{~N}^{\mathrm{d}}\right]$}

1489 Paper $\quad \mathrm{mm} 293 \times 213$ ff. III + 362 (vacua: $73 v-80 v)+$ III

Watermarks: "Échelle” (e.g. ff. 20/21, 35/38, 76/77, 253/254, 358/359) identical to Échelle 14 Harlfinger (1489); “Arbalète” (e.g. ff. 260/265) identical to Arbalète 31 Harlfinger (1489). ${ }^{35}$

Scribes: Anonymus 38 Harlfinger: 1r-73r; Antonios Markoutzas: 81r-362v (cf. 362v:

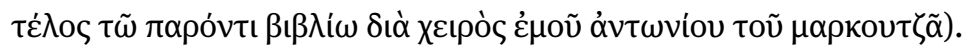

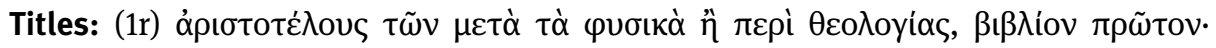

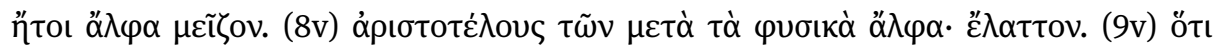

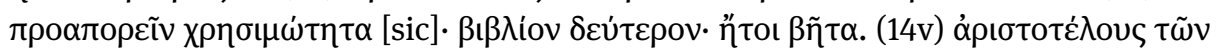

34 Silvia Fazzo (Fazzo 2017/2018: 684) curiously affirms that $\mathbf{M}$ was the chief manuscript used by Brandis for his edition of Alexander's commentary ("le manuscrit qui a été passé au crible en premier, celui qui a été pris au début comme point de repère pour la collation, est un manuscrit qui se trouve à Munich, le Monacensis gr. 81"). Does she think so because $\mathbf{M}$ was in Bavaria and Brandis was German? Be that as it may, Brandis himself says that the main manuscript he used for Alexander's commentary was A (see below, Section 5.1, n. 26), which he fully transcribed. This transcription must have happened during Brandis' stay in Paris from late September 1819 to May 1820; cf. Brandis 1869: 270-271: "Im übrigen lebten wir [i.e. Brandis und Immanuel Bekker] [in Paris] in großer Zurückgezogenheit, fast nur unseren weitschichtigen Arbeiten; und wenigstens meine Beschäftigung mit den unsäglich weitschweifigen gedruckten und ungedruckten Commentatoren des Aristoteles (von letzterem mußten manche dickleibige Folianten in schlechtester Schrift, gewöhnlich mit höchst dürftiger Ausbeute, durchgearbeitet werden) waren nicht geignet, die gesellige Laune zu wecken”. The (partial) collation of $\mathbf{M}$ must have happened afterwards.

35 Harlfinger 1974 wrongly dates both watermarks to 1484; see above, n. 25. 


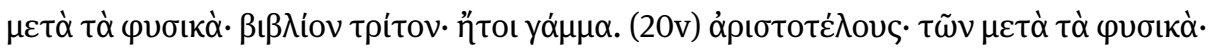

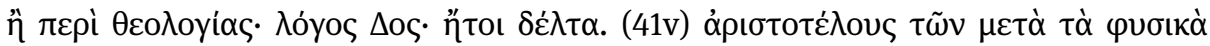

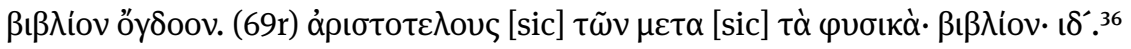

Contents: (1r-73r) Aristotle, Metaphysics. (81r-258v) Alexander, In Metaph. A$\Delta$. (259r-264r) <Anonymus>, In Metaph. E. (264r-362v) <Michael of Ephesus>, In Metaph. Z-N (des. imp. 825,14 H.).

Text: This manuscript was copied for Ermolao Barbaro on paper partly identical with the paper used for the production of $\mathbf{D}$ (Ambr. D 115 sup.), probably in Ferrara. It is a descendant of P (Par. gr. 1878) and was extensively used by Sepúlveda (several marginal corrections are probably by his hand). ${ }^{37}$

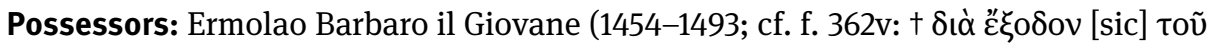

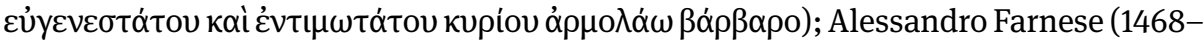
1549).

Bibliography: Harlfinger 1971a: 420; Formentin 2008; Golitsis 2016b; Golitsis (forthcoming).

\section{Neapolitanus III. E. $6\left[\mathrm{~N}^{\mathrm{e}}\right]$}

1540-1550 Paper $\mathrm{mm} 325 \times 238 \quad$ ff. IV + $263+\mathrm{IV}$

Watermarks: "Arbalète” (e.g. f. 21, 162, 228), similar to Briquet 749 (Lucques, 1548); "Flèche" with a star (e.g. f. 63, 115) similar to Flèche 23 Harlfinger (Venice, 1540).

Scribe: Giovanni Onorio da Maglie.

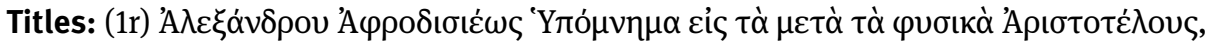

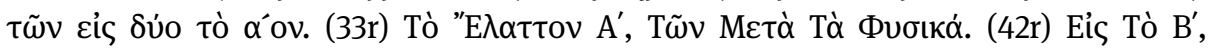

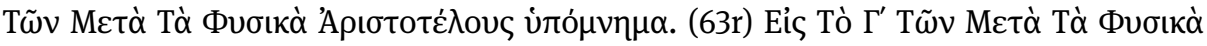

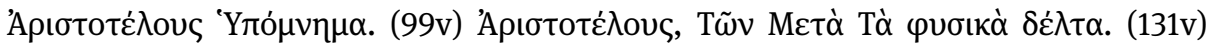

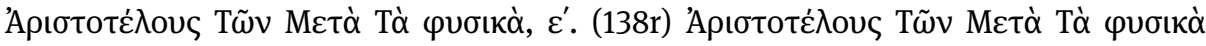

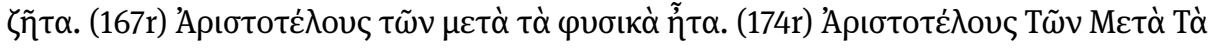

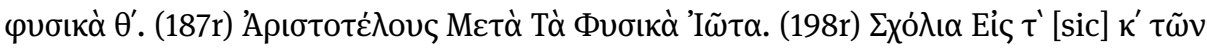

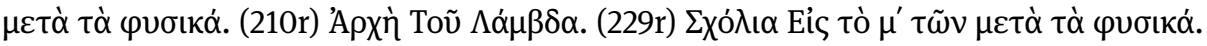

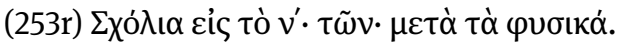

36 There are no titles for the rest of the books of the Metaphysics nor for the commentary, which is curiously ascribed to Simplicius on f. Ir ("Simplicii (ut videtur) in eos [sc. Metaphysicorum libros] Commentar. ined.") but to Alexander on f. 80v ("Aphrodisiei”).

37 See plate XI. 
Contents: (1r-131r) Alexander, In Metaph. A- $\Delta . \quad$ (131v-137v) <Anonymus>, In Metaph. E. (138r-263r) <Michael of Ephesus>, In Metaph. Z-N (des. imp. 825,14 H.).

Text: This manuscript is a joint copy of $\mathbf{E}^{\mathbf{a}}$ and $\mathbf{R}$ (Angelicus 102), two manuscripts that belonged to members of the Roman intellectual circle, to which Sepúlveda also belonged while he was residing in Rome.

Possessors: Alessandro Farnese il Giovane (1520-1589).

Bibliography: Formentin 2008; Golitsis 2016b.

\section{PARIS, Bibliothèque nationale de France}

\section{Parisinus gr. 1876 [A]}

Ante $1289^{38} \quad$ Bombycine $\mathrm{mm} 335 \times 240 \quad$ ff. IV $+288(-235)+$ III

Scribes: Four scribes of the last quarter of the thirteenth century: Anonymus $\Gamma: 1 \mathrm{r}-$ $75 \mathrm{r} 2,75 \mathrm{v}-91 \mathrm{r}^{1}, 91 \mathrm{r}^{17}-140 \mathrm{r}^{33}, 142 \mathrm{r}-177 \mathrm{v}^{34}, 178 \mathrm{r}^{7}-181 \mathrm{r}, 182 \mathrm{r}-191 \mathrm{v} ; \mathrm{B}: 75 \mathrm{r}^{3-40}, 91 \mathrm{r}^{2-17}$, 181v; C: $141 \mathrm{r}-\mathrm{v}, 192 \mathrm{r}-288 \mathrm{v}$; D: $177 \mathrm{v}^{35}-178 \mathrm{r}^{6}$. <Malachias>: f. $140 \mathrm{r}^{34}-140 \mathrm{v}$ (Malachias also completed several fenestrae left by Anonymus $\Gamma$ in ff. 142-191 and by the scribe $C$ in ff. $198 \mathrm{r}^{14}$ and $203 \mathrm{r}^{28-29}$ ).

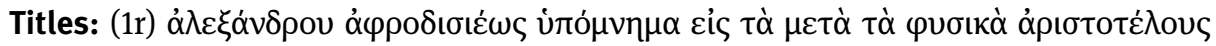

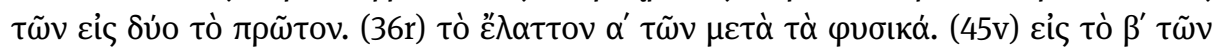

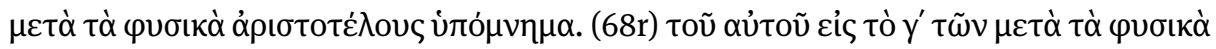

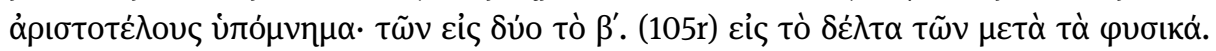

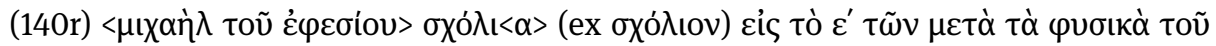

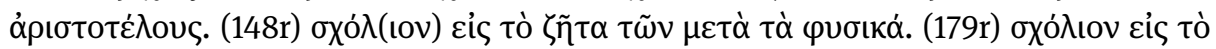

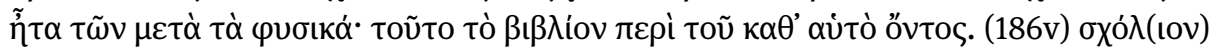

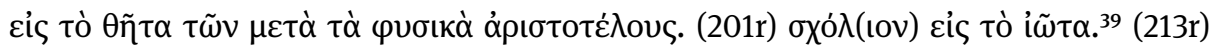

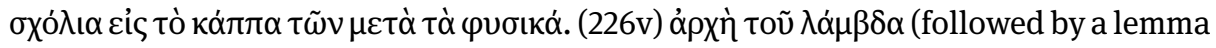

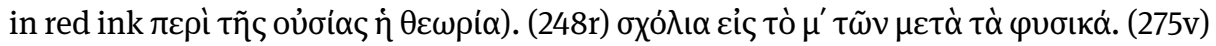

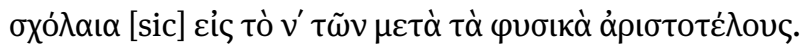

Contents: (1r-140r) Alexander, In Metaph. A- $\Delta$. (140r-148r) [Michael of Ephesus], In Metaph. E. (148r-288v) Michael of Ephesus, In Metaph. Z-N 6, $1092 \mathrm{~b} 30$ (des. imp.

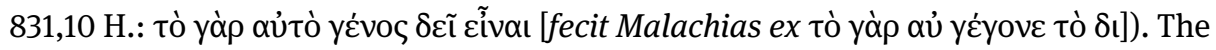

38 On this terminus ante quem see above, p. liii-liv.

39 The commentary stops with I 6 but there follows a lemma that corresponds to the beginning of I 7

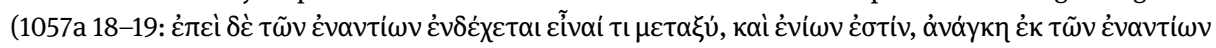

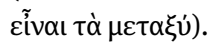


disposition of the text is more complicated though; the last folio stops at 828,13 H. $\tau \tilde{\eta}$ S

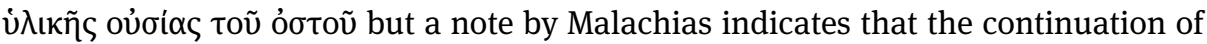
the text, i.e. 828,13-831,10 H., is found within book Epsilon (f. 146v22-147v22).

Text: This is the second independent copy of Alexander's commentary (the other is 0), made in Constantinople, probably in the 1280's, chiefly by two scribes, the socalled Anonymus $\Gamma$ and by another anonymous scribe (scribe $\mathrm{C}$ ). Anonymus $\Gamma,{ }^{40}$ who also partook in the production of $\mathbf{O}$ (ff. 14-17), copied several marginal notes after his model. As one of these notes has absolutely no connection with the commentary, we should think of him not as a scholar but as a professional scribe, who copied its model rather mechanically.

The several fenestrae that we observe from book Epsilon onwards, as well as the fact that the manuscript did not originally contain the beginning of the commentary on Epsilon (440,1-444,23 H.), imply that, as also happened with $\mathbf{0}$, a different model was used for the continuation of the commentary, ${ }^{41}$ namely a manuscript which was damaged through holes and whose first folio was lost. In the hope that he will later fill in the missing beginning of the commentary on book Epsilon, Anonymus $\Gamma$ left blank the bottom of f. 140r, in which the commentary on Delta ends, and the three following pages within the quire numbered in' (ff. 136-143), that is, the actual folia 140v and 141r-v. ${ }^{42}$ While f. 140 was completed significantly later by the monk Malachias, f. 141 was completed by a contemporary scribe of Anonymus $\Gamma$, that is, scribe $C$. How is this peculiarity to be explained?

The manuscript originally did not only lack the beginning of the commentary on book Epsilon but also integrates within the commentary on $\mathrm{E} 4$ a part of the commentary on N 5-6 (828,13-831,10 H. $\tau \tilde{\omega}$ 'Е confusion if we posit a defective model which had lost not only its first but also its last three folia (containing respectively 440,1-442,21 H. and 831,10-837,11 H.), whose then last folio (containing 828,13-831,10 H.) was placed within the first quire and whose

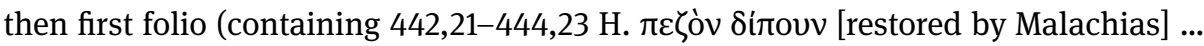
$\tau \iota \pi \rho \tilde{\alpha} y \mu \alpha)$ was put at the end of the codex. When scribe $C$ arrived at the end of the

40 So called because of the noticeability of the letter $\Gamma$ (" $a$ falce") in his script. This scribe is also responible for two manuscripts of Plato, namely the Vindobonensis Suppl. gr. 39 and the Laurentianus plut. 85,6, as well as for the first nine folia of Parisinus gr. 2063 (Philoponus, In Analytica Posteriora); see Menchelli 2007.

41 This was a richly annotated manuscript, especially for the commentary on books Zeta, Eta and Theta; some of these annotations, reproduced in A, address Michael of Ephesus critically.

42 We should notice in this regard that the first quire of the manuscript lacks its first folio ( $\left.\alpha^{\prime}: 1-7\right)$. This was probably a folio left blank in the hope that the missing beginning of the commentary would be found and added. This unfortunately never happened, and the folio disappeared in the subsequent bindings of the manuscript. 
model, ${ }^{43}$ he took notice of the misplacement of the last folio and copied it into the actual f. 141 of the codex, which was previously left blank by Anonymus $\Gamma$; this is also suggested by the "raccord imparfait" at the end of f. 141v. Malachias later indicated the misplacement of the commentary on N 5-6 in f. $146 \mathrm{v}-147 \mathrm{v}$ (f. $146 \mathrm{v}$, in margine:

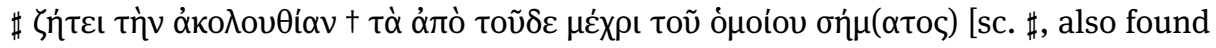

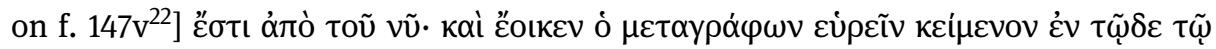

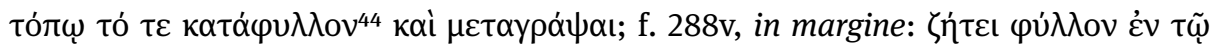

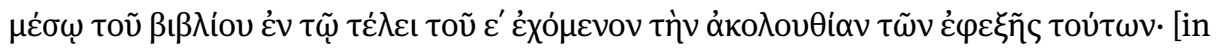
rubro] $\left.\lambda \varepsilon i ́ \pi \varepsilon ı ~ \varphi u ́ \lambda \lambda \alpha \delta^{\prime}\right)$.

Malachias used $\mathbf{A}$ as the main model for the production of the actual Parisinus Coisl. $161[\mathrm{C}]$ in the third quarter of the fourteenth century. On that occasion, and having access (at least) to a manuscript of the so-called "recensio altera", he made some corrections and completions on the first part of the commentary (f. $17 \mathrm{v}, 41 \mathrm{r}, 63 \mathrm{v}$, $65 \mathrm{r}, 65 \mathrm{v}, 84 \mathrm{v}, 86 \mathrm{v}, 88 \mathrm{r}, 97 \mathrm{v}, 111 \mathrm{v}, 114 \mathrm{r}),{ }^{45}$ supplied the still missing part (i.e. $440,1-$ $442,21 \mathrm{H}$.) of the beginning of the commentary on book Epsilon, restored several fenestrae in the next fifty folios, and attributed the commentary on E-N to Michael of Ephesus (probably in accordance with Parisinus Suppl. gr. 642 [S], which must have

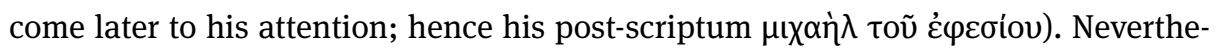
less, Malachias did not bother to restore in $\mathbf{A}$ the last part of the commentary on $\mathrm{Nu}$, which is present in his own copy Parisinus Coislin 161.

A later scholar, whom Harlfinger identified with Bessarion but who seems to me to be John Chortasmenos, ${ }^{46}$ added throughout the manuscript several notable marginalia ${ }^{47}$ and thoroughly corrected the text, in particular from book Beta onwards.

Possessors: This manuscript belonged, in all probability, to the library of the Prodromou-Petra monastery in Constantinople, where it was restored by the monk Malachias

43 This perturbation of folios in the model of A was restored when Parisinus Suppl. gr. 642 [S] was produced. The beginning of the text copied by Ioannikios in $\mathbf{S}$ practically coincides with the beginning of the text copied by scribe $\mathrm{C}$ in $\mathbf{A}$. On $\mathbf{S}$ see above, p. lii-liii.

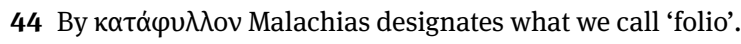

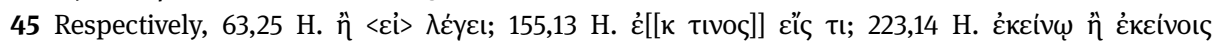

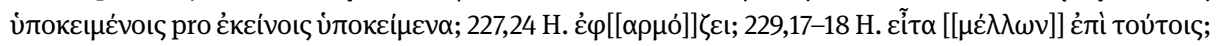

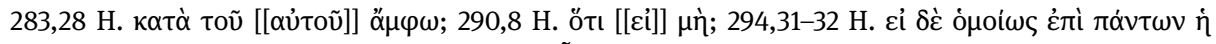

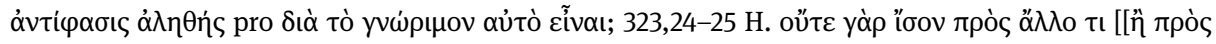

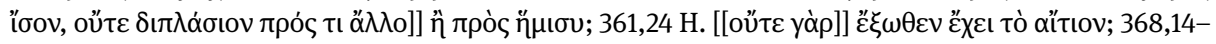

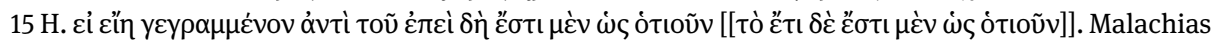

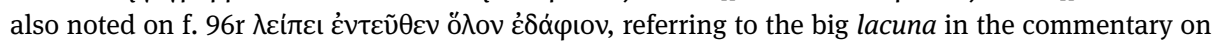
book Gamma (318,21-319,27 H.), notably noted by Bonitz. He also seems to be the scribe who rewrote

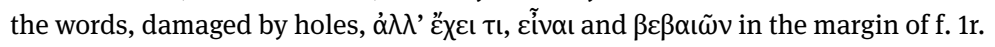

46 See above, Section 2.2.

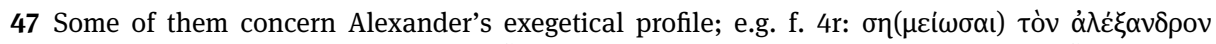

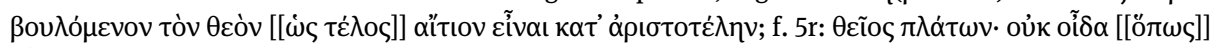

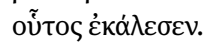




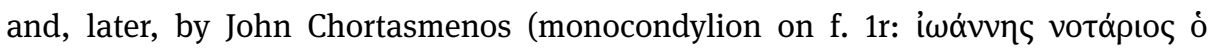

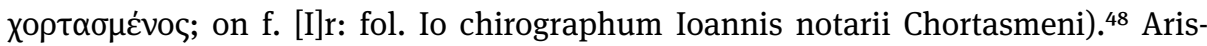
toboulos Apostoles used it as a model (for the production of the actual Vaticanus Reg. gr. 115 [V]) around 1530 probably in Venice, where it was acquired in 1538-1539 by Girolamo Fondulo, who brought it to Francis I.

Bibliography: RGK II 61; Mondrain 2000; Groisard 2006-2009; Golitsis 2016b; Martínez Manzano 2019.

\section{Parisinus gr. $1877\left[\mathrm{P}^{\mathrm{a}}\right]$}

1548-1549 Paper mm 343×235 ff. IV + (1+) $279(+4)+$ IV

Watermarks: Three flowers in a circle (e.g. ff. (1)/7 and 184/189); Scissors (e.g. ff. 8/15); “Arbalète dans un cercle sommé d'une fleur de lys” (e.g. ff. 190/197 and 199/204); Arrows (ff. 279+1).

Scribe: $<$ Ioannes Franciscus $>$.

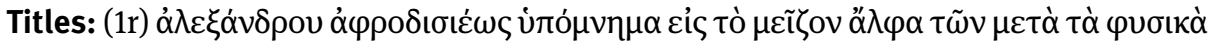

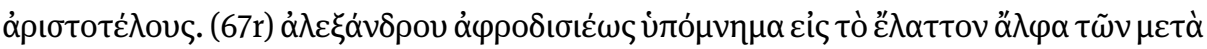

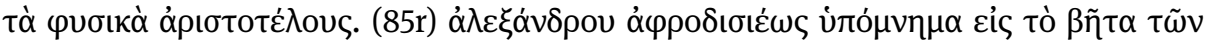

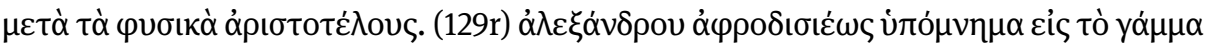

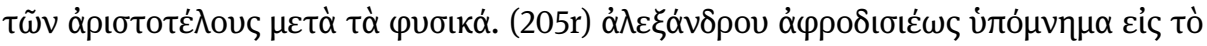

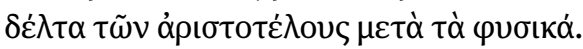

Contents: (1r-279r) Alexander, In Metaph. A- $\Delta$.

Text: This manuscript is a copy of Par. gr. 1878 [P], made by Ioannes Franciscus a couple of years before the death of Cardinal Ridolfi, who owned P, that is, in 1548-49

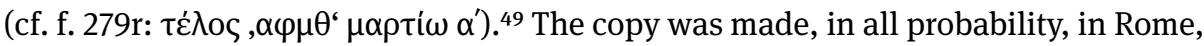
where Franciscus was active as a scriptor of the Bibliotheca Vaticana. ${ }^{50}$ A contemporary hand collated anew the copy with $\mathbf{P}$ and made extensive corrections in the margins. ${ }^{51}$

Possessors: This manuscript was acquired, in all probability, in Italy by Henri de Mesmes (1532-1596) - and not, as believed until now, by his father Jean-Jacques de Mesmes (1490-1559) - together with the actual Parisini gr. 1904 (Asclepius, In

\footnotetext{
48 See plate VII.

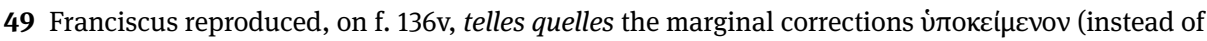

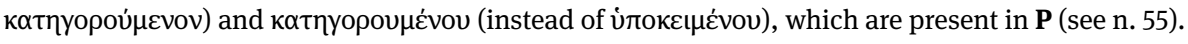
50 See Dorez 1909: 171 and 184.

51 As Groisard 2006-2009 points out, it is the same corrector who added the words Aotáotos and

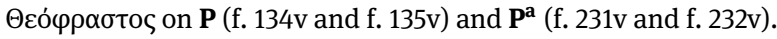


Metaph.) and gr. 2354 (second part: Syrianus, In Metaph.), also copied by Ioannes Franciscus on partly identical paper. Henri (and not Jacques) undertook several missions in Italy and the Vatican. The shelfmark 466, which corresponds to the de Mesmes' collection, is traced on $\mathrm{f}$. 1r. The manuscript entered the Bibliothèque royale together with the manuscripts of Émery Bigot (1626-1696) already in 1706 (and not in 1732 with the manuscripts of Jean-Baptiste Colbert [1619-1683], to whom Henri de Mesmes' daughter, the duchess of Vivonne, offered the major part of her father's library).

Bibliography: RGK II 247; Groisard 2006-2009; Jackson 2009; Golitsis 2016b.

\section{Parisinus gr. 1878 [P]}

1471-1472 Paper $\quad \mathrm{mm} 290 \times 205 \quad$ ff. III + (1) + $162(+2)+$ III

Watermarks: 1) Scissors, quires $\alpha^{\prime}-y^{\prime}$ and ff. 26/34; 2) Arbalète 22 Harlfinger (Rome, 1471/72), e.g. ff. 38/41; 3) Chapeau 12 Harlfinger (Venice, 1471), e.g. ff. 45/54.

Scribes: <the (hiero)monk Gregorios >: 1r-24v, 26rv; <Andronicus Callistus >: 25rv and $27 \mathrm{r}-162 \mathrm{v}$, lemmas in $1-24 \mathrm{v}$ and $26 \mathrm{rv}$.

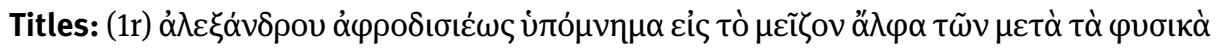

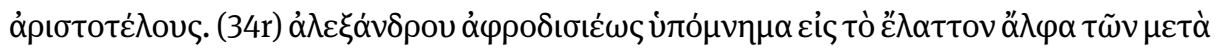

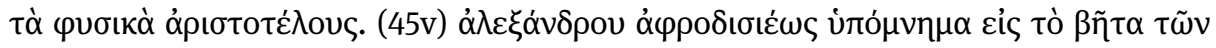

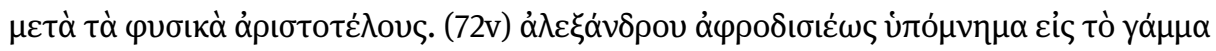

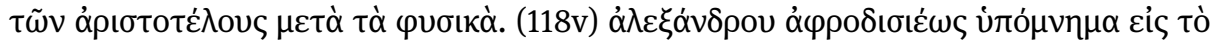

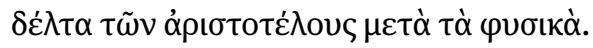

Contents: (1r-162v) Alexander, In Metaph. A- $\Delta$.

Text: This is a composite codex copied probably in Rome by two scribes using each one his own paper, which is an indication that its production was not a joint enterprise stricto sensu. Nonetheless, all the quires ( $\alpha^{\prime}-1 \zeta^{\prime}$; actually three quaterniones and fourteen quiniones) are numbered by the second scribe, namely Andronicus Callistus. ${ }^{52}$ The first scribe is the (hiero)monk Gregorios, ${ }^{53}$ who copied the first three quaterniones

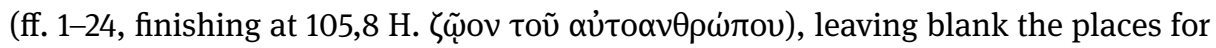
the title of the work and the lemmata, which were to be added later, probably in red ink; he continued his work on the first folio (the actual f. 26) of a further bifolium,

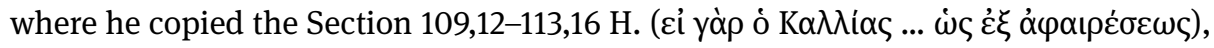
thus leaving out the Section 105,9-109,12 H. probably because of a defective model

52 On Andronicus Callistus see lately Martinelli-Tempesta 2013: 131-133.

53 I owe this identification to David Speranzi, whom I warmly thank. On the (hiero)monk Gregorios, earlier known as ‘Anonymus K-B’ (see Harlfinger 1971a: 249-251), see lately Giacomelli - Speranzi 2019. 
(a lost folio?). After that, he abandoned the enterprise, which was taken over by the second scribe, namely Andronicus Callistus. Callistus copied the title of the work and the lemmata in the first three quaterniones, one quaternio and the subsequent thirteen quiniones; he actually integrated the separate bifolium in the fourth quaternio (thus

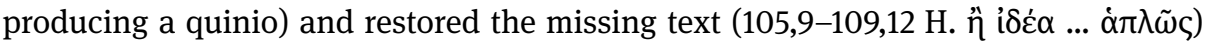
on the first folio of the newly produced quinio, which characteristically finishes with a "raccord imparfait". Callistus used red ink for the title and the lemma on f. 1r, ${ }^{54}$ of which he subsequently made no further use (except for f. 6r, where he added in red

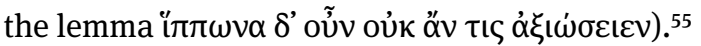

Possessors: The manuscript was acquired by Niccolò Leoniceno (1428-1524), when Callistus, en route to France and ultimately Britain, sold his books in Milan in 1475/76. After Leoniceno's death, the manuscript became a possession of Cardinal Niccolò Ridolfi (1501-1550): a pinax by Matthaios Devaris, who was Cardinal Ridolfi's librarian, is found on f. (1)v together with two different shelf marks ("no 44, no 43 secundae [sc. capsae], no 44 [ex 54] $\mu \delta o v$ ") that correspond to Ridolfi's collection. ${ }^{56}$ Catherine de Médicis (1519-1589) acquired the collection through Piero Strozzi; in 1599, it was added to the Fontainebleau Library. ${ }^{57}$

Bibliography: RGK II 25; Jackson 2003; Groisard 2006-2009; Golitsis 2016b.

54 See plate IX.

55 Callistus also marked as lemmata, through the use of $\delta เ \pi \lambda \eta \dot{n}(»)$, passages copied by Gregorios as parts of Alexander's text, supplied missing phrases or words in the first three quaterniones, and added

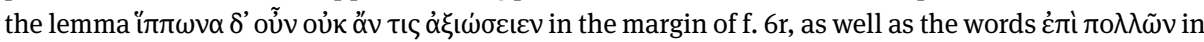
the margin of f. $21 \mathrm{r}(\tilde{\varepsilon} v<<\dot{\varepsilon} \pi \mathrm{i} \pi 0 \lambda \lambda \tilde{\omega} v>$ ). A scholar using a handwriting similar to Callistus' but considerably smaller occasionally corrected $\mathbf{P}$ in the margin: f. 2v: Évvoía correcting in the margin aitias;

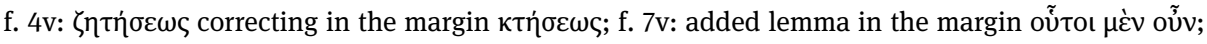

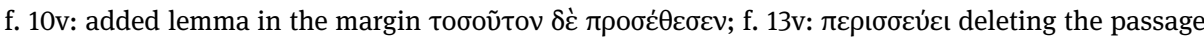

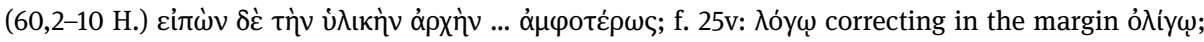

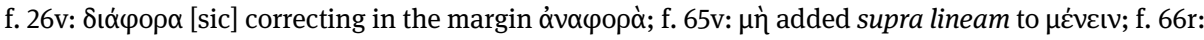

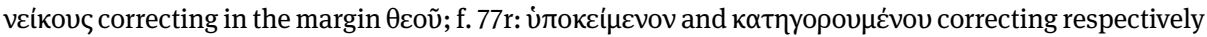

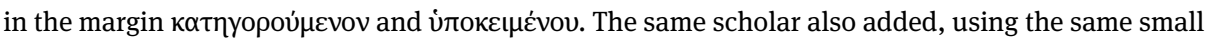

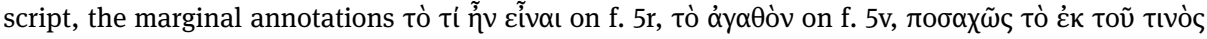

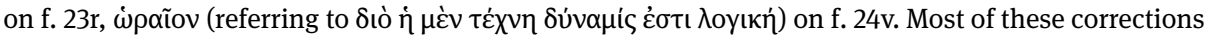
have been reproduced by Demetrios Moschos in $\mathbf{D}$, so that they should be dated some time between 1475/76 and 1489. They may be due to Niccolò Leoniceno, to whom $\mathbf{P}$ was sold. In his descriptions of Parisini gr. 1878 and 1879, Groisard 2006-2009 seems to confound this small script with the script of Baldassarre Migliavacca, who intervened, however, only on the latter manuscript.

56 On the same external parchment folio the words $\dot{\alpha} \pi$ ' $\alpha \lambda \lambda$ ov can be read, written probably by the scholar who could be identified with Leoniceno (see previous note). This would mean that this parchment folio was used as "feuille de garde" already in Callistus' and Leoniceno's time.

57 Several $c \eta(\mu \varepsilon i \omega \sigma \alpha \mathrm{l})$ - f. 3r, 61r, 64r and 64v - as well as a note in Latin on f. 39r date from this later epoch. 


\section{Parisinus gr. $1922\left[\mathrm{P}^{\mathrm{d}}\right]$}

Originally two manuscripts: I. ff. 1-153, beginning of the sixteenth century; II. ff. 154$230(+3)$, end of the fifteenth century

Paper mm $319 \times 236$ ff. II + 230 (vacua: $126,152 v, 153)(+3)+$ III

Watermarks: "Dreiberg im Kreis darüber dreikonturiges Kreuz” (e.g. f. 57, 126 and 153), similar to Monts 90 Harlfinger (1504). “Anker im Kreis (ohne Beizeichen)”, e.g. f. 230+1, quite similar to Piccard IV 129 (Innsbruck, 1496 and 1497).

Scribes: A. <Constantine Mesobotes >: 1-153; B: 154-230.

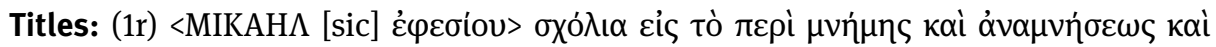

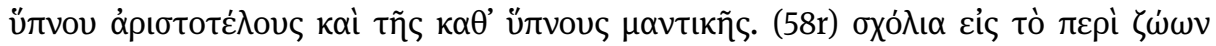

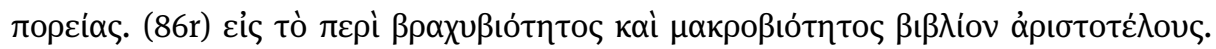

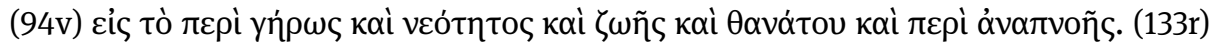

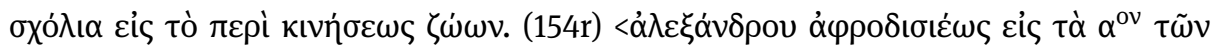

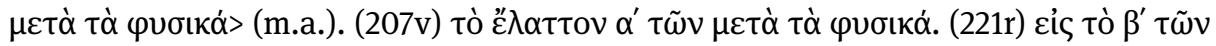

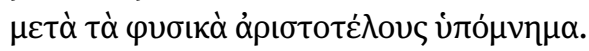

Contents: (1r-153v) Michael of Ephesus, In Parva naturalia. (154r-230v) Alexander,

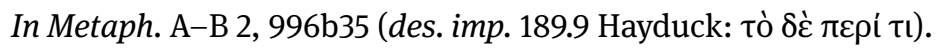

Text: This manuscript is a descendant of $\mathbf{A}$ through an intermediate lost manuscript (к), which was probably an unfinished copy of $\mathbf{A} .{ }^{58}$ In the left margin of f. $184 \mathrm{v}$, the anonymous scribe reproduced in rubro the marginal note by Chortasmenos, which we

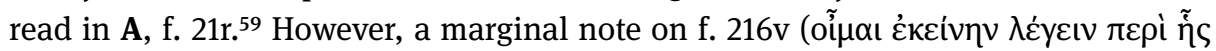

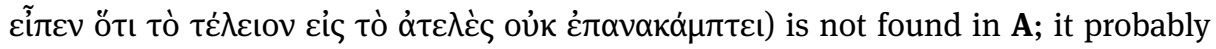
derives from the lost intermediate model.

Possessors: Gian Francesco d'Asola (1498-1557/8) owned at least the second part of the codex, as is revealed by his autograph note on f. 154r: "cosi sono dui <primi> libri da Alex(andr)o sopra la methaphisica (sic) il p(rim)o è compito il secondo è imp(er)fetto". D’Asola was thus aware of two manuscripts conaining Alexander's commentary on $\mathrm{A}-\Delta$, which he calls "primi", the other of which contained this commentary in its entirety. ${ }^{60}$ It seems that D'Asola envisaged to producing an aldine of Alexander's commentary. His books were later acquired by Francis I through the intermediary of his ambassador in Venice, Guillaume Pélicier, and arrived at the Bibliothèque royale in Fontainebleau some time between 1542-1545.

Bibliography: RGK II 315; Cataldi Palau 1998: 413 and 537; Golitsis 2016b.

58 See below, Section 4.1.1.

59 See above, p. lxxxv.

60 Notice that D'Asola also owned Par. gr. 1879, which contains the commentary on E-N attributed to Alexander, in other words the "second" part of (pseudo-)Alexander's commentary. 


\section{Parisinus Coislin $161[\mathrm{C}]$}

1350-1375 Paper mm $300 \times 224$ ff. IV + 458 (vacua: 166, 167, 225v, 227r, 406-409, 448v-458v) + II

Watermarks: Sirene (e.g. 219v); Bell (e.g. f. 225), cf. Briquet 3940 (Florence, 1355); “Clé de Sol” (e.g. f. 450, 454, 455, 456).

Scribe: <The monk Malachias>. The bottom part of f. 447v and f. 448r are written by a different contemporary hand. The same holds for the lower half of f. 168r.

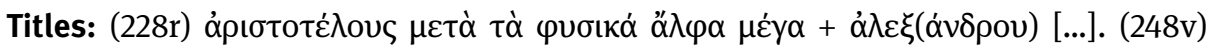

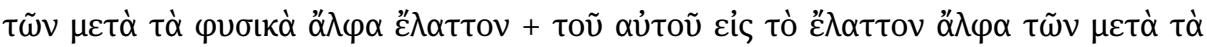

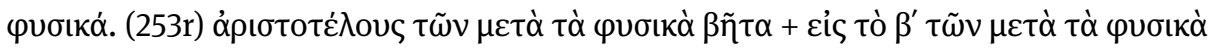

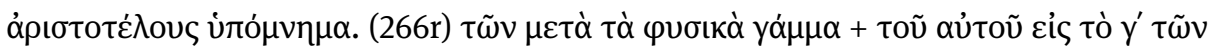

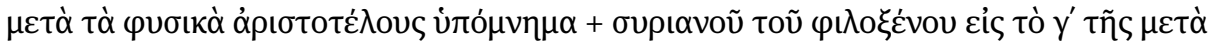

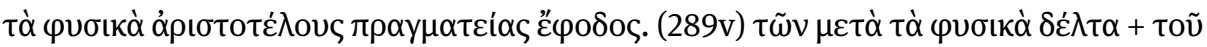

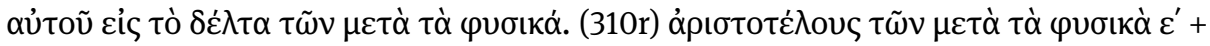

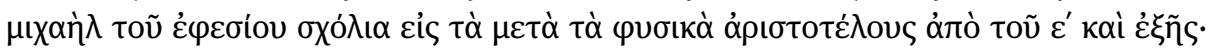

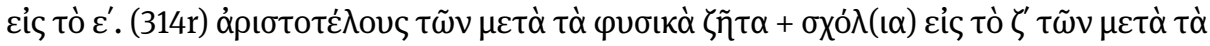

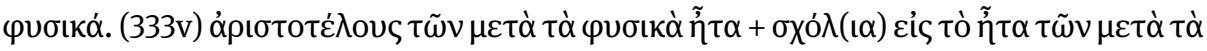

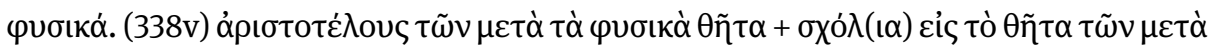

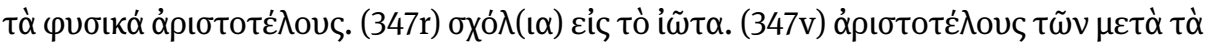

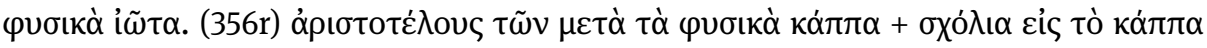

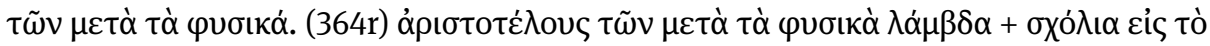

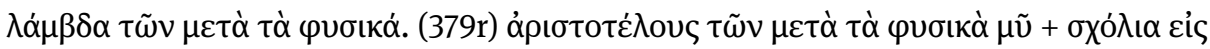

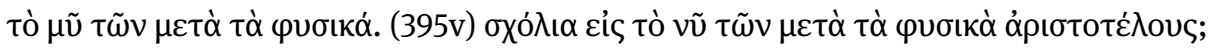
(396r) ả

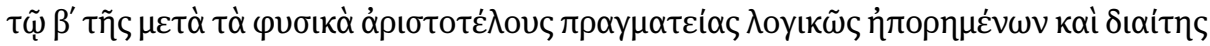

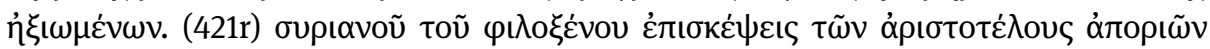

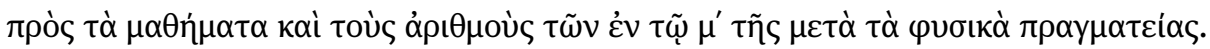

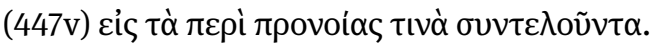

Contents: (1r-40r) Aristotle, Magna Moralia. (40v-165v) Aristotle, Nicomachean Ethics with commentaries. (168r-219v) Aristotle, Politics with annotations by Matthaios Camariotes. (220r-225r) Aristotle, Oeconomics. (226r-v) Anonymous prolegomena to the Metaphysics. (228r-405r) Aristotle, Metaphysics; (228r-309v) Alexander, In Metaph. A- $\Delta$; (266r-289r) Syrianus, In Metaph. Г; (310r-314r) [Michael of Ephesus], In Metaph. E; (314r-405v) Michael of Ephesus, In Metaph. Z-N. (410r-447r) Syrianus, In Metaph. B, M, N.

Text: $\mathbf{C}$ and its apograph $\mathbf{M}^{\mathbf{0}}$ are the only manuscripts that contain Aristotle's text, which is surrounded by Alexander's commentary. The scribe Malachias, earlier 
known as 'Anonymus aristotelicus', ${ }^{61}$ copied Alexander's text after A, which he occasionally restored.62 'Malachias' was probably the monacal name of the ex co-emperor of Byzantium Matthew Cantacuzenus (ca. 1325-1383), ${ }^{63}$ and thus this editorial enterprise must have taken place after 1357, when Matthew was deposed. The ex co-emperor was admittedly working in a well equipped library, probably the library of the Prodromou-Petra monastery. When there was need, he consulted a copy of the anonymous commentary, from which he probably transcribed the anonymous prolegomena to the Metaphysics (f. 226), ${ }^{64}$ as well as the missing part of the commentary on $\Gamma 6(318,21$

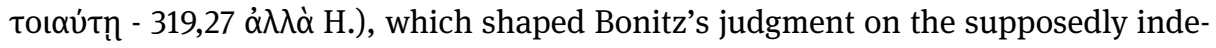
pendent value of Sepúlveda's translation. ${ }^{65}$ The latter addition occurs somewhat later than it should (i.e. after 321,1 H. oü $\omega \varsigma$ ), as explained by Malachias himself in the margin (f. $284 \mathrm{~V}$; see plate VI):

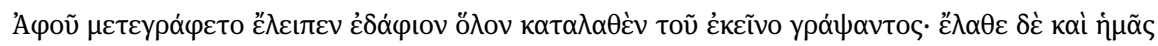

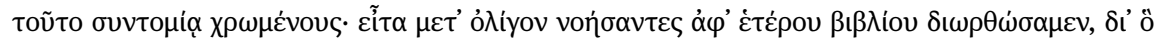

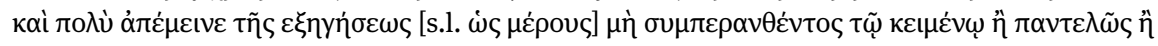

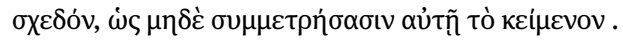

This marginal note aptly illustrates Malachias' occasional use of other manuscripts, whenever he would perceive a textual problem. As a collation of 318,21-319,27 H. illustrates, he used a copy that was textually independent from the common model of $\mathbf{L}$ and $\mathbf{F} .{ }^{66}$ Thus, $\mathbf{C}$ is the sole testimony to a text that is unknowingly corrupt in Hayduck's edition (318,21-319,12 H.):

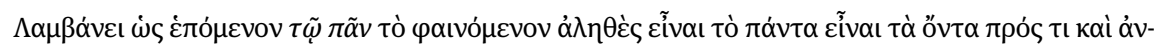

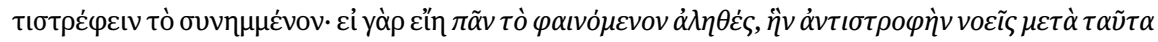

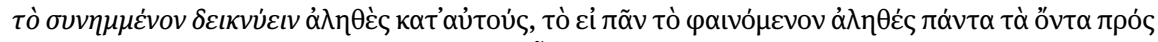

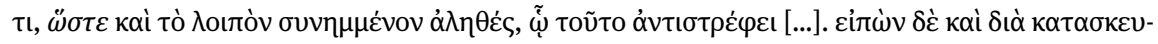

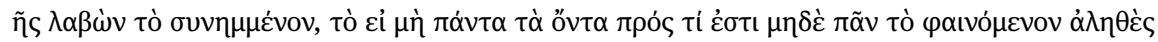

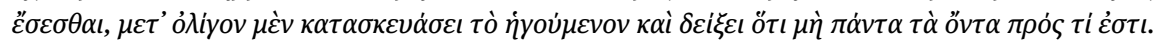

61 See Harlfinger 1971a: 55-58.

62 See above n. 45.

63 See Martínez Manzano 2019.

64 See above, p. xli-xlii.

65 See below, Section 5.1.

66 Nonetheless, this copy was not the archetype of the textual tradition of the anonymous commen-

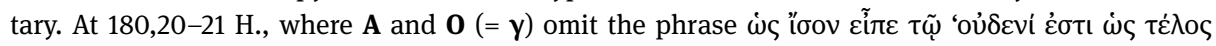

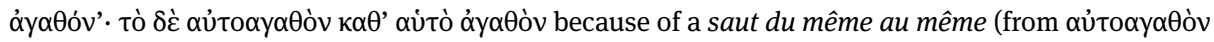

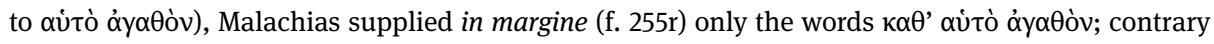
to $\mathbf{L}$ and $\mathbf{F}$, which conserve the integral text, Malachias' model must have lacked the phrase $\dot{\omega} \varsigma$ í $\sigma o v$

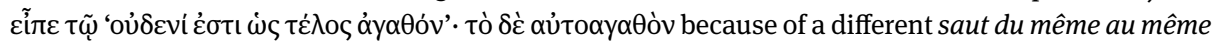

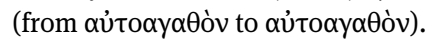




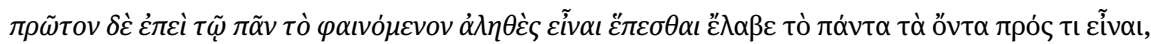

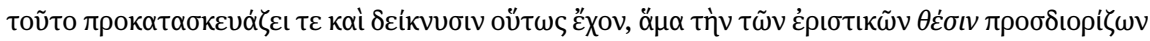

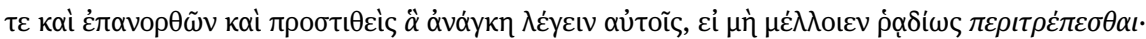

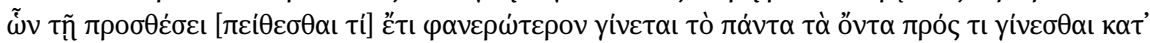

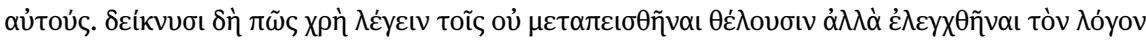

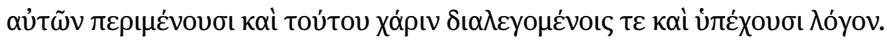

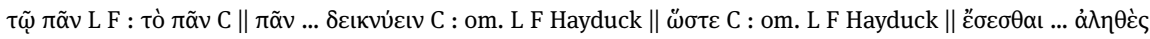

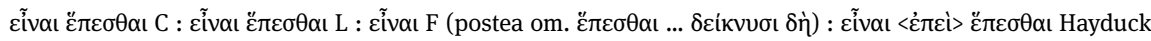

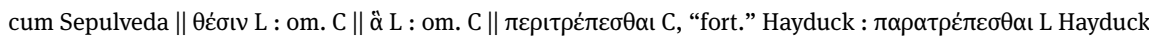

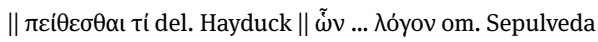

Apart from this manuscript, ${ }^{67}$ Malachias had access to one more manuscript, since on f. 302v he explains to his reader the presence of an omission (404,19-21 H.: $\dot{\omega} \varsigma$

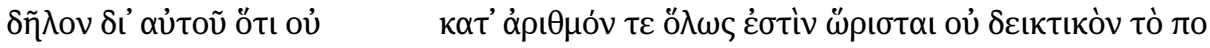

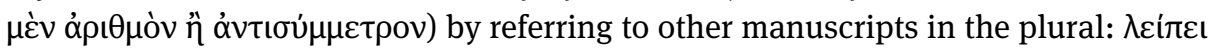

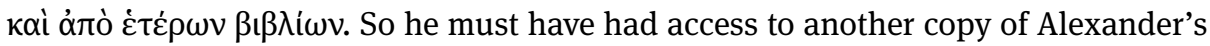

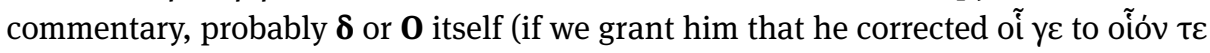
and $\pi \rho \circ \sigma \theta \dot{\sigma \varepsilon \varepsilon}$ to $\pi \rho o ́ \sigma \theta \varepsilon v$ by himself). ${ }^{68}$

Malachias designates as $\pi \alpha \lambda \alpha$ เ $\alpha$ the comments that he found in A. It is worth

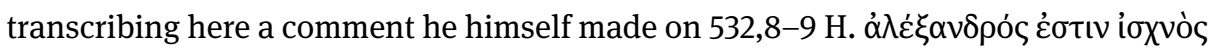

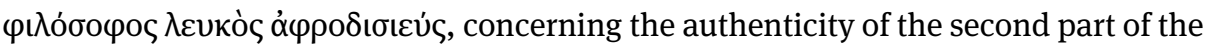
commentary (f. 330v):

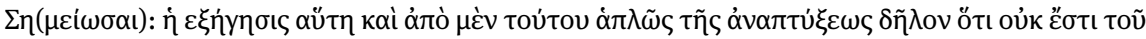

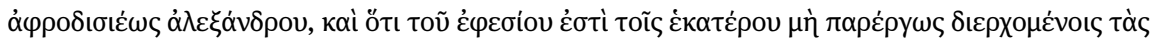

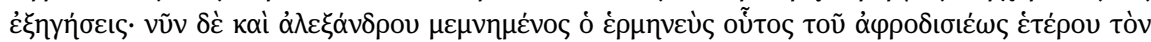

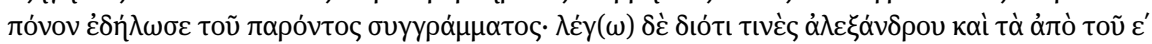

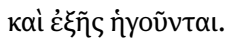

This observation, which invalidates Sepúlveda's later argumentation to the contrary, hints at discussions held by Byzantine Aristotelian scholars on questions of authentic-

67 Malachias restored further problematic passages with the help of the anonymous commentary; cf.

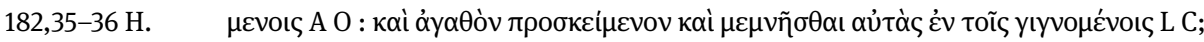

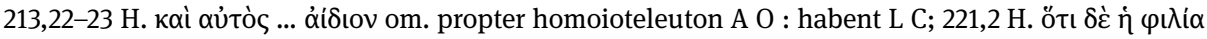

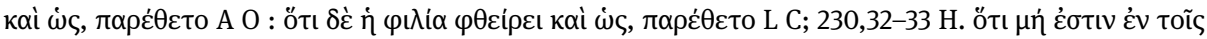

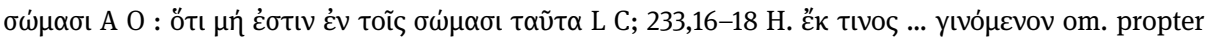
homoioteleuton A 0 : habent L C.

68 Cf. the apparatus criticus ad 222,4-19 H., where $\mathbf{C}$ agrees in most cases with $\mathbf{O}$ against $\mathbf{A}$ and against L and F; see, in particular, the addition at 222,10-11 H. $\tilde{\omega}$... $\alpha$ ox $\alpha$ í habent O C : om. A L F. C also provides

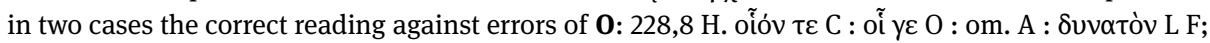

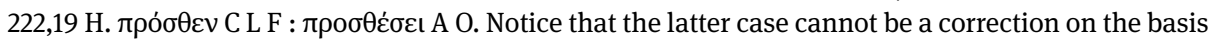
of the anonymous commentary; were it so, Malachias would also have corrected the passage that he designates as $\dot{\varepsilon} \sigma \varphi \alpha \lambda \mu \varepsilon \dot{\varepsilon} v \alpha$ a couple of lines above (see the critical apparatus ad locum). At 222,10 H., C

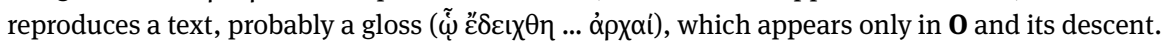


ity. ${ }^{69}$ Another comment by Malachias (f. 333v, in margine inferiore), this time of philo-

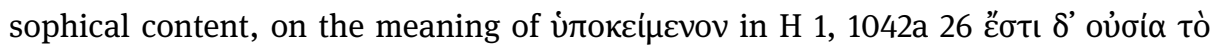
ن்

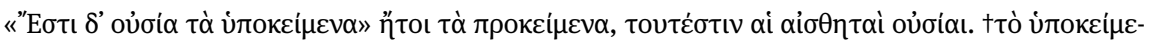

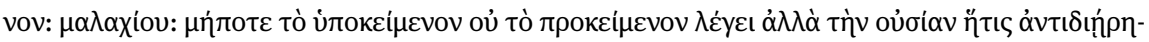

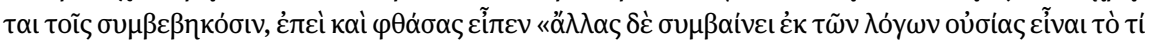

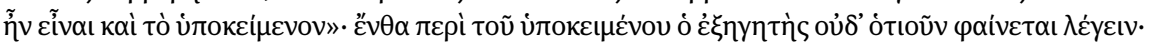

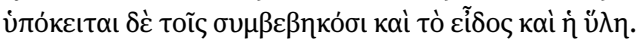

This comment confirms the identification of the Anonymus aristotelicus as Malachias. $^{70}$

Possessors: This manuscript bears annotations on the Politics by Matthaios Camariotes (†ca. 1490), who was possibly the first Megas Rhetor of the Patriarchate of Constantinople after the Fall of Byzantium (Manuel Korinthios, who used $\mathbf{C}$ as a model of $\mathbf{M}^{\mathbf{0}}$, was Camariotes' disciple). The manuscript was brought to Pierre Séguier (15881672) by the priest Athanasios the Rhetor from the Monastery of Great Lavra (cf. f. 1r:

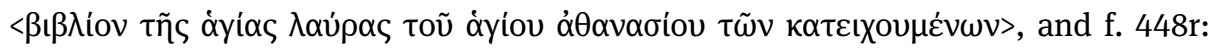

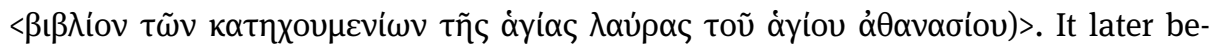
longed to Séguier's grandson Henri-Charles du Cambout, duc de Coislin (1665-1732), who between 1715 and 1720 gave his grandfather's collection to the Benedictines of Saint-Germain-des-Prés. The library of Saint-Germain was transferred to the Bibliothèque nationale in the winter of 1795/1796.

Bibliography: Devreesse 1945: 145-146; Harlfinger 1971a; Moraux 1980; Mondrain 2005; Golitsis 2016b.

\title{
16. Parisinus Coislin $331\left[\mathrm{P}^{\mathrm{C}}\right]$
}

17th cent., middle Paper mm $248 \times 175$ ff. [II] $+627(+86 a)+[628]$ (vacua: 279v-280r, 300v-301r, 616v-628v)

Watermark: "Fleurs de lis posées dans un écu couronné” (unknown).

Scribe: $<$ Honorat $>$.

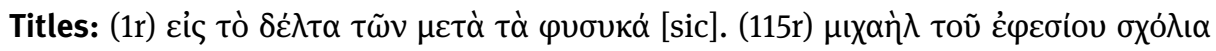

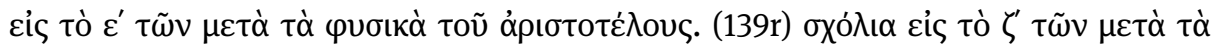

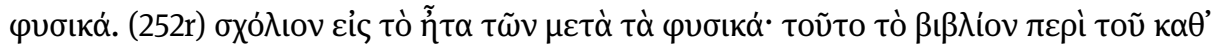

69 About a hundred years later, however, Andronicus Callistus, the scribe of Par. gr. 1879, explicitly ascribed the second part of the commentary to Alexander.

70 As proposed by Mondrain 2004 and Mondrain 2005. 


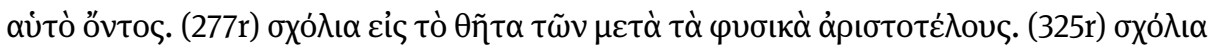

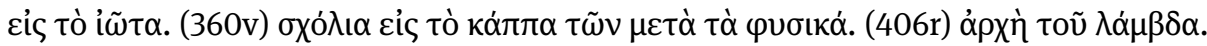

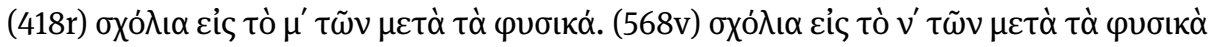

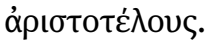

Contents: $(1 \mathrm{r}-114 \mathrm{v})<$ Alexander>, In Metaph. $\Delta . \quad$ (115r-138v) <Anonymus >, In Metaph. E. (139r-616r) <Michael of Ephesus>, In Metaph. Z-N 6 (des. imp. 831,10 H.: tò yò $\rho$

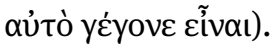

Text: This manuscript was meant to supplement Parisinus Coislin 328, which contains books $\mathrm{A}-\Gamma$ of the so-called "recensio altera" (itself the first part of a divided manuscript, copied by Sebastianus Ducius, whose second part is the actual Vaticanus Reginensis gr. 126) and was bought by Séguier in 1645 . Honorat used as his model A, by then in Paris, also reproducing its marginalia; he abandoned them, however, toward the end of book $\mathrm{Z}$. Honorat also failed to correctly transcribe the correction made by Malachias at the imperfect end of the commentary in A. ${ }^{71}$

Possessors: Pierre Séguier (on the inside binding: "Alexandre Aphrodisiensis sur le quatrième livre et livres suivants de la Métaphysique. Codex p(et)ri se(guieri)”, probably by the hand of priest Athanasius Rhetor); Henri-Charles du Cambout, duc de Coislin (1665-1732); Benedictines of Saint-Germain-des-Prés.

Bibliography: Devreesse 1945: 315-316; Golitsis 2016b.

\section{Parisinus Suppl. gr. $306\left[\mathrm{P}^{\mathrm{s}}\right]$}

1489 Paper mm $292 \times 202 \quad$ ff. III + 212 (vacua: $32-36$ )

Watermarks: "Dreiberg mit Kreis” (e.g. ff. 31/34), identical to Monts 69 Harlfinger (1489); "Pfeile” (e.g. ff. 71/74), variation of IX 945-946 Briquet; “Cercle” (e.g. ff. 110/115), variation of I 107-119 Briquet.

Scribe: $<$ Georgios Alexandros Chomatas $>$ : 1r-31v; <Demetrios Moschos $>$ : 37r-212v.

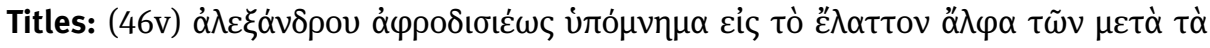

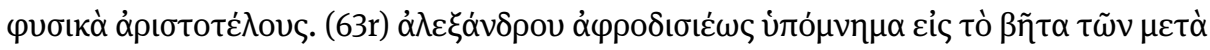

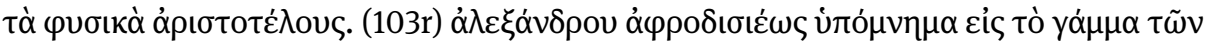

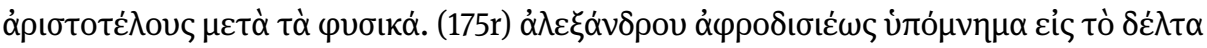

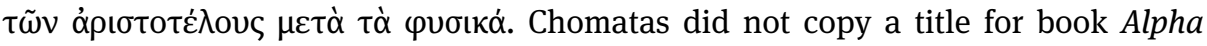
meizon, which was to be added in rubro.

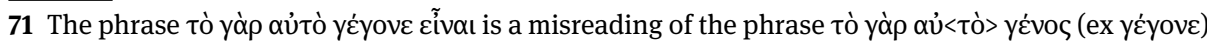

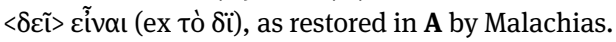




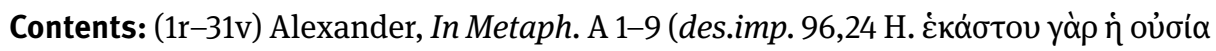

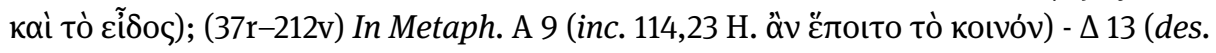
mut. 397,19 H. $\mu \varepsilon \gamma \varepsilon \theta \tilde{\omega} \nu \delta \dot{\varepsilon} \dot{\varepsilon} \kappa \alpha ́ \sigma \tau o v)$. It originally contained the entire commentary on $\mathrm{A}-\Delta$.

Text: This is a further copy of Alexander's commentary that was made, in all probability, in Ferrara, partially by Demetrios Moschos. In light of the different paper used by the two scribes, we should posit that Moschos finished a copy that was left unfinished by Chomatas. ${ }^{72}$ Chomatas used as model the codex $\mathbf{D}-$ his part stops ex abrupto inside a quire at $96,24 \mathrm{H}$., which precisely coincides with the ending of the quire numbered $\varepsilon^{\prime}$ (f. 40v) in D -, a manuscript entirely copied by Moschos shortly before; but Chomatas abandoned the enterprise possibly because $\mathbf{D}$ was not yet finished. Moschos went on with this enterprise using as model not his own copy but $\mathbf{P}$, as he also did for $\mathbf{D}$. As the part copied by Moschos actually begins with the quire numbered $\zeta^{\prime}$ and ends with the quire numbered $\kappa \eta^{\prime}$, we should posit that its first $\left(\sigma \tau^{\prime}\right)$ and its two last quires $\left(\kappa \theta^{\prime}\right.$, $\left.\lambda^{\prime}\right)$ were subsequently lost.

Possessors: According to an inscription on the inside binding, the manuscript was bought for the prince de Stigliano on 31 November 1659 and was the twenty-fourth manuscript (?) of his collection ("Prince d. Astillana (de Stigliano)/emptus 31 nove. 1659. 24")..$^{73}$ The Parisinus Suppl. Gr. 307 (see below, under nr. 33) also comes from this collection.

Bibliography: RGK II 72 and 131; Golitsis 2016b.

\section{ROME, Biblioteca Angelica}

\section{Angelicus gr. 102 [R]}

Originally two distinct manuscripts: I. ff. 1-79, around 1490; II. ff. 80-367, around $1510^{74}$ Paper $\mathrm{mm} 330 \times 235 \quad$ ff. I $+367+$ II

Watermarks: I: “Anker im Kreis” (e.g. f. 79), very similar to Piccard IV 108 (Wien, 1490); II: “Anker im Kreis mit Stern” (e.f. f. 80, 367), similar to Piccard V 329 (Kaufbeuren, 1511).

72 On this scholar-scribe, professor of Greek at the University of Padua between 1475/76-1479, previously known as Georgios Alexandrou (or even as Alexandros Zenos), see Despotakis - Ganchou 2018. 73 As Thierry Ganchou tells me (per litteras), the prince of Stigliano in 1659 was Nicola Maria de Guzmàn Carafa (1638-1689).

74 Alessi (2009: 451) dates the manuscript in accordance with Egidio Canisio da Viterbo's interests to the end of the fifteenth century. The watermark (anchor in circle with a star, very similar to Piccard V 329), however, points to a date around 1510. 
Scribes: I. <Aristoboulos Apostoles>; II. <Giovanni Puccini>.

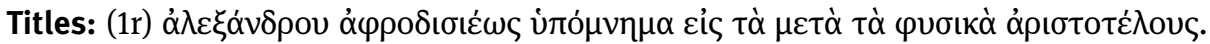

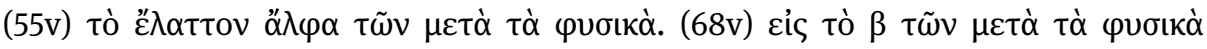

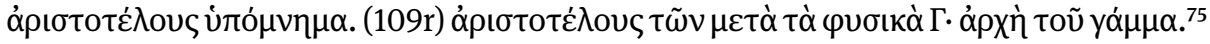

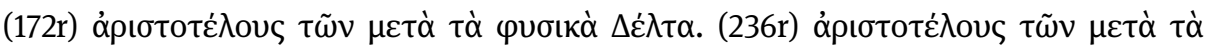

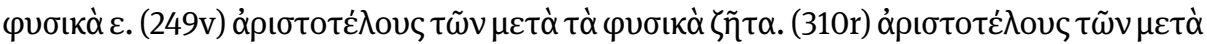

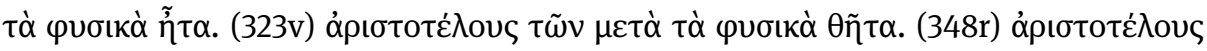
$\tau \tilde{\omega} \nu \mu \varepsilon \tau \dot{\alpha} \tau \grave{\alpha} \varphi v \sigma \iota \kappa \grave{~} i \tilde{\omega} \tau \alpha$.

Contents: Alexander, In Metaph. A-B 2 (996b 35). <Anonymus>, In Metaph. B 2 (996b 35)- $\Delta$. <Anonymus>, In Metaph. E. <Michael of Ephesus>, In Metaph. Z-I 6, 1056b

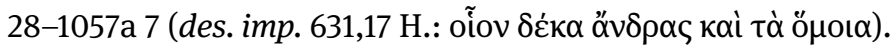

Text: This is a composite codex of two originally distinct manuscripts, produced for Egidio Canisio da Viterbo by the Florentine scholar Giovanni Puccini. It is one of the four manuscripts that Sepúlveda used for his translation. ${ }^{76}$ Puccini bound together an incomplete manuscript (ff. 1r-79v of the actual codex; it stops imperfectly on f. $77 \mathrm{v}$

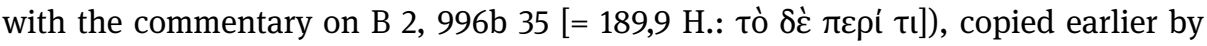
Aristoboulos Apostoles (1468/69-1535; attested in Florence in 1492), and a partial copy of the so-called "recensio altera" (ff. 80r-367r) made by himself. His text starts with

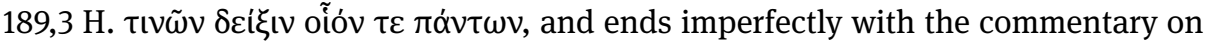

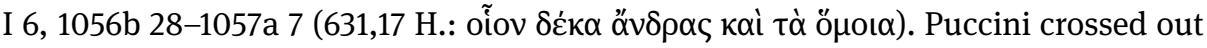

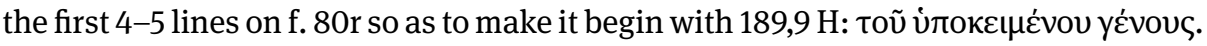
A note at the end of his copy (f. 367r: "in exemplari non sunt reliqua alexandri dicta") suggests that he used as a model a manuscript deriving from Ambrosianus F 113 sup. [F], which by that time was in Milan. Indeed, after the commentary on I 6, 1057a 7-17, F contains George Pachymeres' commentary on books K-N.

Possessors: Egidio Canisio da Viterbo (1469-1532).

Bibliography: RGK III 46 and 295; Alessi 2009; Golitsis 2016b.

\section{VATICAN, Biblioteca Apostolica Vaticana}

\section{Vaticanus gr. $1425[U]$}

ca. 1550 Paper $\mathrm{mm} 360 \times 245 \quad$ ff. II $+240+$ III

Scribe: $<$ Michael Maleas $>$.

75 The commentary starts on f. $108 \mathrm{v}$.

76 See below, Section 5.1 . 


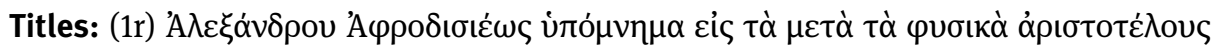

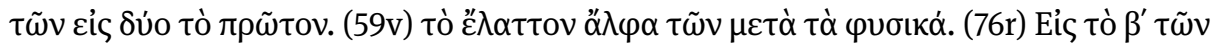

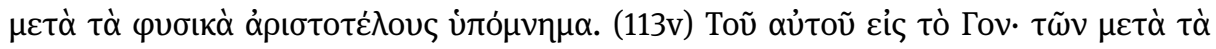

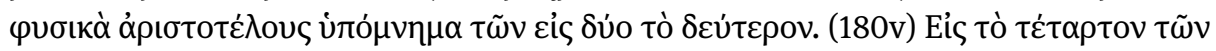
$\mu \varepsilon \tau \grave{\alpha} \tau \dot{\alpha} \varphi v \sigma ı \alpha \alpha ́$.

Contents: (1r-239v) Alexander, In Metaph. A- $\Delta$.

Text: As is suggested by the peculiarity of the titles and is established by omissions that can be explained only through codicological peculiarities in $\mathbf{0}$, this manuscript is a copy of $\mathbf{0}$, as is also $\mathbf{M}$, in which Maleas also took part.

Possessors: Cardinal Guglielmo Sirleto (1514-1585; his ex libris is found on f. Iv).

Bibliography: Golitsis 2016b.

\section{Vaticanus gr. $1621[\mathrm{Y}]$}

ca.1550 Paper $\mathrm{mm} 330 \times 245 \quad$ ff. II + $270+$ III

Scribe: One Greek scribe with two writing styles (cf. e.g. 99r).

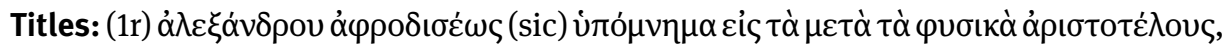

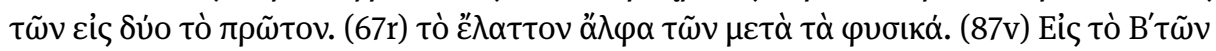

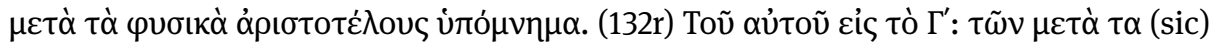

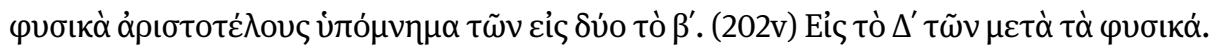

Contents: (1r-269r) Alexander, In Metaph. A- $\Delta$. Marginalia from a western scholar.

Text: This is also a copy of $\mathbf{O}$ and the first volume of an edition whose second volume (codex Vaticanus gr. 1620) contains, as $\mathbf{O}$ does, Michael's commentary on books I-N 4, $1092 \mathrm{a} 9$ (824,4 H.).

Bibliography: Golitsis 2016b.

\section{1-22. Vaticani Ottoboniani gr. 120-121 [ $\left.\mathrm{V}^{0}\right]$}

1605-1620 Paper mm $280 \times 200 \quad$ I. ff. II + 395 + I; II. ff. II + 456 + I

Watermarks: Bird in a circle with a star (e.g. II, f. 233), cf. Briquet 12211 (Rome, 15931599) and 12212 (Ferrara 1599); “Anker im Kreis mit Stern” (e.g. II, f. 236), similar to Piccard V 351 (Rome, 1593-1594).

Scribe: One unknown western scribe, who was active in Rome.

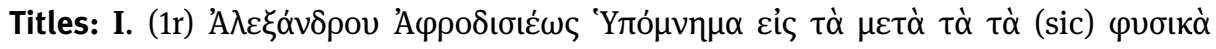

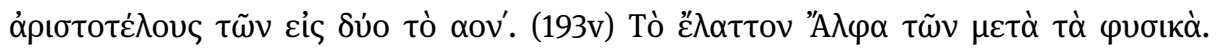




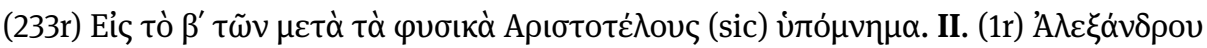

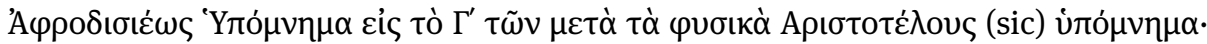

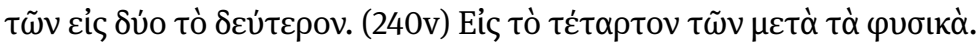

Contents: I. (1r-395v) Alexander, In Metaph. A-B. II. (1r-456v) Alexander, In Metaph. $\Gamma-\Delta$.

Text: This is a copy of $\mathbf{U}$ (Vat. gr. 1425) in two volumes.

Possessors: Marco Giovanni Angelo Altemps (1576-1620); cf. I, IIr: Alexandri Aphrodisei (sic) Commentarium in Metaphysicam Aristot. Pars Prima. Unus e codicibus centum bibliothecae Altempsianae a Paulo V. manu regia exceptis nunc vero a Ioanne Angelo ab Altaemps Duce propriis sumptibus fidelissime ex originalibus transumptis, ut bibliotheca praedicta tanto splendore iam decorata non careret. Graece 120; II, f. IIr: Alexandri Aphrodisei (sic) Commentarium in III Metaph. Arist. Lib. Graece. Unus ex codicibus Bibliothecae Altempsianae a Paulo Quinto manu regia exceptis nunc vero a Ioanne Angelo ab Altaemps duce propriis sumptibus ex originalibus fidelissime transumptis, ut bibliotheca praedicta tanto honore iam decorata non careret. 121.

Bibliography: Golitsis 2016b.

\section{Vaticanus Reginensis gr. 115 [V]}

Around $1530 \quad$ Paper $\quad$ mm $290 \times 205 \quad$ I. ff. II + $160+$ III

Scribe: <Aristoboulos Apostoles $>$.

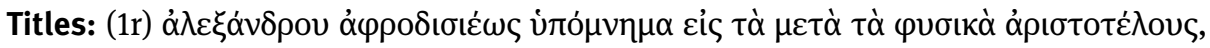

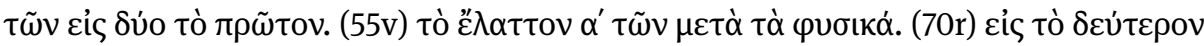

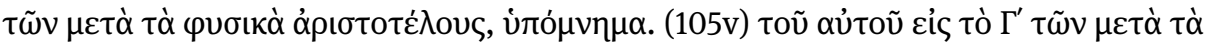

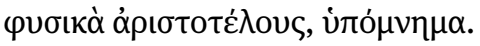

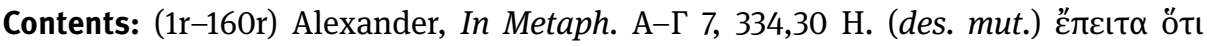

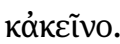

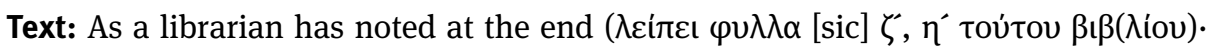

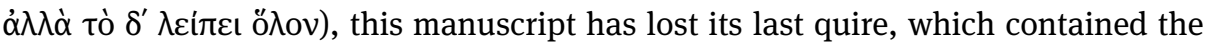
end of Alexander's commentary on book Gamma. In all probability, this second copy of Alexander's commentary by Aristoboulos Apostoles (the first is $\mathbf{R}$ ) was meant to supplement the codex Vaticanus Reginensis gr. 126, which contains the commentary on books $\Delta-\mathrm{I}$ of the so-called "recensio altera". ${ }^{77} \mathrm{It}$ is a direct copy of $\mathbf{A}$.

77 The original manuscript of Sebastianus Ducius, therefore, which should be dated because of its watermark around 1510, was split into what are now Par. Coisl. 328 and Vat. Reg. gr. 126 shortly thereafter. The fact that this manuscript, in its original state, precisely contained the commentary on books 
Possessors: Christina Queen of Sweden (1626-1689).

Bibliography: Stevenson 1888: 81 and 89; RGK III 46; Golitsis $2016 \mathrm{~b}$.

\section{VENICE, Biblioteca Marciana}

\section{Marcianus gr. Z 255 (=coll. 872) [Z]}

13th cent., end Bombycine $\quad \mathrm{mm} 246 \times 150 \quad$ ff. II + 130 (vacua: 129-130) + I

Scribes: A. A Constantinopolitan scribe using the Fettaugen style; B. f. 128v has been copied by a different contemporary scribe (pace Mioni), who was supposed to go on with the copy of Simplicius' commentary.

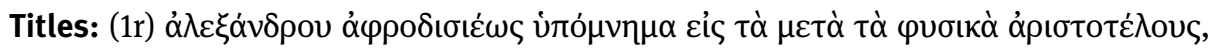

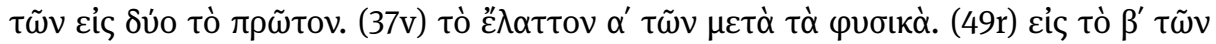

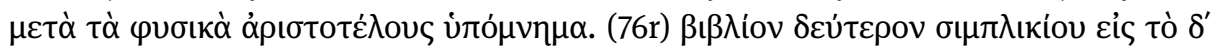

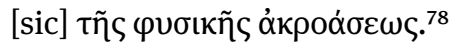

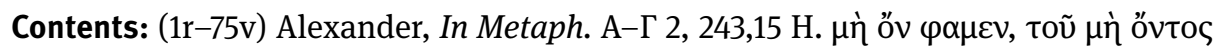

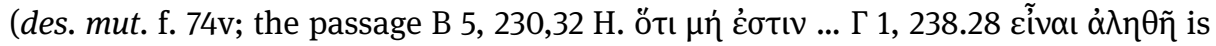
also missing due to a loss of folia between f. 72 and f. 73). (76r-128v) Simplicius, In

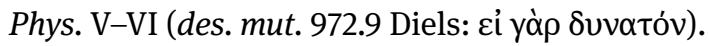

Text: As it has been pointed out by Dieter Harlfinger, an omission (restituted in

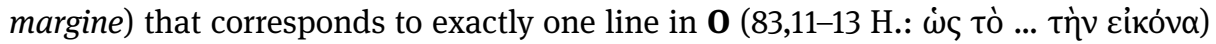

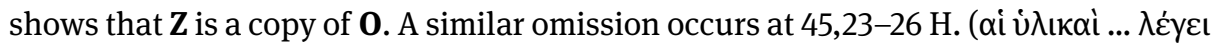
$\delta \dot{\varepsilon})$. The readings of $\mathbf{Z}$ occasionally help us to reconstruct readings that are no longer readable in $\mathbf{0}$. A later hand $\left(\mathrm{Z}^{2}\right)$ made some conjectures, e.g. at 70,12-13 H. $\chi \omega \rho i \zeta \zeta \iota ~ \alpha \tilde{u}$

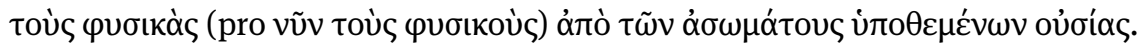

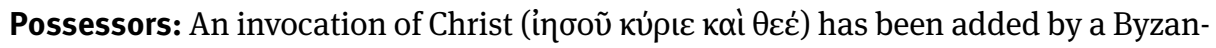
tine reader in the upper margin of $\mathrm{f}$. 48r. The codex belonged to the first lot of Bessarion's manuscripts that arrived in Venice in 1469.

Bibliography: Harlfinger 1975; Labowsky 1979: 172 ( $\mathrm{n}^{0}$ 377); Mioni 1981: 369; Golitsis 2016b.

\footnotetext{
A-I shows that it derives from the same model from which the second part of Angelicus 102 [R], copied by Giovanni Puccini, also derives. As textual criticism suggests, this nowadays lost manuscript was a copy of Ambrosianus F 113 sup. corrected according to Laurentianus 87,12 at the time the former was still in Florence (i.e. before 1491).

78 Simplicius' commentary actually starts with Physics V; this particular error also occurs in Marcianus gr. Z 226, a codex vetustissimus, suggesting that this part of $\mathbf{Z}$ belongs to its descent.
} 


\subsection{Pseudo-Alexandrea}

\subsection{1 'Recensio altera'}

\section{FLORENCE, Biblioteca Medicea Laurenziana}

\section{Laurentianus plut. 87,12 [L]}

11th cent., end $\quad$ Parchment $\quad$ mm $295 \times 1920 \quad$ ff. II $+603+\mathrm{I}$

Scribes: A: 1r-456r. B: 456v-485r. C: 485v-603r (Text). <Francesco Zanetti >: 485v-593r (commentary).

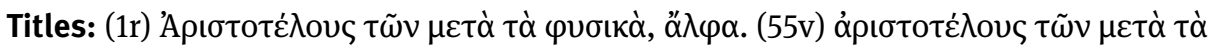

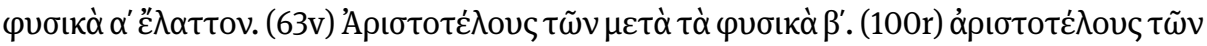

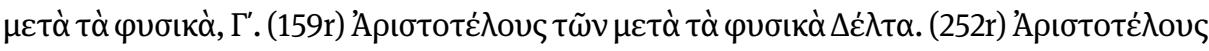

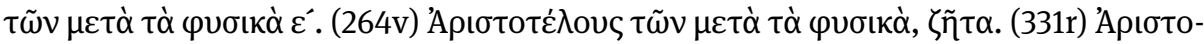

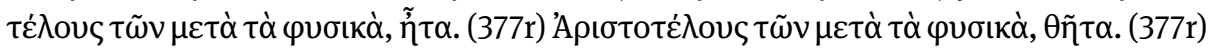

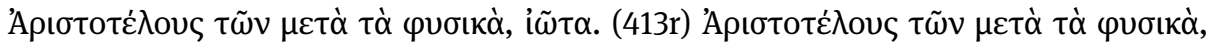

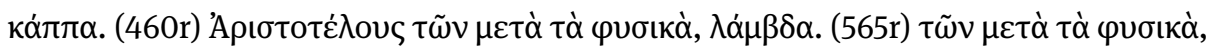
$\beta ı \beta \lambda$ iov I $\Gamma^{\prime}$ (sic). There are no titles for book $M u$ (503r) or for the books of the commentary. It is worth noticing that the titles of books Delta, Zeta, Eta, Theta, Iota and Lambda are written at the end of the preceding book, which might be an indication that the model used for the copy of the Metaphysics goes back to a papyrus edition.

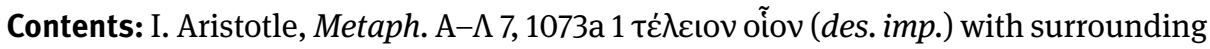
commentary by Anonymus, In Metaph. A-E and <Michael of Ephesus>, In Metaph. Z-

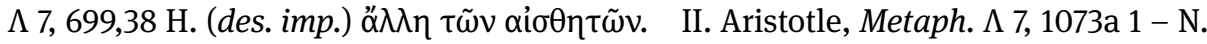
III. <Michael of Ephesus>, In Metaph $\Lambda$ 7, 699,38 H. - N 4, 1092a 9824.4 H. (des. imp.)

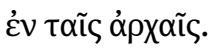

Text: A luxurious but incomplete Constantinopolitan manuscript from the end of the eleventh century, made by two contemporary scribes (A and B). It originally stopped imperfectly in the middle of a quire at f. 485r, with the commentary on $\Lambda 7,1072 \mathrm{~b} 30$ (= 699,38 H.). ${ }^{79}$ It also lacks the initial letters of each book (both of the Metaphysics and the commentary), which were to be added in rubro. A scribe from the fourteenth century (scribe C) completed the copy of the Metaphysics adding new quires from

79 There was once a manuscript which belonged to Giovanni Pico della Mirandola (see Kibre 1936: no. 730) and whose content was described in 1498 by Domenico Grimani, who acquired (a part of) Pico's collection of books, as "Alexandri Aphrodisei commentaria in .7. libros posteriores primae philosophie Aristotelis" (I thank Giovanna Murano for pointing this out to me). As the "last seven books" may only designate books E- $\Lambda$, Pico's manuscript must have been a copy of L. Pico probably wanted to have such a copy as a complement to D (Ambr. D 115 sup.). 
f. 490 onwards. At the occasion of the opening of the Biblioteca Laurenziana in 1571, Francesco Zanetti restored the missing bottom right corner of the first folio of the manuscript and added the missing commentary on book $N u$ (until 824,4 H.) using $\mathbf{O}$ as a model. Before Zanetti $\left[=\mathrm{L}^{3}\right]$ and probably before 1491 (when $\mathbf{F}$ was transported to Milan), the Dominican friar Zanobi Acciaioli $\left[=\mathrm{L}^{2}\right]$ reproduced on f. IIv the commentary that appears on the first page of the manuscript; for the missing part he used the Ambrosianus F 113 sup. [F], which he did not hesitate to emend. ${ }^{80}$ Acciaioli ascribed the anonymous commentary to Alexander (f. IIv: "Metaphysica aristotelis cum comento Alexandri in margine o(mn)ia in greco").

Possessors: This manuscript belonged to Cosimo de' Medici (1389-1464), who donated it to the monastery of San Marco after the foundation of its library in 1444; cf. f. IIv: "Iste liber est conventus sancti marci de florentia ordinis fratrum predicatorum quem dicto conventuj donavit Magnificus vir cosmas johanis de medicis civis clarissimus florentinus" (from the hand of Zanobi Acciaioli).

Bibliography: Bandini 1770: 392-393; Ullman - Stadter 1972: 255; Harlfinger 1975; Moraux et alii 1976: 302-304; Cavallo 2000; Gaspari 2010: 173; Golitsis 2016a; Golitsis 2016b.

\section{MILAN, Biblioteca Ambrosiana}

\section{Ambrosianus A 8 inf. (Martini-Bassi 786)}

16th cent., 3rd quarter Paper $\quad \mathrm{mm} 312 \times 212 \quad$ ff. VIII + 346 (vacua: 71v, 114v, $179 v, 181 v, 249 v, 346 v)+I V$

Watermarks: “Anker im Kreis”, similar to Piccard IV 31 (Milano, 1566).

Scribe: One Italian scribe, possibly Ottaviano Ferrari or Cesare Rovida.

Title: (1r) Graeci interpretis Commentarii in Aristotelis Metaphysica.

Contents: Anonymus, In Metaph. A-E. <Michael of Ephesus>, In Metaph. Z- $\Theta$ 1,

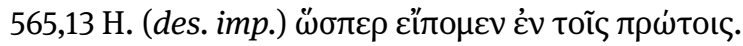

Text: This is an incomplete Milanese copy (it lacks the rubricatio) of F. The scribe recorded on $\mathrm{f}$. IVr the titles that should be added in red ink ("literis rubris..."), which

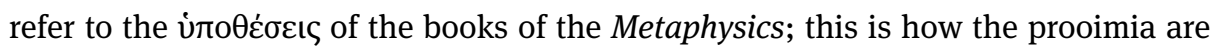

80 This has not been noticed by previous editors. Here is a list of peculiar readings of $\mathrm{L}^{2}$ and $\mathrm{L}^{3}: 2,3 \mathrm{H}$.

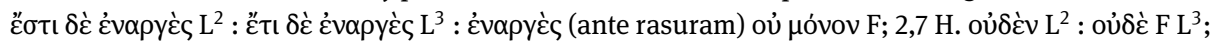

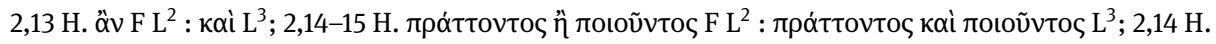

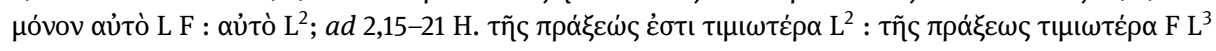
(but there was no place for copying $\dot{\varepsilon} \sigma \tau \mathrm{\tau}$ ). 
named in F. Moreover, the manuscript omits, as F does, some exegetical blocks (55.1757.34 H.; 58,26-31 H.) that are present in Laur. 87.12 [L] and in Parisinus Coisl. 328. ${ }^{81}$ Note finally that, had this manuscript been a copy of $\mathbf{L}$, it would not have been labelled "Graeci interpretis" but "Alexandri”, as surmised by Acciaioli.

Possessors: Cesare Rovida (1549-1592), who succeeded Ottaviano Ferrari (1518-1586) in the chair of natural philosophy at the University of Pavia.

Bibliography: Pasini 2004: 378; Martinelli Tempesta 2013: 146; Golitsis 2016b.

\section{Ambrosianus F 113 sup. (Martini-Bassi 363) [F]}

14th cent., 2nd quarter $\quad$ Paper $\quad$ mm $295 \times 200 \quad$ ff. V + 273 (vacua: $239-240)+$ IV

Watermarks: Two circles (f. 103r), similar to Briquet Nr. 3198 (Bergamo, 1337).

Scribes: A: 1r-240v; B: 241r-273v.

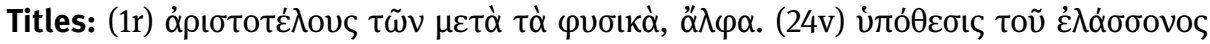

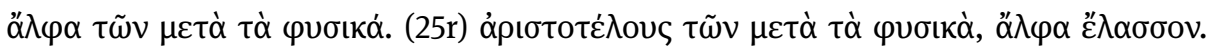
(29v) d’

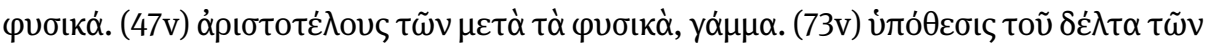

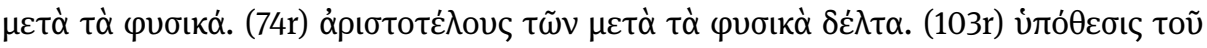

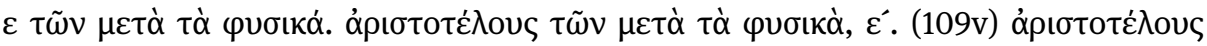

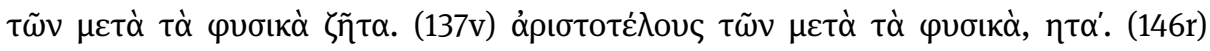

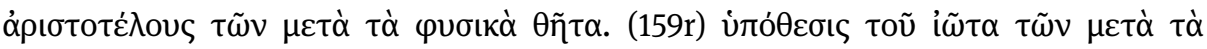

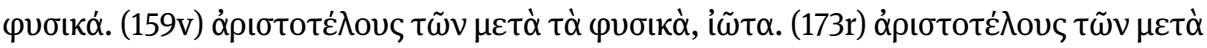

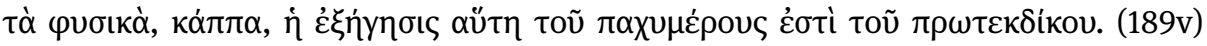

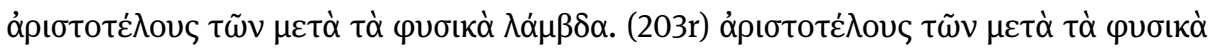

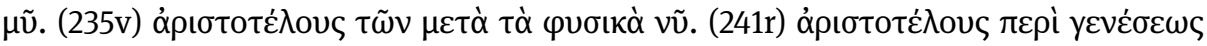

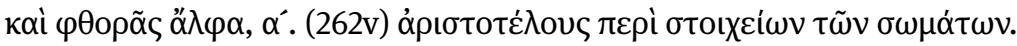

Contents: I. (1r-240v) Aristotle, Metaph. A-N with surrounding commentary by Anonymus, In Metaph. A-E, <Michael of Ephesus>, In Metaph. Z-I, and George Pachymeres, In Metaph. K-N. II. Aristotle, Gener. Corr. A-B alternatively with scho-

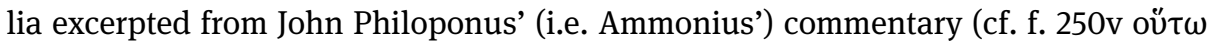

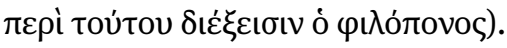

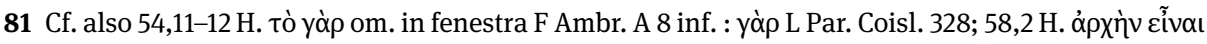

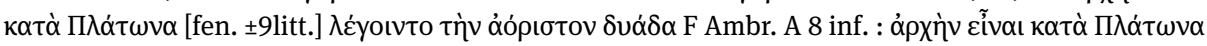

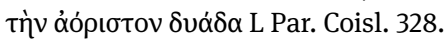


Text: This is a composite codex of two originally distinct manuscripts, containing respectively the Metaphysics and the On Generation and Corruption, copied by two differents scribes. The numbering of the quires stops with the Metaphysics (f. 233r: $\lambda \alpha^{\prime}$ ).

Possessors: Ioannes Argyropoulos (monocondylion on f. IVv); Demetrios Trachaniotes (subscription on f. IVv); Demetrios Chalcondyles (1423-1511; he added on f. IIr a short text that tacitly opposes the traditional division of Aristotle's natural philosophy by positing the treatise On the Soul in the third place, after the Physics and the

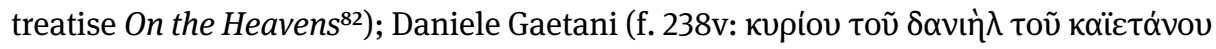

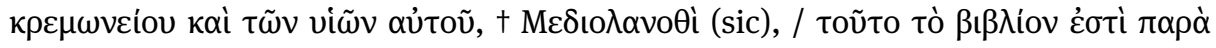

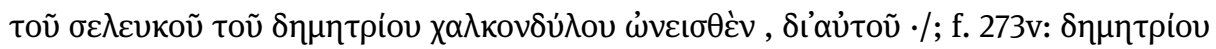

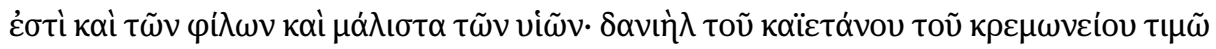

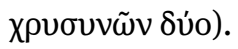

Bibliography: Harlfinger 1975; Rashed 2001; Golitsis 2016b.

\section{PARIS, Bibliothèque nationale de France}

\section{Parisinus Coislin gr. 328}

Around 1510 Paper mm $220 \times 190 \quad$ ff. III $+330(+107 a, 107 b,-65,116,287$, 288) + II

Watermarks: “Anker im Kreis mit Stern” (e.g. f. 324/329, 325/328), almost identical to Piccard V 350 (St. Veit, 1511).

Scribes: $<$ Sebastianus Ducius $>$. On the inside of the binding "Alexandri Aphrodisiensis In [del. quattor] tres primos libros Metaphysicorum codex p(et)ri se(guieri)”, in all probability by the hand of Athanasius Rhetor.

Titles: No titles due to lack of rubrication; (130r) $\beta$.

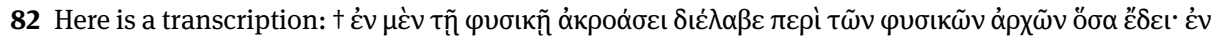

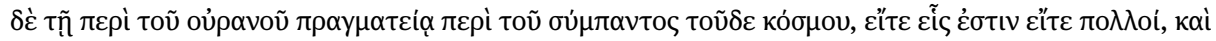

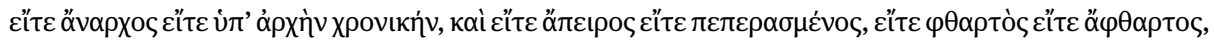

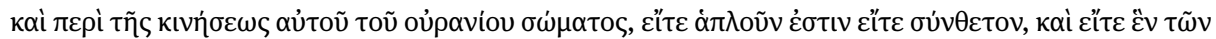

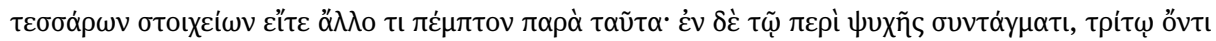

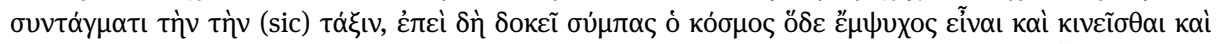

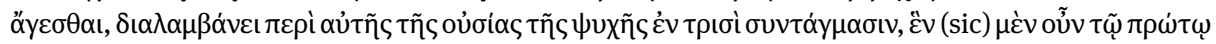

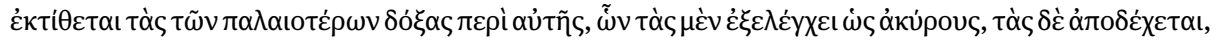

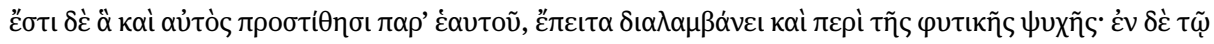

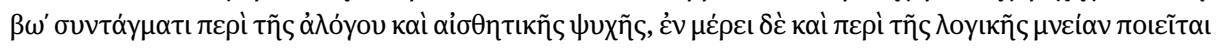

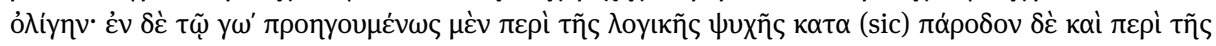

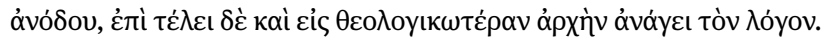


Contents: (1v-330v) Anonymus, In Metaph. A- - . On f. 330v, one reads the first words

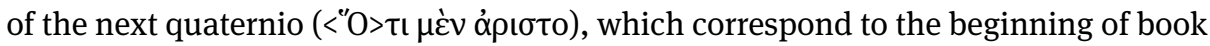
Delta.

Text: This is the first part of an edition that originally comprised the anonymous commentary on Metaphysics A-E continued by Michael of Ephesus' commentary on books Z-I; its second part is the actual Vaticanus Reg. gr. 126. It is a copy of a lost apographon of $\mathbf{F}$, in which Pachymeres' commentary on books $\mathrm{K}-\mathrm{N}$ had been left out and which was corrected with the help of $\mathbf{L}$, when both manuscripts were in Florence (that is, before 1491, when Demetrios Chalcocondyles transferred $\mathbf{F}$ to Milan). The second part of Angelicus 102 [R], copied by Giovanni Puccini, was also a copy of this lost manuscript. The Par. Coisl. 328 was also copied in Florence, if we trust Cypriani's report that a lot of Greek manuscripts was granted to him in Marseille by a Florentine man.

Possessors: This manuscript was among the lot of manuscripts brought to Cypriani in Marseille and bought by Pierre Séguier in 1645. As all manuscripts of Séguier, it subsequently belonged to Séguier's grandson Henri-Charles du Cambout, duc de Coislin (1665-1732) and later to the library of the Benedictines of Saint-Germain-des-Prés.

Bibliography: Devreesse 1945: III-IV ("Les manuscrits de Marseille”) and 314; Golitsis 2016b.

\section{VATICAN, Biblioteca Apostolica Vaticana}

\section{Vaticanus Reginensis gr. 126 [V']}

Around 1510 Paper $\mathrm{mm} 225 \times 195 \quad \mathrm{ff}$. I +352

Watermarks: “Anker im Kreis mit Stern” (e.g. f. 324/329, 325/328), almost identical to Piccard V 350 (St. Veit, 1511).

Scribes: <Sebastianus Ducius>. On the inside of the binding "Alexandri Aphrodisiensis In [del. quattor] tres primos libros Metaphysicorum codex p(et)ri se(guieri)”, in all probability by the hand of Athanasius Rhetor.

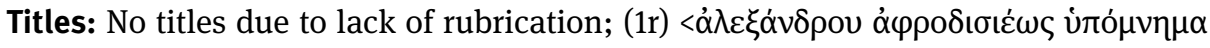

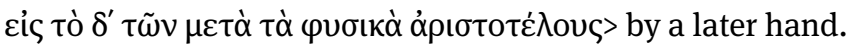

Contents: (1r-352v) Anonymus, In Metaph. $\Delta$-E. <Michel of Ephesus>, In Metaph. Z-I.

Text: This manuscript is the second part of an edition that originally comprised the anonymous commentary on Metaphysics A-E continued by Michael of Ephesus' commentary on books Z-I; its first part is the actual Par. Coisl. 328 (see description above). The missing initial part was later supplemented through Vat. Reg. gr. 115 [V].

Possessors: Christina Queen of Sweden (1626-1689).

Bibliography: Stevenson 1888: 81 and 89; RGK III 571; Golitsis 2016b. 


\subsubsection{Michael of Ephesus}

MILAN, Biblioteca Ambrosiana

\section{Ambrosianus Q 107 sup. (Martini-Bassi 698)}

Around 1580 Paper $\quad \mathrm{mm} 330 \times 230 \quad$ ff. I + 122 (vacua: $1-4,76 \mathrm{v}, 116 \mathrm{r}, 117 \mathrm{v}-$ 122) $+\mathrm{I}$

Watermarks: A crown with a star and letters GB, quite similar to fig. 8 in Sosower 2006. Scribe: $<$ Camillo Zanetti $>$.

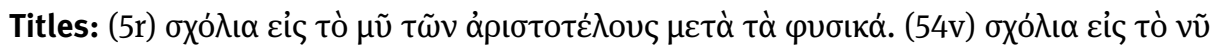

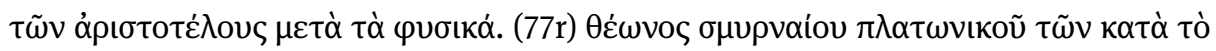

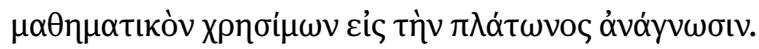

Contents: (1r-76r) <Michael of Ephesus>, In Metaph. M-N 5, 825,14 H. (des. imp.; in mrg.

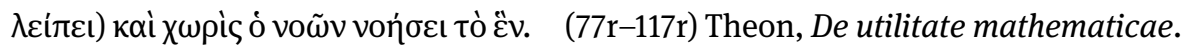

Text: This is one of the four manuscripts of Michael's commentary on books M-N 5, 825,14 H. copied by Camillo Zanetti - the other copies are Ambrosiani C 110 sup. and C 111 sup. and the Oxoniensis, Merton College 304. The production of numerous selfstanding copies of the commentary on books $\mathrm{M}$ and $\mathrm{N}$ by Zanetti may be related to the fact that Sepúlveda omitted these two books from his translation.

Bibliography: Martini - Bassi 1906: 805-806; Golitsis 2016b.

\section{PARIS, Bibliothèque nationale de France}

\section{Parisinus gr. 1875}

Around 1548 Paper $\quad \mathrm{mm} 348 \times 240 \quad \mathrm{ff} .[\mathrm{I}]+(1)+60+(1)+[\mathrm{I}]$

Watermarks: “Cercle surmonté d'un trait et d'une étoile” (e.g. ff. (1)/7); “cercle” (e.g. ff. 25/31 and 26/30) identical to "Cercle 52" Harlfinger (Venice, 1548), also used by Karnabakas for the Monacensis gr. 49; "Ancre” (e.g. ff. 48/55 and 56/(1)) identical to Ancre 56 Harlfinger (Venice, 1548).

Scribe: $<$ Petros Karnabakas $>$ (Karneades).

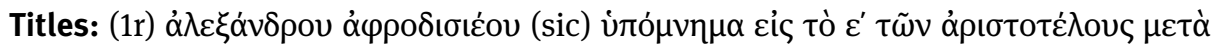

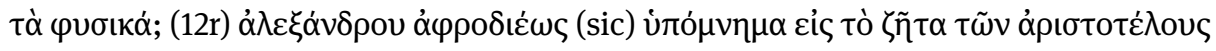

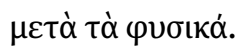

Contents: $(1 \mathrm{r}-11 \mathrm{v})<$ Anonymus>, In Metaph. E. $\quad(12 \mathrm{r}-60 \mathrm{v})<$ Michael of Ephesus>, In Metaph. Z. 
Text: This manuscript was copied in Venice, where Karnabakas and other professional scribes from Monemvasia established themselves after the conquest of their town by the Turks in 1540; it belongs to the descent of Parisinus gr. 1879.

Possessors: This manuscript later belonged to Jean-Baptiste Colbert (1619-1683; the shelfmark (1330) of Colbert's collection can be read on $\mathrm{f}$. 1r). It entered the Bibliothèque royale along with the library of Colbert in 1732.

Bibliography: RGK II 474; Groisard 2006-2009.

\section{Parisinus gr. 1879}

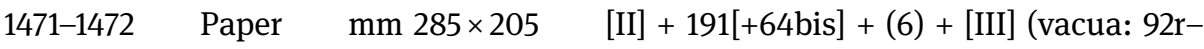
$95 v)^{83}$

Watermarks: “Chapeau” (e.g. ff. 31/40, 94/95 and 191/(197)) identical to Chapeau 12 Harlfinger (Venice, 1471); the same paper has been also used for P (Par. gr. 1878).

Scribe: <Andronicus Callistus >; marginal annotations and variant readings by $<$ Baldassarre Migliavacca $>$.

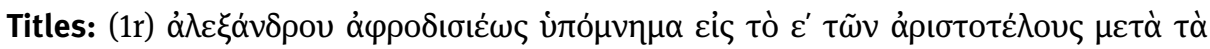

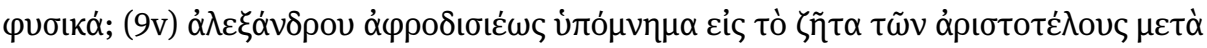

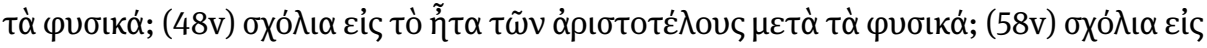

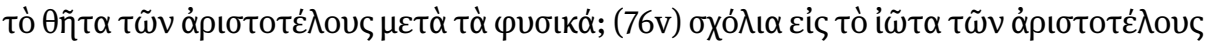

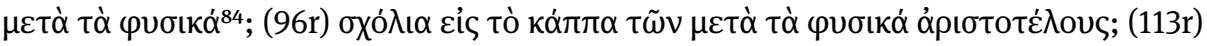

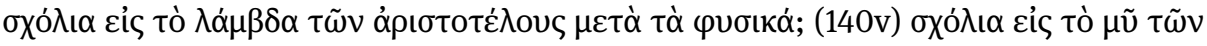

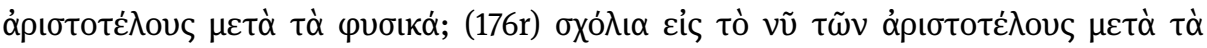

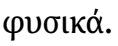

Contents: $(1 \mathrm{r}-9 \mathrm{v})<$ Anonymus>, In Metaph. E. (9v-191v) <Michael of Ephesus>, In

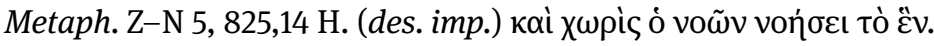

Text: This is the second tome of a complete edition, whose first tome is $\mathbf{P}$ (Par. gr. 1878), also copied (except the first three quires and a folio in the next quinio) by Andronicus Callistus. It seems that Callistus is at the origin of the attribution of the commentary on books E-N to Alexander. ${ }^{85}$ Although Baldassarre Migliavacca does not

83 These blank pages display the absence of commentary on book I 7-10.

84 The commentary stops with I 6 but there follows a lemma that corresponds to the beginning of I 7

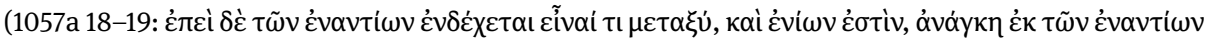

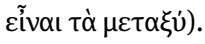

85 Par. gr. 1879 should also be taken into consideration in a new edition of this commentary. M (Monac. 81), which previous editors used, probably derives from Callistus' copy for books E- $\Theta$, which 
seem to have laid hands on $\mathbf{P}$, he did acquire Par. gr. 1879 , as is shown by the variant readings and the annotations added from his hand on several folia. ${ }^{86}$ The absence of variant readings from book Kappa onwards suggests that Migliavacca used for his collation F (Ambr. F 113 sup.), which transmits for books K-N Pachymeres' commen-

are not contained in $\mathbf{0}$. Thus, the previous editors may have unconsciously integrated Callistus' interpolations.

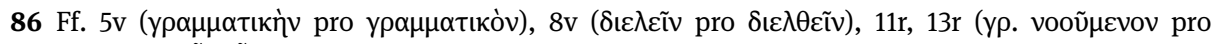

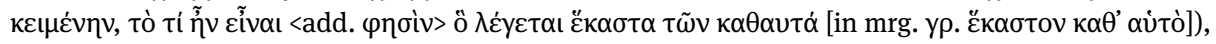
$14 \mathrm{r}, 14 \mathrm{v}, 15 \mathrm{r}, 15 \mathrm{v}, 17 \mathrm{r}, 19 \mathrm{v}, 21 \mathrm{r}, 25 \mathrm{r}, 25 \mathrm{v}, 32 \mathrm{r}, 34 \mathrm{v}, 37 \mathrm{r}$ (restitution of two passages omitted propter ho-

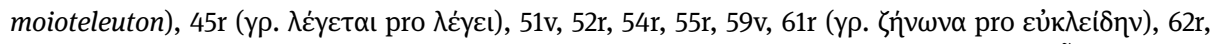

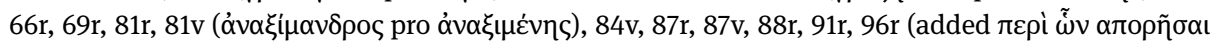

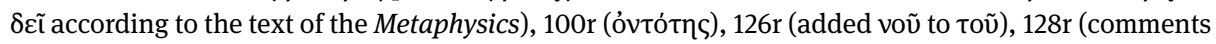

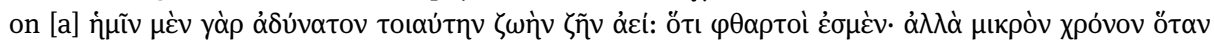

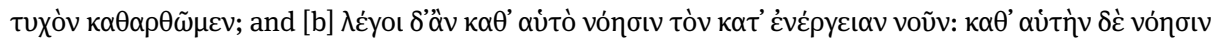

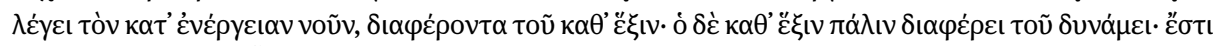

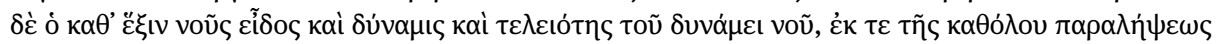

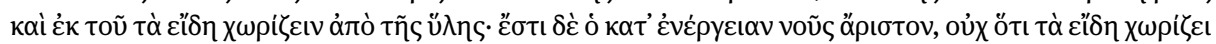

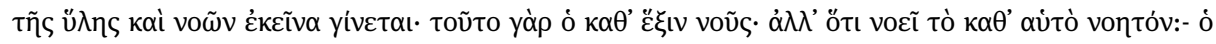

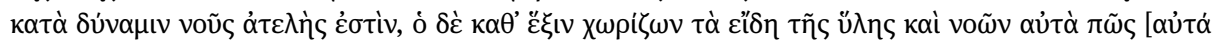

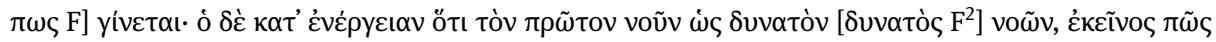

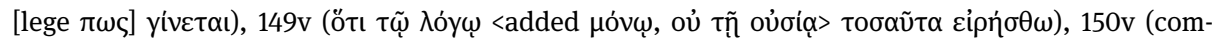

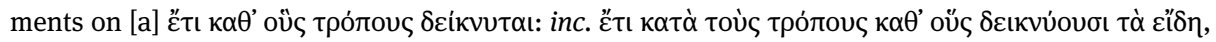

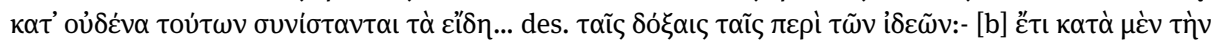

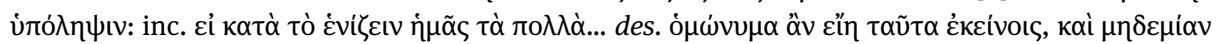

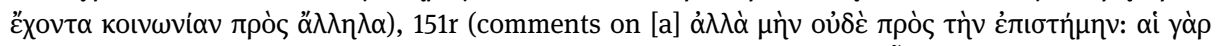

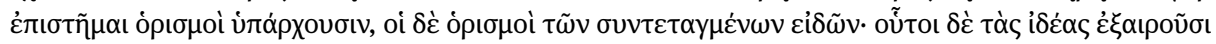

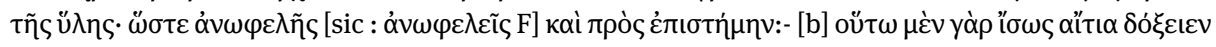

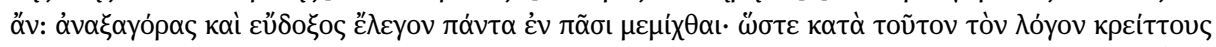

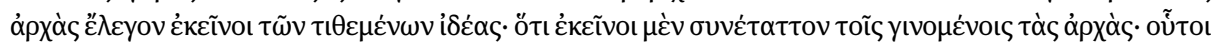

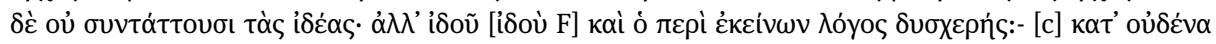

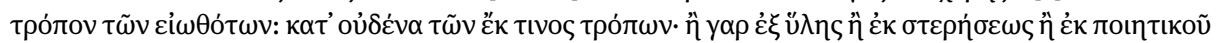

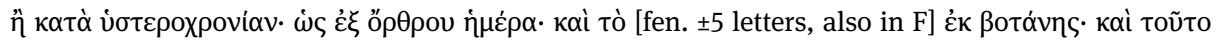

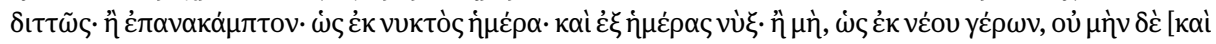

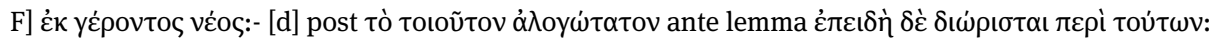

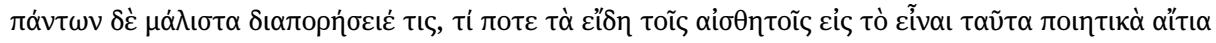

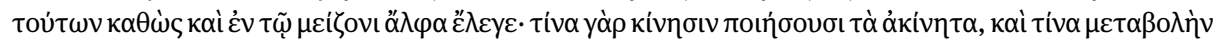

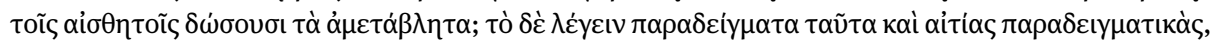

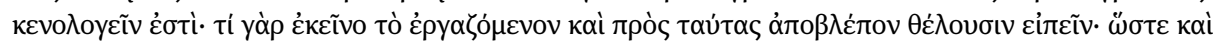

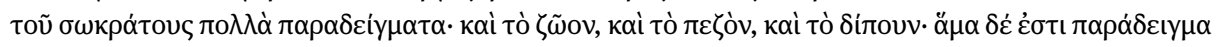

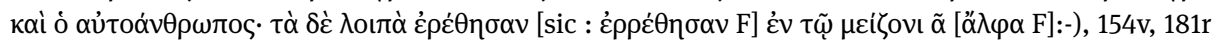

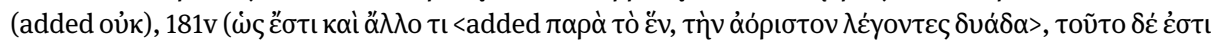

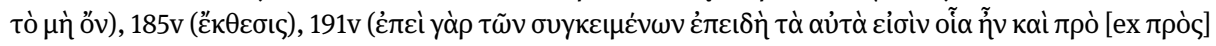

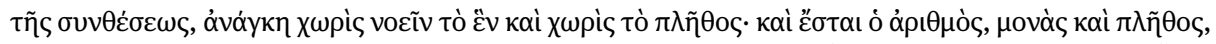

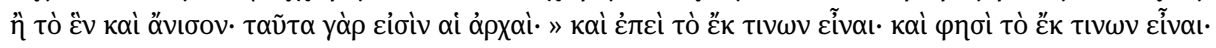

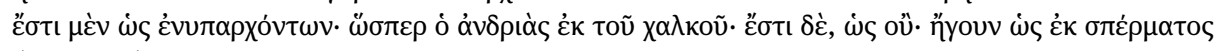
ơvos. oủ yàp). 
tary and which Migliavacca also used for the variant readings recorded on $\mathbf{D}(\mathrm{Ambr}$. D 115 sup.). ${ }^{87}$

Possessors: Baldassarre Migliavacca; Gian Francesco d'Asola (although erased, his ex-libris is still visible on f. 1r). Although the Parisini gr. 1878 and 1879 stem from Callistus' collection, they reached Paris by different channels. A pinax is added on f. IIv

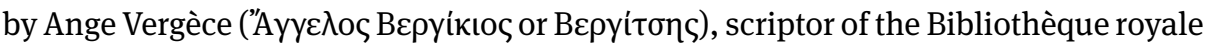
de Fontainebleau.

Bibliography: RGK II 25; Cataldi Palau 1998; Groisard 2006-2009; Orlandi 2014: 167169; Golitsis 2016b.

\section{Parisinus Suppl. gr. 307}

Around 1504 Paper $\quad \mathrm{mm} 333 \times 228 \quad$ ff. V $+169+\mathrm{V}$

Watermarks: “Dreiberg”, identical to Dreiberg 90 Harlfinger (1504).

Scribe: One unknown scribe of the late fifteenth-early sixteenth century.

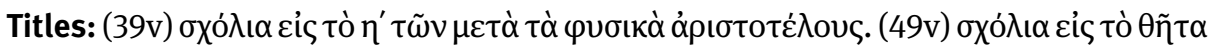

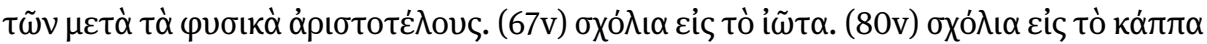

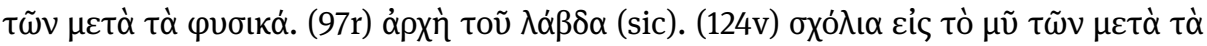

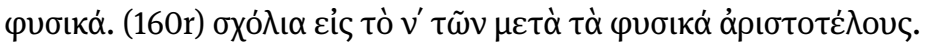

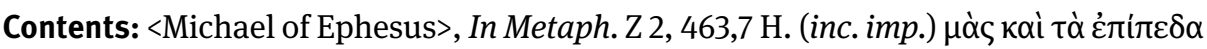

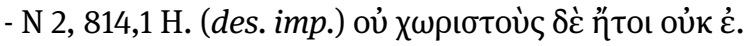

Text: The titles of the books, in particular of book Lambda, suggest that this manuscript, for chronological reasons, is a copy of the manuscript, from which $\mathbf{E}^{\mathbf{a}}$ and $\mathbf{E}^{\mathbf{b}}$ (Mut. gr. 208 and 214) also derive.

Possessors: According to an inscription on the inside binding, the manuscript was bought for the prince de Stigliano, i.e. Nicola Maria de Guzmàn Carafa, from a certain Boitier on 31 December 1659 and was numbered, together with the Par. Suppl. Gr. 306 $\left[\mathbf{P}^{\mathbf{s}}\right]$, as the twenty-fourth manuscript (?) of Guzmàn's collection ("Prince d. Astillana/ Emptus a Boitier 31 decembris 1659. 24”).

87 This is confirmed by the variant reading recorded by Migliavacca on f. 62r: whereas Callistus'

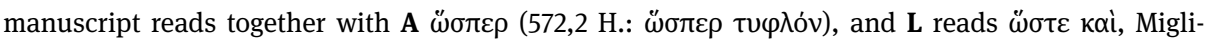

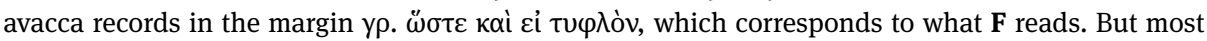
importantly, Migliavacca has reproduced on f. 66r a comment by George Pachymeres (inc. Toṽto tò

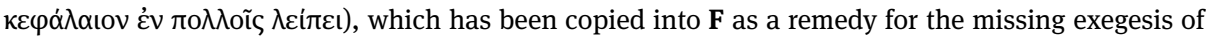
Michael on $\Theta$ 6; see Golitsis 2014: 223-224 [= Golitsis 2016: 584]. Migliavacca's additions on books Lambda (128r) and $M u(150 \mathrm{v}-151 \mathrm{r}, 154 \mathrm{v})$ also derive from Pachymeres' commentary; cf. F, f. 195v, 208v209v, 210r. 


\section{VATICAN, Biblioteca Apostolica Vaticana}

\section{Vaticanus gr. 1776 (ff. 31-94)}

1489 Paper mm $276 \times 203 \quad$ ff. 31r-93r (vacua: 93v, 94)

Watermarks: “Arbalète” (e.g. f. 88, 93), identical to Arbalète 31 Harlfinger (1489).

Scribe: $<$ Demetrios Moschos $>$.

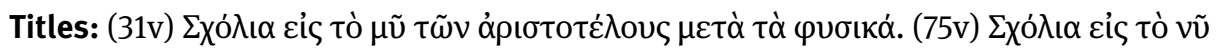

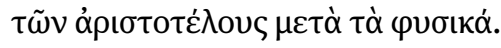

Contents: (31r-94v) <Michael of Ephesus>, In Metaph. $\Lambda$ 10, 720,24 H. (inc. mut.) عi்

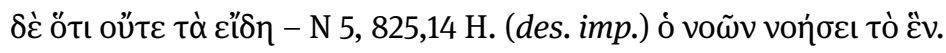

Text: These eight quires, numbered $\kappa \gamma^{\prime}-\lambda^{\prime}$, are what remains from the second volume of an edition, whose first volume is $\mathbf{D}(A m b r$. D 115 sup.). They are bound together with two different codicological unities (1r-29v: John Pediasimos, In Anal. Post.; 95r-127v: Eusebius, De laudibus Constantini).

Bibliography: RGK III 165; Golitsis 2016b.

\section{Vaticanus Reginensis gr. 109}

15th cent., end Paper mm 320 × 200 ff. 1-195 (vacua: 94-96)

Watermarks: Arbalest with a star (ff. 94-96 [last folios of a quire]), unknown.

Scribes: A. $1-22 \mathrm{v}^{30}$; B. $22 \mathrm{v}^{30}-193 \mathrm{r}$.

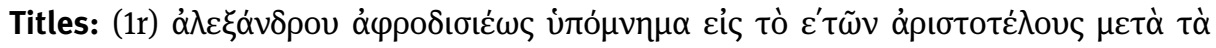

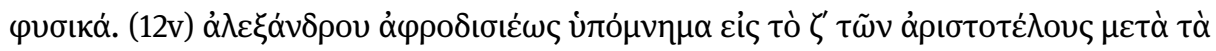

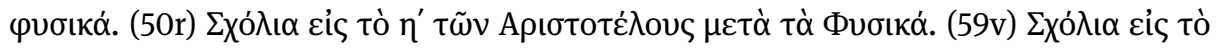

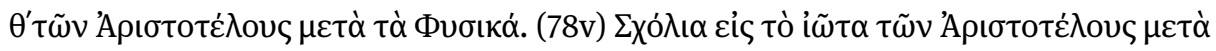

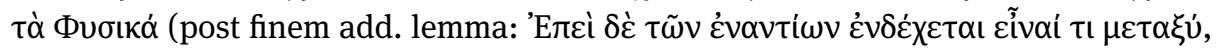

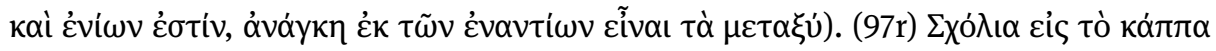

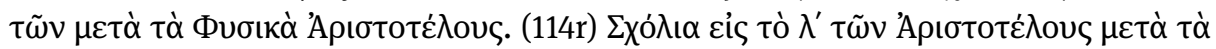

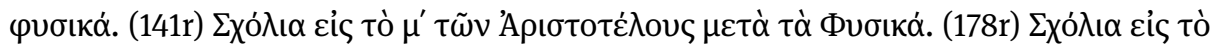

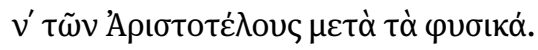

Contents: <Anonymus>, In Metaph. E. < Michael of Ephesus>, In Metaph. Z-N 5, ca. $825,22 \mathrm{H}$. 


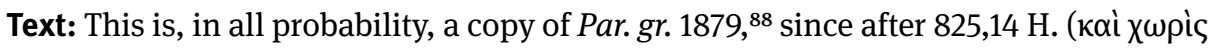

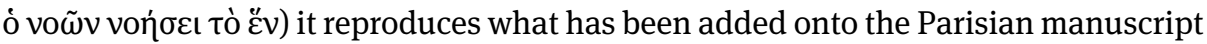

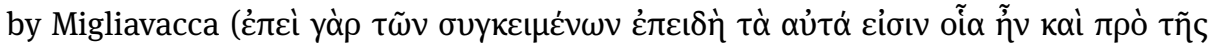

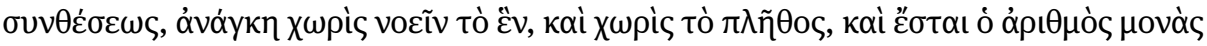

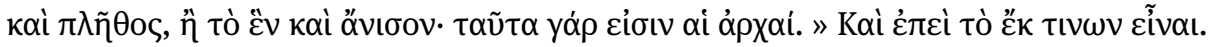

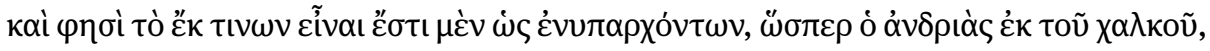

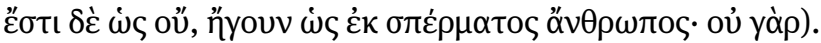

Bibliography: Golitsis 2016b.

\subsection{Pseudo-Philoponea}

\section{MILAN, Biblioteca Ambrosiana}

\section{Ambrosianus C 254 inf. (Martini-Bassi 894)}

16th cent., middle Paper $\quad \mathrm{mm} 346 \times 240 \quad$ ff. II +295 (vacua: $87 v, 156-158)+$ II

Watermarks: A tree in a circle with a star, very similar to Zonghi Nr. 1733 (1546); “Anker im Kreis mit similar”, Stern to Piccard Online Nr. 119123 (1555).

Scribe: Four unknown scribes (A. 1r-80v; B. 81r-110v; C. 111r-152r, 159r-295v; D. 152v155r).

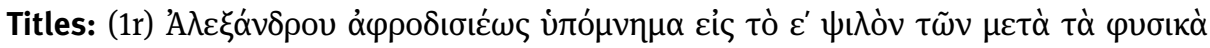

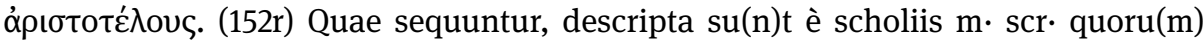

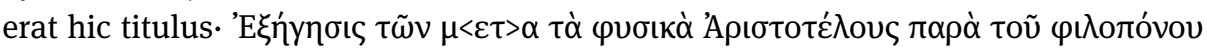

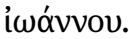

Contents: (1r-152r) <Anonymus>, In Metaph. E + <Michael of Ephesus>, In Metaph. Z-

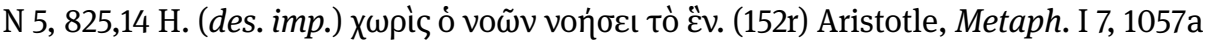

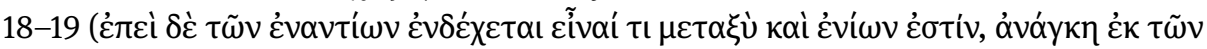

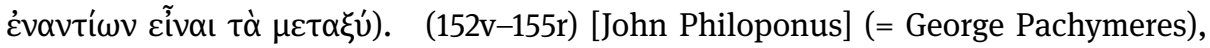

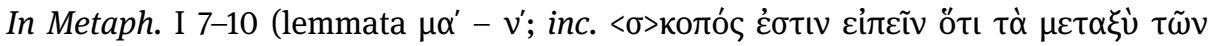

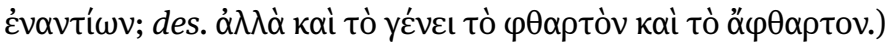

Text: The presence of the first lemma of Metaph. I 7 suggests that this manuscrpit derives from Par. gr. 1879. The scholia from pseudo-Philoponus' commmentary were probably copied from manuscript of Francesco Patrizzi (see the description of the fol-

88 And not of a common lost model, as I have suggested in Golitsis 2016b. 
lowing codex), who translated pseudo-Philoponus' commentary into Latin. They were meant to supplement the commentary of Michael, who did not comment on I 7-10. Pinelli, who also owned D, which contains Alexander's commentary on Metaph. A- $\Delta$, was obviously interested in having a complete commentary on the Metaphysics.

Possessor: Gian Vicenzo Pinelli (1535-1601).

Bibliography: Martini - Bassi 1906: 996.

\section{Ambrosianus C 268 inf. (Martini-Bassi 908)}

16th cent., 3rd quarter Paper $\quad \mathrm{mm} 331 \times 234 \quad$ ff. IV + $347(+152 \mathrm{a}, 167 \mathrm{a}$; vacua: 152a, 283v-287, 343) + III

Watermarks: A crown with a star, unknown (cf. Zonghi Nr. 274 [1555]).

Scribes: I. Manuel Moros. II. Unknown scribe.

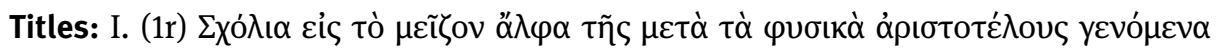

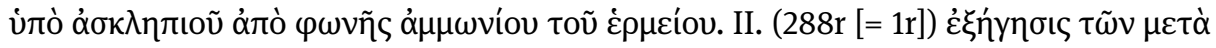

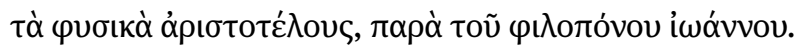

Contents: I. (1r-283r) Asclepius, In Metaph. A-Z. II. 288r-342r (= 1r-55r) [John Philo-

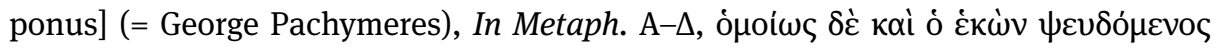

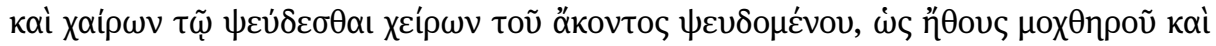

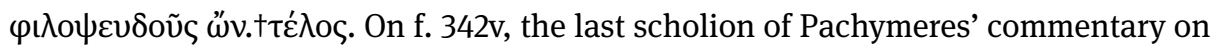

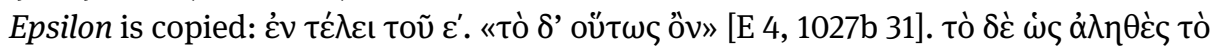

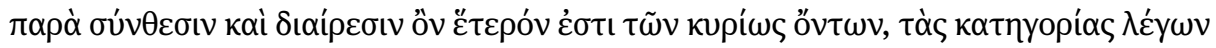

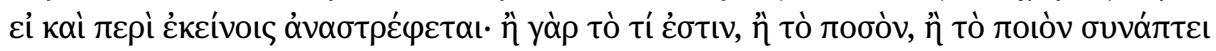

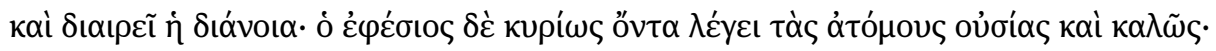

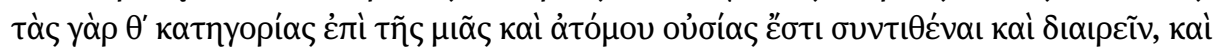

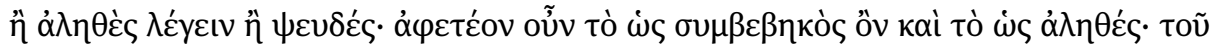

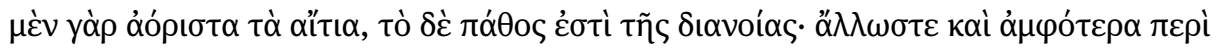

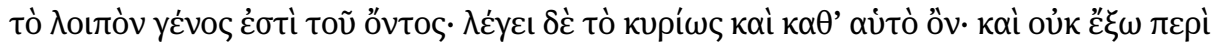

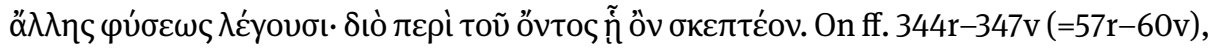
"ex libro Francisci Patritij. schol·a in fine(m) libri N Metaph Arist. ${ }^{\text {lis }}$ in $\mathrm{q}^{\mathrm{am}}$ partem meus Alex ${ }^{\mathrm{r}}$ no(n) habebat”.

Text: These are two codicologically distinct manuscripts copied for Pinelli. The scholia on book $\mathrm{Nu}$ copied from "Francesco Patrizzi's book" were meant to supplement the missing last part of Pinelli's copy of "Alexander's" commentary, i.e. Ambr. C 254 inf. Patrizzi's book was, in all probability, codex Scorialensis $\Gamma$. III. 19,89 destroyed in the

89 See De Andres 1968: 86-87 (ms. nº 188). 
fire of 1651. As this manuscript was transferred to Spain in $1575,9^{90}$ it provides a terminus ante quem for the production of Pinelli's manuscript.

Possessor: Gian Vicenzo Pinelli (1535-1601).

Bibliography: Martini - Bassi 1906: 1020-1021.

\subsection{Excerpta}

\section{MILAN, Biblioteca Ambrosiana}

\section{Ambrosianus D 473 inf. (Martini-Bassi 979), ff. 1-19}

16th cent., beginning Paper $\quad \mathrm{mm} 368 \times 425$

Watermarks: Balance in a circle with a star, similar to Mazzoldi Nr. 331 (1505).

Scribe: <Michael Damascenus> (identified by Stefano Martinelli Tempesta).

Titles: (1r) Philoponi fragm · comm • in finem libri Z $\Theta$ et principiu(m) I metaph. (7v)

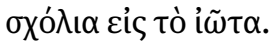

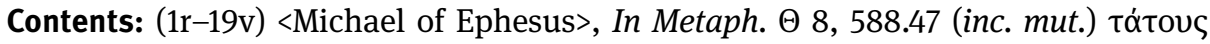

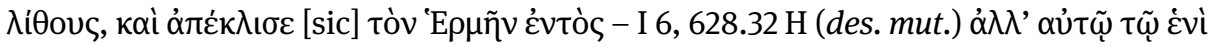

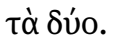

Text: These are two and a half quires $\left(\eta^{\prime}-\theta^{\prime}\right)$ of a manuscript that must have originally contained the commentary from book Epsilon onwards. The attribution to (pseudo-)Philoponus (f. 1r), probably caused by the fact that Pachymeres (= pseudoPhiloponus) heavily relies on Michael, is false.

Possessor: Gian Vicenzo Pinelli (1535-1601).

Bibliography: Martini - Bassi 1906: 1060-1062.

\section{Ambrosianus I 117 inf. (Martini-Bassi 1061)}

16th cent., 2nd quarter Paper mm 325 × 225 ff. 1-48 (vacua: 28-29, 38-39, 48)

Watermarks: “Chapeau” (e.g. f. 29r), similar to Chapeau 75 Harlfinger (Rome, 1537). 
Scribe: One unknown scribe.

Titles: (27v) E scholiis (sup. lin. manuscriptis) in aristot. metaphisica quorum est

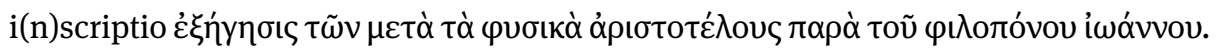

Contents: [John Philoponus] (= George Pachymeres) In Metaph. N 6, 1093a 26: «ő $\mu$ oı

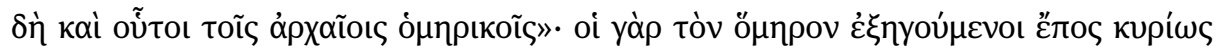

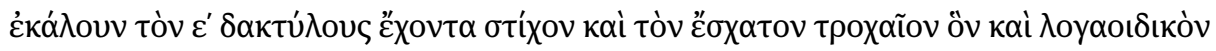

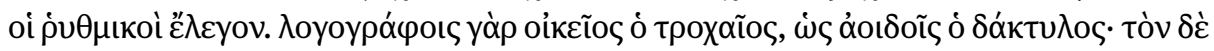

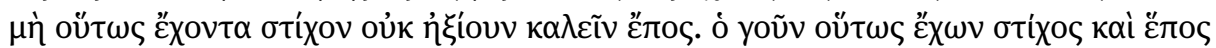

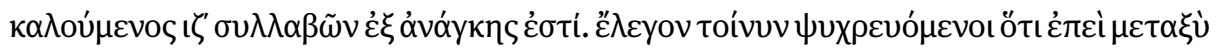

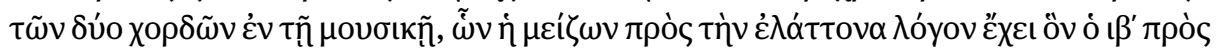

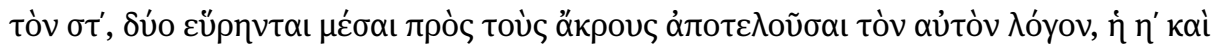

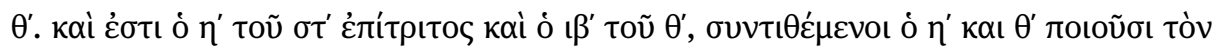

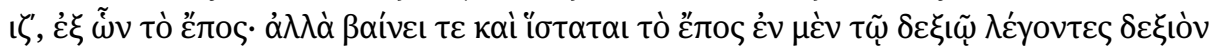

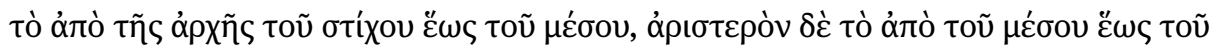

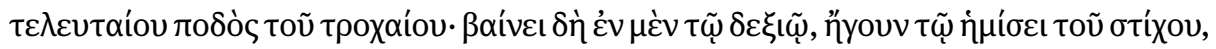

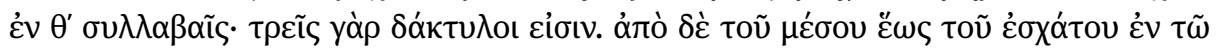

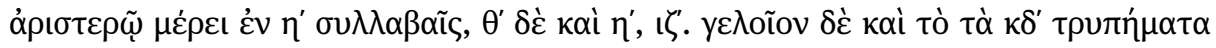

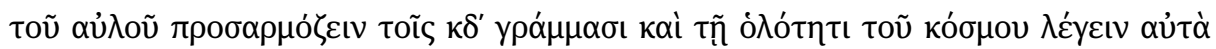

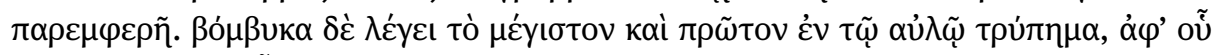

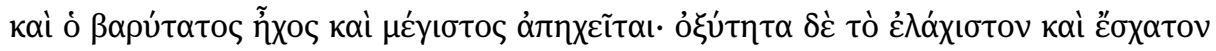

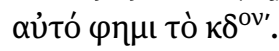

Bibliography: Martini - Bassi 1906: 1132-1135.

\section{NAPLES, Biblioteca statale oratoriana dei Gerolamini}

\section{Oratorianus C. F. 2. 11 (olim XXII.1)}

1450-1460 Paper mm $290 \times 200 \quad$ ff. 474

Scribes: Eight scribes, among them Anonymus 40 Harlfinger (who copied the excerpt of Michael's commentary), Antonios Pyropoulos and John Dokeianos.

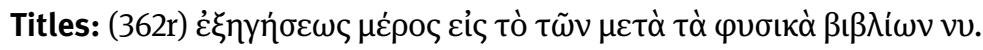

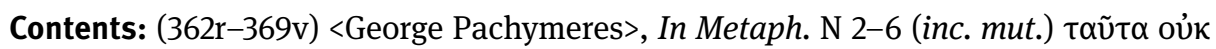

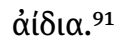

91 Martini 1896 misleadingly identifies this text with Michael’s commentary $(804,34-837,11$ H.). 
Text: This is a part of a miscellany that belonged to John Dokeianos, who was active at the Patriarchal School of Constantinople in the third quarter of the fifteenth century.

Possessor: John Dokeianos (ex-libris in the inside binding: $\dot{\eta} \beta i \beta \lambda$ oৎ $\pi \varepsilon \dot{\lambda \varepsilon \iota) .}$

Bibliography: Martini 1896: 397-415; Harlfinger 1971a: 420; Pontani 2014: 26-30.

\section{VATICAN, Biblioteca Apostolica Vaticana}

\section{Ottobonianus gr. 109}

16th cent., middle $\quad$ Paper $\quad \mathrm{mm} 340 \times 230 \quad$ ff. $(3)+[\mathrm{I}]+107$ (vacuum: 106v) + (2)

Scribes: One unknown western scribe. Pinax (f. I) by Ioannes Honorius (scriptor of the Vatican Library from 1535 to 1563).

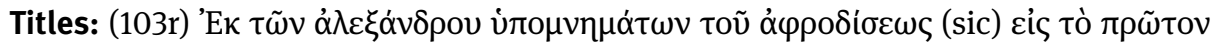

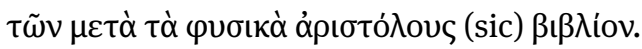

Contents: (103r-106r) Alexander, In Metaph. A 4, 985b 20 - 5, $986 \mathrm{~b} 8$ (= 37,2-42,17 H.

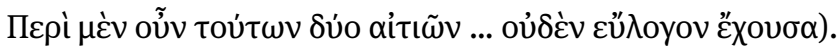

Possessor: Marco Giovanni Angelo Altemps (†1620) (f. IIr: "Ex codicibus Ioannis Angeli Ducis ab Altaemps”). 


\section{Eliminatio codicum}

\subsection{The three families}

The manuscripts of Alexander's commentary on the Metaphysics can be distributed into three families in accordance with their (ultimate) dependence on $\mathbf{A}, \mathbf{O}$ or $\mathbf{P}$. Although $\mathbf{P}$ is substantially not an independent manuscript, because of its numerous interpolations it is a sort of recensio of Alexander's commentary and has its own descendence, small in number, which is easily recognizable. On the other hand, because of its large dimensions and its small script, $\mathbf{0}$ is a manuscript difficult to copy and was also not particulary proliferous. The majority of manuscripts through which Alexander's commentary circulated in late Byzantium and in Italy (and later in Spain and in France) sprang from $\mathbf{A}$.

\subsubsection{The descent of $A$}

The manuscripts stemming from $\mathbf{A}$ have its significant omissions, which we quoted earlier. ${ }^{1}$ We may quote here some further errors that originated in $\mathbf{A}$ and were proliferated in its descendants:

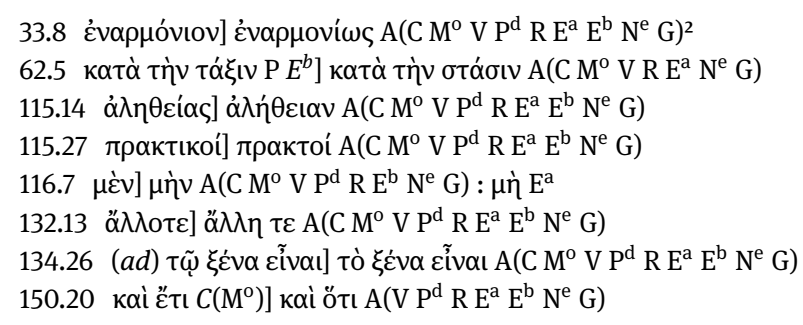

$\mathbf{C}$ and its apographon $\mathbf{M}^{\mathbf{0}}$ are the sole copies made in Byzantine East. ${ }^{3}$ The rest of the manuscripts that belong to the descendence of $\mathbf{A}$ were produced in Italy, except for two

1 See above p. xlvii, n. 1

2 N.B.: Manuscripts put in (...) stem, either directly or indirectly, from the manuscript that precedes the brackets. Manuscripts put in italics deviate from their main source through either conjecture or collation (to so-called “contamination”) with another manuscript. I present more cases in Golitsis 2016b: Appendix II.

3 On the textual affiliation of $\mathbf{C}$ see above, p. cxiii-cxiv. Here are some readings peculiar to $\mathbf{C}$ and $\mathbf{M}^{\mathbf{o}}$ :

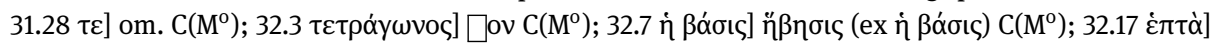

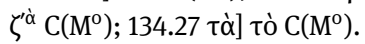


late copies of the late sixteenth and the seventeenth century, namely $\mathbf{G}$ and $\mathbf{P}^{\mathbf{c}}$, which were produced by Andreas Darmarios and Honorat in Granada and Paris respectively. ${ }^{4}$

Two of the manuscripts produced in Italy, namely $\mathbf{P}^{\mathbf{d}}$ and $\mathbf{R}$, which were copied toward the end of the fifteenth century by an anonymous scribe and Aristoboulos Apostoles respectively, stop imperfectly with 189,9 H. Apostoles was living in Florence around 1492 and his manuscript (R) was later completed by the Florentine scholar Giovanni Puccini. It is thus possible that both $\mathbf{P}^{\mathbf{d}}$ and $\mathbf{R}$, as well as their lost model, ${ }^{5}$ say $\mathbf{\kappa}$, were by that time in Florence:

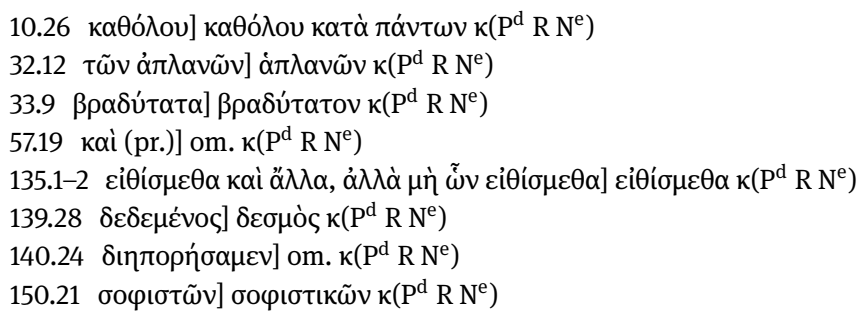

Several years later, Apostoles made another copy of Alexander's commentary (books $\mathrm{A}-\Gamma),{ }^{6}$ namely $\mathbf{V}$, which does not share the peculiar readings of $\mathbf{\kappa}$ and was in all probability directly copied from $\mathbf{A},{ }^{7}$ before the latter manuscript was acquired in Venice by Girolamo Fondulo. ${ }^{8}$ Not only $\mathbf{V}$ but also $\mathbf{\kappa}$, which was apparently an unfinished copy of $\mathbf{A}$, were made after Chortasmenos' interpolations. ${ }^{9}$

By contrast, two further manuscripts copied in Rome at roughly the same time, namely $\mathbf{E}^{\mathbf{a}}$ and $\mathbf{E}^{\mathbf{b}}$, do not integrate Chortasmenos' interventions. They are copies,

4 On the textual affiliation of these two manuscripts, see above, p. xcvi and cxvi.

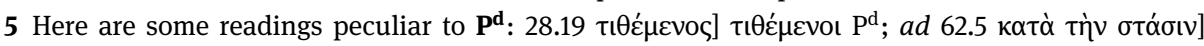

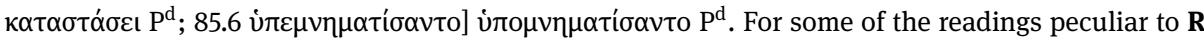
see next page.

6 This manuscript was meant as a supplement to Vat. Reg. gr. 126; see above, p. cx.

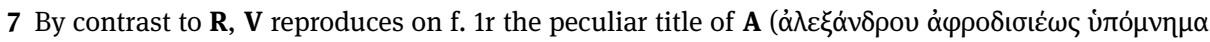

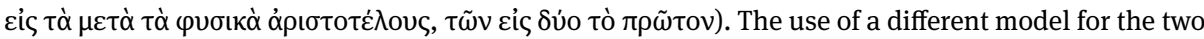

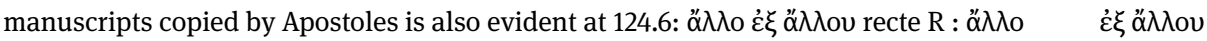

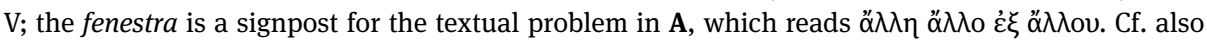

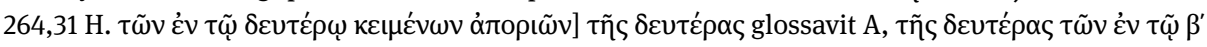

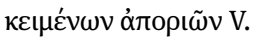

8 Aristoboulos Apostoles himself lived his last years in Venice, where he died in 1535.

9 Thus, Chortasmenos' interventions in A reappear in all $\mathbf{P}^{\mathbf{d}}, \mathbf{R}$ and $\mathbf{V}$. Cf. characteristically 153.12-13

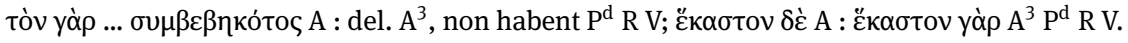


therefore, of a Palaeologan copy of A, namely $\boldsymbol{\lambda} \cdot{ }^{10}$ Here are some readings peculiar to $\mathbf{E}^{\mathbf{a}}$ and $\mathbf{E}^{\mathbf{b}}$ :

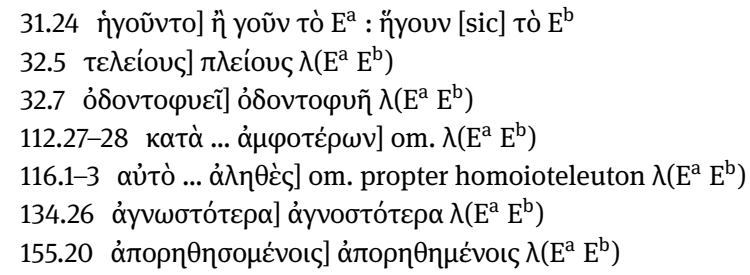

In the beginning of the sixteenth century, $\mathbf{R}$ was in Egidio Canisio's collection in Rome, where it was used as one of the two models of $\mathbf{N}^{\mathbf{e}}$, copied in the middle of the sixteenth century by Giovanni Onorio; the second model was $\mathbf{E}^{\mathbf{a}}$, which was in the collection of Rodolfo Pio in the same city:

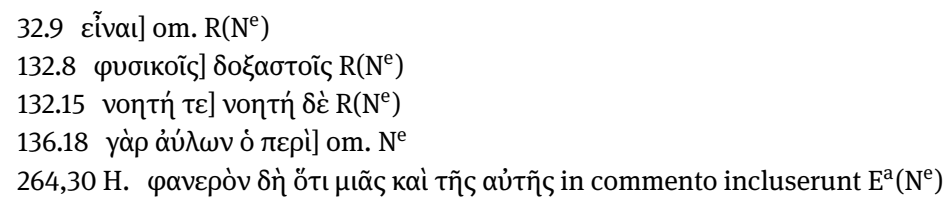

\subsubsection{The descent of 0}

The manuscripts that descend from $\mathbf{0}$ share its significant omissions, which we quoted earlier. ${ }^{11}$ There is an early (Palaeologan) copy of $\mathbf{0}$, i.e. $\mathbf{Z}$, which omits twice a text that corresponds to a line in $\mathbf{0 . 1 2} \mathbf{Z}$, a mutilated manuscript, became in the first half the sixteenth century the forefather of a lacunary manuscript produced probably in Milan, namely $\mathbf{H} .^{13}$

O was brought from Crete to Florence by Janus Lascaris in 1492 and remained there, except for a short period during which Lorenzo il Magnifico's big collection of

10 As we have seen (see above, p. lvi-lvii), the model used by Callistus for the production of the second part of $\mathbf{P}$, namely $\boldsymbol{\mu}$, was also a copy of $\boldsymbol{\lambda}$. Here are some further cases of agreement between $\mathbf{P}$ and

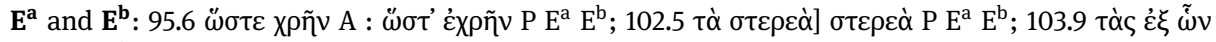

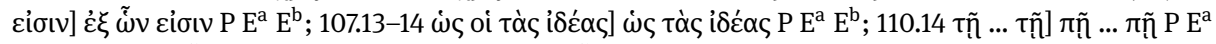

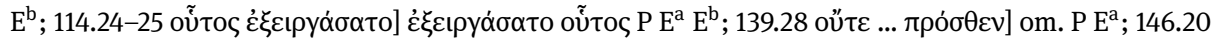

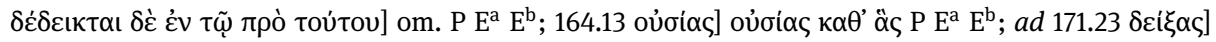

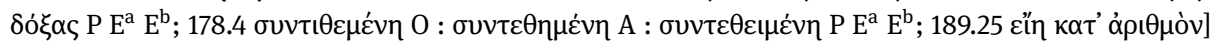

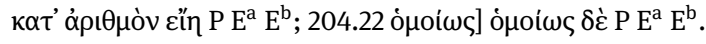

11 See above p. xlvii, n. 1

12 See above, p. cxxi.

13 On the textual affiliation of $\mathbf{H}$, see above, p. xcviii. Here are two errors peculiar to $\mathbf{Z}$ and $\mathbf{H}: 28.12$

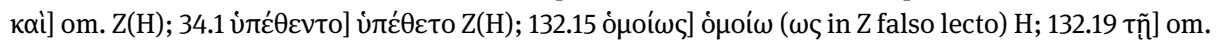
$\mathrm{Z}(\mathrm{H})$. 
books was transferred to Rome. When the books were sent back to Florence by Giulio de' Medici (later Pope Clement VII) in 1521, they were kept in cases until the opening of the Bibliotheca Medicea Laurentiana in 1571 under Cosimo I de' Medici - at least in principle. In the middle of the sixteenth century, $\mathbf{O}$ was curiously copied three times in a Venitian atelier of Greek scribes. The dependence of these three copies, namely $\mathbf{M}, \mathbf{U}$ and $\mathbf{Y}$, on $\mathbf{O}$ may be quickly exemplified by the two following cases:

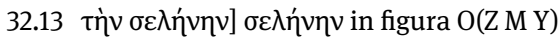

$61.30 \tau \tilde{\omega} \delta \mathrm{i}] \tau \tilde{\omega} \delta^{\prime}$ M Y U (male lecto 0)

Here are further compelling agreements between these manuscripts in an error:

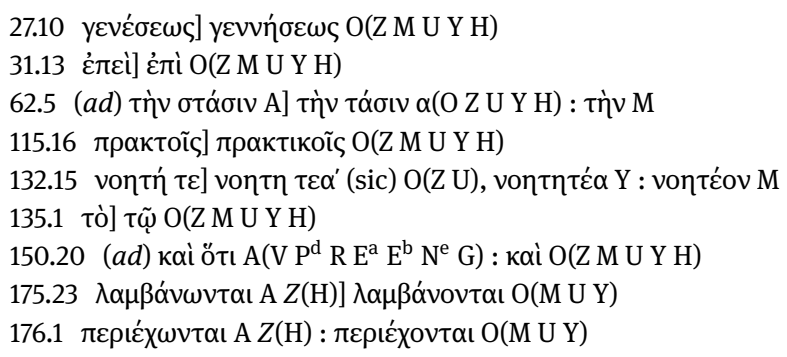

Here are some cases of errors peculiar to $\mathbf{M}, \mathbf{U}$ and $\mathbf{Y}$ :

32.12 тทेv] om. U

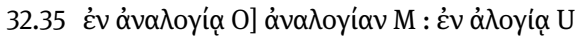

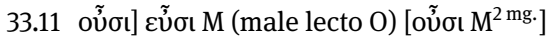

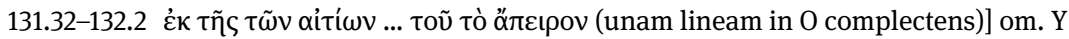

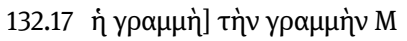

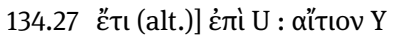

U was the model of a manuscript produced in Rome for Marco Giovanni Angelo Altemps in the beginning of the seventeenth century, namely $\mathbf{V}^{\mathbf{0}} .^{14}$

\subsubsection{The descent of $P$}

All interpolations by Andronicus Callistus, which I record in Appendix B, are present in the following manuscripts: $\mathbf{D}, \mathbf{P}^{\mathbf{s}}, \mathbf{N}^{\mathbf{d}}$ and $\mathbf{P}^{\mathbf{a}}$. We may quote here some real errors that these manuscripts share, which originated in $\mathbf{P}$ :

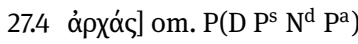

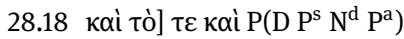

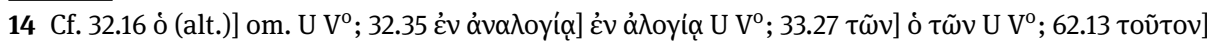

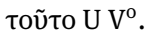




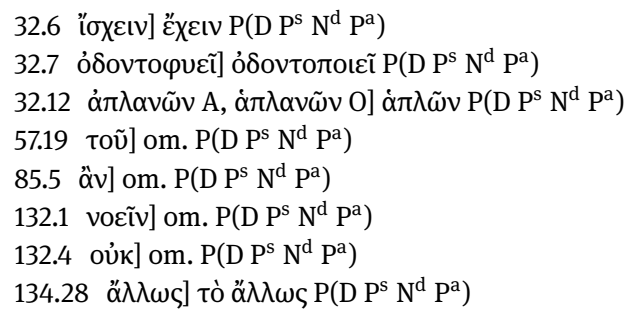

The first three of the above manuscripts, i.e. $\mathbf{D}, \mathbf{P}^{\mathbf{s}}$ and $\mathbf{N}^{\mathbf{d}}$, were copied on partly identical paper in 1489, in all probability in Ferrara, when $\mathbf{P}$ belonged to Niccolò Leoniceno. ${ }^{15}$ Demetrios Moschos, who is attested to have worked in Ferrara, ${ }^{16}$ made a first copy of $\mathbf{P}$, namely $\mathbf{D}$, possibly for Giovanni Pico della Mirandola. Georgios Chomatas undertook a copy of $\mathbf{D}$, namely $\mathbf{P}^{\mathbf{s}}$, which he abandonned at $96,24 \mathrm{H}$. possibly because $\mathbf{D}$ was not yet ready. Moschos went on with the copy of both $\mathbf{D}$ and $\mathbf{P}^{\mathbf{s}}$ using as a model P. Antonios Markoutzas, an otherwise unknown scribe, undertook a copy of $\mathbf{D}$ until ca. 181,16 H., where he switched to $\mathbf{P}$ possibly because $\mathbf{D}$ was still not finished. All this makes the production of $\mathbf{D}, \mathbf{P}^{\mathbf{s}}$ and $\mathbf{N}^{\mathbf{d}}$ a sort of joint enterprise under the patronage of Niccolò Leoniceno and the supervision of Demetrios Moschos. The textual affiliation between these three manuscripts may be quickly exemplified by the following case:

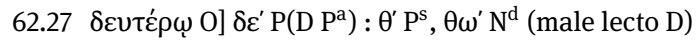

The dependence of $\mathbf{P}^{\mathbf{s}}$ and $\mathbf{N}^{\mathbf{d}}$ on $\mathbf{D}$ (until 96,24 H. and ca.181,16 H. respectively) and on $\mathbf{P}$ (for the rest of Alexander's commentary) may be seen in the following examples:

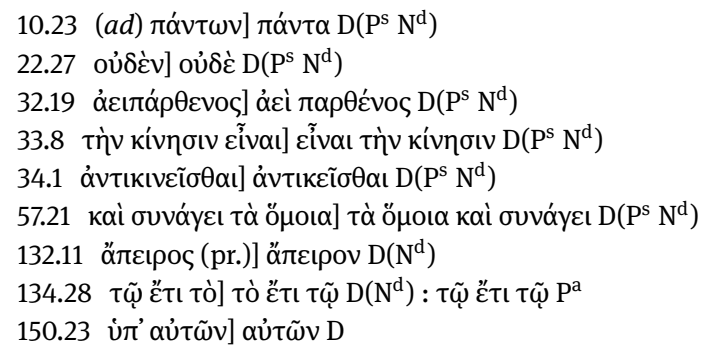

Finally, $\mathbf{P}^{\mathbf{a}}$ is a copy of $\mathbf{P}$ made in the middle of sixteenth century by the scriptor of the Vatican Library Ioannes Franciscus, when $\mathbf{P}$ belonged to Cardinal Niccolò Ridolff. ${ }^{17}$

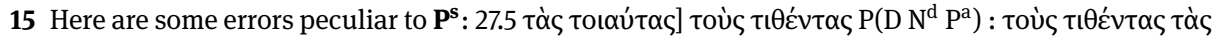

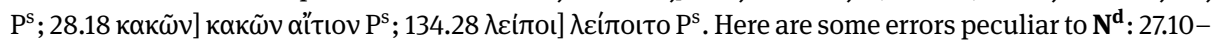

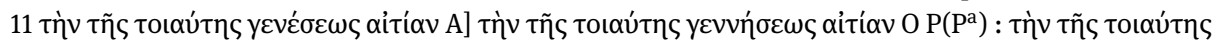

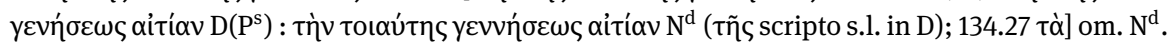
16 See Formentin 1998.

17 See above, p. cviii. 


\subsection{4 'Contaminations'}

As we saw in the previous chapter, $\mathbf{C}$, a copy of $\mathbf{A}$, bears readings that stem from a lost independent copy of the anonymous commentary and possibly from $\mathbf{0} .{ }^{18}$ We also saw, in Chapter 2, that the lost models of the (hiero)monk Gregorios and Andronicus Callistus, which were used for the production of $\mathbf{P}$, were "contaminated" copies of $\mathbf{O}$ and $\lambda .{ }^{19} \boldsymbol{\lambda}$ itself, which was a Byzantine manuscript available in Rome or in Florence, was collated with $\mathbf{0}$ and with a lost Florentine copy of the anonymous commentary ${ }^{20}$ after ca. 1510 and before the confection of $\mathbf{E}^{\mathbf{b}}$ in $c a .1515$. Here are some compelling examples:

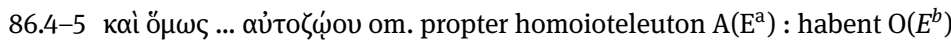

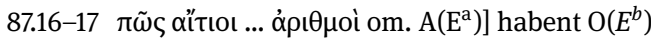

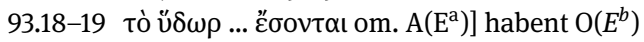

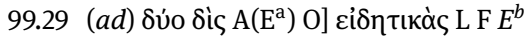

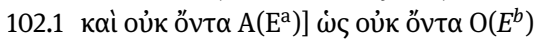

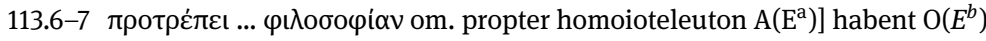

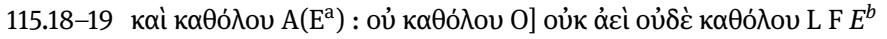

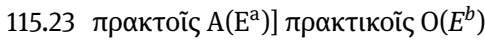

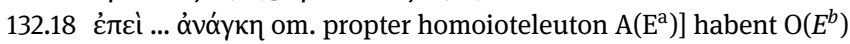

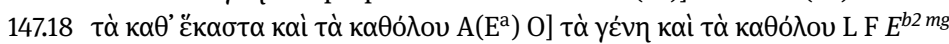

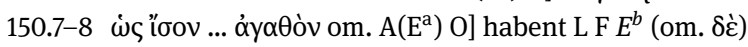

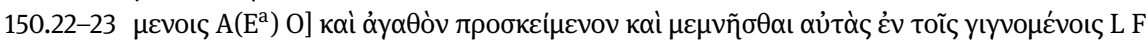
$E^{b}$

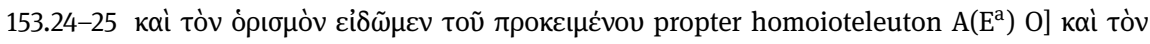

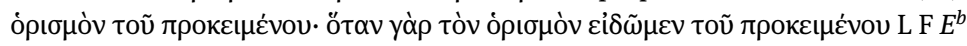

\subsection{Stemma codicum}

Here follows a stemmatic representation of the Byzantine and Western descendence of the derivative manuscripts.

N.B.: Sigla put into brackets (F, L, $\mathrm{V}^{\mathrm{r}}$ ) denote manuscrpts of the so-called "recensio altera". The dashed line denotes complementary or auxiliary consulation. References to page and line numbers are made in accordance with Hayduck's edition. On the manuscripts, for which the sigla stand, see previous chapter.

18 See above, p. cxiii-cxiv.

19 See above, Section 2.1.1.

20 On this copy see above, p. cxviii. 


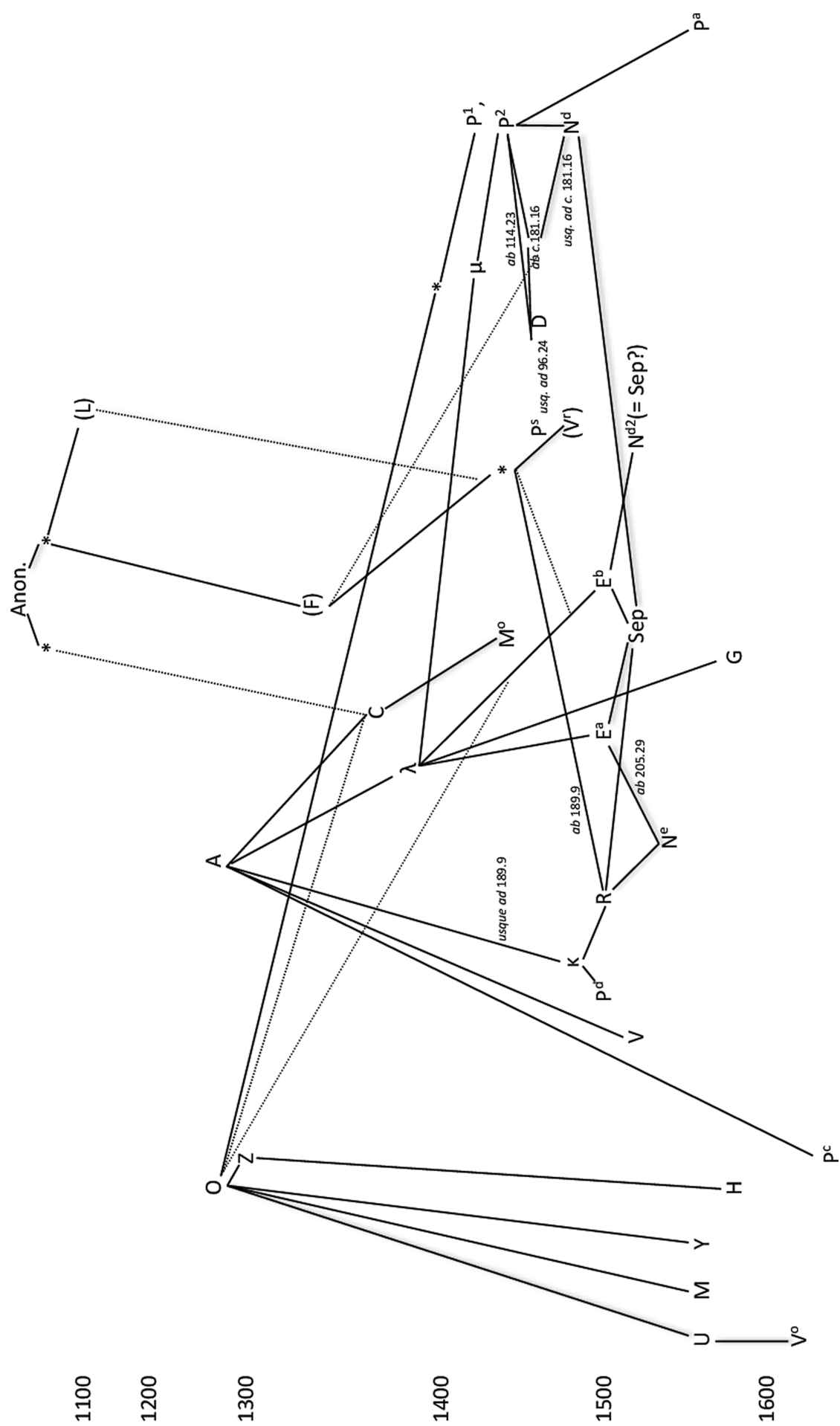




\section{The present edition and its relation to previous editions}

\subsection{The previous editions and Sepúlveda's translation}

As we saw in Chapters 2 and 3, Alexander's commentary on Metaphysics A- $\Delta$ is stricto sensu transmitted in twenty-three manuscripts, ${ }^{1}$ of which only two (leaving aside the authentic readings attested in $\mathbf{P}$ ) are independent witnesses: $\mathbf{A}$ and $\mathbf{0}$. Of these witnesses only $\mathbf{A}$ has been used in the previous editions of the commentary. ${ }^{2}$ This promptly shows that the previous editions are based on an inadequate recensio et examinatio codicum.

Christian August Brandis (1790-1867) was the first to transcribe A, along with further four manuscripts, for his Scholia in Aristotelem, published in $1836 .^{3}$ Brandis made several mistakes of transcription, the majority of which were corrected in the subsequent edition by Hermann Bonitz (1814-1888), published in $1847 .{ }^{4}$ As Michael

1 The manuscripts of the so-called "recensio altera" also contain extensive parts of Alexander's commentary; see above, p. xlix-li.

2 It is worth noting that, in a letter addressed to Hermann Usener (1834-1905) on 24 January 1878, Hermann Diels (1848-1922), who was by then the "Redakteur" of the editorial project Commentaria in Aristotelem Graeca in the Borussian Academy - he had succeeded Adolf Torstrik (1821-1877), who died prematurely -, appears aware of the importance of $\mathbf{O}$ for the constitutio textus of Alexander's commentary: "Darunter wird wohl die Metaphysik [Alexanders] zuerst kommen, die durch einen Laurentianus (Sepulvedaklasse) total neu gestaltet wird" (Ehlers 1992, I: 151). Since L is a manuscript of the altera classis, this "Laurentianus" can be no other than $\mathbf{0}$. The qualification "total neu", however, suggests that Diels was momentarily confusing the "Sepulvedaklasse" with the altera classis.

3 Brandis 1836.

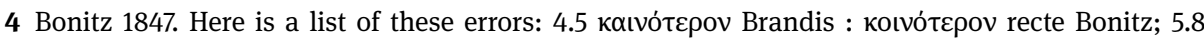

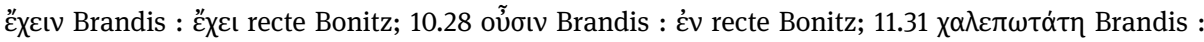

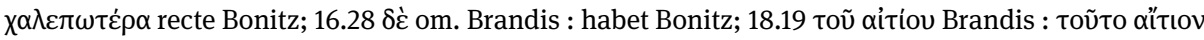

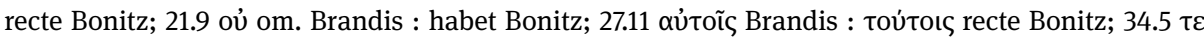

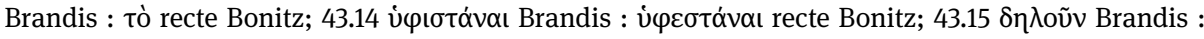

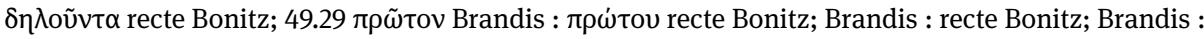

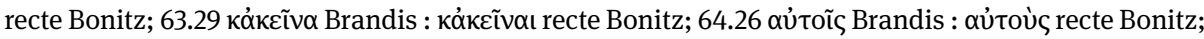

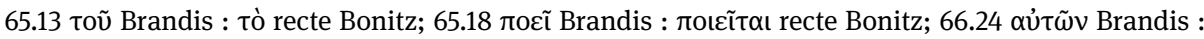

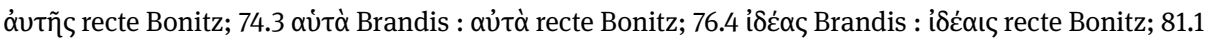

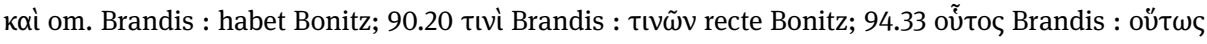

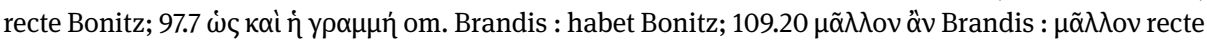

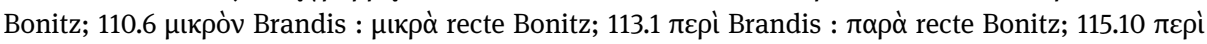

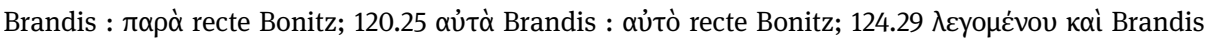

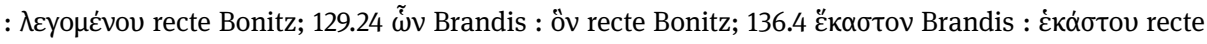

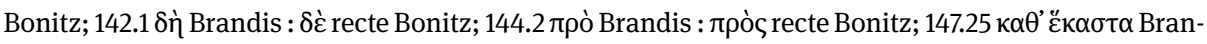

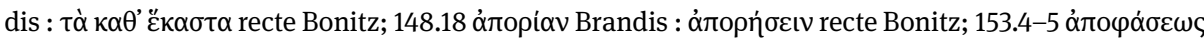

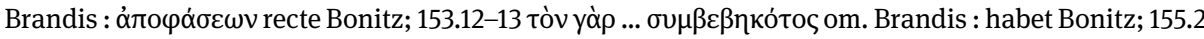


Hayduck (1838-1909) did not undertake a fresh collation of A, the remaining of Brandis' mistakes were also reproduced in his edition, published in $1891 .{ }^{5}$ In the introduction to his edition, Bonitz affirms, not without exaggeration, that he collated $\mathbf{A}$ "as diligently as he could". ${ }^{6}$ As said, he corrected the majority of Brandis' mistakes and also distinguished between original readings in $\mathbf{A}$ and those due to later interventions, ${ }^{7}$ to which Brandis had remained indifferent. Next to A and the manuscripts - i.e. Laurentianus plut. 87,12 [L], Monacensis gr. 81 [M], Parisinus Coislin gr. 161 [C] and Vaticanus

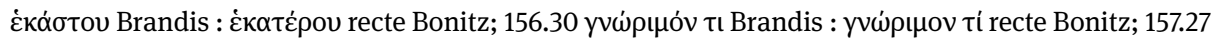

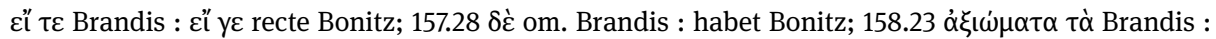

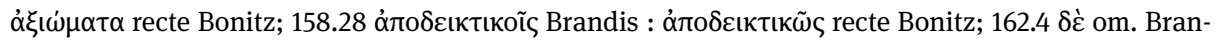

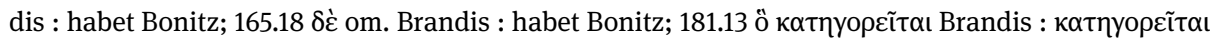

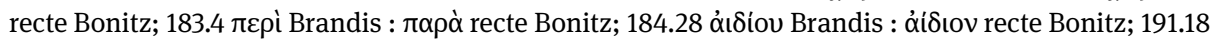

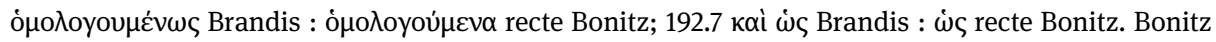

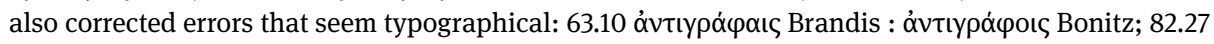

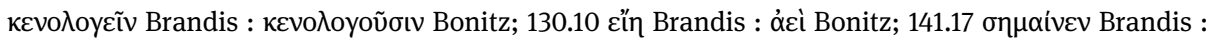

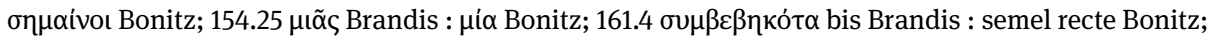

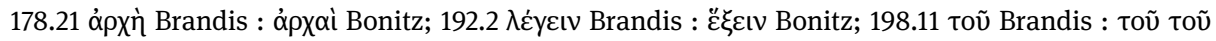
recte Bonitz.

5 Hayduck 1891. These mistakes are marked in the critical apparatus of the present edition through the mention "perperam". It is worth knowing that Hayduck was only posteriorly involved in the edition of Alexander's commentary on the Metaphysics. Indeed, in as early as 1878, Diels was ready to hand over the apparatus criticus to Alexander's commentary, which he himself had prepared on the basis of Torstrik's preliminary work, to Jacob Freudenthal (1839-1907), who was initially asked to produce the edition (see Ehlers 1992, II: 21 and 26-27). It seems, however, that Freudenthal did not want to rely on Torstrik's observations and wished for a six-months journey in Europe, which the Borussian Academy did not fund except for a trip to Milan (see Ehlers 1992, II: 28). The edition was subsequently assigned to Christian Belger (1847-1903) and finally to Hayduck; see Eduard Zeller's report on the "AristotelesCommentatoren" on the occasion of the Öffentliche Sitzung zur Feier des Allerhöchsten Geburtstages (23 March 1882: “Hr. Chr. Belger, der Alexander zur Metaphysik seit längerer Zeit bearbeitet ...”), as well as Diels' report in the Monatsberichte der königlich preussischen Akademie der Wissenschaften zu Berlin (26 March 1885: "Für Hrn. Belger hat Hr. Hayduck die Herausgabe des Asclepius und Alexander zur Metaphysik übernommen”).

6 Bonitz 1847: VII: "hunc ego librum [A], utpote optimum et certissimum, ad universum Alexandri commentarium qua potui diligentia excussi”. Bonitz's clarification that he collated the Monac. 81 selectively (ibid., p. VIII: "Ex hoc igitur codice [sc. Monac.] in posteriore parte commentarii transscripsi primum quae omiserat Brandisius; sed quum eo, quo id faciebam, tempore edendi Alexandri consilium nondum cepissem, ad priores libros non contuli universum codicem, sed inspexi modo iis locis, quos depravatos esse intellexeram, et plerumque quidem frustra: reliquam varietatem inde enotatam ex apparatu Brandisii petii”) also implies that he collated A fully.

7 Bonitz signals these readings in his critical apparatus as readings by $\mathrm{A}^{2}$. These are not variant readings coming from a different manuscript but corrections through conjecture by an erudite scholar, probably John Chortasmenos (see above, Section 2.2). As the monk Malachias intervened in A before Chortasmenos, the latter's interventions should be described more properly as those by $\mathrm{A}^{3}$ (which is the convention used in the present edition). 
Reg. gr. $109[\mathbf{V}]^{8}$ - excerpted by Brandis, ${ }^{9}$ Bonitz used pro libro manuscripto the Latin translation of the commentary by Juan Ginés de Sepúlveda (1490-1573), published for the first time in Rome in 1527;10 Bonitz considered that the Spanish humanist had access to manuscripts better than we have. ${ }^{11}$ This, as we shall now see, is not true. ${ }^{12}$

Sepúlveda, who records in his praefatio that he produced his translation [Sep] on the basis of "quattor antiquissima exemplaria", published his work in Rome, where he had joined the papal curia. He was working on this translation already in 1523, since in a letter dated 1 September 1523 Girolamo Nigri of Venice (Hieronymus Niger Venetus), who belonged to the roman circle of the pontifical datary Gian Matteo Giberti (14951543), later bishop of Verona, says that "the Spaniard has received [the large sum of] two hundred ducats by Cardinal de' Medici to translate Alexander's commentary on the Metaphysics". ${ }^{13}$ Sepúlveda had met Cardinal de' Medici, i.e. Giulio de' Medici (1478-1534), who was elected Pope Clement VII on 19 November 1523, in Bologna during the time of his studies in the Spanish college between 1515 and 1523. ${ }^{14}$ In Bologna he had also become acquainted with Alberto Pio (1475-1531), Prince of Carpi, ${ }^{15}$ who is known to have favoured the election of Giulio de' Medici to the Papacy and who in 1525 fled to Rome. Alberto's nephew Rodolfo Pio (1500-1564) also took up a church career in Rome under Clement VII. Textual criticism suggests that two manuscripts of the library of Rodolfo Pio, i.e. the Mutinenses gr. 208 [ $\left.\mathbf{E}^{\mathbf{a}}\right]$ and $214\left[\mathbf{E}^{\mathbf{b}}\right]$ (the former previously belonged to his oncle) were used by Sepúlveda. Although $\mathbf{E}^{\mathbf{a}}$ and $\mathbf{E}^{\mathbf{b}}$ are copies

8 This manuscript, wrongly quoted by Brandis as Vaticanus Reg. gr. 108, contains only pseudoAlexander's commentary on books E-N; see above, p. cxxxi.

9 Brandis used $\mathbf{A}$ as his main manuscript and collated against it $\mathbf{M}$ (for books A, $\alpha, \Gamma 4-8$, and $\Delta$ ) and $\mathbf{C}$ (for books B and $\Gamma$ 1-3); he also used $\mathbf{L}$ and Asclepius as indirect sources of Alexander's commentary; see Brandis 1836: 518, in apparatu (quoted below, n. 26). I have the feeling that when Brandis speaks of "dickleibige Folianten in schlechtester Schrift, gewöhnlich mit höchst dürftiger Ausbeute" (quoted above, p. ciii n. 34), he had $\mathbf{C}$ in mind; had he continued with the collation of $\mathbf{C}$, he would have spotted the missing comment on $\Gamma 6$, which shaped Bonitz's erroneous judgment on the value of Sepúlveda's translation, on which see below.

10 Sepúlveda 1527; second edition Paris 1536. Sepúlveda did not include in his translation the commentary (by Michael of Ephesus) on books $M u$ and $N u$. This omission is certainly related to the fact that Sepúlveda, unlike the Greek manuscripts, provided each time before Alexander's lemmata and comments the full text of the Metaphysics, in bigger letters, in John Argyropoulos' translation, which does not include books $M u$ and $N u$. Argyropoulos' translation was published in Paris in 1515 together with Bessarion's translation of all fourteen books of the Metaphysics (see Argyropoulos 1515). This suggests that Sepúlveda, probably in the spirit of Argyropoulos himself who was in turn influenced by Averroes, considered book Lambda to represent the culmination of the Metaphysics and neglected the subsequent books.

11 Cf. Bonitz 1847: VIII: "Ac Sepulvedam quidem quae habet meliora, quam in nostris reperiuntur codicibus, ex libris melioribus non ex ingenio petiisse..."

12 I here resume my findings published in Golitsis 2016b.

13 See Coroleu 1996: 327-328 with n. 21.

14 Coroleu 1996: 325 with n. 3.

15 See Schmitt 1981: 50-51 and 61-63. 
of the same model, namely $\boldsymbol{\lambda}, \mathbf{E}^{\mathbf{b}}$ generally provides a better text than $\mathbf{E}^{\mathbf{a}}$, since it was made after $\boldsymbol{\lambda}$ was at places corrected with the help of $\mathbf{O}$ and a copy of the anonymous commentary. ${ }^{16}$ Here are some compelling agreements:

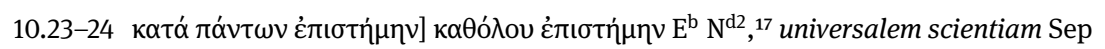

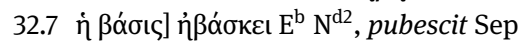

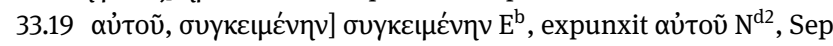

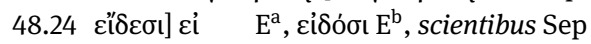

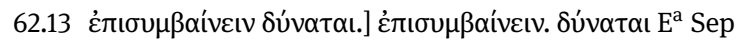

$62.15 \pi \lambda \dot{n} \theta$ ouৎ $\mathrm{P}\left(\mathrm{N}^{\mathrm{d}}\right), \pi \lambda \tilde{\eta} \theta$ ouৎ (sic) $\left.\mathrm{E}^{\mathrm{b}}\right] \pi \lambda \tilde{\eta} \theta$ os $\mathrm{E}^{\mathrm{a}} \mathrm{R}$ Sep

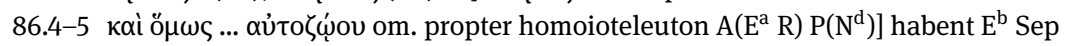

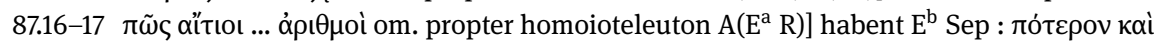

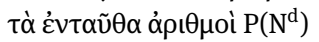

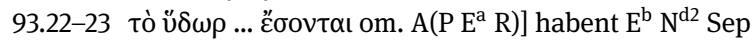

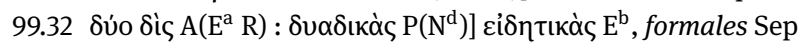

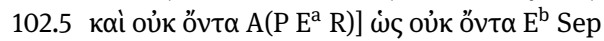

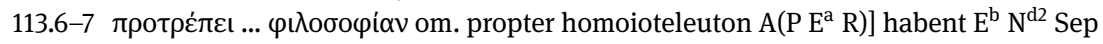

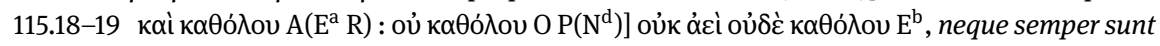
neque universaliter Sep

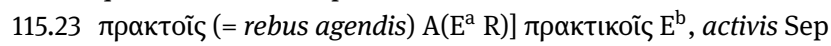

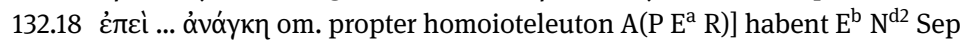

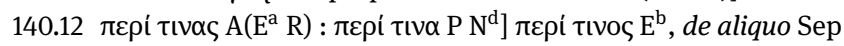

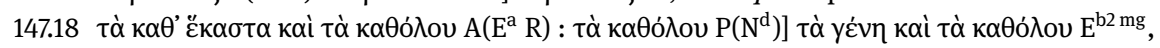
genera universaliaque Sep

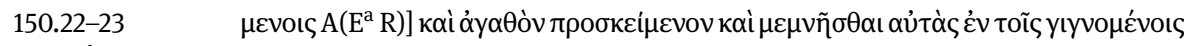

$\mathrm{E}^{\mathrm{b}}$, bonumque propositum et ab ipsis suis operibus edendis mentionem fieri causae Sep

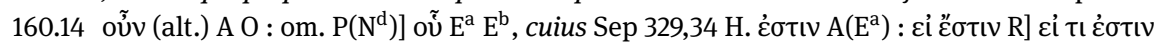
$\mathrm{E}^{\mathrm{b}}$ Sep

The further two manuscripts that were known to Sepúlveda also belonged to friends of Giulio de' Medici's. Egidio Canisio da Viterbo (1469-1532), whom Giulio as Clement VII appointed bishop of Viterbo in 1523, must have provided Sepúlveda with his (chronologically) first exemplar, namely Angelicus $102[\mathbf{R}],{ }^{18}$ an apographon of the unfinished manuscript $\mathbf{\kappa}$, which up to $189,9 \mathrm{H}$. has integrated John Chortasmenos' interpolations. ${ }^{19}$ Thanks to $\mathbf{R}$, which from $189,9 \mathrm{H}$. onwards transmits the text of the

16 See above, p. xcix-c.

17 Notice that $\mathbf{N}^{\mathbf{d}}$ was corrected $\left(=\mathrm{N}^{\mathrm{d} 2}\right.$ ) probably by Sepúlveda himself; see Golitsis (forthcoming) and plate XI.

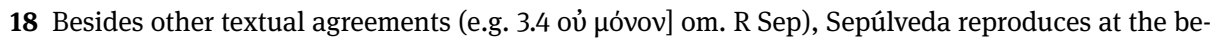

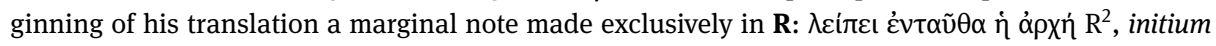
desideratur Sep.

19 See above, p. cxxxviii. Thus, the presence of Chortasmenos' interpolations in Sepúlveda's trans-

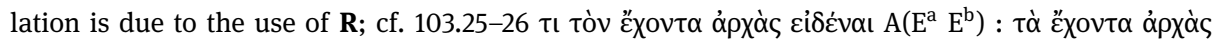

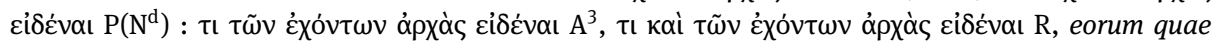
habent principia quidquam intelligamus Sep. At 155.3-4 Sepúlveda combined the reading of $\mathbf{R}$ with 
anonymous commentary, ${ }^{20}$ Sepúlveda was able to include in his translation phrases and passages that are omitted in both $\mathbf{A}$ and $\mathbf{0}$, most notably the missing part of the

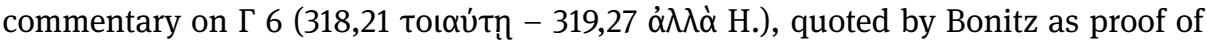
Sepúlveda's disposing of better sources. ${ }^{21}$

Giulio de' Medici's ally Alessandro Farnese (1468-1549), who succeeded him in the papacy as Pope Paul III (1534-1549), provided Sepúlveda with the fourth manuscript, namely Neapolitanus III. D. $35\left[\mathbf{N}^{\mathbf{d}}\right]$, which he acquired after Ermolao Barbaro's death in 1493. $\mathbf{N}^{\mathbf{d}}$ has been thoroughly collated with $\mathbf{E}^{\mathbf{b}}$ and bears in the margin variant readings $\left[=\mathrm{N}^{\mathrm{d} 2}\right.$ ] probably written by Sepúlveda himself. Thanks to $\mathbf{N}^{\mathbf{d}}$, which is a copy of $\mathbf{D}$ and $\mathbf{P},{ }^{22}$ Sepúlveda had access to the 'recensio callistiana', which remained unknown to both Bonitz and Hayduck, ${ }^{23}$ who thus occasionally record in their apparatuses Sepúlveda's Latin text as stemming from an unknown Greek source. Here are some compelling agreements between $\mathbf{N}^{\mathbf{d}}$ and Sep:

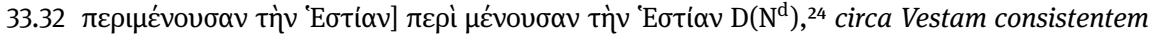
Sep

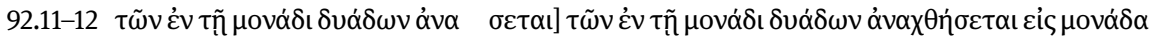
$\mathrm{P}\left(\mathrm{D} \mathrm{P}^{\mathrm{s}} \mathrm{N}^{\mathrm{d}}\right)$, horum dualitatum in unitate contentarum referetur ad unitatem Sep

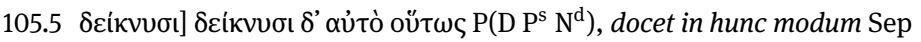

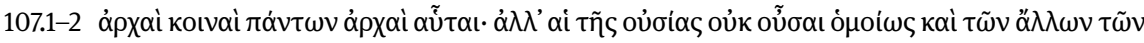

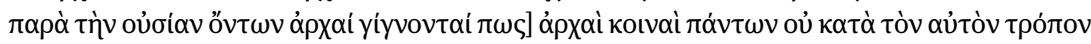

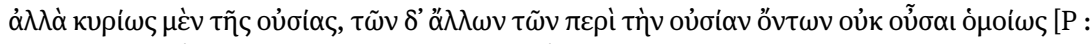

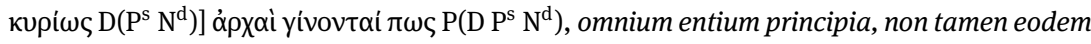
modo, sed proprie substantiae, caeterorum vero a substantia, cum proprie non sint principi, efficiuntur quodam modo Sep

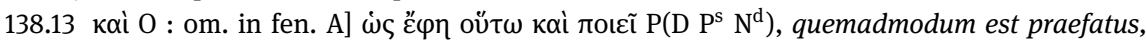
persequitur Sep

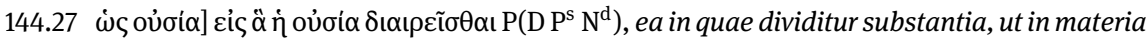
et forma dividi videtur Sep

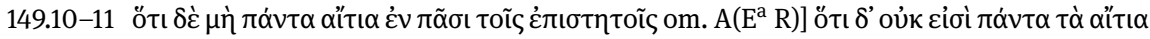
$\dot{\varepsilon} v \pi \tilde{\alpha} \sigma \mathrm{P}\left(\mathrm{D} \mathrm{P}^{\mathrm{s}} \mathrm{N}^{\mathrm{d}}\right)$, non haberi autem in cunctis scibilibus omnes causas Sep

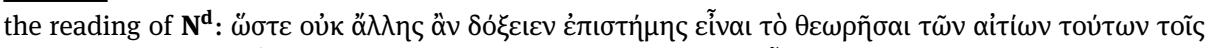

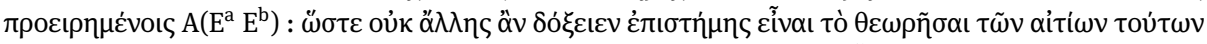

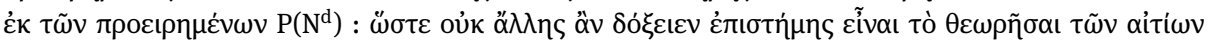

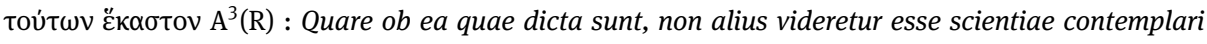
harum causarum quanque Sep. See at 194.24 for an example of Sepúlveda's preference to $\mathbf{R}$.

20 See above, p. cxviii.

21 Cf. Bonitz 1847: IX.

22 See above, p. cxli.

23 Hayduck, however, could have known this 'recensio', had he continued the collation of D; see below, p. cli.

24 Notice that $\mathbf{D}$, which in light of 33.32 and 107.1-2 could have been Sepúlveda's model, belonged to the Milanese scholar Baldassarre Migliavacca (with whom Sepúlveda is not reported to have had acquaintance), when the Spaniard began his translation. Besides, the corrections made in $\mathbf{N}^{\mathbf{d}}$ with the help of $\mathbf{E}^{\mathbf{b}}$ cannot but have a connection with Giulio de' Medici's project of having translated Alexander's commentary. 


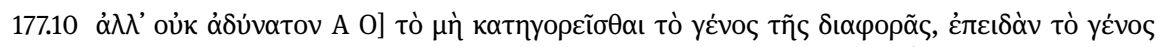

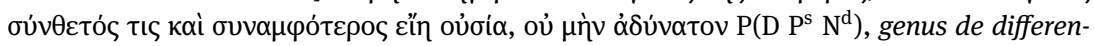
tia non praedicari, propterea quod genus sit composita quaedam substantia, non tamen est impossibile Sep

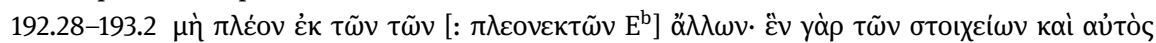

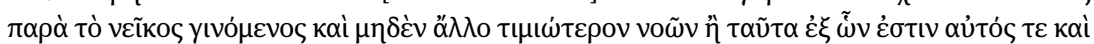

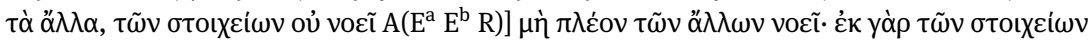

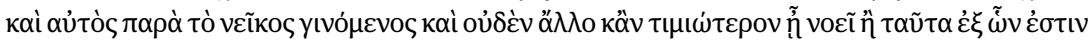

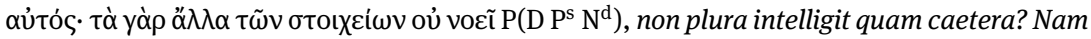
cum ipse ex elementis praeterquam ex discordia gignatur, nihil aliud licet praestantibus sit intelligit quam ea ex quibus constat, neque alia principia intelligit Sep

All four manuscripts were produced shortly before $\left(\mathbf{N}^{\mathbf{d}}, \mathbf{R}\right)$ or in Sepúlveda's time $\left(\mathbf{E}^{\mathbf{a}}\right.$, $\left.\mathbf{E}^{\mathbf{b}}\right)$ and thus discredit his claim that he had access to "antiquissima exemplaria". Nonetheless, Sepúlveda's translation is an impressive philological achievement, based on the main branches of the direct manuscript tradition of Alexander's commentary ( $\mathbf{A}$ through $\mathbf{E}^{\mathbf{a}}$ and $\mathbf{O}$ through $\mathbf{E}^{\mathbf{b}}$ ), as well as on the anonymous commentary (through $\mathbf{R}$ ) and the 'recensio callistiana' (through $\mathbf{N}^{\mathbf{d}}$ ), and improved through conjectures made by him and his Hellenist colleagues namely Gian Matteo Giberti and Niccolò Giudecco (died 1527/1528), ${ }^{25}$ whom he mentions in his introduction. Some of these conjectures, rejected or neglected by the previous editors, have been accepted in the present edition.

Next to Sepúlveda's translation, Bonitz also stressed the importance of L, excerpted earlier by Brandis and expressed the wish for its full collation. Brandis, however, had transcribed from $\mathbf{L}$ as from "Cod. Laur.", which he considered to be different from Alexander's commentary (quoted as “Alex.”). ${ }^{26}$ The full collation of $\mathbf{L}$, which was

25 On Giudecco, a former member of the Accademia Aldina in Venise and associate of Johannes Corycius (ca. 1455-1527) in Rome, see Firmin-Didot 1875: 149 and Gaisser 1999: 243.

26 In the comments to his own edition of the Metaphysics, Albert Schwegler also distinguishes between "Alex." and "commentator Laur." (see Schwegler 1847, passim). Recently, Silvia Fazzo curiously affirmed that "[Brandis] attribue [le Laurent. 87.12] à Alexandre sans aucune mise en doute de cette attribution” (Fazzo 2017/2018: 699). But it is hard to square Fazzo's claim with what Brandis himself writes (Brandis 1836: 518, in apparatu): "Alexandri Commentarii in Aristotelis Metaphysicorum quinque libros priores e cod. Reg. Paris. 1876 (A) vel descripti vel cum eo collati sunt, adhibitis ad libros $\mathrm{A}, \alpha, \Gamma$ a quarto inde capite, et $\Delta$ codice Monacensi (M), ad libros $\mathrm{B}$ et priorem partem libri $\Gamma$ codice Coisliniano 161 (C) [in other words, Brandis produces a sort of critical edition of Alexander's commentary - hence the designation "Alex." - by using A as his main manuscript and by collating against it $\mathbf{M}$ (for books A, $\alpha, \Gamma 4-8$, and $\Delta$ ) and $\mathbf{C}$ (for books B and $\Gamma$ 1-3)]. ad loca insigniora omnium quinque librorum, praeter cod. Coisl., excussi sunt cod. Vatican. Bibl. Reginae 108 (V), cod. Laurent. 8712 (L) et Asclepii codices [in other words, $\mathbf{L}$, just as the manuscripts of Asclepius' commentary, is collated as an indirect witness of Alexander's text for some remarkable passages]. accedunt scholia partim ex illo L, partim ex Asclepii codd. Reg. Par. 1901 (B) Monac. (M) et Laurentiano 811 (A), partim e cod. Reg. Par. 1853 [that is, supplementary scholia on the Metaphysics are then transcribed from L, together with scholia excerpted from Asclepius' commentary and some anonymously transmitted scholia in Parisi- 
undertaken in Florence in all probability by the Florentine scholar Girolamo Vitelli, ${ }^{27}$ was text-critically evaluated by Michael Hayduck, who confirmed Bonitz's observation that the text contained in $\mathbf{L}$, despite its being (as Bonitz claimed) by Alexander, ${ }^{28}$ was not fully identical with the text known through Sepúlveda's translation and other manuscripts. ${ }^{29}$ Since Bonitz seemed to hesitate as to the value of these two versions with regard to Alexander's genuine text, Hayduck named the former recensio altera and the latter recensio vulgata of Alexander's commentary on the Metaphysics, ${ }^{30}$ deciding to use both 'recensiones' as equally legitimate testimonies of Alexander's text. He recorded "the more serious discrepancy of the recensio altera" (alterius recensionis gravior discrepantia) into a separate apparatus, relegating slighter discrepancies to the usual critical apparatus. This was an erroneous procedure, since, in this way, Hayduck not only interrupted the continuity of the anonymous commentary but he also mixed the rewriting of Alexander's text by Anonymous with real errors that occurred in the manuscript tradition. ${ }^{31}$ Nonetheless, thanks to his collation of L, Hayduck was able to restore several omissions that occurred in the direct tradition of the text and were not emended by Brandis or Bonitz. The most spectacular case is

nus gr. 1853]". There is nothing suggesting that Brandis attributed the commentary contained in $\mathbf{L}$ to Alexander.

27 In a letter addressed to Eduard Zeller (1814-1908) on 5 January 1878, Diels mentions "Vitellis Collation v. Alexanders Metaphysik" (Ehlers 1992, II: 19), which Vitelli had undertaken at the instigation of Torstrik, first "Redakteur" of the Commentaria in Aristotelem Graeca. As $\mathbf{0}$ was not collated for Alexander's commentary, the manuscript which Vitelli collated in Florence was, in all probability, $\mathbf{L}$.

28 By making this claim, Bonitz apparently followed Angelo Maria Bandini's attribution of the contents of $\mathbf{L}$ to Alexander (see Bandini 1770: col. 392-393). Bandini himself must have relied on Zanobi Acciaioli's inscription on $\mathrm{f}$. IIv of the codex: 'Metaphysica aristotelis cum comento Alexandri in margine $o(m n)$ ia in greco'.

29 Cf. Bonitz 1847: XXVII: "Etenim amplissimus ille commentarius in margine Metaphysicorum scriptus [sc. in Laur. 87,12] manifesto Alexandri est [my italics], sed quantum ex apparatu critico Brandisii colligi potest $\mathrm{ab}$ ea quidem recensione, quae et in libris reliquis manuscriptis et in interpretatione Sepulvedae cernitur, adeo differt, ut ea diversitas non simplicii librario, sed interpreti retractanti et modo excerpenti modo dilatanti verba Alexandri deberi videatur”.

30 As we saw in the beginning of this chapter (see n. 1), Diels had earlier distinguished between "Sepulvedaklasse" and "altera classis"; thus, it was possibly under Diels' instigation that Hayduck had recourse to the concept of the 'recensio altera'.

31 At p. 145-146 H., for instance, Hayduck records the text of the "recensio altera" until 146,12 in the

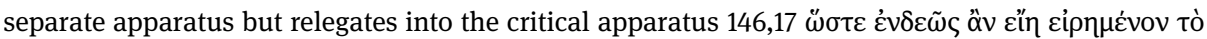

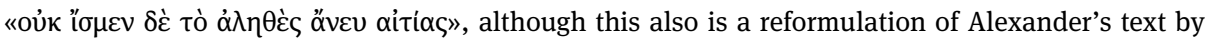

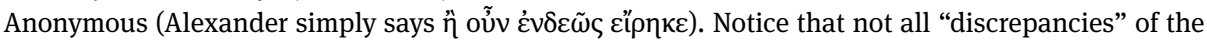
"recensio altera" have been recorded by Hayduck. At the same page, for instance, whereas Alexander

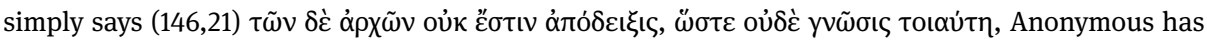

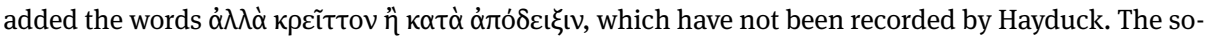
called "recensio altera" should be reedited (on the basis of a fresh collation of $\mathbf{L}$ and $\mathbf{F}$ ) as a selfstanding and continuous text (Paraskevi Naka has undertaken this edition as a doctoral dissertation at the Aristotle University of Thessaloniki). 


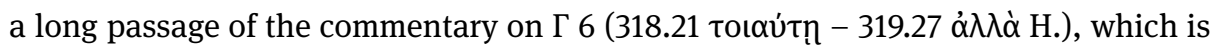
reproduced by Bonitz in the apparatus in Sepúlveda's translation; thanks to $\mathbf{L}$ and $\mathbf{F}$, Hayduck restored the Greek text. ${ }^{32}$ Nonetheless, by failing to see that $\mathbf{L}$ strictly speaking belongs to the indirect tradition of the commentary, Hayduck preferred at several places readings that may well have been adaptations of the anonymous author of the commentary. ${ }^{33}$

In the preface to his own edition, Hayduck mentions seven manuscripts. He added to the five manuscripts known to Brandis and to Bonitz (A, L, M, C, V) the Ambrosianus F 113 sup. [F], which is a further manuscript of the so-called "recensio altera", ${ }^{34}$ and the Ambrosianus D 115 sup. [D]. ${ }^{35}$ Hayduck unfortunately underestimated the value of $\mathbf{D}$ and decided not to collate it fully. ${ }^{36}$ As $\mathbf{D}$ is a copy of $\mathbf{P}$, its collation would have enabled Hayduck to restore at many places the Greek original of Sepúlveda (selectively quoted in the apparatus) and to produce a significantly better edition. The merit of Hayduck's edition is the restitution of omitted passages through the use of the indirect tradition of the commentary, that is, the anonymous commentary preserved in $\mathbf{L}$ and the commentary by Asclepius, which Hayduck had published earlier. ${ }^{37}$ At several places, however, Hayduck provides a text that is less satisfying than the text as established by Bonitz, who follows closer Sepúlveda and whose conjectures are now partly confirmed by $\mathbf{P}$. As a general assessment, one may say that, in spite of improvements at some places, Sepúlveda as a whole provides a better text than the three German editors of the nineteenth century.

A significant step towards a more adequate recensio codicum was made by Dieter Harlfinger in 1975. In his critical edition of the fragments of Aristotle's De ideis, preserved in Alexander's commentary on book Alpha, Harlfinger pointed out that $\mathbf{0}$ - which, although known to the editors of the Commentaria in Aristotelem Graeca, was entirely neglected in Hayduck's edition - is textually independent of the main

32 He neglected, however, a further independent witness of this passage, namely $\mathbf{C}$, which provides a better text; see above, p. cxiii-cxiv. Had Brandis carried on his collation of $\mathbf{C}$ for book Gamma (he only collated the first three chapters), he would have spotted the notorious missing passage.

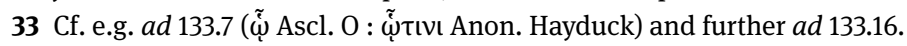

34 As already noted (see p. xlviii, n. 6), F is not fully identical as to its contents with L; from book Kappa onwards, it transmits George Pachymeres' commentary (and not Michael's). Torstrik had already formulated the opinion that $\mathbf{F}$ is an independent witness of the text that it contains (see Ehlers 1992, II: 26) and it was on the basis of Torstrik's judgment that Freudenthal was asked to collate $\mathbf{F}$ (see above, n. 5); it is, however, unclear whether Freudenthal actually made the trip to Milan. If it was not him, it was either Belger (attested in Milan in 1880; see Ehlers 1992, I: 212) or Hayduck himself who collated it.

35 Misleadingly abbreviated by Hayduck as B, due to its misquotation as "Ambrosianus B 115"; see next note.

36 Cf. Hayduck 1891: VIII: "Pauca [...] adscripsi e codice Ambrosiano B 115, qui ad initium commentariorum inspectus neque talis repertus est, ut totus esse conferendus videretur”.

37 Hayduck 1888. 
manuscript used by Brandis, Bonitz and Hayduck, i.e. A. ${ }^{38}$ Reasoning on the basis of a small portion of text, Harlfinger considered also the possibility that A might be a copy of $\mathbf{0}$. This is, however, improbable since $\mathbf{A}$ provides in some cases a text that is not attested in $\mathbf{0 .}{ }^{39}$

\subsection{The present edition}

The present edition differs from the previous ones, first of all, in that it is based on a full and fresh collation of $\mathbf{A}$ and of two other witnesses, namely $\mathbf{O}$ and $\mathbf{P}$, which were left unknown to the previous editors. This has enabled not only a better critical assessment of the transmitted variant readings but also the correction of several misreadings that occur in the previous editions, including the marking off of lemmas that were not recognized as such by Brandis and, subsequently, by Bonitz and Hayduck. ${ }^{40}$ The indirect testimony of the commentaries by Asclepius [Ascl.] and Anonymous [Anon.], when available, is also taken into account. $\mathbf{L}$ and $\mathbf{F}$ have also been collated for those parts that are identical with Alexander's commentary.

Besides those textcritical differences, the present edition gives particular attention to the use of punctuation; it takes into account but does not reproduce the punctuation found in the manuscripts, since it is believed that punctuation should serve the better intelligibilty of the text by contemporary standards. The different steps within an argument or an explanation by Alexander are separated through the distinctive use of semi-colon and full point. Brackets (...) and - ...-, which of course do not exist in the manuscripts, are also used.

Here are some clarifications on the way Alexander's commentary is presented. The separation of the main text into paragraphs follows the pace of Alexander's exegesis, who under one lemma (in which only the beginning of the commented text is quoted) usually explains a rather large portion of Aristotle's text bit by bit. A new paragraph within the commentary proper corresponds to a particular bit among several bits that appear under a single lemma. I quote the Aristotelian passage that is concerned at the beginning of the paragraph in the left margin. This procedure enables the reader to orient himself or herself in Alexander's exegesis with more precision than the simple sequence of lemmas allows. ${ }^{41}$ Alternative intepretations of the same Aristotelian passage, technically introduced by Alexander with an $\ddot{\eta}$, are distinguished through

38 See Harlfinger 1975.

39 See p. xlvii, n. 1.

40 Bonitz and Hayduck reproduce Brandis' division of Alexander's text. Brandis gives abridged versions of the lemmas, quoting only the first and last words of a lemma, a procedure followed by Bonitz but rejected by Hayduck, who transcribes the lemmas fully but not always faithfully.

41 Notice that, when the lemma corresponds strictly to the commentary that follows, the Aristotelian passage is not quoted in the margin. 
the use of numericals $(1,2,3, \ldots)$ inserted in the text. Alexander's comments on Aristotle's wording (the lexis), which are usually made at the end of a commentary on a given lemma, are also printed in separate paragraphs. Thus, when a paragraph starts without reference to Aristotle's text in the margin, one of three things may happen: (i) Alexander's comment corresponds exactly to the lemma; (ii) Alexander comments specifically on the lexis of the passage that he explained philosophically immediately before; (iii) Alexander proceeds to a sort of digression or recapitulation.

The edition consists of Alexander's reconstructed text with three apparatuses: (a) apparatus fontium et locorum aristotelicorum, (b) apparatus criticus et historicus, (c) apparatus lectionum aristotelicarum. These have been put into this order in accordance with the relevance that they may have for the potential (Hellenist) reader of the edition: (a) historians of philosophy interested in Alexander's interpretation of Aristotle's Metaphysics, who would like to know his references to Aristotle's text(s) and other sources; (b) historians of philosophy and philologists, who may have a different (and possibly better than the present editor's) understanding of Alexander's commentary and may prefer a reading rejected by the present editor; (c) historians of the text of Aristotle's Metaphysics, who wish to readily know what was Alexander's reading each time there is a divergence in our textual tradition of the Metaphysics. I take it that (a) concerns more people than (b) and (b) more people than (c).

\subsubsection{Apparatus fontium et locorum aristotelicorum}

The apparatus fontium et referentiarum chiefly records passages that are quoted by

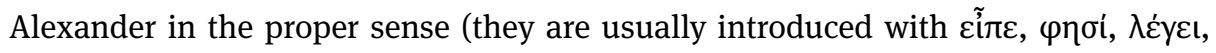
$\pi \rho о \sigma \tau \dot{\varepsilon} \theta \varepsilon \iota \kappa \varepsilon$ and cognates) and are put between «... » in the main text (if present, only the verbum dicendi is referred to in the apparatus). When a passage is not properly quoted, a "cf." precedes the reference to Aristotle's text. Phrases that are present in the lemma are not recorded in the apparatus.

\subsubsection{Apparatus criticus et historicus}

The present edition is not only critical but also historical. Its aim is not merely to reconstruct Alexander's text but also to provide its users with (a) direct access to the manuscript sources that are indispensable for reconstructing Alexander's text and (b) indirect access to Sepúlveda's translation and the previous editions by Brandis, Bonitz and Hayduck.

Thus, the apparatus criticus, which in this sense is also historicus, records (a) the variant readings of the main manuscripts and (b) the preferences and peculiar readings of Sepúlveda, Brandis, Bonitz and Hayduck (and, occasionally, of some other 
scholars too, mostly Harlfinger), ${ }^{42}$ while it also documents their editorial choices. (a) is done positively, whereas (b) is done negatively; in other words, the names of the translator and the editors appear explicitly on the right side of a "variant reading unit" (... : ...), that is, when Sepúlveda, Brandis, Bonitz or Hayduck diverge from the preference and understanding of the present editor. When the editors diverge among themselves, they are all quoted so that confusion be avoided. When Brandis made a correction accepted subsequently by all editors, only Brandis' name is recorded. ${ }^{43}$

$\mathbf{A}$ and $\mathbf{O}$ are quoted in all cases. $\mathbf{L}$ is quoted for that part of the anonymous commentary that is identical to Alexander's text (roughly 141.13-213.8 for this volume). F is quoted only when $\mathbf{L}$ deviates from the reading of $\mathbf{A}$ and $\mathbf{0} .{ }^{44} \mathbf{P}$ has a particular status: it is a derivative manuscript that may preserve some genuine readings and provide some good conjectures; its readings are, of course, quoted when they are preferred by the present editor and also, for historical reasons, when they have been preferred by Sepúlveda (who knew $\mathbf{P}$ through $\mathbf{N}^{\mathbf{d}}$ ). Nevertheless, since we know that $\mathbf{P}$ is an indirect copy of $\mathbf{O}$ for 3.4-85.15 and 88.22-91.26 and an indirect copy of A for the rest of the commentary, its readings are actually recorded, albeit tacitly. By contrast, $\mathbf{P}$ is explicitly quoted when it is expected to agree with $\mathbf{O}$ but agrees with $\mathbf{A}$ and when it is expected to agree with $\mathbf{A}$ but agrees with $\mathbf{0 .}{ }^{45} \mathbf{C}$ and $\mathbf{M}$, which were partly collated by Brandis, are quoted when they justify an editorial choice that he made against $\mathbf{A}$. In some rare cases, $\mathbf{C}$ sole provides the correct reading. Asclepius' testimony [Ascl.] and the testimony of Anonymous [Anon.] are also recorded, when it is possible to tell with certainty what they read. The reading of further manuscripts, especially $\mathbf{E}^{\mathbf{b}}$, is recorded when it justifies Sepúlveda's translation.

\subsubsection{Apparatus lectionum aristotelicarum}

The apparatus lectionum aristotelicarum offers a concordance between Alexander's reading of the Metaphysics and the two branches, $\boldsymbol{\alpha}$ and $\boldsymbol{\beta}$, of the direct manuscript tra-

42 Harlfinger edited separately the so-called De ideis; see Harlfinger 1975.

43 Notice that the errors of transcription made by Brandis and corrected by Bonitz (listed in n. 4) have not been reproduced in the apparatus criticus.

44 The agreement of $\mathbf{L}$ with $\mathbf{A}$ and/or $\mathbf{O}$ renders the quotation of $\mathbf{F}$ useless for reconstructing the text of $\boldsymbol{\alpha}$ : if $\mathbf{F}$ disagrees with $\mathbf{L}$ and $\mathbf{A}$ and/or $\mathbf{O}$, its reading is surely derivative. Nonetheless, when $\mathbf{F}$ disagrees with $\mathbf{L}$ and $\mathbf{L}$ itself disagrees with $\mathbf{A}$ and $\mathbf{0}$, the reading of $\mathbf{F}$ may be authentic; see 155.21 for such a case. Note that $\mathbf{F}$ omits the following bits of the commentary on book Beta: 140.25-141.22; 143.14-25; 145.7-22; 152.6-19; 154.5-155.17; 158.32-159.26; 165.8-20; 172.17-25; 177.20-178.18; 185.2-

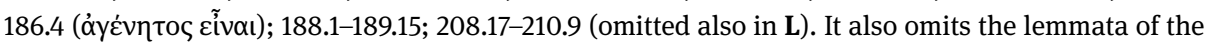
commentary (except for those which were not perceived as such).

45 Except for those cases that are accepted by the present editor, the peculiar readings of $\mathbf{P}$ are relegated into Appendix B (interpolations by Andronicus Callistus) and Appendix C (peculiar readings that do not seem to be interpolations). 
dition of Aristotle's treatise. When Alexander testifies of a peculiar reading, this reading is preceded by "]". By going through the apparatus, it is not hard to see that Alexander's testimony agrees much more with Metaph. ${ }^{\boldsymbol{\beta}}$ than with Metaph. ${ }^{\alpha}$. This agreement enables the future editor of the Metaphysics to discard readings in Metaph. ${ }^{\boldsymbol{\beta}}$ that are not confirmed by Alexander as surely subsequent. ${ }^{46}$

In preparing the apparatuses I have tried to be as accurate as possible. It is my firm belief that the apparatuses of a critical edition are more important than the reconstructed text itself. The most important of my emendations and interventions in the transmitted text are discussed, together with other editorial issues, in endnotes.

46 Kotwick 2016 offers a useful and detailed study of the (reconstructed) manuscript of the Metaphysics used by Alexander, which she calls $\omega^{\mathrm{AL}}$, and its relation to Metaph. ${ }^{\alpha}$ and Metaph. ${ }^{\beta}$. I am convinced by the arguments supporting her claim that Alexander's commentary influenced separately both Metaph. ${ }^{\alpha}$ and Metaph. ${ }^{\beta}$. It has to be stressed, though, that this did not happen through conscious alteration of Aristotle's text but through interpretive glosses; it is important to know in this respect that, whenever Alexanders writes down a better formulation of Aristotle's text, e.g. at 31.16-17 or 139.2-3, his emendations have not found their way into the direct transmission of the Metaphysics. Only one of his suggestions was recorded as a variant reading twice in the twelfth century, namely in the manuscripts Scorialensis Y. III. 18 [ $\mathbf{E}^{\mathbf{s}}$ ] and Parisinus gr. 1853 [E, by the scholar labelled $E^{\Sigma}$ ]; see the apparatus lectionum aristotelicarum ad 155.3. I remain, however, skeptical as to the stemma codicum that she proposes. Besides the fact that Kotwick does not question the authenticity of the lemmata as they appear in the manuscripts (lemmata, of course, can be easily altered in accordance with the direct transmission of the commented text), it seems to me that her reconstruction is weakened by

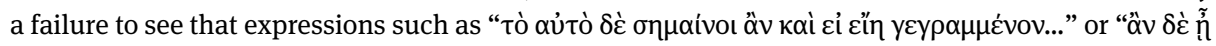

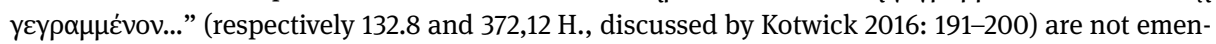
dations by Alexander but actually introduce a variant reading that was known to Alexander. This is

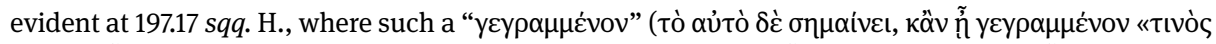

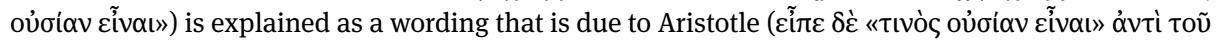
...). Further, Kotwick's study does not prove that $\omega^{\mathrm{AL}}$ is independent from $\omega^{\alpha \beta}$, i.e. the common ancestor of Metaph. ${ }^{\boldsymbol{\alpha}}$ and Metaph. $^{\boldsymbol{\beta}}$; being independent is not the same thing as having peculiar readings. This is how I would present the relation of Alexander's manuscript of the Metaphysics (= Alex.) to Metaph. $^{\boldsymbol{\alpha}}$ and Metaph. ${ }^{\boldsymbol{\beta}}$ (where $\boldsymbol{\alpha}$ and $\boldsymbol{\beta}$ are of course not direct apographa of $\boldsymbol{\omega}$ and ${ }^{\star}$ respectively):

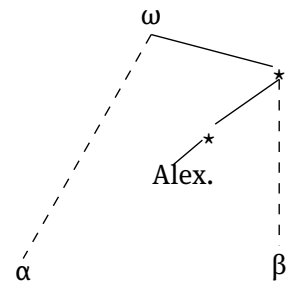


CLVI -5 The present edition and its relation to previous editions

\subsubsection{Conventions}

add. addidit

app. apparatu

a.c. ante correctionem

Alex. Alexander Aphrodisiensis

Arist. Aristoteles, Aristotele

cett. ceteri editores

cf. confer

coni. coniecit, coniectura

corr. correxit, correctura

del. delevit

fen. fenestra

lac. lacuna

lin. linea, lineam

Metaph. Aristotelis Metaphysica ${ }^{\alpha \beta}$

mg. in margine

om. omisit, omisso

p.c. post correctionem

s.l. supra lineam

$\langle\ldots\rangle$ additions of the editor

[...] deletions of the editor 